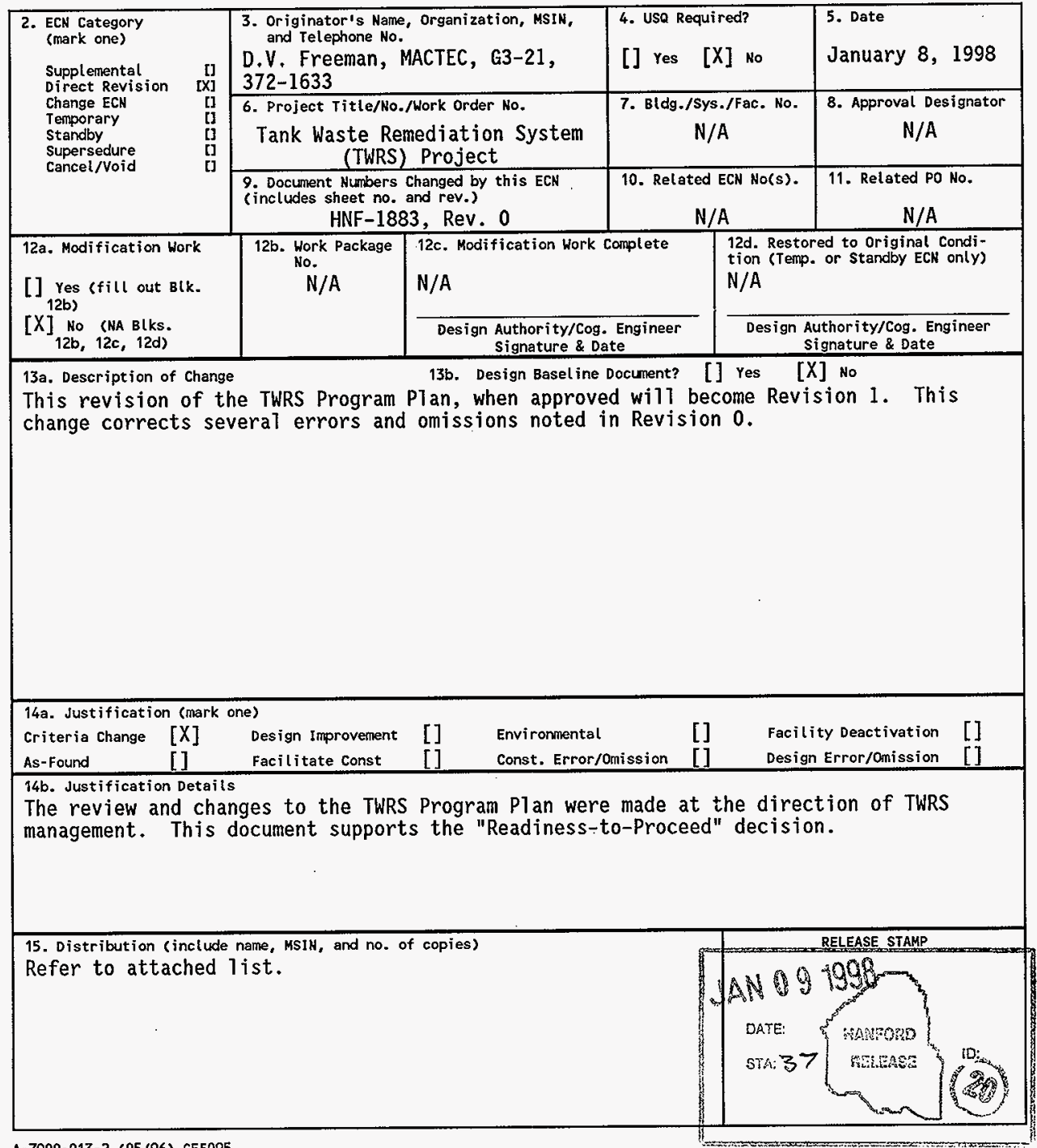




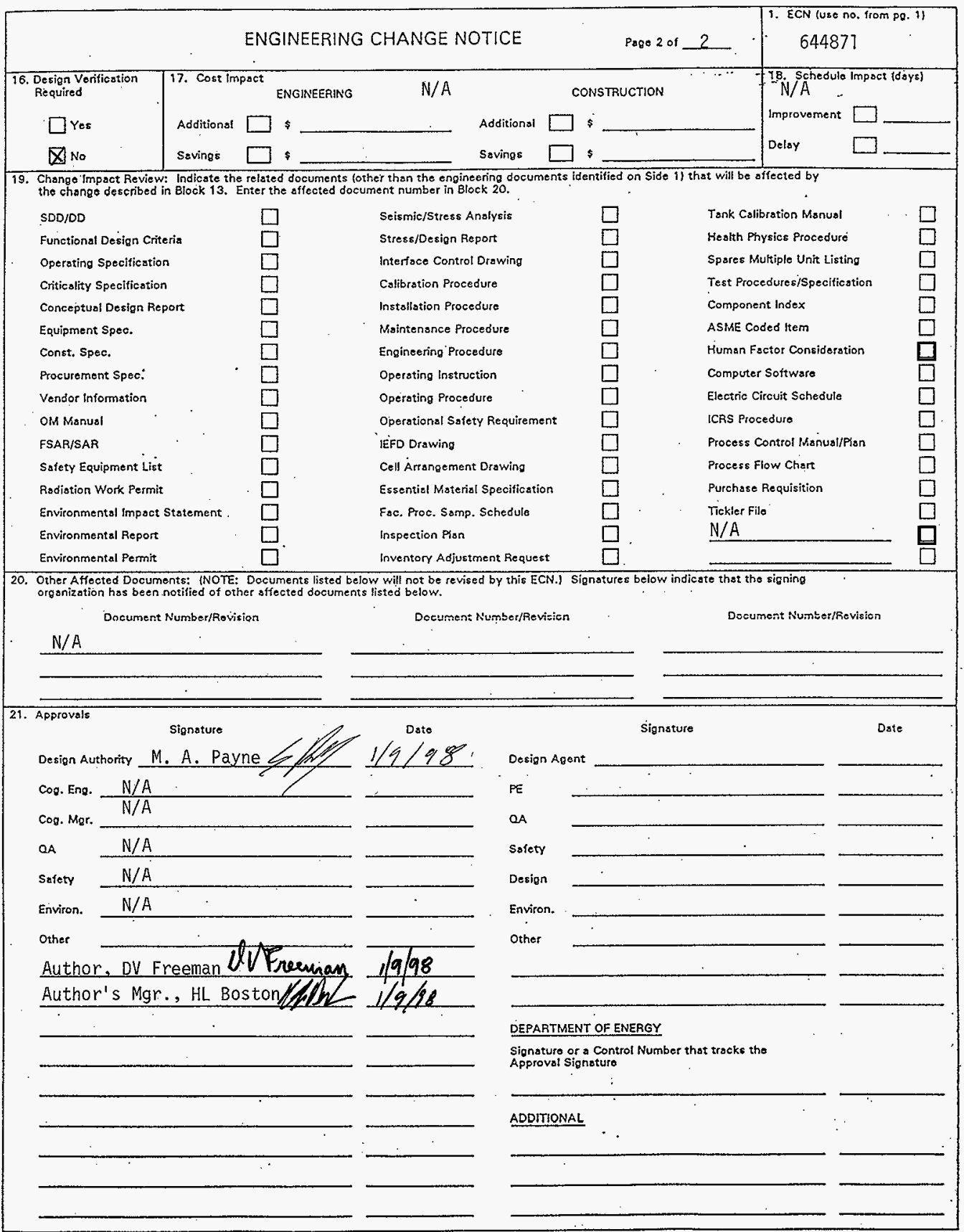




\title{
Tank Waste Remediation System Program Plan
}

\author{
R. W. Powell \\ Lockheed Martin Hanford Company, Richland, WA 99352 \\ U.S. Department of Energy Contract DE-AC06-96RL13200 \\ EDT/ECN: 644871 \\ UC: 2030 \\ Org Code: 73600 \\ Charge Code: D215P \\ B\&R Code: EW3130010 Tota1 Pages: 247 pa $^{-235}$ \\ Key Words: TWRS, System Program P1an 246 DPC per VLB
}

Abstract: This program plan establishes the framework for conduct of the Tank Waste Remediation System (TWRS) Project. The $p 1$ an focuses on the TWRS Retrieval and Disposal Mission and is specifically intended to support the DOE mid-1998 "Readiness to Proceed with Privatized Waste Treatment" evaluation for establishing firm contracts for waste immobilization.

TRADENARK DISCLAIMER. Reference herein to any specific comercial product, process, or service by trade name, trademark, manufacturer, or otherwise, does not necessarily constitute or imply its endorsement, recommendation, or favoring by the United States Government or any agency thereof or its contractors or subcontractors.

Printed in the United States of America. To obtain copies of this document, contact: WHC/BCS

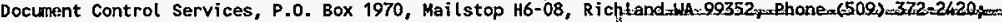
Fax (509) 376-4989.
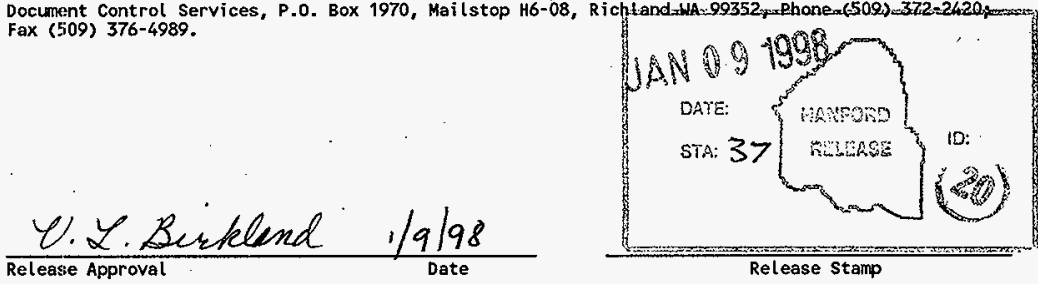


\section{RECORD OF REVISION}

(1) Document Number

HNF- 7883

Page ]

(2) Title Tank Waste Remediation System Program Plan

CHANGE CONTROL RECORD

(3) Revision (4) Description of Change - Replace, Add, and Delete Pages

Authorized for Release

\begin{tabular}{l|l}
0 & (7) EDT-622743, 1/5/98
\end{tabular}

1 RS Direct revision of TWRS Program Plan, per ECN-644871.

(5) Cog. Engr. (6) Cog. Mgr. Date

DV Ereeman HL Boston Doforeman of $=$ reware

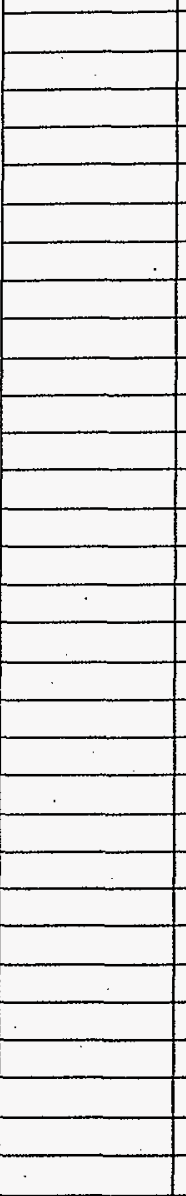
per Eal-644871. 


\section{Tank Waste Remediation System Program Plan.}

Prepared for the U.S. Department of Energy

Fluor Daniel Hanford, Inc.

Richland, Washington

Hanford Management and Integration Contractor for the

U.S. Department of Energy under Contract DE-AC-0696-RL13200 


\section{Tank Waste Remediation System Program Plan}

D. V. Freeman

MACTEC

Date Published

January 1998

Prepared by Lockheed Martin Hanford Corporation Richland, Washington

Prepared for the U.S: Department of Energy

Fluor Daniel Hanford, Inc.

(9) P.O. Box 1000

Richland, Washington

Hanford Mariagement and Integration Contractor for the

U.S. Department of Energy under Contract DE-AC-0696-RL13200 
This page intentionally left blank. 


\section{HNF-1883 Rev 1}

Document Title: Tank Waste Remediation System Program Plan

Approved by:

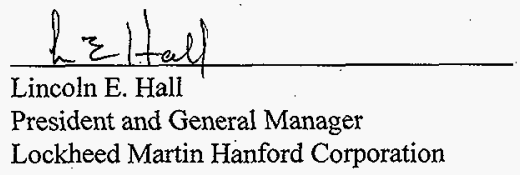

$\frac{1 / 9 / 98}{\text { Date }}$

President and General Manager 


\section{HNF-1883 Rev 1}

This page intentionally left blank. 


\section{CONTENTS}

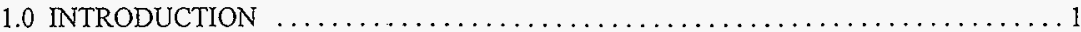

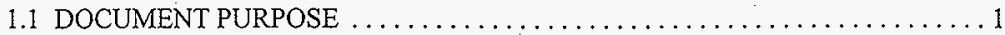

1.2 HANFORD SITE TANK WASTE $\ldots \ldots \ldots \ldots \ldots \ldots \ldots \ldots \ldots \ldots \ldots \ldots \ldots \ldots \ldots$

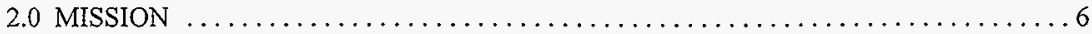

2.1. COMPONENTS OF THE TWRS RETRIEVAL AND DISPOSAL MISSION $\ldots .7$

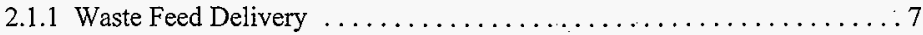

2.1.2 Immobilized Waste Storage and Disposal .................. 8

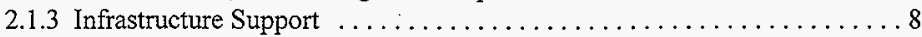

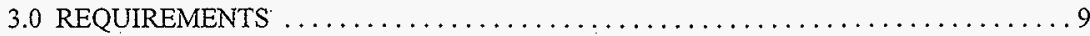

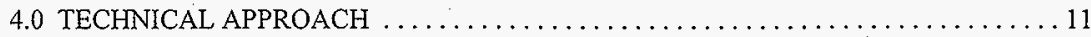

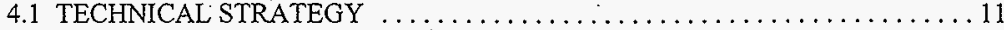

4.2 TECHNOLOGY DEVELOPMENT $\ldots \ldots \ldots \ldots \ldots \ldots \ldots \ldots \ldots \ldots \ldots \ldots \ldots \ldots$

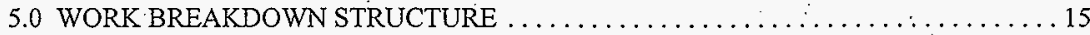

6.0 TANK WASTE REMEDIATION SYSTEM PROJECT LOGIC $\ldots \ldots \ldots \ldots \ldots \ldots . \ldots$

7.0 TWRS RETRIEVAL AND DISPOSAL MISSION SCHEDULE $\ldots \ldots \ldots \ldots \ldots \ldots 21$

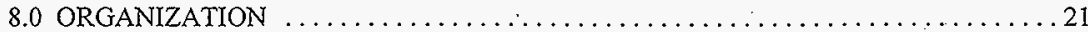

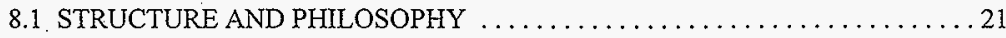

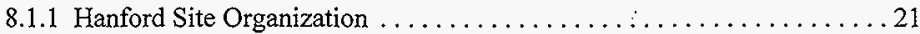

8.1.2 Tank Waste Remediation System Organization ...............26

8.1.3 Organizational Relationship for TWRS Privatization $\ldots \ldots \ldots \ldots \ldots 26$

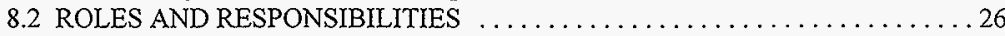

8.2.1 Tank Waste Remediation System Organization $\ldots \ldots \ldots \ldots \ldots \ldots 26$

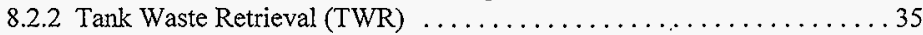

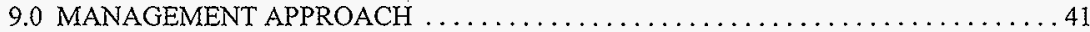

9.1 BUSINESS OPERATIONS $\ldots \ldots \ldots \ldots \ldots \ldots \ldots \ldots \ldots \ldots \ldots \ldots \ldots, \ldots \ldots \ldots$

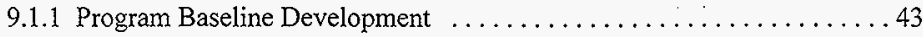

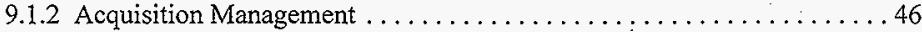

9.1 .3 Performance Assurance $\ldots \ldots \ldots \ldots \ldots \ldots \ldots \ldots \ldots \ldots \ldots . \ldots \ldots$

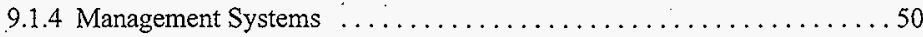

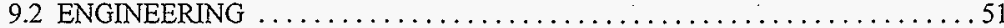

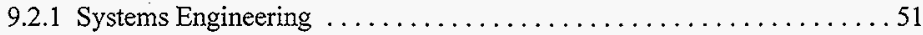

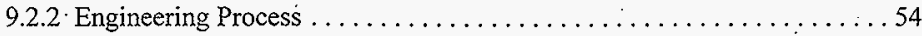

9.2 .3 Technical Baseline .................................. 55

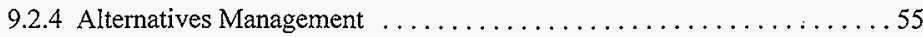


HNF-1883 Rev 1

CONTENTS (Continued)

9.3 INTEGRATED SAFETY MANAGEMENT SYSTEM $\ldots \ldots \ldots \ldots \ldots \ldots . \ldots 6$

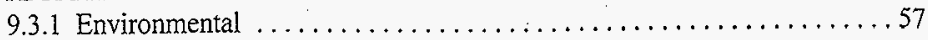

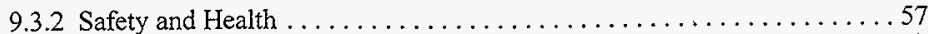

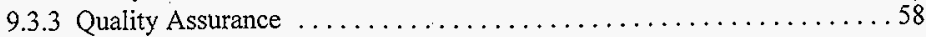

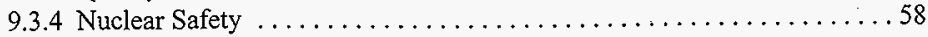

9.3.5 Emergency Preparedness . . . . . . . . . . . . . . . . . . . 59

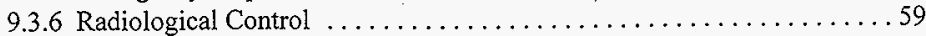

9.3.7 TWRS Engineering and Nuclear Safety . . . . . . . . . . . . . 59

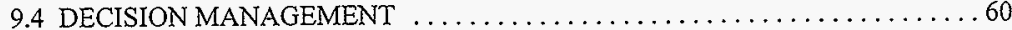

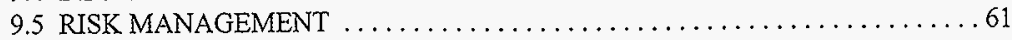

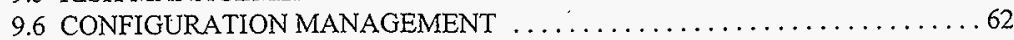

9.7 INTERFACE MANAGEMENT $\ldots \ldots \ldots \ldots \ldots \ldots \ldots \ldots \ldots \ldots \ldots \ldots$

9.8 STAFFING AND PERSONNEL TRAINING AND QUALIFICATIONS . . . . 65

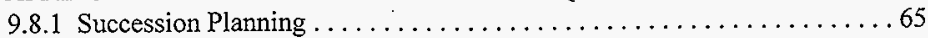

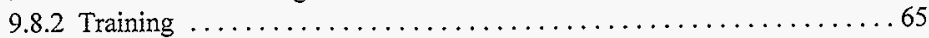

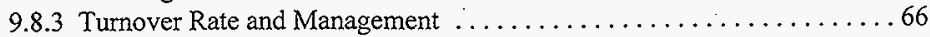

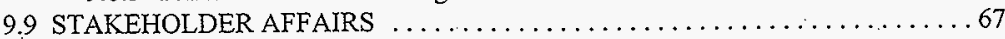

9.9.1. Public Participation ................................. 67

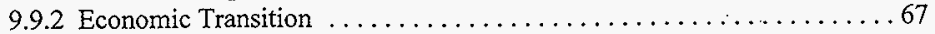

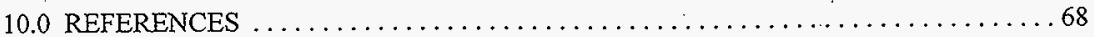

\section{APPENDIXES}

A. MAINTENANCE ORGANIZATION EXECUTION PLAN $\ldots \ldots \ldots \ldots \ldots \ldots$ A-I

B. OPERATIONS ORGANIZATION EXECUTION PLAN $\ldots \ldots \ldots \ldots \ldots \ldots$ B-I

C. CHARACTERIZATION PROJECT EXECUTION PLAN $\therefore \ldots \ldots \ldots \ldots \ldots \ldots$ C-I

D. TECHNICAL OPERATIONS AND ENGINEERING ORGANIZATION

EXECUTION PLAN $\ldots \ldots \ldots \ldots \ldots \ldots \ldots \ldots \ldots \ldots \ldots \ldots \ldots \ldots \ldots \ldots \ldots \ldots$

E. SYSTEMS ENGINEERING \& INTEGRATION ORGANIZATION

EXECUTION PLAN $\ldots \ldots \ldots \ldots \ldots \ldots \ldots \ldots \ldots \ldots \ldots \ldots \ldots \ldots \ldots \ldots \ldots \ldots \ldots$

F. NUCLEAR SAFETY AND LICENSING ORGANIZATION

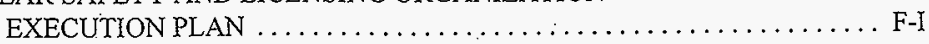

G. PROJECTS AND DESIGN ORGANIZATION EXECUTION PLAN $\ldots \ldots \ldots \ldots$ G-I 


\section{HNF-1883 Rev 1}

\section{CONTENTS (Continued)}

H. SAFETY AND HEALTH ORGANIZATION EXECUTION PLAN ........... H-I

I. BUSINESS MANAGEMENT ORGANIZATION EXECUTION PLAN .......... I-I

J. QUALITY ASSURANCE ORGANIZATION EXECUTION PLAN $\ldots \ldots \ldots \ldots$ J-I

K. GUIDANCE AND REQUIREMENTS TO DELIVERABLES CROSSWALK -

TWRS PROGRAM PLAN $\ldots \ldots \ldots \ldots \ldots \ldots \ldots \ldots \ldots \ldots \ldots \ldots \ldots \ldots \ldots \ldots \ldots \ldots$ 
HNF-1883 Rev 1

\section{LIST OF FIGURES}

1. Tank Waste Remediation System Readiness To Proceed Document Hierarchy $\ldots \ldots \ldots \ldots 2$

2. Tank Waste Remediation System Program Plan Content. ................... 3

3. Tank Waste Remediation System Project Life Cycle ...................... 5

4. TWRS Project Retrieval and Disposal Mission Summary. ................. 7

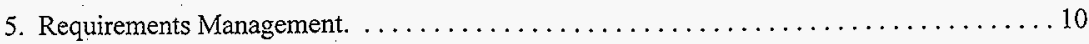

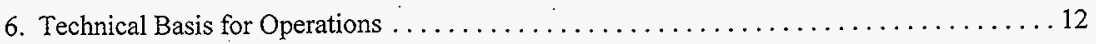

7. Tank Waste Retrieval and Disposal Master Plan $\ldots \ldots \ldots \ldots \ldots \ldots \ldots \ldots \ldots \ldots$

8. Tank Waste Remediation System Work Breakdown Structure. ................. 16

9. Tank Waste Remediation System Retrieval and Disposal Work Breakdown Structure . . . . 17

10. Tank Waste Remediation System Level 0 Logic .......................... 19

11. Tank Waste Remediation System Project Phase 1B Retrieval and Disposal Mission

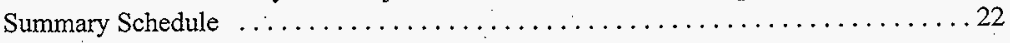

12. Tank Waste Remediation System Retrieval and Disposal Site Master

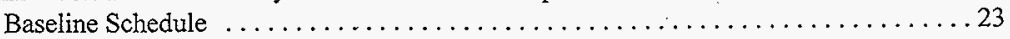

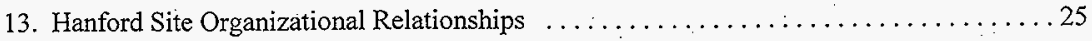

14. Tank Waste Remediation System Retrieval and Disposal Mission Organizational

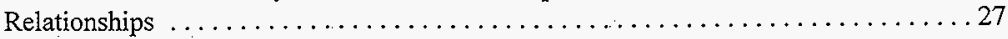

15. Lockheed Martin Hanford Corporation/Tank Waste Remediation System Project

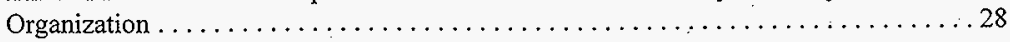

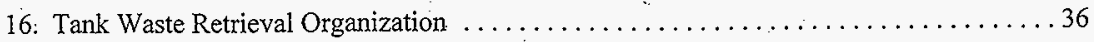

17. Tank Waste Remediation System Management Approach . . . . . . . . . . . . 42

18. Authorization of Work/Direct Funding Process. $\ldots \ldots \ldots \ldots \ldots \ldots \ldots \ldots \ldots \ldots$

19. Tank Waste Remediation System Technical Baseline Development Strategy . . . . . . . . 52 


\section{LIST OF FIGURES (Continued)}

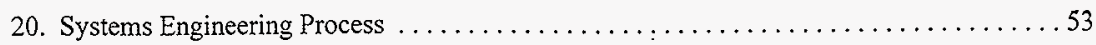

21. Integrated Safety Management System Concept. .................... 56

\section{LIST OF TABLES}

1. Standards and Requirements Identification Documents for Functional Areas. .........9

2. Tank Waste Remediation System Retrieval and Disposal Mission

Work Breakdown Structure Responsibilities ..................... 18

3. Work Breakdown Structure Performance Reporting Levels .................. 49

4. Interface Control Documents Between TWRS Retrieval and Disposal Program and Private

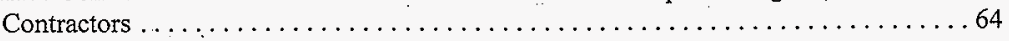




\section{LIST OF TERMS}

\begin{tabular}{|c|c|}
\hline ALARA & as low as reasonably achievable \\
\hline $\mathrm{BIO}$ & Basis for Interim Operation \\
\hline DOE & U.S. Department of Energy \\
\hline DST & double-shell tank \\
\hline Ecology & Washington State Department of Ecology \\
\hline EIS & Environmental Impact Statement \\
\hline EM-50 & DOE Office of Technology Development \\
\hline EPA & U.S. Environmental Protection Agency \\
\hline ERMI & Environmental Requirements Management Interface (database) \\
\hline ESH\&QA & Environmental, Safety, and Health, and Quality Assurance. \\
\hline FDH & Fluor Daniel Hanford, Inc. \\
\hline FY & fiscal year \\
\hline HLW & high-level waste \\
\hline HTWOS & Hanford Tank Waste Operations Simulator \\
\hline ICD & Interface Control Document \\
\hline IHLW & immobilized high-level waste \\
\hline ILAW & immobilized low-activity waste \\
\hline ISMS & Integrated Safety Management System \\
\hline LAW & low-activity waste \\
\hline LLW & low-level waste \\
\hline LMHC & Lockheed Martin Hanford Corporation \\
\hline MAR & Mission Analysis Report \\
\hline MYWP & Multi-Year Work Plan : \\
\hline MUST & miscellaneous underground storage tank \\
\hline PBS & Project Baseline Summary \\
\hline PHMC & Project Hanford Management Contract \\
\hline PNNL . & Pacific Northwest National Laboratory \\
\hline QA & quality assurance \\
\hline QAPD & Quality Assurance Program Description \\
\hline QAPP & Quality Assurance Program Plan \\
\hline $\mathrm{RC}$ & radiological control \\
\hline RL & DOE Richland Operations Office \\
\hline SE\&I & Systems Engineering and Integration \\
\hline SEMP & Systems Engineering Management Plan \\
\hline S/RID & Standards \& Requirements Identification Document \\
\hline $\mathrm{SSC}$ & systems, structures, and components \\
\hline SST & single-shell tank \\
\hline STCG & Site Technology Coordination Group \\
\hline TENS & TWRS Engineering and Nuclear Safety \\
\hline TFO & Tank Farms Operations \\
\hline TMXS & Training Matrix Subsystem \\
\hline Tri-Party Agreement & Hanford Federal Facility Agreement and Consent Order \\
\hline
\end{tabular}


HNF-1883 Rev 1

LIST OF TERMS (Continued)

TWR

TWRS

USQ

WBS

WFD
Tank Waste Retrieval

Tank Waste Remediation System

unreviewed safety question

Work Breakdown Structure

Waste Feed Delivery 
HNF-1883 Rev 1

\section{TANK WASTE REMEDIATION SYSTEM \\ PROGRAM PLAN}

\subsection{INTRODUCTION}

\subsection{DOCUMENT PURPOSE}

This program plan establishes the management framework for conducting the Tank Waste Remediation System (TWRS) Project. It is consistent with the guidance provided by U.S. Department of Energy (DOE) Order 430.1, Life-Cycle Asset Management, and DOE Good Practice Guide GPG-FM-010, Project Execution and Engineering Management Planning.

This TWRS Program plan presents the planning requirements and schedules and management strategies and policies for accomplishing the TWRS Project mission. It defines the systems and practices used to establish consistency for business practices, engineering, physical configuration and facility documentation, and to maintain this consistency throughout the program life cycle, particularly as changes are made. Specifically, this plan defines the following:

- Mission needs and requirements (what must be done and when must it be done)

- Technical objectives/approach (how well must it be done)

- Organizational structure and philosophy (roles, responsibilities, and interfaces)

- Operational methods (objectives and how work is to be conducted in both management and technical areas).

The plan focuses on the TWRS Retrieval and Disposal Mission support the DOE mid-1998 Readiness to Proceed with Privatized Waste Treatment evaluation for establishing contracts with private contractors for the treatment (immobilization) of Hanford tank high-level radioactive waste.

Figure 1, TWRS Project Readiness To Proceed Document Hierarchy, identifies the key documents supporting the readiness-to-proceed evaluation. Figure 2, TWRS Program Plan Content, identifies the subordinate execution plans that are an integral part of this document. The execution plans provide the responsibilities, interfaces and strategies of the TWRS functional organizations in support of the Retrieval and Disposal Mission. The TWRS Program Plan will be updated to reflect changes in requirements and assumptions resulting from the DOE's immobilization contracts and to more fully incorporate the entire TWRS Project. 
Figure 1. Tank Waste Remediation System Readiness To Proceed Document Hierarchy.
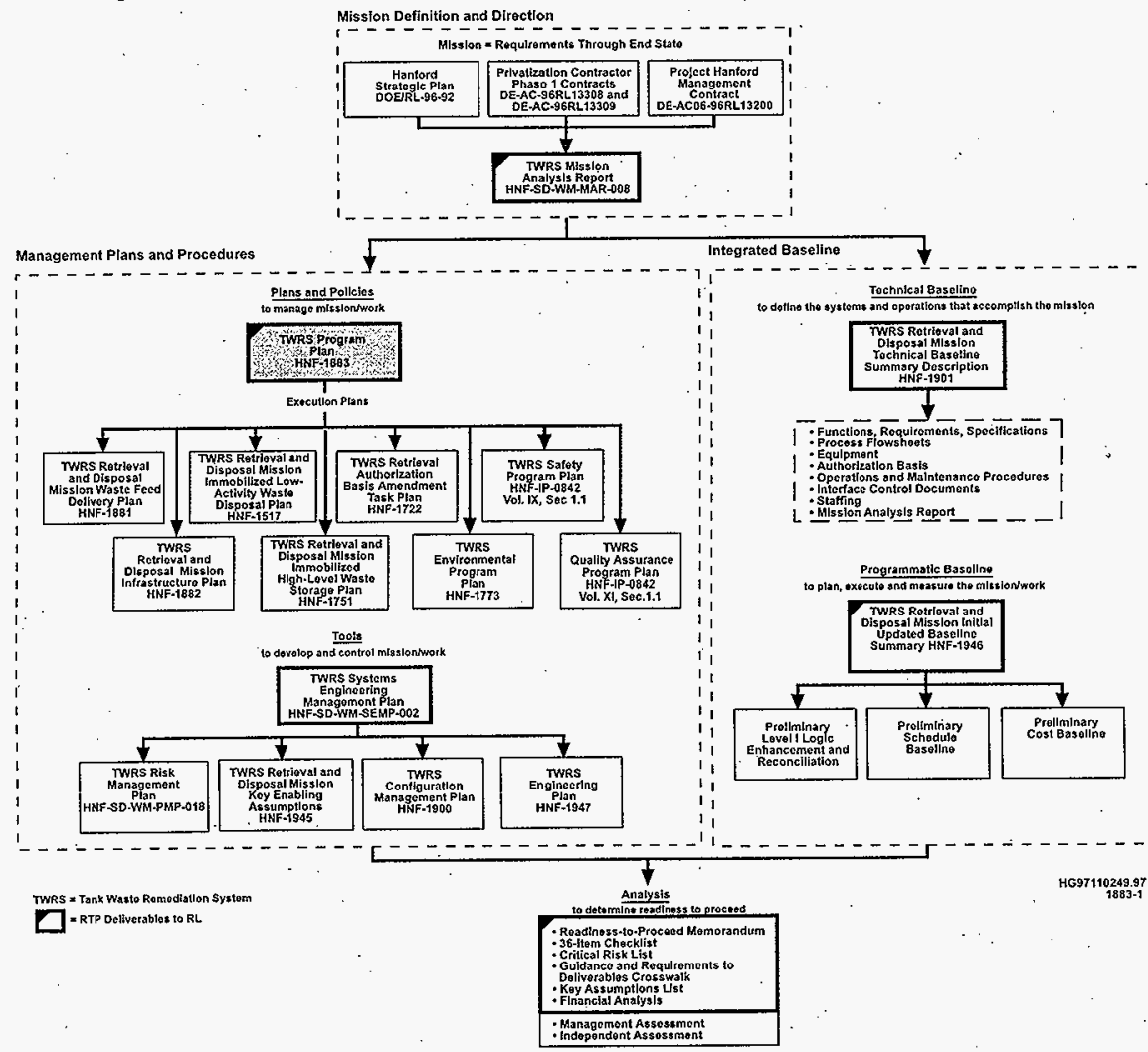
Figure 2. Tank Waste Remediation System Program Plan Content.

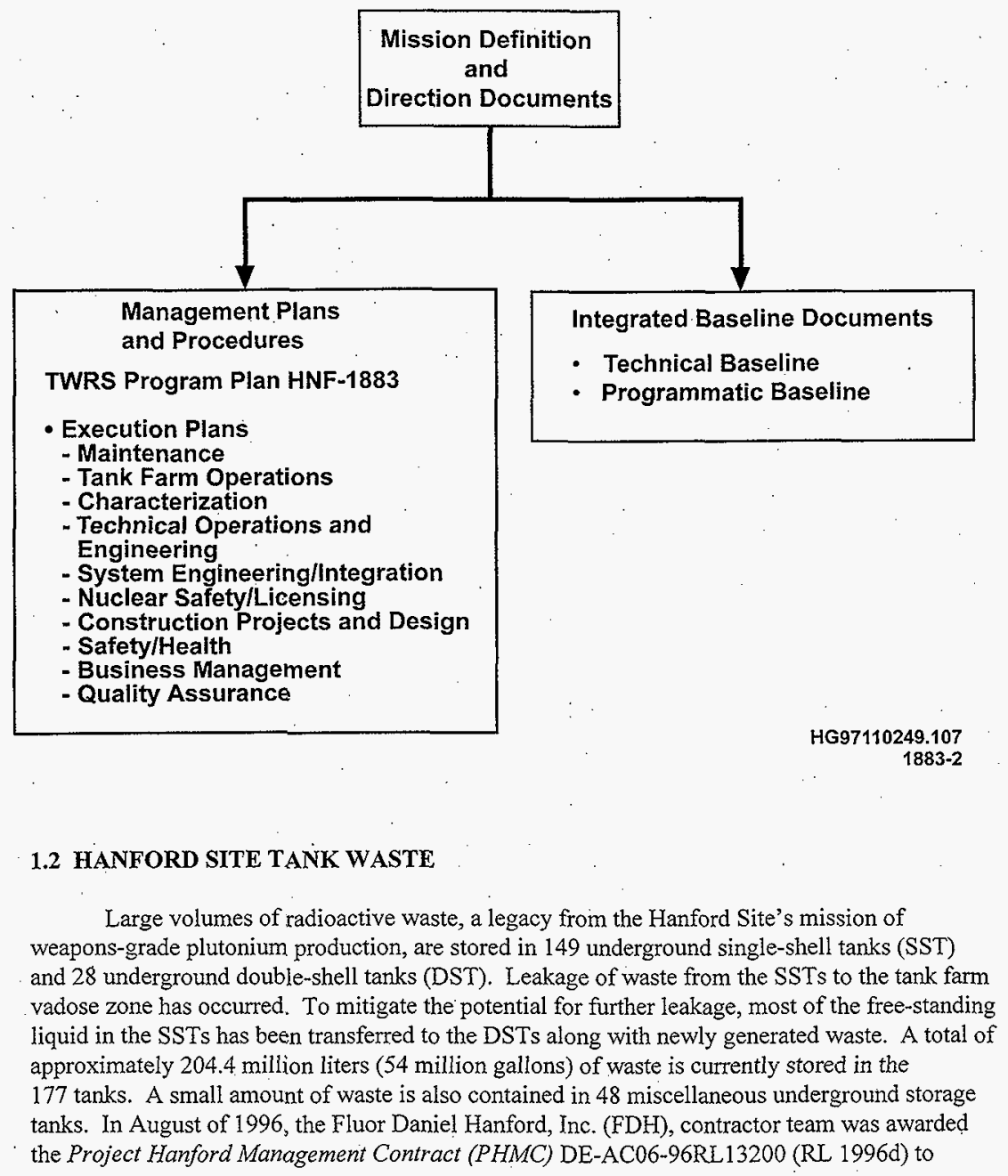


perform the management and integration (M\&I) contractor function for the DOE's Hanford Site. As part of that contract, Lockheed Martin Hanford Corporation (LMHC) was assigned responsibility for the TWRS Project.

The DOE has completed an environmental impact statement for the TWRS Project, DOE/EIS-0189, Tank Waste Remediation System, Hanford Site, Richland, Washington, Final Environmental Impact Statement (DOE and Ecology 1996). In the Environmental Impact Statement (EIS) record of decision (ROD), Record of Decision for the Tank Waste Remediation System, Hanford Site, Richland, WA (62 FR 8693), the DOE identified actions to be taken to manage and dispose of the radioactive, hazardous, and mixed waste within the Hanford Site tank farms. The DOE plans to conduct this waste remediation mission in two phases and to use private contractors to design, build, and operate the facilities for immobilizing the waste. During Phase 1, the TWRS Project is responsible for all TWRS Project mission components except for the waste immobilization function. The major activities that support Phase 1 are depicted in Figure 3, TWRS Project Life-Cycle. The scope and schedule for these activities are consistent with guidance provided from the U.S. Department of Energy, Richland Operations Office (RL) to FDH and the TWRS Project. The TWRS Project responsibilities will be modified to support subsequent phases of the mission. Interfaces outside of TWRS, including those with other Hanford Contractors, are the responsibility of FDH, HNF-MP-001, Project Hanford Management Contract Management and Integration Plan (FDH 1997y).

Under the National Environmental Policy Act of 1969 (NEPA), the TWRS ROD also committed the project to the additional reviews listed below. Support of these reviews is planned and discussed in further detail in HNF-1773, TWRS Environmental Program Plan (Borneman 1998).

- Review of the upgrade of certain instrumentation, tank ventilation, and electrical. systems to upgrade the regulatory compliance status of the current tank farm facilities (i.e., Project W-314). This review is complete.

- Review of the entire TWRS Project before proceeding into Privatization Phase 1, Part B (scheduled for May 1998) and prior to the start of Privatization Phase 1, Part B hot operations (scheduled for December 2002).

- Review of documentation addressing the site selection for privatization facilities (complete in 1996).

- Review of documentation addressing the on-site disposal of immobilized lowactivity waste (planned for completion in fiscal year [FY] 1998).

- Review of documentation addressing single-shell tank and double-shell tank closure (planned to complete in 2002). 
Figure 3. Tank Waste Remediation System Project Life Cycle.

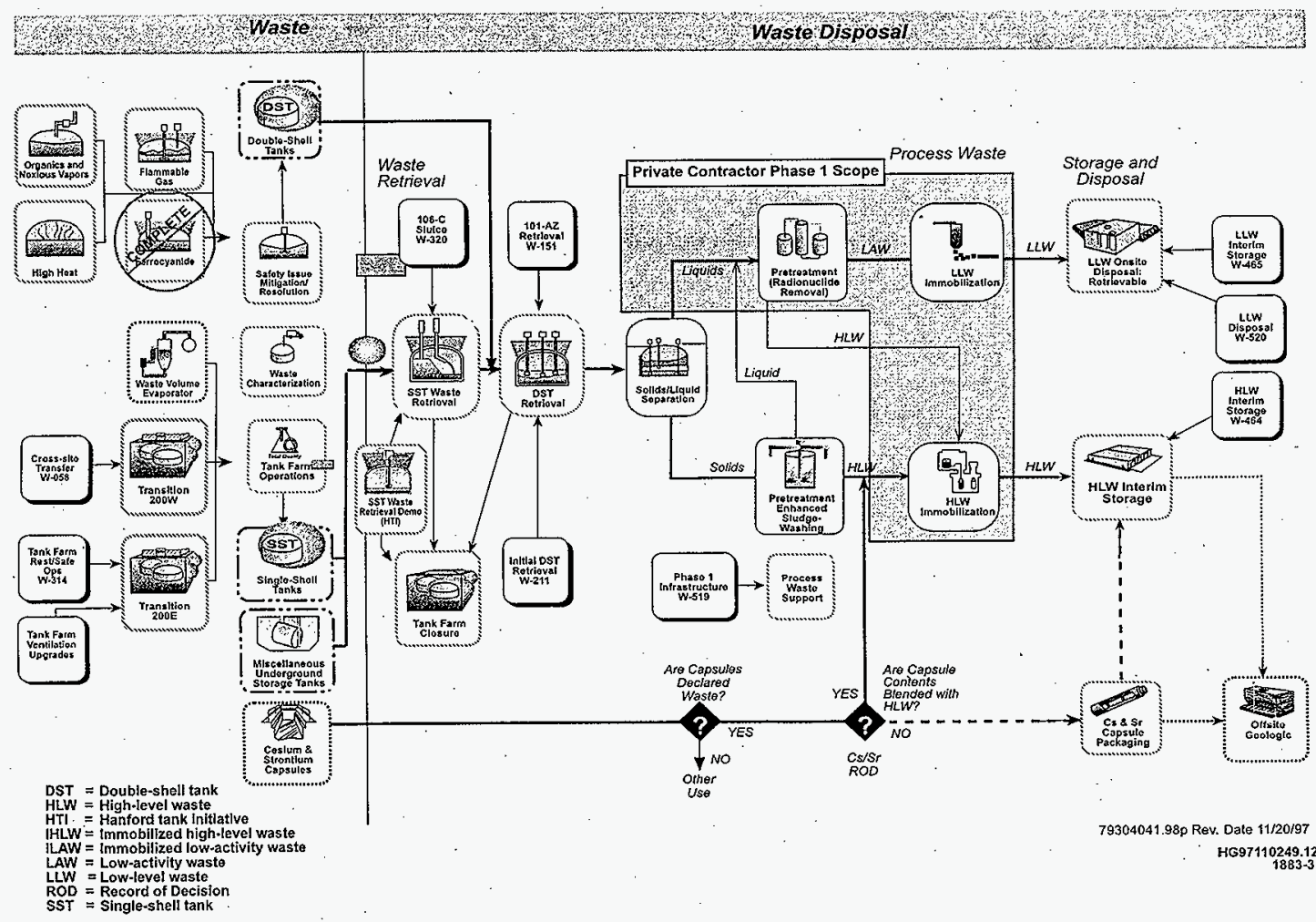




\subsection{MISSION}

The TWRS Project mission is described and analyzed in HNF-SD-WM-MAR-008, Tank Waste Remediation System Mission Analysis Report (TWRS MAR) (Acree 1998). The TWRS Project mission scope includes the activities needed to (1) resolve safety issues; (2) operate, maintain, and upgrade the tank farms and supporting infrastructure; (3) construct, operate, and maintain facilities that are necessary for waste storage, retrieval, separation, immobilization, and disposal or shipment; (4) characterize, retrieve, separate, and immobilize the waste for disposal; (5) provide for the disposition of the cesium and strontium capsule contents; (6) provide disposal of immobilized low-activity waste (ILAW) on site; (7) provide interim storage of immobilized high-level waste (IHLW) until it is shipped to the national geologic repository; and (8) provide for the decontamination and decommissioning and closure of TWRS Project facilities and postclosure monitoring.

On September 25, 1996, the DOE signed contracts with two private contractor teams to provide conceptual designs for an LAW treatment facility and a combined LAW/HLW treatment facility (i.e., Phase 1A). In May 1998, DOE will decide whether to proceed with the definitive design, construction, and operation (i.e., Phase 1B). The selected contractors will then build and operate the required facilities to produce ILAW and IHLW products that DOE will accept for storage and disposal. Hot operations of these contractor facilities is planned to begin in June 2002 and run through December 2011 (provided that DOE decides to contract for processing the maximum order quantities of waste). During this period, the private contractors will immobilize tank waste, meeting specified composition envelopes (three for LAW and one for HLW). TWRS Project planning assumes that DOE will award contracts for one LAW immobilization facility and one combined LAW/HLW immobilization facility. This approach will result in immobilizing up to $13 \%$ of the Hanford Site tank waste.

As noted in Section 1.1, this plan focuses on the TWRS Project contractor roles and responsibilities during the Phase 1 mission (1998 through 2011). The major areas of responsibility of the TWRS Project contractor for this demonstration phase of the mission are ensuring that (1) the required feed is retrieved and delivered to the private contractors on schedule; (2) the resulting waste products are accepted from the private contractors, and safely stored/disposed; and (3) the required infrastructure is provided to support the private contractor facility operations. The TWRS Retrieval and Disposal Mission (and components) is shown in the context of the entire TWRS mission in Figure 4. The components of the Retrieval and Disposal Mission are summarized in the following sections. 
Figure 4. TWRS Project Retrieval and Dispoșal Mission Summary.

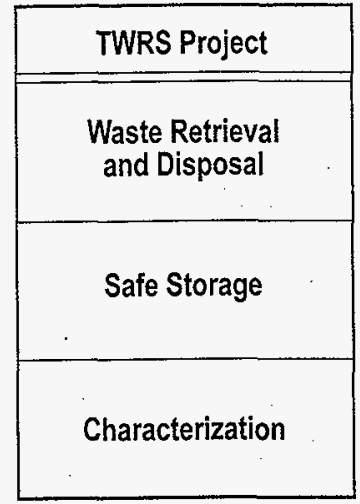

SST $=$ Single-shell tank

TWRS $=$ Tank Waste Remediation System
Phase 1

- Waste Feed Delivery

- Infrastructure Support

- Immobilized Waste Storage and Disposal

- Technology Development and Demonstration

\section{Phase 2}

- SST Waste Retrieval

- Immobilized Waste Disposal

- Site Closure

\subsection{COMPONENTS OF THE TWRS RETRIEVAL AND DISPOSAL MISSION}

The TWRS Phase IB Retrieval and Disposal Mission is addressed through three key mission components (Waste Feed Delivery, Immobilized Waste Storage and Disposal, and Infrastructure Support). The mission of each is summarized in the following sections. The Tank Closure component of the mission is being developed in parallel. Tank Closure is not, however, an issue for near-term support of Phase $I$ and is not detailed in this plan.

\subsubsection{Waste Feed Delivery}

The operating scenarios defining the operational and process activities that comprise the Phase $1 \mathrm{~B}$ mission have been thoroughly analyzed. Activities required to successfully deliver waste feed meeting the required composition envelopes to the private contractors have been identified. The sequence in which these activities must be performed and the schedules for these activities have been identified and documented. Activities have been assigned to "owner" organizations, and schedule details and cost estimates have been generated. New and upgraded facilities and/or equipment to support waste feed delivery to the private contractors have been identified and are being assigned to projects. This process will continue as the requirements to support tank waste retrieval mature. 
Four major projects currently support waste feed delivery. Project W-151 demonstrates, at full scale, the effectiveness of mixer pumps in mobilizing waste sludge for transfer. Project W-211 provides the required retrieval and processing systems for ten DSTs for delivery of feed to the private contractors. A follow-on project will be needed to provide retrieval systems for four additional tanks under current baseline assumptions. Project W-314 provides tank farm system upgrades in support of continued operations and waste feed delivery. These upgrades cover waste transfer systems, instrumentation, electrical systems, and ventilation systems. Project W-320 resolves the high-heat safety issue associated with tank C-106 and provides HLW sludge to be used as feed to the private contractor. These activities are described in more detail in HNF-1881, Tank Waste Remediation System Retrieval and Disposal Mission Waste Feed Delivery Plan (Potter and Treat 1998).

\subsubsection{Immobilized Waste Storage and Disposal}

All activities required to safely store and dispose of the immobilized waste products from the private contractors are known and included in the program baseline. Under current baseline assumptions, there will be approximately $1200 \mathrm{IHLW}$ canisters that are $0.6 \mathrm{~m} \mathrm{x} 3 \mathrm{~m}$ ( $2 \mathrm{ft} \times 10 \mathrm{ft}$ ). They will be stored in the interim in two vaults of the Canister Storage Building until they are disposed in the national geologic repository. Project W-464 provides these two cells. Also, under current baseline assumptions, a maximum of approximately 18,000 ILAW packages that are $1.2 \mathrm{~m} \mathrm{x} 1.2 \mathrm{~m} \times 1.8 \mathrm{~m}$ ( $4 \mathrm{ft} \times 4 \mathrm{ft} \times 6 \mathrm{ft}$ ) will be produced and disposed of. Project W- 465 will convert the three remaining TWRS grout vaults to dispose of the first 3 years' of production of ILAW packages. A follow-on project, Project W-520, will build the additional facilities to dispose the remainder of Phase 1 ILAW product.

These activities are described in more detail in HNF-1517, Tank Waste Remediation System Retrieval and Disposal Mission Immobilized Low-Activity Waste Disposal Plan (Shade 1997) and HNF-1751, Tank Waste Remediation System Retrieval and Disposal Mission Immobilized High-Level Waste Storage Plan (Calmus 1997).

\subsubsection{Infrastructure Support}

The supporting infrastructure needed by the private contractors will be provided by Project W-519. This project will provide access roads and land for facility siting, raw and potable water, electricity, and transfer pipelines for liquid effluents.

These activities are described in more detail in HNF-1882, Tank Waste Remediation System Retrieval and Disposal Mission Infrastructure Plan (Root and Potter 1998). 


\subsection{REQUIREMENTS}

The TWRS Project and its programs, systems, and processes must satisfy numerous requirements and guidance documents. These requirements dictate, to a substantial degree, the work scope, schedule, and budget for the tasks supporting the TWRS Retrieval and Disposal Mission. The sources of these requirements and guidance include promulgated laws and regulations (e.g., U.S. Environmental Protection Agency, Washington Department of Ecology), orders and directives (e.g., DOE Orders 425.1, Startup and Restart of Nuclear Facilities, and 430.1, Life Cycle Asset Management), implementing procedures (e.g., safety authorization bases), professional organizations and societies (e.g., American National Standards Institute), contractual documents (e.g., PHMC), and planning guidance (e.g., Good Practice Guide GPG-FM-010, Project Execution and Engineering Management Planning).

The requirements derived from these sources are categorized in 20 functional areas (Table 1), organized by facility (e.g., 200 Area Tank Farms and 242-A Evaporator), and are maintained in the Environmental Requirements Management Interface (ERMI n.d.) database. This database also maintains a link between the identified requirements and the implementing plans and procedures.

Table 1. Standards and Requirements Identification Documents for Functional Areas.

$\begin{array}{|ll|}\text { 1. Management Systems } & \text { 11. Radiation Protection } \\ \text { 2. Quality Assurance } & \text { 12. Fire Protection } \\ \text { 3. Configuration Management } & \text { 13. Packaging \& Transportation } \\ \text { 4. Training \& Qualification } & \text { 14. Environmental Restoration } \\ \text { 5. Emergency Management } & \text { 15. Decontamination \& Decommissioning } \\ \text { 6. Safeguards \& Security } & \text { 16. Waste Management } \\ \text { 7. Engineering Program } & \text { 17. R\&D and Experimental Activities } \\ \text { 8. Construction Program } & \text { 18. Nuclear Safety } \\ \text { 9. Operations } & \text { 19. OS\&H } \\ \text { 10. Maintenance } & \text { 20. Environmental Protection }\end{array}$

OS\&H = Occupational Safety and Health

$R \& D=$ Research and Development

The requirements and guidance from all sources are considered when developing the TWRS Project technical baseline, defining mission work scope, and for establishing administrative systems. Figure 5 illustrates the integration of these requirements and guidance in support of the integrated baseline. In addition to use of the Standards and Requirements Identification Document (S/RID), key requirements for the Retrieval and Disposal Mission are also captured in documents such as the HNF-1901, Tank 
Figure 5. Requirements Management.

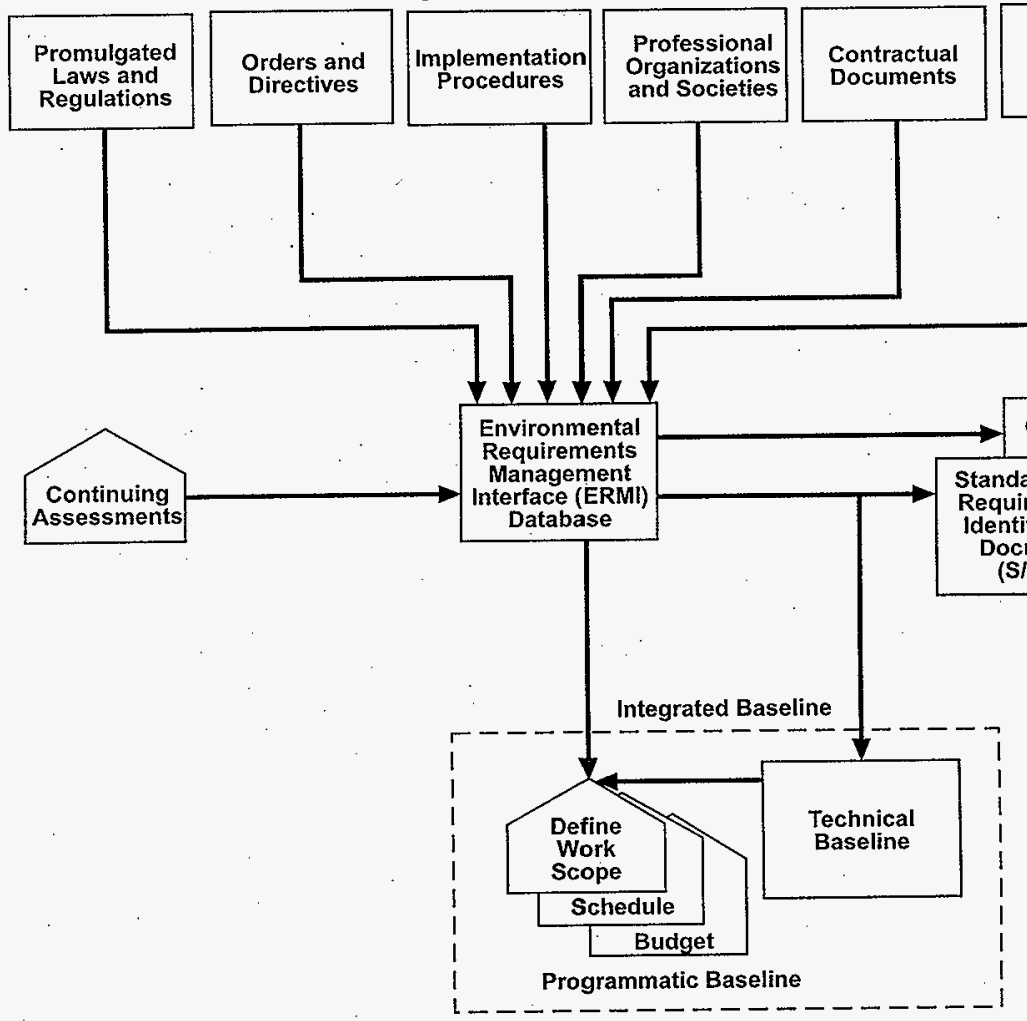

Other Reports 
Waste Remediation System Retrieval and Disposal Mission Technical Baseline Summary Description (Treat et l. 1998), HNF-1947, Tank Waste Remediation System Engineering Plan (Rifaey 1998); HNF-1900, Tank Waste Remediation System Configuration Management Plan (Vann et al. 1998), and HNF-1945, Tank Waste Remediation System Retrieval and Disposal Mission Key Enabling Assumptions (Baldwin et al. 1998).

Key technical and programmatic requirements that must be satisfied by the TWRS Project are integrated into the management practices and systems described in Section 9.0, and it is through these management practices and systems that such requirements are satisfied. As noted in Figure 5, this is an iterative process of continuing assessments as the project matures and source requirements and guidance are revised.

\subsection{TECHNICAL APPROACH}

\subsection{TECHNICAL STRATEGY}

The technical strategy for developing the technical baseline and program (scope, schedule, and cost) baseline for the TWRS Retrieval and Disposal Mission described here focuses on Phase 1 of TWRS Privatization. The Technical Baseline is the science and engineering, equipment, facilities, materials, qualified staff, and enabling documentation needed to startup and complete mission objectives. It is an integral element of the Technical Basis for Operations (Figure 6). Systems engineering methodology is applied to develop the Technical Baseline. This methodology transforms and integrates the operational needs into a system of defined performance characteristics. The Technical Baseline is essentially a solution set to the mission requirements (i.e., how we ensure that systems and operations perform as needed and that functions and requirements are satisfied). The HNF-2016, Tark Waste Remediation System Technical Baseline Summary Description (Raymond 1998), summarizes the current state of the TWRS Project technical baseline. The HNF-1901, Tank Waste Remediation System Retrieval and Disposal Mission Technical Baseline Summary Description (Treat et al. 1998), summarizes the TWRS Retrieval and Disposal Mission Technical Baseline and specifically identifies the documents that represent the Retrieval and Disposal Mission Technical Baseline and the official sources of information contained in each document.

To develop the Technical Baseline, the upper level requirements and constraints were analyzed and assigned to components of the TWRS Project (e.g., feed delivery system; immobilized waste storage and disposal systems; infrastructure support systems; waste management facilities) (see HNF-SD-WM-MAR-008, Tank Waste Remediation System Mission Analysis Report [Acree 1998]). The DOE contracts with the private contractors for waste immobilization (DE-RL06-96RL13308 [RL 1996a] and DE-RL06-96RL13309 [RL 1996c]) established operational interfaces and requirements that were used to derive planning assumptions for the Retrieval and Disposal Mission (see Section 2.0 of this plan). Studies have 
Figure 6. Technical Basis for Operations.

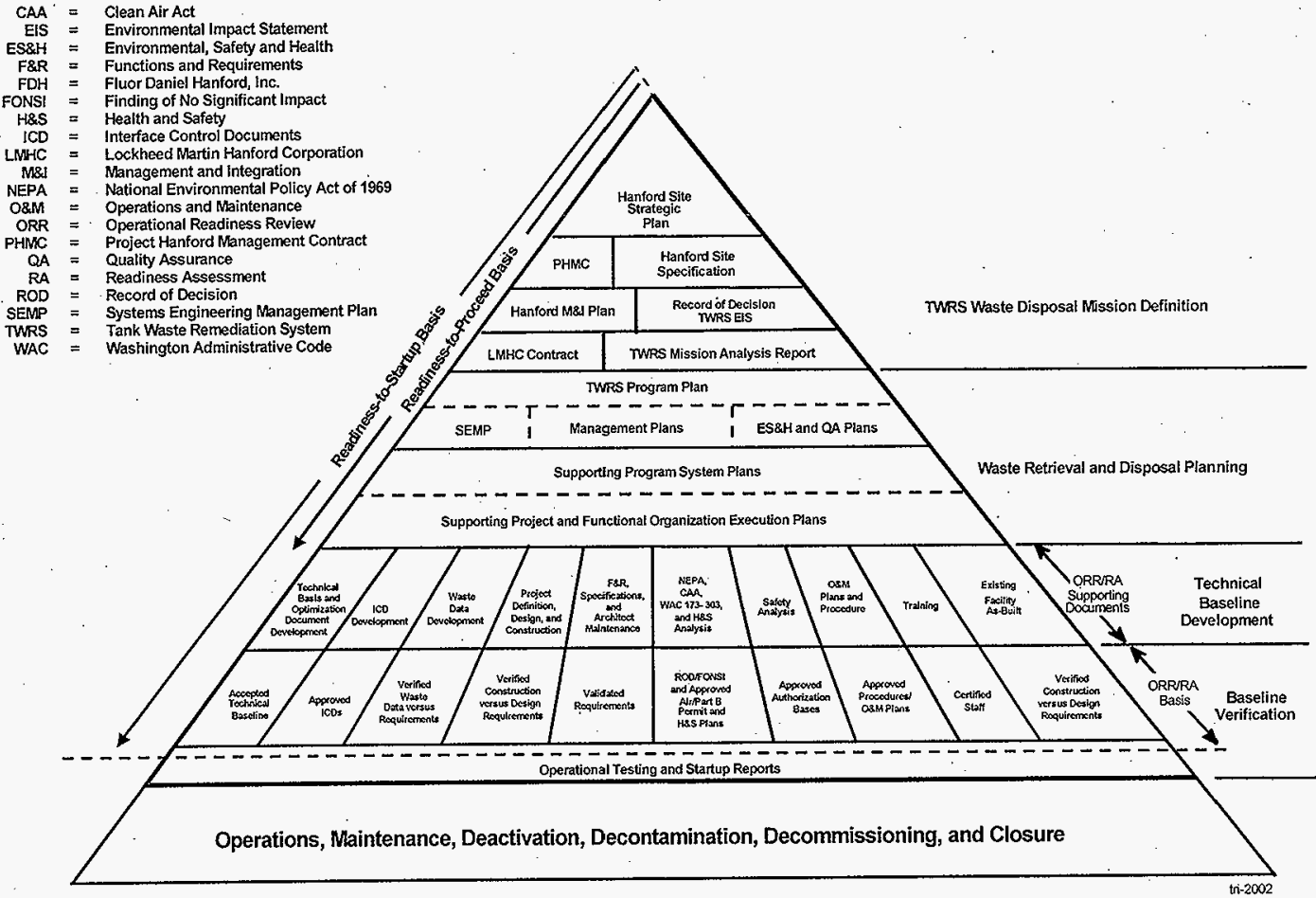


been conducted (or are planned) to develop process and equipment requirements (e.g., HNF-SD-WM-WP-012, Tank Waste Remediation System Operations and Utilization Plan [Kirkbride et al. 1997]) for the Retrieval and Disposal Mission. The existing TWRS Project facilities and operations perform many of the functions required for the Retrieval and Disposal Mission. For example, equipment and facilities to store, prepare, and transfer waste exist or are planned (i.e., addressed in ongoing projects). Existing facilities (TWRS Project grout vaults) or facilities under construction (Spent Nuclear Fuel Canister Storage Building) can be modified to accommodate the initial immobilized waste products. As system and component requirements are developed from upper-level requirements, the capabilities and constraints of the existing hardware and facilities are evaluated to determine if components need to be added or replaced to meet mission requirements (e.g., to move LAW feed from source tanks to staging tanks with the required system level performance characteristics). Plans for technical studies, process tests, equipment design and installation are then incorporated into the program planning base.

As illustrated in Figure 7, TWRS Retrieval and Disposal Master Plan, activity schedule logics were developed using mission-based planining assumptions, process requirements, and information for existing or planned hardware and facilities. The activity schedule logics (e.g., the Level 1 Logics [FDH 1998] discussed in Section 6.0), reflect the understanding of the activities (studies, analyses, hardware, process, and key documentation) needed to carry out the Retrieval and Disposal Mission. The logics (and backup material) describe the activities, their sequence, duration, and relationships. This information is used to develop a critical path schedule for the Retrieval and Disposal Mission. The detailed schedules (at the work package level) are resource loaded and costs are developed. The integrated scope, schedule, and cost program baseline for the mission is rolled up to create a master plan. This master plan is the upper-level schedule for activities, relationships and dependencies, funding profile, and other resources required for the mission life cycle. The integrated program baseline and the master plan then drive the multi-year work plan and annual updates for work authorization. This is discussed in the following sections and in HNF-1946, Tank Waste Remediation System Retrieval and Disposal Mission Initial Updated Baseline Summary (Swita et al. 1998).

\subsection{TECHNOLOGY DEVELOPMENT}

The TWRS Project works through RL with the DOE Office of Technology Development (EM-50) to provide safe and cost effective technical solutions for this mission. The DOE EM-50 office is an important source of information on new technologies that might improve operational performance. The DOE EM-50 provides information on the performance of currently deployed technologies which helps TWRS Project decision making regarding technical alternatives. The DOE EM-50 office has been an important collaborator in developing and deploying technologies that support the TWRS Project mission. Examples include the light duty utility arm, Hanford Tanks Initiative, and laboratory studies of sludge washing and waste glass performance. 
Figure 7. Tank Waste Retrieval and Dispoșal Master Plan.
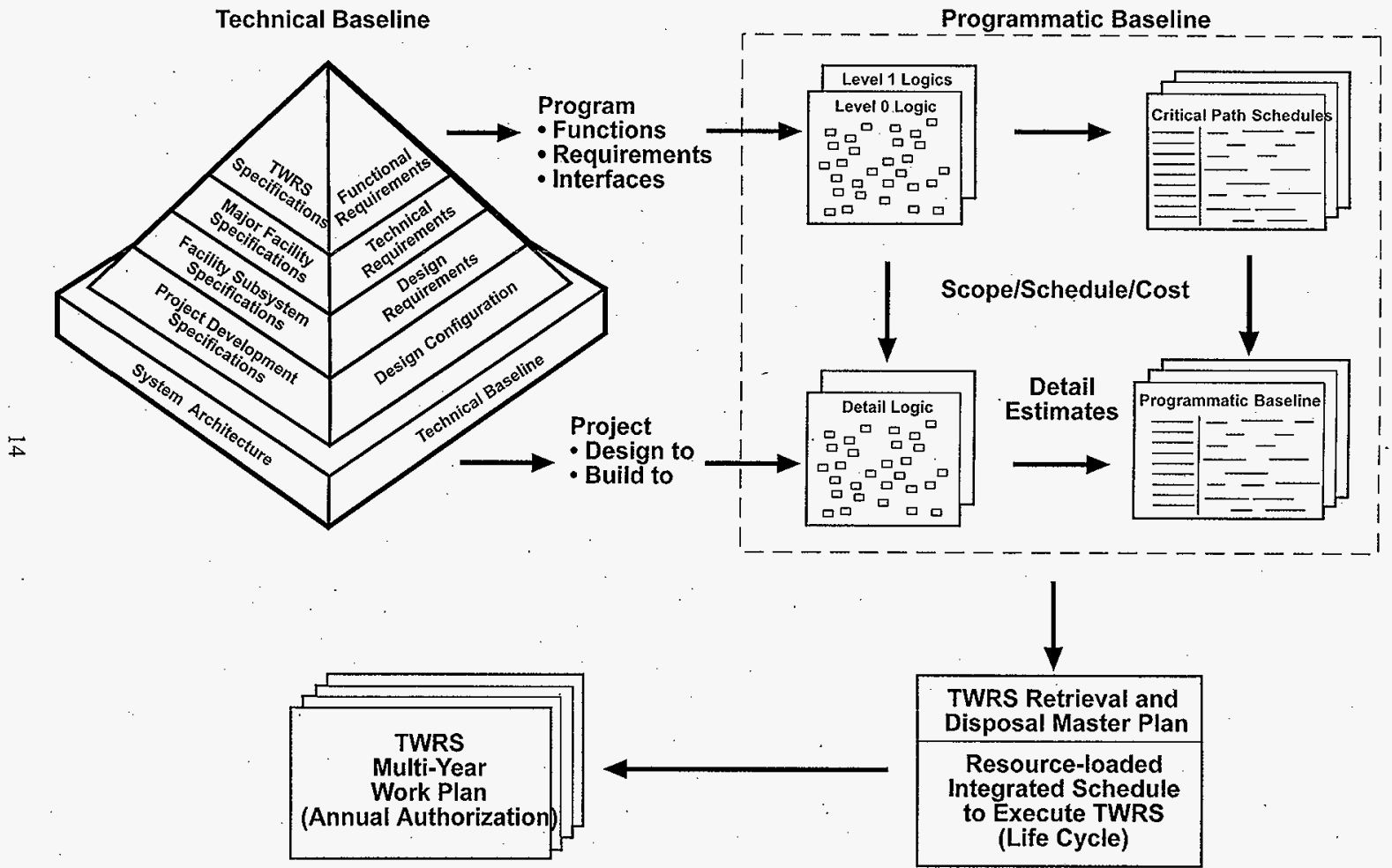

TWRS $=$ Tank Waste Remediation System 
A Site Technology Coordination Group (STCG) at Hanford also helps the TWRS Project to gain an awareness of technical opportunities that could result in significant cost and schedule improvements to the TWRS Project baseline program. The STCG reviews site technical needs and makes funding recommendations for technologies supporting Hanford Site (and TWRS Project) needs. Funding and staff support for the STCG and technology needs identification are included in the TWRS Project budget.

\subsection{WORK BREAKDOWN STRUCTURE}

Figure 8, Tank Waste Remediation System Work Breakdown Structure (WBS), is the framework for organizing work for the TWRS Project. This WBS is consistent with the TWRS Project life-cycle requirements and responds to the functions and requirements identified in the TWRS Project Technical Baseline. The WBS divides the retrieval portion of the TWRS Project work scope into six functional areas or programs identified by a unique Project Baseline Summary (PBS) number (e.g., Retrieval is PBS TW04).

Figure 9, TWRS Retrieval and Disposal Work Breakdown Structure, identifies a subdivision of these programs into 11 activities that have been further subdivided into 73 cost accounts to better define work scope. Work that is designated as Phase 2 is shaded and will be covered in more detail in a later revision to this program plan. The TWRS Project has been assigned responsibility for Phase 1 work scope in Waste Retrieval (TW04), Privatization Infrastructure (TW.08), and Immobilized Tank Waste Storage \& Disposal (TW09). The TWRS Project has also been assigned the "M\&I Vendor Interface" component of the Process Waste . Support PBS (TW05). Other components of the WBS are assigned to DOE (TW05) or to the private contractors (TW07).

Table 2, Tank Waste Retrieval Work Breakdown Structure Responsibility, summarizes the organizational responsibility for the WBS Level 4 (PBS) and Level 5 (Activity) work scope. Section 8.0 provides additional detail on the roles and responsibilities of the TWRS Project organizational elements.

\subsection{TANK WASTE REMEDIATION SYSTEM PROJECT LOGIC}

The TWRS Project Level 0 Logic (FDH 1998) (Figure 10) is a tool for translating the TWRS Project mission requirements identified in the TWRS MAR (Acree 1998) into a sequence 
Figure 8. Tank Waste Remediation System Work Breakdown Structure.

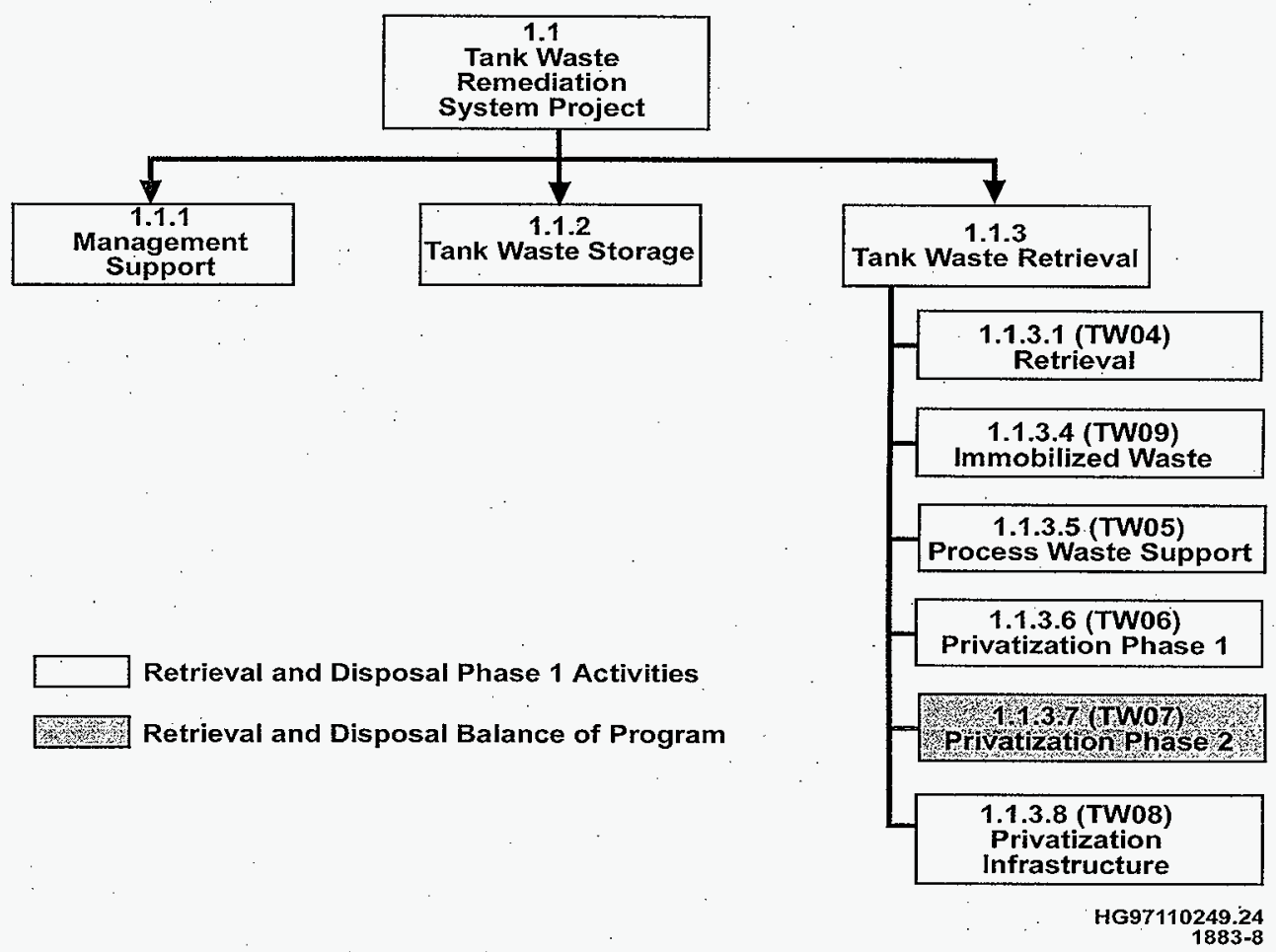




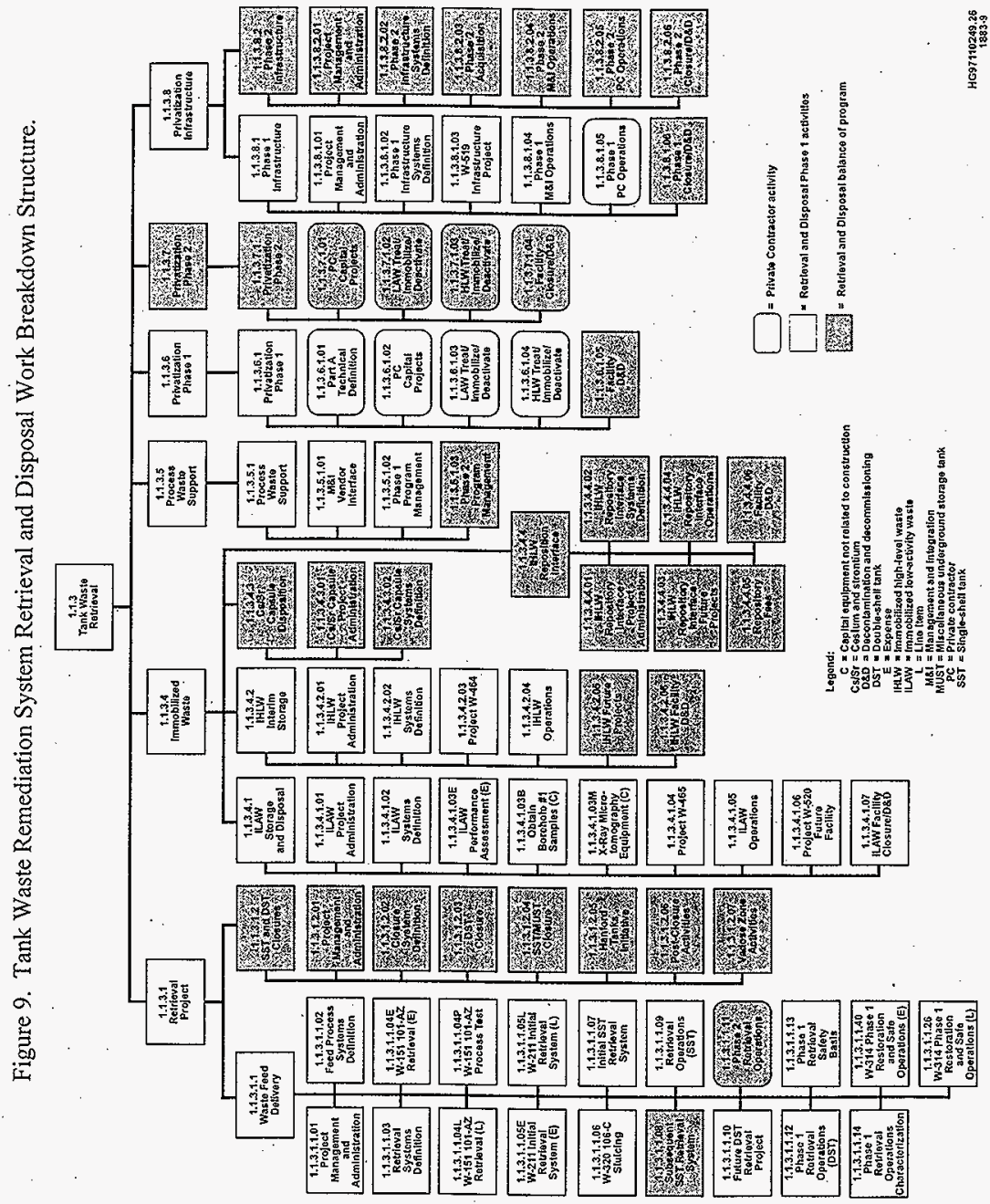


Table 2. Tank Waste Remediation System Retrieval and Disposal Mission Work Breakdown Structure Responsibilities.

\begin{tabular}{|c|c|c|c|}
\hline \multicolumn{2}{|c|}{$\begin{array}{c}\text { Project Baseline Summary } \\
\text { (Level 4) }\end{array}$} & \multirow[t]{2}{*}{$\begin{array}{c}\text { Activity Description } \\
\text { (Level } 5 \text { except as noted) }\end{array}$} & \multirow{2}{*}{$\begin{array}{l}\text { Responsible Tank Waste } \\
\text { Retrieval Organization } \\
\text { (except as noted in italics) }\end{array}$} \\
\hline PBS \# & PBS description & & \\
\hline \multirow[t]{3}{*}{ TW04 } & \multirow[t]{3}{*}{ Waste Retrieval } & Waste Feed Delivery. & Waste Feed Delivery \\
\hline & & SST \& DST Closure & Tank Closure \\
\hline & & $\begin{array}{l}\text { Hanford Tanks Initiative } \\
\text { (6) }\end{array}$ & $\begin{array}{l}\text { Development and } \\
\text { Demonstration }\end{array}$ \\
\hline \multirow[t]{2}{*}{ TW05 } & \multirow{2}{*}{$\begin{array}{l}\text { Process Waste } \\
\text { Support }\end{array}$} & Process Waste Support & $P N N L$ \\
\hline & & M\&I Vendor Interface (6) & Planning \& Integration \\
\hline TW06 & Privatization Phase 1 & Privatization Phase 1 & $R L$ \\
\hline TW07 & Privatization Phase 2 & Privatization Phase 2 & $R L$ \\
\hline TW08 & $\begin{array}{l}\text { Privatization } \\
\text { Infrastructure }\end{array}$ & Phase $1 \& 2$ Infrastructure & Infrastructure Support \\
\hline \multirow[t]{4}{*}{ TW09 } & \multirow{4}{*}{$\begin{array}{l}\text { Immobilized Tank } \\
\text { Waste Storage \& } \\
\text { Disposal }\end{array}$} & ILAW Storage/Disposal & \multirow{4}{*}{$\begin{array}{l}\text { Immobilized Waste Storage } \\
\text { and Disposal }\end{array}$} \\
\hline & & IHLW Storage & \\
\hline & & Cs/Sr Capsule Disposal & \\
\hline & & $\begin{array}{l}\text { IHLW Repository } \\
\text { Interface }\end{array}$ & \\
\hline \multicolumn{2}{|c|}{$\begin{array}{l}\text { Cs = cesium. } \\
\text { DST = double-shell tank. } \\
\text { IHLW = immobilized high-level waste. } \\
\text { ILAW = immobilized low-activity waste. } \\
\text { M\&I = Management and Integration. }\end{array}$} & \multicolumn{2}{|c|}{$\begin{array}{l}\text { PNNL = Pacific Northwest National Laboratory. } \\
\text { PBS = Project Baseline Summary. } \\
\text { RL = U.S. Department of Energy, Richland Operations } \\
\text { Office. } \\
\text { Sr }=\text { strontium. } \\
\text { SST }=\text { single-shell tank. }\end{array}$} \\
\hline
\end{tabular}

of activities necessary to achieve the mission objectives. Figure 10 illustrates the tasks necessary to perform safe and compliant waste storage, the phased approach to tank waste retrieval, waste separation, and immobilized waste storage/disposal, and their logical inter-dependencies. The logic also illustrates how the private contractor activities integrate with the M\&I contractor activities. Included in the logic are reevaluation points for Phase 1 and Phase 2 Privatization as committed to in the Record of Decision for the Tank Waste Remediation System, Hanford Site, Richland, WA (62 FR 8693). 


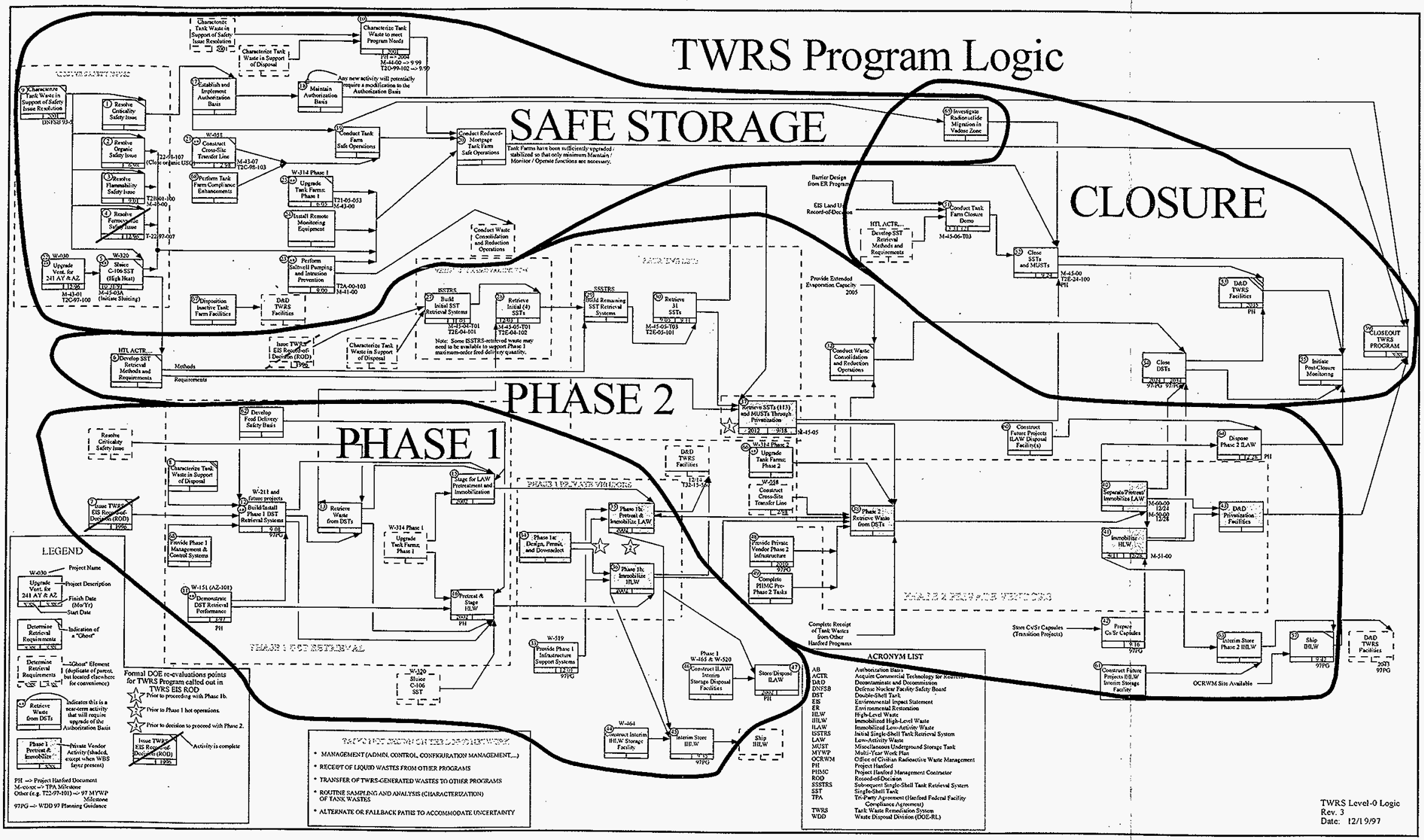


Further decomposition of the TWRS Project Level 0 Logic (FDH 1998) activities generates a set of detailed activities as identified in HNF-1946, Tank Waste Remediation System Retrieval and Disposal Mission Initial Updated Baseline Summary (Swita et al. 1998). The Level 1 Logics evolve from the HNF-1901, Tank Waste Remediation System Retrieval and Disposal Mission Technical Baseline Summary Description.(Treat et al. 1998), and establish the logical relationships and sequence of detailed activities necessary to achieve the TWRS Retrieval and Disposal Phase 1 Mission. The decomposed work scope is organized into a master WBS as a framework for scheduling, estimating resources, and pricing the Phase 1 work scope. The result is a resource-loaded, logic-driven, critical path schedule with supporting activity-based cost estimates that constitutes the program baseline (Swita et al. 1998). Together, the Technical Baseline and the programmatic baseline constitute an executable integrated baseline against which performance is measured and baseline changes are controlled.

\subsection{TWRS RETRIEVAL AND DISPOSAL MISSION SCHEDULE}

The TWRS Project Phase 1B Retrieval and Disposal Mission Summary Schedule is illustrated in Figure 11. The summary schedule depicts the major start and end points of the Phase 1B processing mission. Figure 12 depicts the TWRS Retrieval and Disposal Site Master Baseline Schedule and provides additional detail for the Phase 1B mission activities.

\subsection{ORGANIZATION}

\subsection{STRUCTURE AND PHILOSOPHY}

\subsubsection{Fanford Site Organization}

Figure 13, Hanford Site Organization, identifies the reporting relationships and responsibilities for the contractors supporting the DOE in the Hanford Site cleanup activities. The $R L$ is responsible for overall site management to meet the site cleanup objectives as defined in DOE/RL 96-92, Hanford Strategic Plan (RL 1996b). The FDH (PHMC prime contractor) role is to organize, plan, integrate, and manage all site activities with the exception of the environmental restoration activities, science and technology activities, and TWRS Privatization, which are assigned to other prime contractors. The FDH accomplishes the site cleanup objectives through its contracts with five best-in-class corporations. The LMHC has been assigned responsibility for the TWRS Project and several sitewide function. (e.g. site systems engineering). 
Figure 11. Tank Waste Remediation System Project Phase 1B Retrieval and Disposal Mission Summary Schedule.

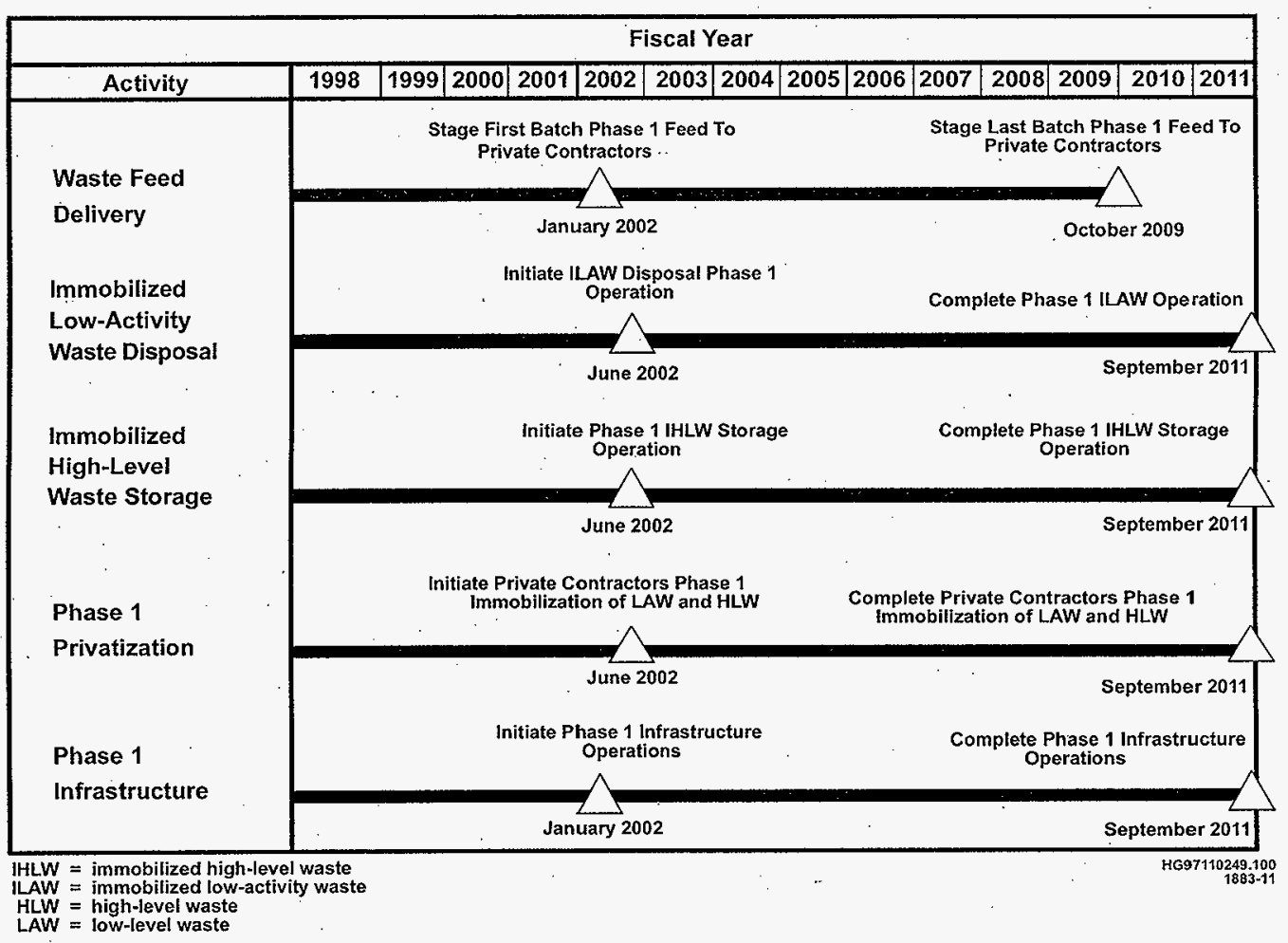




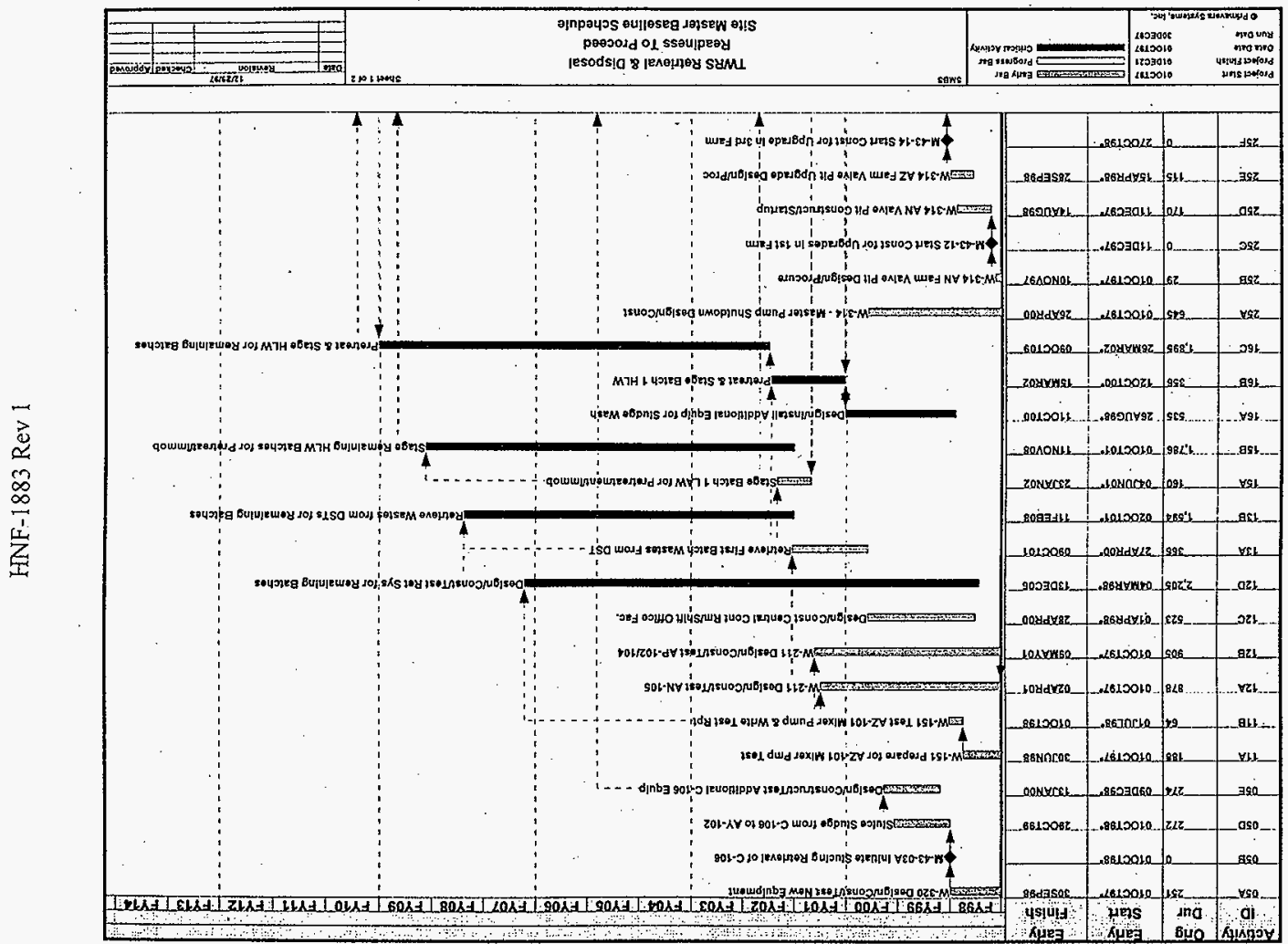

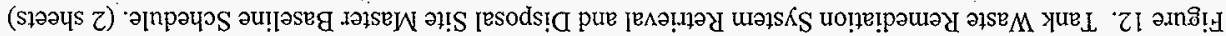


Figure 12. Tank Waste Remediation System Retrieval and Disposal Site Master Baseline Schedule. (2 sheets)

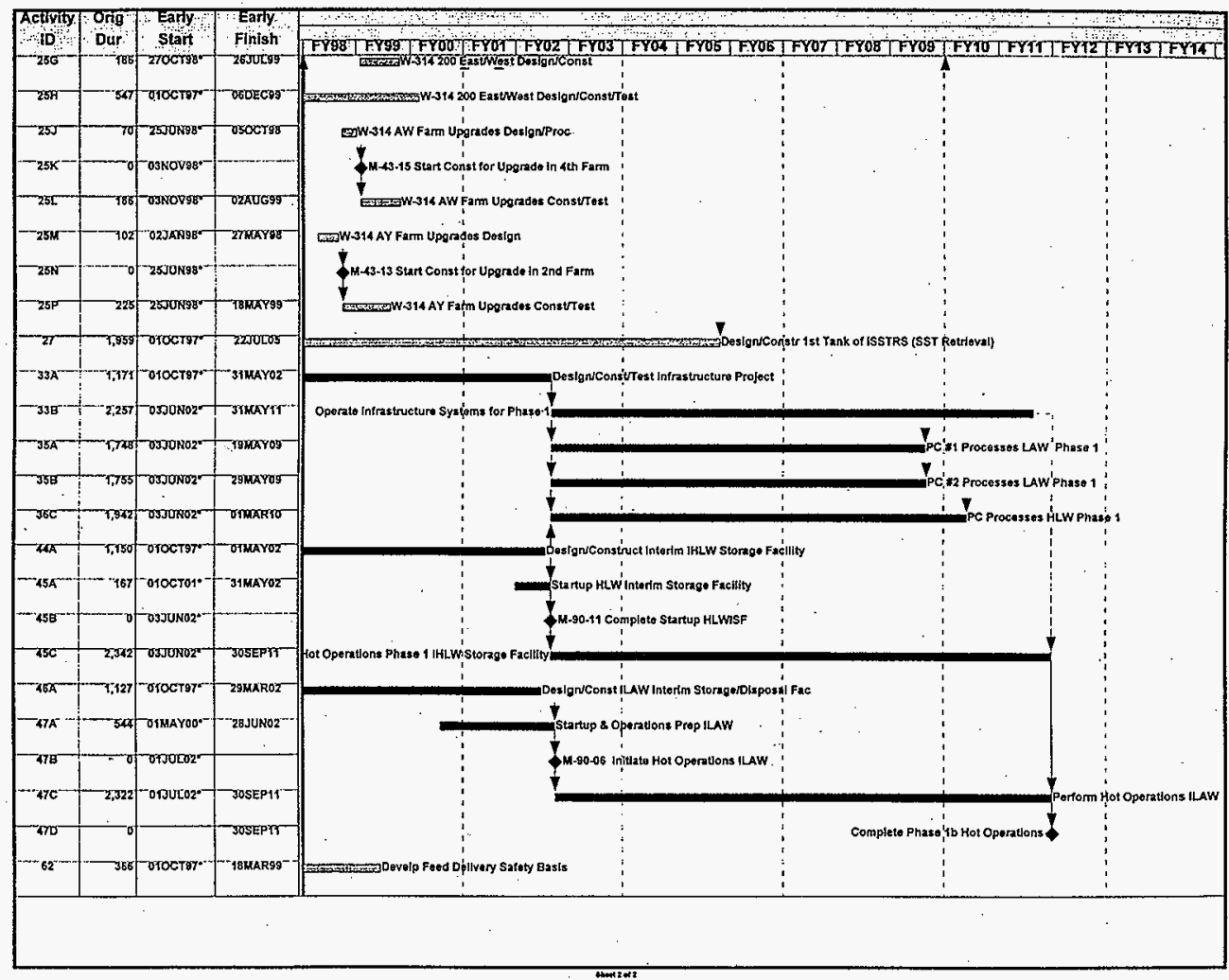


Figure 13. Hanford Site Organizational Relationships.

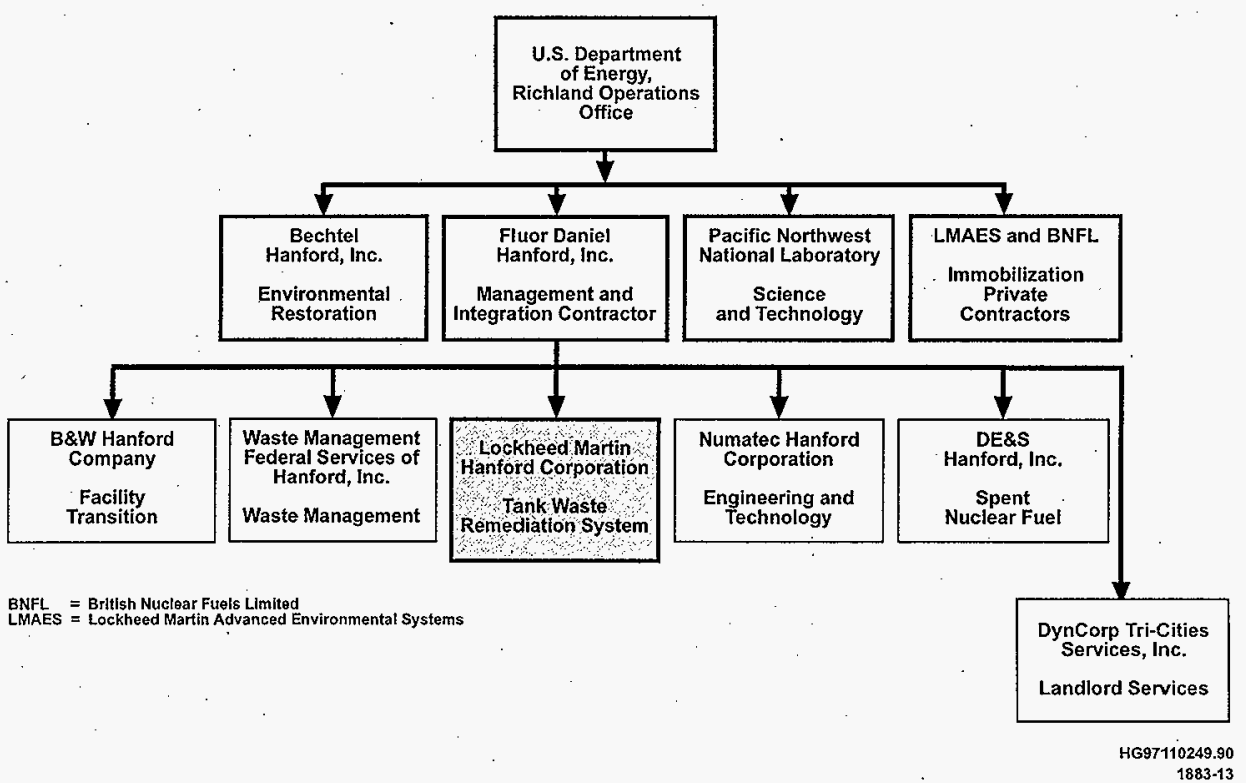




\subsubsection{Tank Waste Remediation System Organization}

The FDH Project Director is responsible for the TWRS Project, as shown in Figure 14, and provides direction to the TWRS subcontractor, LMHC. In accordance with the Subcontract between Fluor Daniel Hanford Company and Lockheed Martin Hanford Corporation Contract 80232764-9-K001 (FDH 1996b), LMHC has established an organizational structure (Figure 15, LMHC/Tank Waste Remediation System Project Organization) to manage TWRS as a project and to provide requisite corporate support. This structure is designed to support all TWRS Project mission objectives (resolve safety issues, safe storage, characterization, retrieval/disposal, etc.) and is aligned with the TWRS Project WBS. The organization is flexible and a matrix management approach is used to support individual programs such as the.TWRS Retrieval and Disposal Program. The primary roles and responsibilities of each TWRS Project organizational element is discussed in Section 8.2.1.

\subsubsection{Organizational Relationship for TWRS Privatization}

Figure 14, TWRS Retrieval and Disposal Mission Organizational Relationships, identifies the relationship of RL to the FDH TWRS Project and the TWR organizations. The FDH Project Director serves as the contractor interface between RL and the TWRS Project. The RL TWRS Program Office provides requirements and oversight for the performance of the TWRS Project work scope. Within the RL TWRS Program Office, the Waste Disposal Division has primary responsibility for oversight of the FDH/LMHC TWRS Project activities and oversight of the private contractors responsible for designing, constructing, and operating the facilities to immobilize the tank waste.

The Pacific Northwest National Laboratory (PNNL) Waste Integration Team supports the RL TWRS Program Office, Waste Disposal Division in this effort. Specifically, the PNNL Waste Integration Team will assist the RL Waste Disposal Division during the life of the program in management, administration, planning, work definition and work performance measurement.

\subsection{ROLES AND RESPONSIBILITIES}

\subsubsection{Tank Waste Remediation System Organization}

The FDH Project Direction Organization is responsible for managing the TWRS Project in accordance with agreements with the DOE and is responsible for integrating the TWRS Project with the remainder of the PHMC projects. The following describes the roles and responsibilities for the LMHC TWRS Project organizations identified in Figure 15.

8.2.1.1. Business Management. Business Management is responsible for the TWRS Project Business Operations, Financial Management, Contracts and Procurement, Corporate Accounting, and Corporate Integration and Development. 
Figure 14. Tank Waste Remediation System Retrieval and Disposal Mission Organizational Relationships.

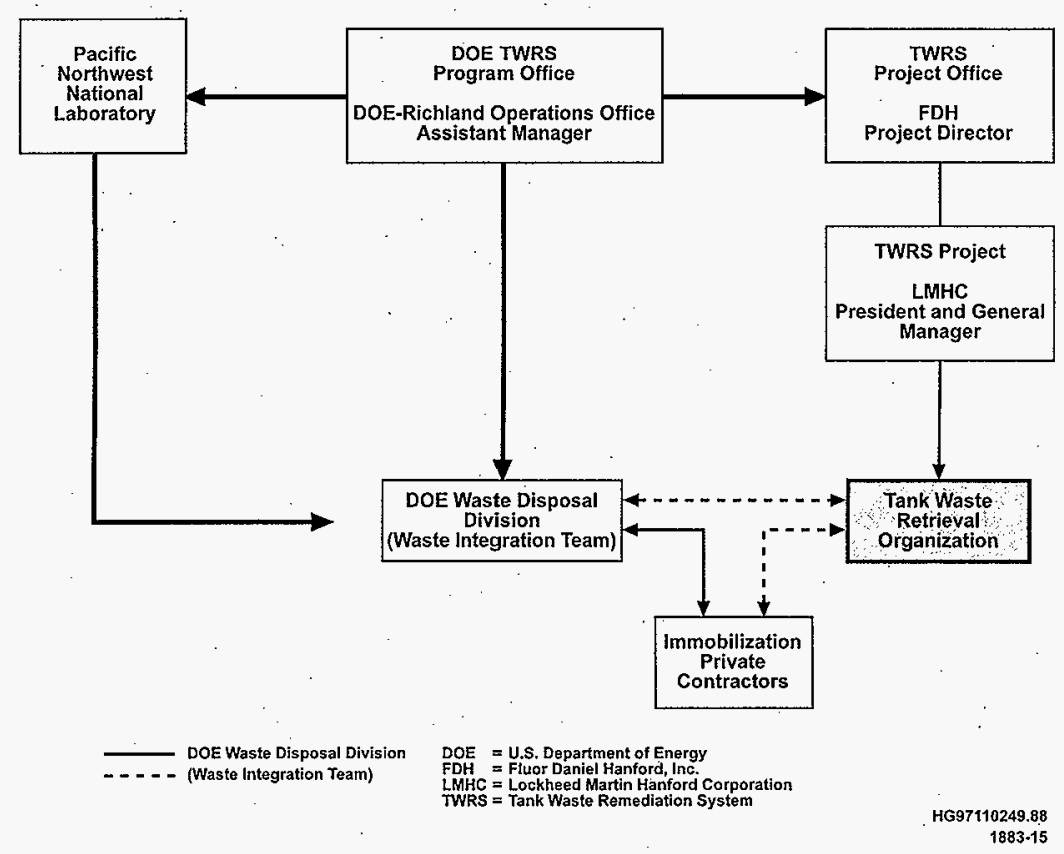


HNF-1883 Rev 1

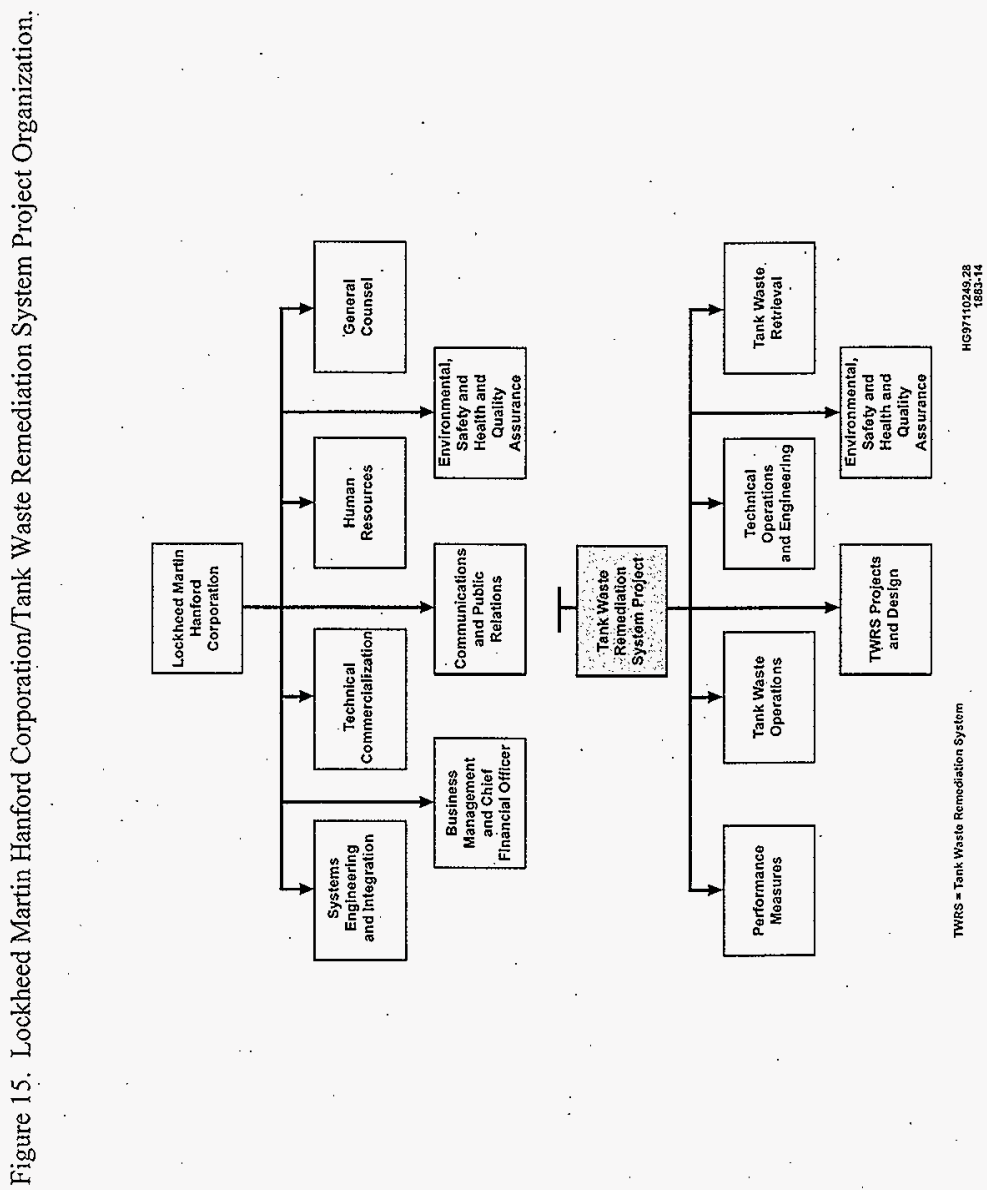


Business Management provides direct support to the TWRS Project in planning, financial management, and business operations coordination/administration. The Business Operations organization provides planners/schedulers to managers of TWRS Project programs and projects to develop PBS schedules as well as detailed level working schedules. This effort includes: ensuring roll-up capability to the Level 1 and Level 0 Logics (FDH 1998) and the Site Master Baseline Schedule; loading resource estimates for each schedule activity and maintaining cost estimate worksheet files; statusing schedules at least once a month; and ensuring the Budgeted Cost of Work Scheduled performance progress is consistent with current schedule status.

The Financial Management organization provides budget analysts to develop financial reports, staffing reports, work orders, purchase orders, and spending forecasts and to assist in developing change requests. The Financial Management organization ensures TWRS personnel are following LMHC Business and Accounting principles.

The Business Operations Coordination/Administration organization provides business representatives and administrative staff to support preparation of multi-year work plans, PBS, unit of analysis sheets, performance agreements, sub operations directives, monthly performance reports, change requests, and other business-related reports as requested by management. This organization also provides training coordination, property management, performance indicator trending and analysis support.

Additional details on the key programmatic and management aspects of the Business Management Organization are provided in Appendix I, TWRS Business Management Organization Execution Plan.

8.2.1.2. Systems Engineering and Integration. The TWRS Project Systems Engineering and Integration (SE\&I) organization manages and administers the systems engineering process and the supporting tools used to develop and maintain a technically defensible integrated TWRS Project technical baseline. It provides systems engineering services to the TWRS Programs and construction projects. SE\&I maintains the TWRS MAR (Acree 1998), which defines and analyzes the TWRS Project mission, identifies the top-level requirements for Phase 1, and establishes the major TWRS Project facilities required to support the mission. The TWRS Project portion of the Hanford Site Technical Baseline Database (HSTD n.d.), the repository for TWRS Project technical baseline data, is maintained under configuration management to assure traceability and integration of functions, requirements, system components, issues, assumptions and interfaces. Integration with the site systems engineering database ensures traceability of TWRS Project mission needs and requirements and the Phase 1 baseline to the site level. The SE\&I also maintains HNF-SD-WM-SEMP-002, Tank Waste Remediation System Systems Engineering Management Plan (TWRS SEMP) (Peck 1998) and the implementing procedures that guide the systems approach used.by the TWRS Project.

SE\&I assists TWRS Retrieval and Disposal Mission programs and projects in developing traceability of functions, requirements, system components, and interfaces. It assists in the integration between programs and functions by identifying specialty engineering needs and working with other support organizations (e.g., Business management, Performance Measures, 
Engineering and Nuclear Safety, Project Design Management) throughout the life-cycle of the program. SE\&I maintains the TWRS Project Level 0 Logics and supports the development of Level 1 (FDH 1998) and more detailed logics by subordinate programs and construction projects. SE\&I also assists in the application of decision management and risk management by the TWRS Project. The key documents (e.g., TWRS MAR [Acree 1998], TWRS SEMP (Peck 1998), and supporting procedures), the tools (e.g., Hanford Site Technical Baseline Database, Hanford Tank Waste Operations Simulator [HTWOS]), and resources (e.g., trained management and staff, contracts) are in place or planned to be in place to support the TWRS Retrieval and Disposal Mission Phase I activities.

Additional details on the key technical, programmatic, and management aspects of the SE\&I Organization are provided in Appendix E, TWRS Systems Engineering and Integration Execution Plan.

8.2.1.3. Technical Operations and Engineering. The TWRS Technical Operations and Engineering manages and directs the technical and operational activities across the TWRS Project and provides the technical expertise, guidance, and support to ensure technical goals are achieved. The Director, TWRS Technical Operations and Engineering, serves as the TWRS Chief Engineer (design authority) and provides interpretive authority for resolution of technical issues. The Director is responsible for TWRS Project technical integration, coordination of Research and Technology Development, long-range program strategy, Process Engineering, and establishing and maintaining an engineering program infrastructure consistent with the TWRS Project mission scope and program logic. To ensure technical integration, the Characterization Project and Readiness-to Proceed effort are matrixed to the Director, Technical Operations and Engineering. Organizational roles and responsibilities and areas of specific support to the TWRS Retrieval and Disposal Mission include the following.

TWRS Strategic Planning. The TWRS Strategic Planning includes the following:

- Research and Technology Development

- Strategic Analysis

- Stakeholder Technical Interface.

TWRS Process Engineering. Process Engineering includes the following activities:

- Provides process engineering and analysis services to the TWRS Project

- Coordinates identification of characterization information needs

- Maintains characterization information databases.

TWRS Engineering and Nuclear Safety. The TWRS Engineering and Nuclear Safety (TENS) section is responsible for the following. Additional details are provided in Appendix $D$, TWRS Engineering and Nuclear Safety Organization Execution Plan and Appendix F, Nuclear Safety and Licensing Organization Execution Plan. 


\section{HNF-1883 Rev 1}

- DST, SST, and Characterization Engineering includes the following:

- Provides technical expertise during facility operation with qualified cognizant engineers and design authorities

- Identifies and maintains the facility system, structure, and component (SSC) configuration in agreement with technical baseline and Authorization Basis

- Ensures operations are governed by technically correct limits incorporated into procedures

- Monitors equipment and process performance and identifies items for further evaluation

- Reviews and controls proposed changes to the facility/activity to ensure consistency with design basis

- Ensures test and surveillance procedures applicable to safety-related equipment correctly evaluate functionality of such equipment.

- Nuclear Safety and Licensing includes the following:

- Develops, delivers, and maintains Authorization Basis documents for TWRS Project facilities including supporting safety analyses and attendant Techrical Safety Requirements

- Develops, implements, and maintains a system for managing safety documentation

- $\quad$ Maintains Unreviewed Safety Question process

- Coordinates interactions with FDH, DOE, and external agencies (e.g., Defense Nuclear Facilities Safety Board) for safety and licensing issues

- Addresses and resolves waste tank safety issues

- Provides management of the criticality program for the TWRS Project.

- Equipment Engineering includes the following:

- Provides cognizant engineers for cross-cutting technical disciplines and subject matter experts for specific equipment and system components, remote imaging, and technical issue resolution 
- Reviews maintenance procedures/activities to ensure work and testing are adequate for components/systems repair and operations verification

- Reviews maintenance procedures, schedules, and activities to ensure that system reliability is provided.

- Configuration Management includes the following:

- Establishes, coordinates, and maintains process methods, mechanisms, and procedures governing the "Conduct of Engineering"

- Performs interpretive authority responsibilities for assigned S/RID (Biebesheimer 1996) functional areas

- Develops and manages the implementation of the TWRS configuration management program.

8.2.1.4. Environmental, Safety, Health, and Quality Assurance. ESH\&QA provides health and safety services in support of all TWRS activities. The TWRS organizations use the Integrated Safety Management System to ensure safety and health functions are integrated into all aspects of work planning, execution, and follow-up. Programs are in place to oversee implementation of DOE Orders, and federal, state, and local laws/regulations; perform audits to verify compliance with regulatory and legal operational requirements; and provide guidance and policy direction for continuous improvement in conduct of work.

The ESH\&QA organization provides professional services in the areas of environmental permitting and oversight, nuclear safety, industrial safety, industrial hygiene, fire protection, emergency preparedness, and quality assurance. These services include both support and independent oversight functions to maintain and improve public safety, safe and healthful working conditions, and the safety of the environment. Additional details on the key technical, programmatic, and management aspects of the Environmental, Safety, Health, and Quality Assurance organization and are provided in Section 9.3, Integrated Safety Management System, and the plans referenced in that section.

8.2.1.5. Radiological Control. Radiological control is an integral element of the Integrated Safety Management System. The TWRS Radiological Control manages and directs the TWRS Radiological Health and Safety programs to ensure radiological protection of workers, the public, and the environment by providing disciplined, technically sound professional radiological services. Additional details are provided in Section 9.3, Integrated Safety Management System.

8.2.1.6. Performance Measures. The Performance Measures organization is responsible for the identification and development of the technical basis for establishing the TWRS Project strategic performance measures for FY 1998 and beyond. 


\section{HNF-1883 Rev 1}

\subsubsection{Tank Waste Operations.}

Tank Farm Operations. Tank Farm Operations (TFO) is responsible for managing TWRS Project facilities including 177 underground storage tanks (149 SSTs, 28 DSTs) in a safe and efficient manner that (1) ensures compliance with DOE orders and federal, state, and local laws and regulations, and (2) achieves the mission goals and objectives of DOE, FDH, and the TWRS Project. The DST and SST shift managers are the responsible for the safe execution of field activities. The shift managers report directly to the DST and SST Operations facility managers who report to the Director, TFO.

Specifically, TFO is responsible for the safe handling, separation, storage, and monitoring of highly radioactive liquid waste stored in the underground tanks. Radioactive liquid wastes are received for interim storage into the DST system by truck, rail car, or transfer lines from external sources such as B Plant, PFP, and 222-S Laboratory. Liquid wastes are staged as feed for 242-A Evaporator campaigns to conserve DST space through waste volume reduction. The 242-A Evaporator output slurries are received for interim storage. Pumpable liquids are recovered from SSTs into the DST system.

The TFO maintain's a standard of performance for formal conduct of operations, maintenance, and radiological control by its personnel in accordance with the approved TWRS Project S/RIDs. Surveillance activities necessary to support the safe storage mission are performed using approved procedures. An aggressive contamination area reduction program is ongoing. The TWRS Project mortgage reduction is accomplished by preparing retired facilities for turnover to the Environmental Restoration Contractor.

The TFO supports the planning for all tank farm operations, oversees the construction of the retrieval and disposal systems, and operates the retrieval and disposal equipment. Specific responsibilities include the operations required to retrieve and transfer waste, adjust. concentration, and subsequently stage waste for the private contractors. The operations supporting the Phase 1 TWRS Retrieval and Disposal Mission are defined in more detail in Appendix B, Tank Farm Operations Execution Plan.

Characterization Operations. The Characterization Operations organization is responsible for safely managing/integrating the TWRS Project tank waste characterization activities with the TWRS mission requirements. Specific responsibilities include the following.

- Support the TWRS Project in characterization matters dealing with DOE, Washington State Department of Ecology (Ecology), U.S. Environmental Protection Agency (EPA), Defense Nuclear Facilities Safety Board, and other federal and state authorities

- Develop cost effective programs to identify needed engineering and scientific characterization and analytical information to ensure a factual basis for TWRS activities 
- Provide management integration of onsite and offsite research and development efforts related to characterization activities

- Ensure the quality and completeness of engineering and documentation for matters dealing with tank waste characterization

- . Integrate TWRS Retrieval and Disposal tank waste sampling and analyses except for analysis of solid waste designated for land disposal

- Provide the best estimates of tank contents based on historical information, modeling, and actual analytical data

- Maintain and manage tank waste characterization data

- Perform liquid, vapor; and core sampling to provide the data necessary to store, transfer, retrieve, separate, immobilize, and dispose of waste

- Manage sampling and analysis interface, including transporting tank samples to the appropriate onsite laboratories

- $\quad$ Provide tank riser preparations, in-tank photography, and video pit examinations in support of tank sampling activities

- Ensure customer program data quality objectives are met and provide guidance in interpretation and evaluation of analytical results.

Immobilized Waste Storage and Disposal Operations. Storage and Disposal Operations is responsible for managing the TWRS Project facilities that support disposal of the ILAW and interim storage of the IHLW in a safe and efficient manner that ensures compliance with DOE Orders, and federal, state and local laws and regulations and achieves the mission goals and objectives of DOE, FDH, and the TWRS Project.

Maintenance. The Maintenance organization provides overall support to the TWRS Project. The organization's primary responsibility is to ensure Tank Farm SSCs are effectively. maintained in operating condition to support the TWRS Retrieval and Disposal Mission. Specific responsibilities include production control, maintenance program integration, and craft services support. Additional details are provided in Appendix A, TWRS Maintenance - Organization Execution Plan. 
8.2.1.8. Projects and Design. To provide the capital improvements to the tank farms that are necessary to support the TWRS Mission, Projects and Design performs the functions listed below. Additional details are provided in Appendix G, TWRS Projects and Design Organization Execution Plan.

- Organize and maintain the capabilities and qualifications of project management resources

- Organize, maintain, and provide technical direction to process design resources

- Organize, maintain, and provide technical direction to mechanical system design resources

- Organize, maintain, and provide technical direction to Facility Design (e.g., civil engineering, electrical, layout, piping, instrumentation and control), construction management, testing, and start-up resources

- Accept technical baseline and project definitions developed by the TWR . Organization for Retrieval and Disposal Mission projects

- Provide administrative, budget control, scheduling, and planning activities for projects

- Manage design activities performed by internal resources or by other TWRS Project organizations

- Provide oversight for design tasks subcontracted to architect-engineer companies

- Provide oversight of subcontracted configuration management activities

- Manage all testing and start-up activities leading to operational readiness reviews.

\subsubsection{Tank Waste Retrieval (TWR)}

To manage the TWRS Retrieval and Disposal Mission, the TWR organization (Figure 16) is responsible for the following.

- Develop technical, cost, and schedule baselines needed to execute the assigned scope and maintain these baselines under configuration control

- Maintain close interface with FDH counterparts to ensure expectations reflected in the contract are being met 
Figure 16. Tank Waste Retrieval Organization.

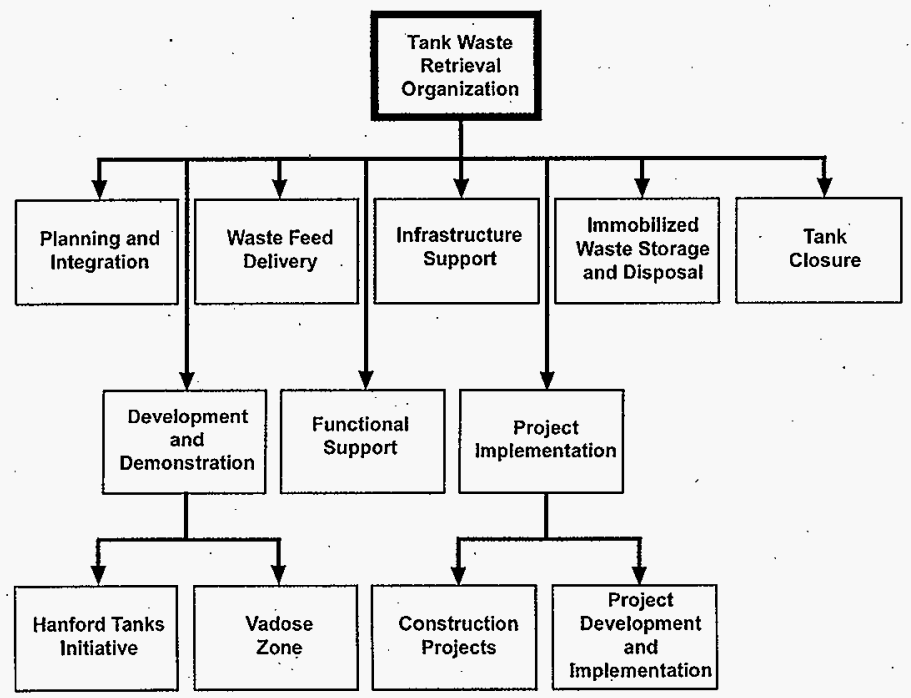


- Complete assigned work scope in accordance with project authorization directives and related performance agreements

- Integrate support service, subcontractor, and corporate service organizations (as needed) into program, project, and operations planning; and clearly communicate support levels, expectations, and changes

- Provide day-to-day direction and supervision to support service personnel matrixed on a full-time basis to the TWR organization

The TWR organization includes five programs: Waste Feed Delivery, Tank Closure, Development and Demonstration, Immobilized Waste Storage and Disposal, and Infrastructure Support. These five programs are interrelated and highly dependent on the successful completion of each of their respective missions. The three programs with substantial Phase 1 privatization involvement (Waste Feed Delivery, Infrastructure Support, and Immobilized Waste Storage and Disposal) have prepared plans covering their responsibilities, program objectives, organizations, and operations. These plans are referenced below, along with summary descriptions of the responsibilities for the five programs.

The TWR organization includes two support operations which provide assistance to the programs: Planning and Integration and Project Implementation. In general, these support operations provide operations and programmatic support for planning, management, performance, and integration efforts. The responsibilities of these support operations are discussed below. Coordination and interfacing between the programs and support operations ensures consistency of planning efforts, concurrence on overlapping or dependent issues and resolutions, and integration of turnover efforts as different project phases begin and end.

8.2.2.1. Waste Feed Delivery. Key Waste Feed Delivery (WFD) Program functions that contribute to the TWRS Retrieval and Disposal Mission include establishing a waste feed strategy (e.g., source tanks, retrieval order, delivery schedule); defining the SSCs needed to implement the waste feed strategy; planning, funding, and monitoring waste feed projects; and coordinating and overseeing the WFD work performed by supporting organizations and projects. These responsibilities, along with specific information on objectives, organization, interfacing, and operation of the WFD Program, are described in more detail in HNF-1881 (Potter and Treat 1998).

The WFD Program is primarily responsible for identifying and defining the work requirements that must be met by the supporting organizations and projects to assure waste feed readiness and performance. The WFD Program tracks and monitors work performance to verify that technical requirements are satisfied. The WFD Program is also responsible for assisting with and supporting an efficient and effective transition between demonstration (Phase 1) and full-scale (Phase 2) operations. The WFD Program functions will be conducted in ways that best accomplish this transition and that support both the option of privatizing WFD activities and the option of continuing government contractor operation of WFD. 
8.2.2.2. Tank Closure. To support tank closure operations during Phase 2, the TWRS Project will conduct engineering studies and technology development in parallel with Phase 1 activities. This transition effort will provide input to specification of waste retrieval performance requirements (i.e., allowable residual waste in tanks and retrieval leakage constraints) during Phase 2.

Other responsibilities of Tank Closure during Phase 1 include developing the strategy for reaching decisions on tank farm end state requirements; providing data necessary for DOE to proceed with closure decision-making under the NEPA process; and preparing design requirements, performance assessments, safety analyses, and closure plans for implementing closure decisions for the first SST farm (Tri-Party Agreement milestone M-45-06) (Ecology et al. 1996). Responsibilities of Tank Closure during Phase 2 are to close SST and DST tank farms following completion of waste retrieval operations by the Phase 2 private contractors.

8.2.2.3. Development and Demonstration. The Development and Demonstration organization is responsible for evaluating waste retrieval technologies and conducting tank farm subsurface characterization as described below.

Hanford Tank Initiative. Hanford Tank Initiate is responsible for deploying technologies to retrieve waste from leaking tanks and for defining retrieval performance criteria. HNF-SD-HTI-PLN-002, Hanford Tank Initiative Plan (Schaus 1997) provides additional detail on this initiative.

Vadose Zone. To support tank farm closure during Phase 2; subsurface characterization in the tank farms will be conducted during Phase 1 to support TWRS Project decisions that relate to the potential groundwater contamination from tank wastes and the potential risk to human health and the environment. This effort focuses on determining what has happened as a consequence of past leaks from tanks and providing this information as input to decision processes affecting SST retrieval project definition and tank waste storage operations.

The results from this investigation are expected to primarily affect decisions on retrieval technology, leak detection technology, retrieval sequence, and retrieval operating procedures, for both Phase 1 and Phase 2 SST retrieval. Waste storage operations in SST farms where large volumes of drainable liquids exist are also potentially affected. The NEPA process for tank farm closure, to be conducted during Phase 1, also depends on results of characterizing the vadose zone. Vadose zone characterization to support TWRS Project decisions on tank farm operations, retrieval, and closure will be conducted within the framework of an integrated sitewide vadose zone/groundwater management program led by Environmental Restoration.

8.2.2.4. Immobilized Waste Storage and Disposal. The Immobilized Waste Storage and Disposal organization is responsible for activities relating to the ILAW disposal and the interim storage of IHLW as received from the private contractors. These responsibilities require that a thorough systems analysis identify what systems are required to complete the storage and disposal mission. A review of possible alternatives has led to the selection of required project/ 
expense activities to meet identified system requirements. On the basis of this selection, a conceptual design/detailed plan has been developed, the required capital/expense funding has been identified, and design and construction is planned. Following a startup period, the facilities will be available for receipt of ILAW and IHLW.

These activities, as well as information on the objectives and operation of the Immobilized Waste Storage and Disposal Program, are described in more detail in HNF-1517, Tank Waste Retrieval System Retrieval and Disposal Mission Immobilized Low-Activity Waste Disposal Plan (Shade 1997), and HNF-1751, Tank Waste Retrieval System Retrieval and Disposal Mission High-Level Waste Storage Plan (Calmus 1997).

8.2.2.5. Infrastructure Support. Infrastructure organization responsibilities include defining the required infrastructure systems (e.g., utilities) required to support the private contractors for both Phase 1 and Phase 2; completing projects (through conceptual engineering) to provide the required Phase 1 and Phase 2 infrastructure; supporting Phase 1 and Phase 2 infrastructure projects (design through turnover); operating Phase 1 and Phase 2 infrastructure systems to support the private contractors; assuring integration of the infrastructure with other TWRS Project and site activities; and closing, decontaminating, and decommissioning the Phase 1 and Phase 2 infrastructure systems. These responsibilities, along with information on objectives, organization, and operation of the Infrastructure Support Program, are described in more detail in HNF-1882 (Root and Potter 1998).

8.2.2.6. Planning \& Integration. The Planning and Integration organization is responsible for achieving a single, cohesive integrated master baseline by being the catalyst for the TWRS Project organizations to work together to achieve the near-term and long-term disposal mission goals and organizational strategic initiatives. Planning and Integration will perform the following functions.

- Provide a Program Plan that meets the criteria of "planning documentation" as defined in GPG-FM-002, Critical Decision Criteria, Section 2.4.9, "Project Management Criteria." The Program Plan describes the basic management approach for executing the mission objectives and is consistent with the TWRS Project strategic initiatives

- Provide an integrated retrieval and disposal master baseline that is based on systems principles, where configuration and risks are managed, and allows TWRS Retrieval and Disposal to start up and operate through Phase 1B

- Facilitate overall retrieval and disposal baseline analysis and report roll up of technical progress and cost and schedule progress and recommend appropriate recovery actions as necessary 


\section{HNF-1883 Rev 1}

- Provide for effective interface among the private contractors, DOE, and PHMC team member by:

- Describing the functional and physical interfaces between the private contractors and DOE and M\&I contractors through interface control documents (ICDs); assigning responsibilities for the resolution of issues and required studies; identifying the requirements, constraints, and responsibilities of different organizations

- Participating as the PHMC team representative on the Integrated Product/Process teams.

- Provide for the effective involvement of other TWRS Project organizations in planning and execution of the Retrieval and Disposal Mission

- Provide for the effective interface between the TWRS Project and other PHMC team members in the planning and execution of the Retrieval and Disposal Mission

- Provide for the overall integration and control of the retrieval and disposal technical requirements.

8.2.2.7. Project Implementation. The Project Implementation organization is responsible for developing project requirements and design criteria using conceptual design or other preliminary engineering products as the basis. These products will provide the direction and foundation for the detail design and follow on project activities to ensure life-cycle definition of projects. The requirements and criteria provide the basis for the contractual relationships with the project management organization, serving to baseline the project requirements to a level that allows for definitive proposals for execution of project activities. While the emphasis will be on technical direction, administrative and project management requirements are included to ensure adequacy and consistency in supporting the TWRS Retrieval and Disposal Mission.

Projects currently underway and in detail design or construction phases are being reviewed against mission requirements to ensure Phase $1 \mathrm{~B}$ can be met. If realignment or redirection is required, Project Implementation is responsible for defining and directing such changes following approved change control procedures.

Monthly project reviews are held to discuss issues and monitor the project against project requirements and design criteria baselines. Project Implementation, therefore, serves as the approval authority for the TWRS Retrieval and Disposal Mission for project documents and activities.

Critical to the success of the TWRS Project is ensuring that the construction projects are consistent with the TWRS Project Technical Baseline. Project implementation has the responsibility of developing and maintaining the project requirement documents to reflect the 
TWRS Technical Baseline and subsequent changes to this baseline. This is achieved by organizing project teams within the TWRS Project that include the representatives necessary for supporting the TWRS Project Technical Baseline. In recognition that the ultimate customer of facilities provided by projects within the TWRS Retrieval and Disposal Mission is the TWRS TFO Organization, Project Implementation will ensure that appropriate support and communication is maintained with this group.

\subsection{MANAGEMENT APPROACH}

This section describes the management approach and key management systems that the TWRS Project uses to ensure that planning and implementation are conducted in accordance with sound business, engineering, integrated safety, decision, risk, configuration, and interface management practices. The requirements of higher tier directives and guidance are used to establish policies and procedures for day-to-day operations and management.

Figure 17, TWRS Management Approach, illustrates the management approach used by the TWRS Project to establish the integrated baseline that forms the basis for the TWRS retrieval and disposal component of the mission. The figure identifies the elements of the Integrated Baseline, their relationship to upper-level guidance documents, and the plans and procedures that control the development of the Integrated Baseline. The key documents used to define and manage the total program are briefly described below followed by a description of the key management systems used.

- Mission Analysis Report (Acree 1998). This report captures the Hanford Site-level requirements assigned to the TWRS Project, the definition of the initial and final end states for the project, the major interfaces, and an initial assessment of the activities that the project must execute to be successful in achieving the defined mission.

- TWRS Program Plan. The program plan constitutes the main driver for the management plans and procedures supporting the TWRS Retrieval and Disposal Misssion readiness-to-proceed checkpoint. The plan presents the planning requirements and schedules and management strategies and policies for accomplishing the mission. Specific details on the management approach for the functional support organizations are included in its appendices. 
Figure 17. Tank Waste Remediation System Management Approach

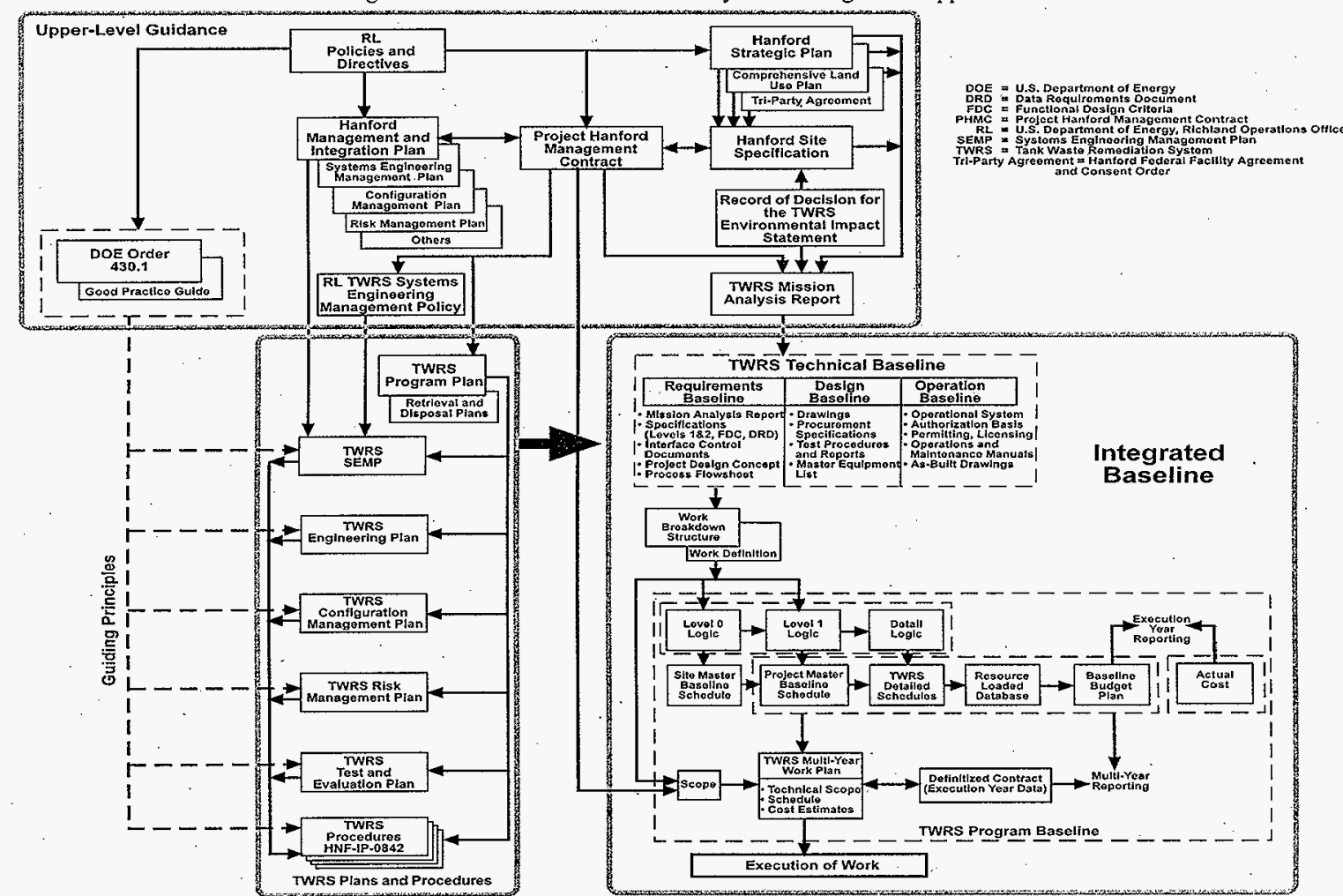


- TWRS Retrieval and Disposal Mission Plans. The Phase 1 aspect of the Retrieval and Disposal Mission encompasses three primary programs: Waste Feed Delivery; Infrastructure Support; and Immobilized Waste Storage and Disposal. Each program has prepared plans covering their responsibilities, program objectives, organizations, and operations.

- TWRS Project Management Plans. Individual management plans have been prepared that flow down the upper-level guidance and direction contained in DOE policies and directives and DOE/FDH/LMHC contractual documents. These plans document the guiding principles to be used in the TWRS Project management approach and are referenced in the following sections.

\subsection{BUSINESS OPERATIONS}

Business operations includes those principal activities necessary to establish and maintain the TWRS Project program baseline. These activities include planning for, and providing input to, the mission scope, and providing for schedule development, cost estimating, acquisition management, and performance monitoring.

\subsubsection{Program Baseline Development}

The Integrated Baseline development process is illustrated in Figure 17. That is, the physical configuration and operational requirements defined in the TWRS Project Technical Baseline drives the WBS, work definition, the Level 0 and Level 1 Logics (FDH 1998), the supporting critical path analyses, and the Site and Project Master Baseline Schedules. Once the work definition is validated from a technical and schedule standpoint, detailed schedules are developed and activities are resource loaded. Adjustments are then made to level resources and meet schedule and budget constraints imposed on the project. The final scope, schedule, and supporting cost estimates constitute the TWRS Project Program Baseline and serve as the basis for developing the Multi-Year Work Plan (MYWP) and reporting execution year performance.

Development of this program baseline is a mature iterative process that considers customer needs, determines organization priorities, defines technical approaches, establishes schedules, and develops annual budgets. This annual process refines execution year planning and further refines and validates the technical baseline and the outyear planning (including budgets). The following program planning requirements apply:

- Detailed schedule activities process will map to an individual activity within the Site/Project Master Baseline Schedules.

- The work package planning process will clearly define the work scope including discrete deliverables, schedules, and phased estimates. 
- The work package planning process will include a make/buy decision to define the method of accomplishment (in-house or subcontract).

- Work package baselines will be developed for the full duration of the work effort in sufficient detail to support program management and performance measurement.

- The degree of compliance and risks are evaluated during the planning process. Decisions are made by the program manager with input from subordinate managers and core support personnel.

The following sections summarize the management approach to developing the program scope, schedule, and cost baseline. Additional details covering this process and the data resulting from this process are provided in HNF-1946, Tank Waste Remediation System Retrieval and Disposal Mission Initial Updated Baseline Summary (Swita et al. 1998).

9.1.1.1. Scope. The TWRS Project work scope is translated to general work descriptions, which are further organized and structured into separate work tasks. Once required work tasks have been identified schedules, cost, and resource estimates can be developed (as discussed in Sections 9.1.1.2 and 9.1.1.3, below).

The gerieral work description for the TWRS Retrieval and Disposal Program scope is established in TWRS Retrieval and Disposal Level 1 Logics (FDH 1998). These logics are, enhanced PERT charts depicting in a box and line format the major activities, their relationships and dependencies, predecessor and successor activities, and projected start/end dates and durations. The logics are derived from the Level 0 Logics for the TWRS Project and other TWRS Project-related work logics. The logics are developed and maintained in a computerbased project planning program referred to as Primavera Project Planner (P3). Input to, and modification of, the P3 database is subject to configuration control, ensuring that the TWRS Program scope cannot be altered without authorization by the appropriate managers.

Activity boxes in the TWRS Project Level 1 Logics (FDH 1998) are further "decomposed" into sets of logically linked tasks. These tasks are defined at a sufficiently low level to support defendable analyses of the duration and cost of each task. Technical Basis Reports (TBR) are generated for each Level 1 Logics activity. These reports provide background summaries and identify enabling assumptions; responsible organizations; technical contacts for activities; interfaces and linkages to other activities; predecessor and successor activities; risks; and other information necessary to describe the essential attributes of each activity and its supporting tasks. The Technical Basis Reports (TBRs) are subject to configuration control.

The TWRS logics; TBRs; and the lists of requirements, enabling assumptions, risks, decisions, approved Technical Baseline documents, and annual DOE guidance are all used to develop annual TWRS Retrieval and Disposal Mission task plans. These task plans describe the purpose, objectives, and scope of work for each task, and the plans are aligned to correspond with the WBS work activities. Each Task Plan includes specific activities to be implemented, 
work products and deliverables required, customer and quality expectations for the work, work product dependencies, product interface agreements, and key assumptions that are necessary for the work to proceed. The task plans establish schedules for work product delivery consistent with program schedules. Finally, these task plans identify resource needs (estimated by discipline and type) and estimated costs based on these projected resource needs. Once resources are agreed to by the responsible program managers, the Task Plans are subject to configuration control.

9.1.1.2. Schedule. The baseline schedule for the TWRS Program is derived by integrating the detailed work schedules identified in the individual task plans. The work schedules are reviewed and adapted as needed to ensure consistency with direction and guidance from RL and FDH on preparing the annual MYWP. The Retrieval and Disposal Mission schedules are aligned with the WBS and are subsequently integrated into the TWRS MYWP.

The TWRS Program management will ensure that schedules are based on current task plans and work authorizations and that work schedules remain consistent with the documented program scope baseline. Periodic reviews will be conducted on the schedule status and variance reports prepared by Business Management. Based on review of these reports, responsible management will identify work-arounds or other actions that may be required to eliminate variances or mitigate the impact of such variances.

9.1.1.3. Cost. A primary TWRS Project objective is achieving cost-effectiveness throughout its life cycle while meeting or exceeding technical and schedule objectives. Toward this end, the TWRS Project has implemented a streamlined management system and will continue to improve productivity and optimize resources. Risk assessments will be incorporated into program decisions. Activity-based cost estimating will be used to ensure appropriate evaluation of work scope, schedule, cost, and business risk. Estimating commitments serve as the basis for establishing budgets and ultimately as the basis for performance measurement. The pricing rates and factors used to support the budget planning process are directed by FDH. Changes to these rates and factors will be addressed through the formal change control process.

The baseline cost for TWRS is derived by rolling up the cost estimates from the individual task plans. These cost estimates are reviewed and modified as required to ensure consistency with direction and guidance from $\mathrm{RL}$ and $\mathrm{FDH}$.

In addition to the cost estimates, the resource estimates from individual task plans are used to develop an annual TWRS Resource Needs Forecast. This forecast provides a roll up of the general disciplines (e.g., clerical, chemist, process engineer, accountant), resources needed, and anticipated levels of support (e.g., manhours, work weeks, full-time equivalents) needed for each type of resource. This forecast also identifies critical subcontracting or specialty resources (e.g., those resources required in response to brief workload excursions or for highly specialized technical expertise). The Resource Needs Forecast projects program needs for the next 2 to 5 years and is used to plan for the manpower and support required to perform program work. The forecast is developed at about the same time as the MYWP. It is an internal planning and management tool that is subject to configuration control at the TWRS PBS level. 
The TWRS Program Managers will ensure that cost estimates and revised estimates are based on current task plans and work authorizations and that the basis for cost estimates is consistent with the documented program scope and schedule baselines. Periodic reviews will be conducted on the financial status and variance reports prepared by Business Management. Based on review of these reports, responsible management will identify work-arounds or other actions that may be required to eliminate variances or mitigate the impact of such variances.

\subsubsection{Acquisition Management}

9.1.2.1. Work Authorization. Figure 18, Authorization of Work/Direct Funding Process, depicts the general approach that will be used to authorize and fund TWRS Project activities. Work is initially authorized by FDH through Project Authorization Directives under Major Subcontract No. 80232764-9-K001 (FDH 1996b). Work authorized through the MYWP and associated funding will be made by Executive Management at WBS Level 4 PBS through use of TWRS Project Operations Directives. Division Directors/PBS Managers authorize work at WBS Level 5 (Activity) through use of Sub-Operations Directives. The PBS Managers/Activity Managers authorize work at WBS Level 6 (Cost Account) through use of Cost Account Authorizations. At each level (e.g., activity, cost account) the assigned manager is vested with the responsibility, along with the appropriate authority, for the satisfactory performance and completion of assigned work within the defined schedule and cost constraints and in compliance with S/RIDs.

Cost Account Managers will issue documentation that defines work at the Cost Account level, Work Package Level, and associated Task Package level. These documents, constitute a scope, schedule, and cost "agreement," and will be approved by the responsible Cost Account Managers through a formal "sign-up" process. Individual agreements will not be changed unilaterally. Changes will be negotiated, modifications agreed to by affected parties, and processed in accordance with TWRS Project configuration management and change control requirements. The PBS Managers will serve as the final authority during the negotiation process.

9.1.2.2. Subcontracting. The Cost Account Manager will determine the work scope to be subcontracted when it is identified that "in-house" personnel do not have the required expertise for, or need support in, accomplishing the particular cost account, work package, or task. The Cost Account Manager is responsible for developing any required task orders, specifications, statements of work, and/or acceptance criteria. The Cost Account Manager will obtain the required program approvals and forward the identified work to LMHC Contracts and Procurement for developing a Request for Proposal and for other functions.

Major Subcontract No. 80232764-9-K001 (FDH 1996b) states that the regional economic base will be stable and diverse to the maximum extent possible. To effect this stability and diversity, the contract requires that enterprise companies be subcontracted to provide services within their areas of expertise. When it is determined that required services are not within enterprise company scope, procurement practices set forth below are followed to acquire the necessary resources. Contracting methods are defined in the Major Subcontract with 
Figure 18. Authorization of Work/Direct Funding Process.

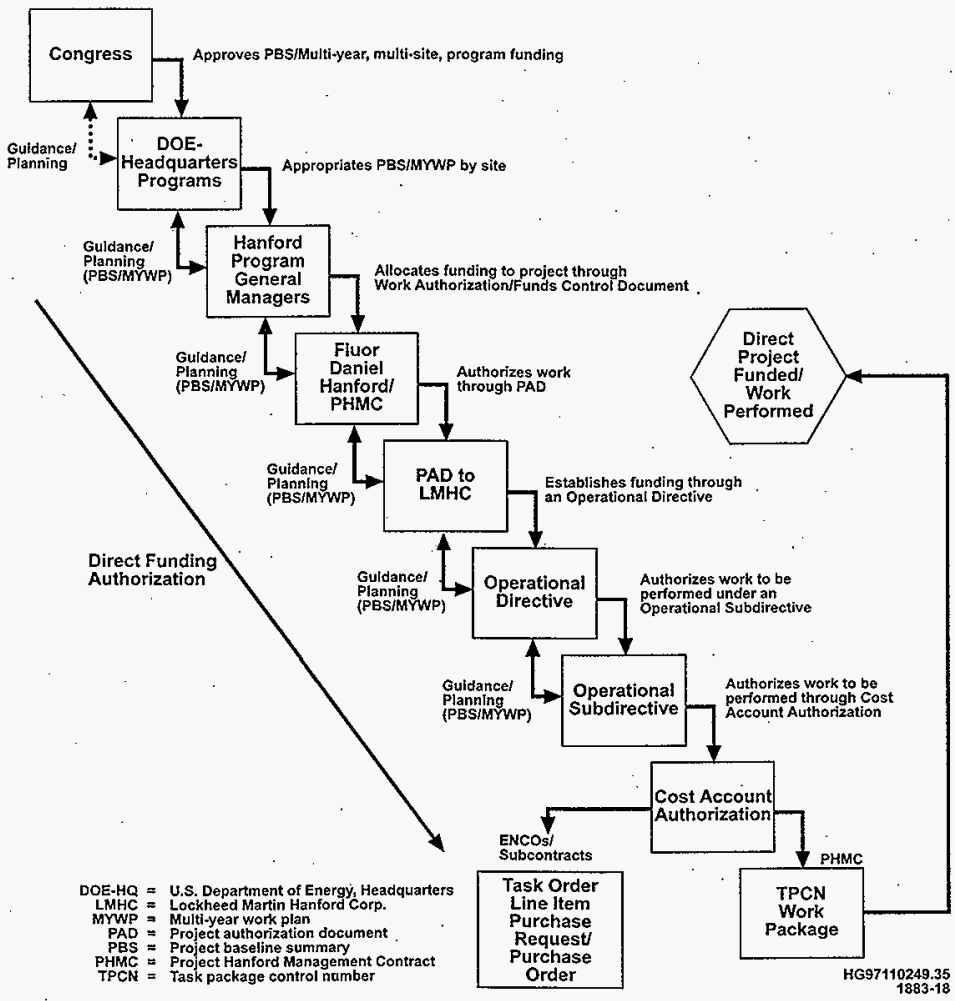


FDH, Part I (Statement of Work), Part II (Commercial Terms), and Part II (General Terms). Management of subcontract task orders will be through the controlled discipline of the LMHC purchasing representatives.

LMHC Contracts and Procurement will be responsible for satisfying requirements and obligations under the LMHC Subcontracting Plan (Dunbar 1996) as well as applicable state and federal standards. The acquisition of materials, services, supplies, and the subcontracting of systems development, to include design and construction contracts, will be conducted in accordance with the Federal Acquisition Regulations and the sitewide PHMC Procirement Policy Manual (FDH 1996d). The uniform flow down of requirements, standards, statements of work, performance specifications, drawing test plans, test procedures, and safety and quality criteria will be controlled through the PHMC sitewide approved procurement system.

9.1.2.3. Industrial Relations. At the Hanford Site, certain work (e.g., carpentry, electrical) is preferentially performed by personnel who are members of various craft and trade unions.

Bargaining Unit agreements and other arrangements have been developed that address union and trade relations with the PHMC team. These arrangements are administered directly by FDH as the overall manager of the PHMC team.

Bargaining Unit workers are assigned to major projects (e.g., TWRS Project) and are leased by major subcontractors (e.g., LMHC). The subcontractor, working within the terms of the Agreement Between Fluor Daniel Hanford Atomic Metal Trades Council (HAMTC 1997), is fully responsible for the supervision of Bargaining Unit employees.

\subsubsection{Performance Assurance}

9.1.3.1. Performance Measurement and Reporting. Performance measures are developed at all management levels (activity, cost account, etc.) and are aimed at achieving best-in-class performance in cost, schedule, quality, and workforce productivity. Performance versus plan is measured, and performance variances are monitored and controlled. Recovery plans are developed by the responsible manager for variances that exceed identified threshold tolerances. Performance measurement is also used to develop trends and predict future performance. Responsible managers will monitor performance of internal support service personnel and resolve noted deficiencies with the appropriate support service managers. The responsible managers also have the authority to reject erroneous costs charged to their work accounts.

Table 3 identifies the minimum levels of performance reporting. Reporting at a more detailed level will be at the discretion of the responsible manager. Performance metrics will additionally be developed for each cost account and reported to TWRS Project Executive Management monthly. 
Table 3. Work Breakdown Structure Performance Reporting Levels.

\begin{tabular}{|l|c|c|c|c|c|}
\hline \multirow{2}{*}{$\begin{array}{c}\text { Work Breakdown Structure } \\
\text { Reporting Level }\end{array}$} & \multicolumn{5}{|c|}{ Tank Waste Remediation System Project } \\
\cline { 2 - 6 } & $\begin{array}{c}\text { Cost Account } \\
\text { Manager }\end{array}$ & $\begin{array}{c}\text { Program } \\
\text { Manager }\end{array}$ & $\begin{array}{c}\text { Division } \\
\text { Director }\end{array}$ & $\begin{array}{c}\text { Executive } \\
\text { Management }\end{array}$ & $\begin{array}{c}\text { Fluor Daniel } \\
\text { Hanford, Inc. } \\
\text { Project } \\
\text { Direction }\end{array}$ \\
\hline 4 Project Baseline Summary & $\checkmark$ & $\checkmark$ & $\checkmark$ & $\checkmark$ & $\checkmark$ \\
\hline 5 Activity & $\checkmark$ & $\checkmark$ & $\checkmark$ & & \\
\hline 6 Cost Account & $\checkmark$ & $\checkmark$ & & & \\
\hline 7 Work Package & $\checkmark$ & & & & \\
\hline 8 Task & $\checkmark$ & & & & \\
\hline
\end{tabular}

9.1.3.2. Startup and Operational Readiness. Planning for the TWRS Retrieval and Disposal Program was based on the core criteria in DOE Order 425.1, Startup and Restart of Nuclear Facilities, for achieving Startup Readiness, and meeting the RL Phase 1B private contract deadlines and delivery specifications (e.g., waste envelope concentration limits, minimum quantities). Each of the logically linked tasks included in the schedule is supported with a documented analysis of cost and duration. The rigor behind the analyses ensures defensible cost and schedule baselines, enables routine and non-routine analysis of progress, and allows the TWRS Program to make timely corrections as necessary.

9.1.3.3. Testing and Evaluation. The TWRS Program requires implementation of a test and evaluation program for major projects to ensure that the completed SSCs (including preexisting equipment) meet performance specifications. Detailed test plans, specifications, and procedures are prepared, approved, controlled, and maintained in accordance with the requirements of the applicable TWRS Technical Baseline. The test plans, specifications, and/or procedures will address testing requirements for modified or new SSCs. The major elements of the testing and evaluation program include:

- Construction Testing. Construction testing activities are factory acceptance tests and construction acceptance tests that demonstrate compliance with procurement and construction specifications

- Preoperational Testing. Preoperational testing is performed on individual segments of project or facility SSCs to demonstrate that modified or new systems or subsystems perform as designed

- Operational Testing. Systems are brought on line and operated under standard operating conditions and off-normal conditions to demonstrate integration of the entire project or facility. This operational testing is performed using actual 
equipment, operating procedures, and personnel. Walk-throughs and dry runs may be employed for selected complex operations to demonstrate that operators, procedures, and equipment are in a final satisfactory state of readiness to safely and efficiently initiate testing.

Documented results of testing and evaluation are included as part of the Technical Baseline (see Section 9.2.3, below).

9.1.3.4. Continuous Process Improvement. The TWRS Project Quality Policy commits all organizations to the principle of continuous process improvement. Process improvement is achieved when key processes are well understood and regularly examined for improvement opportunities. Each TWRS manager is required to plan, schedule, and conduct assessments of their management systems and processes. The HNF-IP-0842, Tank Waste Remediation System Administration, Volume XI, Quality Assurance, Section 1.1, "TWRS Quality Assurance Program Plan" (LMHC 1997) identifies implementing procedures for management assessment and other evaluative processes. The TWRS Quality Assurance organization provides oversight of the TWRS Project self-assessment processes. In addition, TWRS Project facilities are regularly reviewed by the PHMC Facility Evaluation Board, as well as by other organizations external to TWRS.

\subsubsection{Management Systems}

The following sections describe the information resource management and decision modeling systems and tools in use by the TWRS Project. Other key systems and processes are described in the remainder of Section 9.0 .

9.1.4.1. Information Resource Management Systems. Much of the success of the TWRS Project management approach will rely on the ability to acquire and analyze management information. Currently the TWRS Project uses several sitewide (e.g., Financial Data System, P3, Job Control System) and in-house systems (e.g., Process Monitoring and Control Systems) to manage information. Most of these systems are stand-alone systems that need improvements in integration and data sharing to be effective management tools.

The TWRS Project will make extensive use of the PHMC Hanford Data Integration (HANDI) 2000 system to assist in its management processes. The FDH HANDI 2000 Project, described in HNF-1743, HANDI 2000 Project Execution Plan (FDH 1997c), will integrate the major Hanford Site business processes and their supporting information systems. It will establish industry-standard work processes through business process enhancement and implementation of a set of integrated, commercial off-the-shelf enterprise resource planning software products. This integration system will reduce costs, provide better control, reduce the risk of non-conformance, improve safety, improve productivity, and improve overall process integrity. 


\section{HNF-1883 Rev 1}

The core business processes that HANDI 2000 will address are project management; financial management; supply management; human resources; Environmental, Safety, and Health (ES\&H), and Work Management. Current plans are to implement these processes sitewide, with the exception of Work Management, by FY 2000; Work Management has not received sitewide implementation approval, and is expected to be piloted by the TWRS Project in FY 1998 and implemented thereafter.

9.1.4.2. Decision Models. The TWRS Project uses process models and analysis tools to assist in decision-making processes. The most popular of these models is the scheduling and resource planning tools for program planning, particularly the $\mathrm{P} 3$ application, that will produce schedules with logic ties defining interdependence of the activities. These tools help assure the resources are available to perform timely work.

For technical applications, models such as the HTWOS will be used to help TWRS Project management plan the waste transfers and the feeds to private contractor immobilization facilities. The HTWOS, a state-of-the-art knowledge-based simulator, will take input from other information systems and track the current tank waste volumes and tank contents at the individual element level. Using this information and the rules and the requirements of the waste feed envelopes that are programmed in the system, HTWOS determines optimal transfer scenarios to guide management decisions throughout the TWRS Retrieval and Disposal Mission.

\subsection{ENGINEERING}

The engineering process applied to the TWRS Project uses a systems approach. This process ensures that the Technical Baseline supports the identified mission needs and requirements. In this process the requirements are determined; the system is assessed; the existing Technical Baseline verified; new hardware is designed, constructed/procured, installed, tested; and operations and maintenance supported. An overview of the engineering process is shown in Figure 19, TWRS Technical Baseline Development Strategy.

The engineering approach takes into account the fact that a majority of the waste feed delivery system already exists and modifications to support the TWRS Retrieval and Disposal Mission are underway. The existing system and these ongoing projects are being assessed to assure they will perform the required functions and meet performance requirements. The systems engineering focus on the development of the functions, requirements, concepts, and integration of activities; whereas, the engineering focus is on the existing Technical Baseline/system, design/construct/test, and operations and maintenance support.

\subsubsection{Systems Engineering}

Systems engineering is the fundamental tool for understanding and developing complex systems throughout their life cycle. A simplified systems engineering process is shown in Figure 20, Systems Engineering Process. It assures that the Technical Baseline is technically 
Figure 19. Tank Waste Remediation System Technical Baseline Development Strategy.

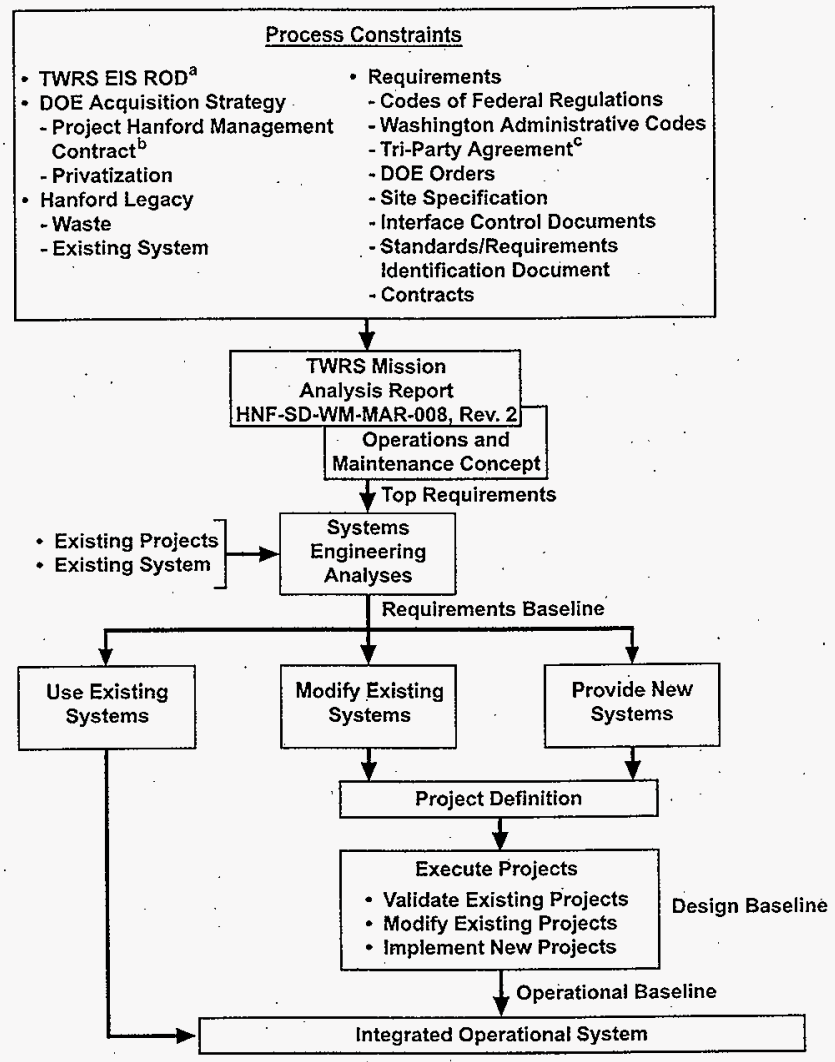

DOE = U.S. Department of Energy

ROD = Record of Decision

EIS = Environmental Impact Statement

TWRS = Tank Waste Remediation System

Tri-Party Agreement $=$ Hanford Federal Facility Agreement and Consent Order

- DOE, 1997, Record of Decision (ROD) on the Final Environmental Impact Statement for the Tank Waste Remediation System, U.S. Department of Energy, Washington D.C., February 26.

${ }^{\mathrm{b}} \mathrm{RL}, 1996$, Fluor Daniel Hanford, Inc., Project Hanford Management Contract, DE-AC06-96RL13200, U.S. Department of Energy, Richland Operations Offlce, Rlchland, Washington.

Ecology, EPA, and DOE, 1996, Hanford Federal Facility Agreement and Consent Order, as amended, Washington State Department of Ecology, U.S. Environmental Protection Agency, and U.S. Department of Energy, Olympia, Washington. 
HNF-1883 Rev 1

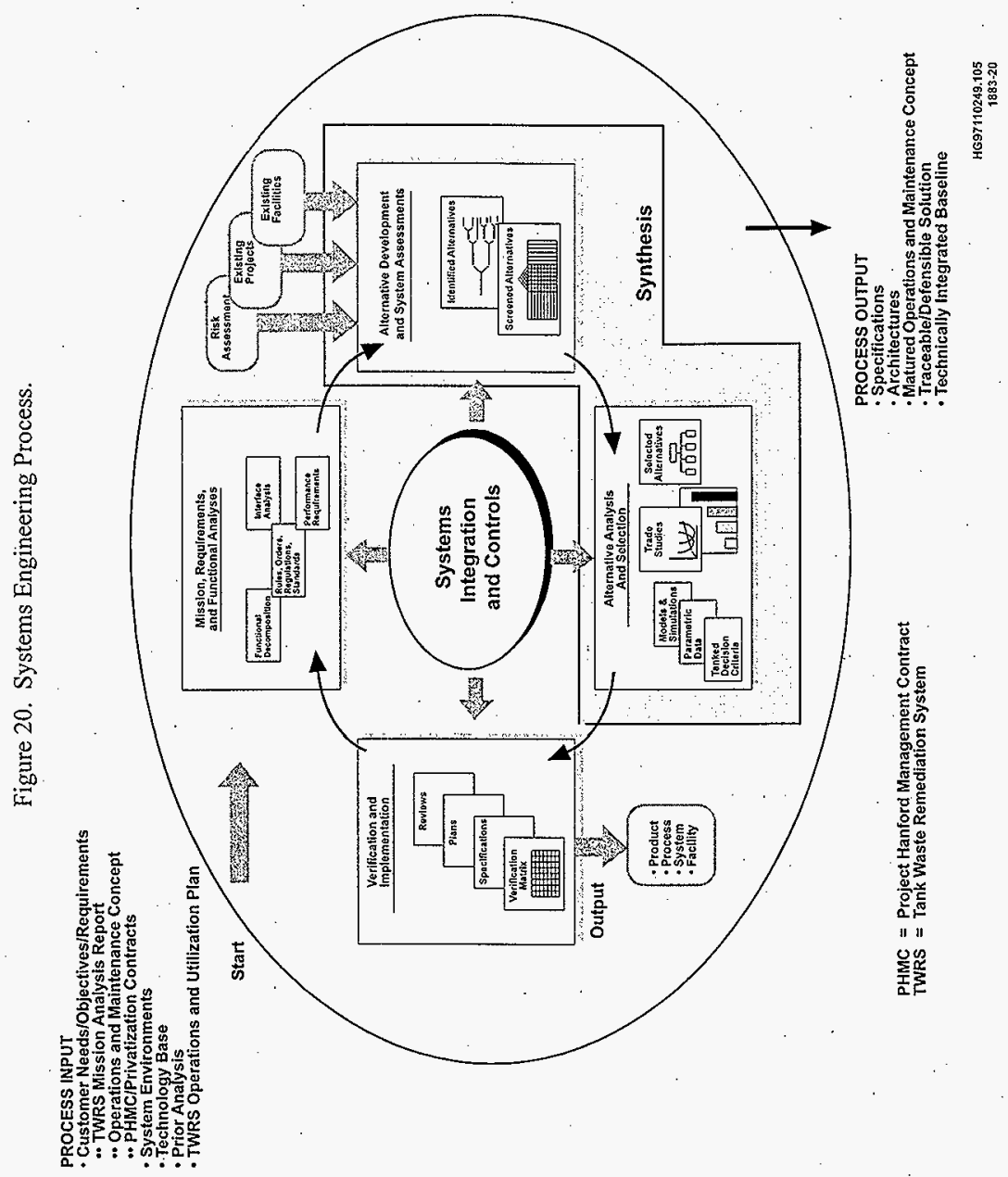


defensible and integrated. Systems engineering is required by the PHMC team and RL. The systems engineering plan and process are documented in the TWRS SEMP (Peck 1998) and the implementing procedures contained in HNF-IP-0842, TWRS Administration (LMHC 1997).

The top-level elements of the process include a mission analysis and definition of an operations and maintenance concept. The TWRS Project mission has been analyzed with a particular focus on the Phase 1 mission, and the TWRS MAR (Acree 1998) has been generated. Top level functions, requirements, and major facilities are identified and have been integrated with the Hanford Site Technical Baseline Database (site systems engineering), the Authorization Basis, regulations and DOE orders, TWRS Project ROD (62 FR 8693), and the Tri-Party Agreement (Ecology et al. 1996). The operations and maintenance concept is being defined and is strongly influenced by the need to support the immobilization facilities operated by the private contractors. This concept will assure that in case of failure there will be minimum disruption of the immobilization operations.

The mission functions have been decomposed, performance requirements analyzed, and requirements allocated. This results in systems specifications and ICDs for the major Phase 1 facilities (DST, ILAW Disposal, ILAW Disposal Addition, and Canister Storage Building) and infrastructure support for the private contractors. The technical alternatives are evaluated in accordance with the Decision Management and Alternatives Analysis and Selection processes described in the TWRS SEMP (Peck 1998). Based on these alternatives, the TWRS Project systems will be optimized to the extent practical to meet reliability, availability, and maintainability needs. The existing facilities and ongoing projects are being assessed to determine the applicability of existing systems/components and to identify the new systems/ components that need to be deployed and the requirements for documentation (e.g., new specifications or updates of existing Functional Design Criteria). Technical performance measures will be established, based on the specifications and risk evaluations, to gain insight into the evolving capability of the system and to manage risk. Test and evaluation will be planned and conducted to verify that the systems and components meet the specified requirements and support integration. The TWRS Project Level 0 and Level 1 Logics (FDH 1998) are the bridges to the programmatic baseline forming the integrated baseline.

\subsubsection{Engineering Process}

The engineering process is documented in HNF-1947, Tank Waste Remediation System Engineering Plan (Rifaey 1998). This plan describes the engineering process and the controls being put in place to support the Technical Baseline definition and to manage its control, evolution, and implementation to field operations. The engineering plan provides the vision for the engineering required to support the Retrieval and Disposal Mission through Phases 1 and 2, which includes integrated data management of the Technical Baseline. Further, this plan describes the approach for moving from the "as is" condition of engineering practice, systems, and facilities to the desired "to be" configuration.

The systems engineering process described in Section 9.2.1 is an integral part of the overall engineering process. Existing systems are analyzed to ensure that their functionality and 
operability will meet mission needs and system specifications. New systems are defined through alternative generation analysis, trade studies, engineering studies, and specialty engineering analysis against the requirements and projects defined. Conceptual designs are generated and project baselines established. Technical authorities (design authorities and cognizant engineers) direct this process once the formal assessment/evaluation assures the need for new or modified hardware. Design, construction, and testing activities follow conceptual design. The engineering organization supports Operations and Maintenance by managing technical information (e.g., drawings, analysis, vendor information, and equipment).

\subsubsection{Technical Baseline}

The Technical Baseline generated by this process is summarized in HNF-2016, Tank Waste Remediation System Technical Baseline Summary Description (Raymond 1998) and further detailed in HNF-1901, Tank Waste Remediation System Retrieval and Disposal Mission Technical Baseline Summary Description (Treat et al. 1998). The latter document is a roadmap of the key technical documents (existing and planned) that are required to successfully complete the TWRS Retrieval and Disposal Mission. Specifically, the TWRS Retrieval and Disposal Mission Technical Baseline Summary Description:

- Identifies and summarizes documents representing the bases for the technical components of retrieval and disposal

- Designates source information for each document to assure the use of consistent technical bases

- Defines the person and/or organization responsible for each Technical Baseline document and the preparation status, frequency of revision, and current applicability

- Defines hierarchical relationships for Technical Baseline documents

- Provides the basis for maintaining configuration management of the Technical Baseline documents.

\subsubsection{Alternatives Management}

Alternatives Management can generally be categorized into three major areas:

- Evaluation of technical alternatives for processes, system designs and specifications, and equipment selection

- Contingency planning 
- Identification and development of optimization opportunities.

Technical altematives are evaluated in accordance with alternatives generation and analysis practices described in the TWRS SEMP (Peck 1998). The various existing alternatives generation and analysis studies and those that are planned in support of retrieval and disposal are (or will be) described in HNF-1901 (Treat et al. 1998).

Contingency planning and budgeting is normally included in line-item capital projects, such as Project W-211. Contingency planning for expense-related activities is captured in risk management plans. Additional detail on cost and schedule contingencies may be included in the TWRS Retrieval and Disposal Mission task plans.

\subsection{INTEGRATED SAFETY MANAGEMENT SYSTEM}

The objective of the ISMS is to facilitate safe work. The ISMS integrates requirements into the work planning and execution and identifies a set of requirements that reflects DOE's commitment to a "standards-based" safety program. This concept is illustrated in Figure 21, Integrated Safety Management System Concept.

Figure 21. Integrated Safety Management System Concept.

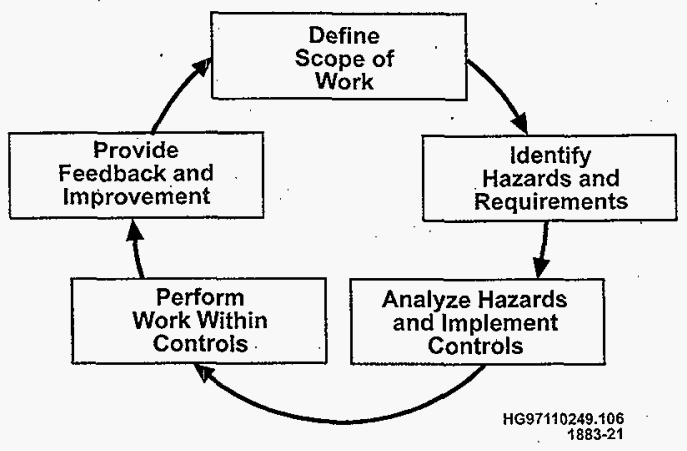

The ESH\&QA organization, TWRS Radiological Control, and TWRS Engineering and Nuclear Safety (TENS) provide health and safety services to the TWRS Project. These organizations use the ISMS to guide the integration of safety and health functions into work planning, execution, and follow-up. The programs are in place to oversee the implementation of DOE Orders and federal, state, and local laws and regulations; perform audits to verify compliance with regulatory and legal operational requirements; and provide guidance and policy direction for continuous improvement in the conduct of work. These services provide both 
support and independent oversight functions to maintain and improve public safety, safe and healthful working conditions, and the safety of the environment.

The ESH\&QA and Radiological Control organizations perform review and oversight of engineering and nuclear safety analyses and documents developed by the TENS organization. This organizational structure ensures the integrity of an independent technical review is preserved.

All three organizations, ESH\&QA, Radiological Control, and TENS, provide safety and health services to the TWRS Project and the Retrieval and Disposal Mission as described below. The following appendices summarize technical, programmatic, and management aspects that are relevant to privatization support achieving and maintaining readiness-to-proceed.

- Appendix F, Nuclear Safety and Licensing Execution Plan for the TWRS Retrieval and Disposal Program

- Appendix H, Safety and Health Execution Plan for the TWRS Retrieval and Disposal Program

- Appendix J, Quality Assurance Execution Plan for the TWRS Retrieval and Disposal Program.

\subsubsection{Environmental}

The Environmental Program facilitates TWRS Project compliance by definition and oversight of environmental regulatory requirements. The HNF-1773, Tank Waste Remediation System Environmental Program Plan (Borneman 1998), provides additional detail on the Environmental Program and the specific responsibilities in each of the following areas:

- Planning

- Implementation and Operation

- $\quad$ Reports, Notifications, and Records

- Verification and Corrective Actions.

\subsubsection{Safety and Health}

The Safety and Health Program within the TWRS Project is a multi-disciplined approach encompassing industrial safety, industrial hygiene, and fire protection. In support of the Retrieval and Disposal Mission, TWRS Safety and Health is responsible for integrating development and implementation of specific safety-and health-related programs, technical support to work planning and performance, and compliance oversight and assessment. Responsibilities are implemented through sitewide occupational health and safety procedures, WHC-SD-WM-HSP-002, Tank Farm Health and Safety Plan (Mickle 1995); HNF-IP-0842, 
Volume IX, Section 1.1, TWRS Safety Program Plan (LMHC 1997); and other TWRS-specific administrative and operational procedures. These responsibilities are grouped into the following areas:

- Safety operations

- Safety compliance and oversight

- Employee involvement and investigations.

\subsubsection{Quality Assurance}

The PHMC Quality Assurance Program is described in HNF-MP-0599, Quality Assurance Program Description (Byers 1997). The Quality Assurance Program Description (QAPD) identifies the quality assurance requirements that the PHMC team is obliged to implement, and is based on Title 10, Code of Federal Regulations (CFR), 830.120, "Quality Assurance" (for non-reactor nuclear facilities) and DOE Order 5700.6C, Quality Assurance (for the balance of the plant). The TWRS Project contractor supplements the FDH QAPD requirements in TWRS Project documentation. The QAPD presents the quality assurance requirements within the following topical areas:

- Program

- Personnel Training and Qualification

- Quality Improvement

- Documents and Records

- Work Processes

- Design

- Procurement

- Inspection and Acceptance Testing

- Management Assessment

- Independent Assessment.

The TWRS Project contractor implements its Quality Assurance Program through HNF-IP-0842, Volume XI; Section 1.1, "TWRS Quality Assurance Program Plan" (QAPP) (LMHC 1997) and the Quality Assurance organization. An implementation matrix in the QAPP summarizes the flow down of requirements to procedures. These procedures are used to execute the quality assurance process for the entire TWRS Project, including the Retrieval and Disposal Mission. The QAPP is reviewed and revised annually to accommodate changes in requirements, activities, organization, or facilities.

\subsubsection{Nuclear Safety}

Nuclear safety encompasses systems and activities that prevent the potential for a criticality and the release of fission products or other radioactive materials that could adversely affect the environment, the workers, and the public. The scope of the safety activities cover all 
TWRS Project SSCs and the activities of storage, characterization, retrieval, disposal, and specific projects.

Nuclear safety activities are covered by two different departments: ESH\&QA and TENS. The primary function of ESH\&QA in the area of nuclear safety is the review and oversight of engineering and nuclear safety analyses and documents developed by the TENS organization (see Section 9.3.7). This organizational structure ensures the integrity of an independent technical review is preserved. Good communication ensures that the roles between the two groups are clearly defined and that duplication of work is avoided.

\subsubsection{Emergency Preparedness}

The Emergency Preparedness Program is an integral element of the ISMS, under the direction of the ESH\&QA Director. The program is conducted in accordance with applicable regulations, requirements, and procedures. The permanent Emergency Preparedness coordinators conduct the day-to-day activities, which include planning, procedure development and review, training, and conduct of drills for TWRS Project facilities, and implement facilityspecific requirements. The Emergency Preparedness organization works in conjunction with the sitewide Emergency Preparedness Program. Emergency services such as fire fighting, ambulance, and security are provided by other Hanford-Site contractors. These activities and facility-specific requirements will be tailored to meet the needs/requirements of the TWRS Project and the Retrieval and Disposal Program.

\subsubsection{Radiological Control}

The Radiological Control organization integrates safety and health functions into all phases of the TWRS Project. The Hanford Site Radiological Control Manual (HSRCM-1 1994) outlines compliance programs with 10 CFR 835, "Occupational Radiation Protection." The Radiological Control organization provides management, support, and oversight in the functional areas listed below.

- Radiological Design Requirements

- Radiological Surveys and Work Practices

- Assessments and Field Observations

- Radiological Problem Reporting System

- As Low As Reasonably Achievable (ALARA) Programs and Practices.

\subsubsection{TWRS Engineering and Nuclear Safety}

For the TWRS Project, the nuclear safety activities will be executed by the Nuclear Safety and Licensing organization, reporting to the TENS Director. This functional support group ensures consistency across all aspects of the TWRS Project in terms of hazard identification; control development; SSC specification; authorization basis document 
preparation; DOE Order compliance; and approaches to dealing with technical uncertainty. Policies, standards, and requirements relevant to nuclear safety and licensing are defined in the TWRS Project S/RIDs, the PHMC (RL 1996d), FDH procedures, TWRS Project procedures, Retrieval and Disposal Mission specific engineering baseline documentation, and project-specific engineering baseline documentation. Nuclear Safety and Licensing activities are grouped into the following functional areas.

- Authorization Basis Documentation

- Safety Documentation

- Unreviewed Safety Question Process

- $\quad$ DOE/DNFSB Safety and Licensing Interactions

- Waste Tank Safety Issues

- Criticality Program Management.

\subsection{DECISION MANAGEMENT}

Decision management provides traceability for affected decisions through the graded use of a rigorous and methodical decision-making process. The TWRS Project decision management process implements the requirements of HNF-IP-0842, Volume IV, Section 1.1, "TWRS Systems Engineering Management Policy" (LHMC 1997); TWRS SEMP (Peck 1998); and WHC-IP-0842, Volume IV, Section 2.7, "TWRS Decision Management Procedure" (LMHC 1997). The TWRS Project decision management procedure requires the following:

- Timely and well-developed decisions .

- Decision traceability back to system requirements

- Tracking and monitoring of decision making progress

- A historical trail for implementing decisions.

In accordance with the documents referenced above, a fully implemented decision management process will be followed for major Retrieval and Disposal Mission decisions. A decision action officer and a decision maker(s) will be identified for each such decision. The decision action officer is responsible for ensuring that the following steps are taken:

- Decision Framing - producing a written Decision Plan

- Decision Analysis - producing a written Decision Analysis Summary

- Deciding - producing a written final Decision Document.

A graded approach to implementing this process is allowed for decisions of lesser impact. It is the responsibility of the designated decision maker to determine the degree to which the full decision management process is applied to individual decisions. In such cases, responsible management will refer to HNF-IP-0842, Volume IV, Section 2.1, "TWRS Project Decision Management Procedure" for specific guidance. 


\subsection{RISK MANAGEMENT}

The TWRS Project has implemented a quantitative, disciplined approach to programmatic risk management to ensure risks are identified and managed in a manner that eliminates or satisfactorily mitigates their impact. Risk evaluation activities are embedded in the TWRS Project management processes and constitute a fundamental input to decision-making processes. Program risks are typically categorized as technical, schedule, or cost related. The sources of such risks include the following:

1. Technical Risks. Uncertainties associated with the planning basis for the tank waste separations technical strategy and retrieval/disposal processes, uncertainties regarding final end-state requirements for tank farms, etc.

2. Schedule Risks. Planning assumptions, interdependent technical issues, program interfaces, and constraints (including impact to critical path schedules resulting from budget shortfalls).

3. Cost Risks. Planning/technical uncertainties, immature state-of -technology development, lack of a definite resolution regarding tank safety issues and tank end-state requirements, minimum schedule flexibility, and HLW repository assumption.

The TWRS Project Risk Management Program is intended to reduce these risks to an acceptable level through a process of risk assessment, analysis, and handling. It is also intended that risks be communicated to the appropriate decisions makers. The TWRS Project Risk Management Program is based on the requirements of HNF-IP-0842, Volume IV, Section 1.1, TWRS Systems Engineering Management Policy (LMHC 1997), and the TWRS SEMP (Peck 1998). These requirements cover risk assessment, risk analysis, and risk handling.

The TWRS Project Risk Management Program will implement these requirements through HNF-IP-0842, Volume IV, Section 2.6, TWRS Project Risk Management Procedure (LMHC 1997); HNF-SD-WM-PMP-018, Tank Waste Remediation System Risk Management Plan (Zimmerman 1998), and risk management implementation plans, as required. In response to this guidance, TWRS Project will:

- Identify and analyze potential technical, schedule, and cost risks for activities

- Develop and maintain risk management lists identifying the risks, their possible consequences, a measure of their relative importance, and the planned mitigation actions 
- Control and track completion of assigned risk management mitigation activities

- Communicate risk program status through rollup of risks to the appropriate management levels and cross communication with the appropriate client counterparts at each level.

The TWRS Project Technical Basis Review reports and the Tank Waste Remediation System Retrieval and Disposal Mission Critical Risk List are the principal management tools used to identify, analyze, and track project risks and their related issues. Technical Basis Review Reports are developed for each key activity identified on the TWRS Project Level 1 Logics (FDH 19.98) and incorporate an assessment of technical, schedule, and cost risks relating to that activity. Risk lists are used to compile, communicate, and track risks and actions taken to mitigate such risks.

\subsection{CONFIGURATION MANAGEMENT}

Configuration management is an integrated approach to controlling the technical, cost, schedule, and administrative information necessary to manage the TWRS Project activities. It supports management of the TWRS Project baseline (technical and contractual) by providing the mechanisms to identify, document, and control the functional and physical characteristics of the TWRS Project products. Configuration management is used to establish and maintain consistency and traceability among source requirements, product information, and products during all phases of the product's life cycle, particularly as changes are being made. This will also include developing alternatives that warrant consideration when changing the configured program elements.

Configuration management focuses on the application of five principal functions: configuration management system management, configuration identification, configuration status accounting, change control, and configuration management assessments. Application of these functions is tailored to project requirements and life-cycle phases. The objectives remain the same throughout the life cycle: identification of configuration items (the functional and physical products that are subject to configuration control), identification of configuration information (for each item, the information or data that is controlled), and control of that item. Critical to this process is the identification of the as-built configuration of TWRS Project SSCs; the change control thresholds for modifying this baseline; and the level of authority required for such changes.

The Hanford Site configuration management policy and requirements are prescribed in HNF-MP-013, Project Hanford Management Contract Configuration Management Plan (FDH 1997x). Implementation of these requirements for the TWRS Project is defined in HNF-1900, Tank Waste Remediation System Configuration Management Plan (Vann et al. 1998) and subtier implementing plans and procedures. This plan also describes the information management, document control, and records management systems and processes that are used to. establish and maintain configuration control. 


\subsection{INTERFACE MANAGEMENT}

The purpose of interface management and control is to form agreements that allow organizations to design adjoining physical systems. Proper application of interface management and control processes result in SSCs that physically fit and function together without mismatch, omission, interferences, or disposition. External interface management must be imposed by the TWRS Retrieval and Disposal Program when there is an identified interface to another program (e.g., private contractor immobilization facility, solid or liquid waste disposal facility). Internal interface control will also be required for those interfaces that exist between major facilities and projects within the TWRS Program (e.g., between the DST facility and the W-211 construction project).

The requirement that a project's technical and organizational interfaces be identified and integrated with other projects and activities is found in the following:

- WHC-SD-WM-SEMP-002, TWRS Systems Engineering Management Plan (Peck 1998) which states that ICDs will be developed throughout the TWRS Project life cycle commencing with preconceptual design

- RL Privatization Contracts (DOE and BNFL 1996 and DOE and LMAES 1996) which require that Integrated Product/Process Teams be established to cover project management; ES\&H; and interfaces. Integrated Product/Process Team membership will include the DOE, private contractor, FDH, and the TWRS Retrieval and Disposal Program staff. The Retrieval and Disposal Program is bounded by 19 draft ICDs (FDH 1997e-w) with the private contractors. Revisions to these ICDs are expected when contracts are executed with the contractors for the Phase 1B mission. The draft ICDs for the TWRS Project are identified in Table 4.

- WHC-IP-0842, Volume IV, Section 2.8, "Interface Control" (LMHC 1997) which establishes requirements/responsibilities for interface management and control and describes the interface control process in the TWRS Project.

The TWRS Project will manage and control its interfaces in Retrieval and Disposal as follows:

- Physical and functional interfaces will be documented and controlled by ICDs. These ICDs will be formally agreed to by both affected parties and will be used to control the design of an interface to a mutually agreed to set of requirements and design parameters (e.g., flange types, bolt hole patterns). The ICDs will provide the TWRS Retrieval and Disposal Program with a formal mechanism for integration at the common interface points. If two hardware elements must be connected in order to pass material, energy, and/or information, the responsible 
Table 4. Interface Control Documents Between TWRS Retrieval and Disposal Program and Private Contractors.

\begin{tabular}{|ll|}
\hline ICD \# & \multicolumn{1}{c|}{ Interface Control Document ${ }^{1}$ Name } \\
\hline ICD-01 & Phase 1 Privatization - Raw Water \\
ICD-02 & Phase 1 Privatization - Potable Water \\
ICD-03 & Radioactive Solid Waste \\
ICD-05 & Non-Radioactive, Non-Dangerous Liquid Effluent for Phase 1 Privatization \\
ICD-06 & Radioactive Dangerous Liquid Effluents \\
ICD-09 & Land for Siting Part A Privatization \\
ICD-10 & Deactivated Facility and Site for Phase 1 Privatization \\
ICD-11 & Electricity \\
ICD-12 & Phase 1 Privatization Roads and Rail \\
ICD-13 & Phase 1.Privatization - Non-Routine High-Level Solid Wastes \\
ICD-14 & Phase 1 Privatization - Immobilized High-Level Waste Product \\
ICD-15 & Phase 1 Privatization - Immobilized Low-Activity Waste Product \\
ICD-16 & Phase 1 Privatization Strontium/Transuranic/Entrained Solids \\
ICD-17 & Phase 1 Privatization - Cesium-137 Intermediate Product \\
ICD-18 & Phase 1 Privatization 99 Technetium Secondary-Product \\
ICD-19 & Low-Activity Waste Feed \\
ICD-20 & Phase 1 Privatization - High-Level Waste Feed \\
ICD-21 & Phase 1 Waste Feed Tank Support Systems \\
ICD-22 & Air Emissions \\
\hline
\end{tabular}

${ }^{1}$ Compilation of Interface Control Documents, Recommendations to Resolve Open Issues, Plans to Resolve All Remaining Interface Issues, July 1997, HNF-SP-1227 (FDH 1997a); Individual documents listed in reference list to Program Plan as FDH 1997e-w. ICD = Interface Control Document.

subprogram or project within the TWRS Retrieval and Disposal Program will identify the need for an ICD. If it is determined that the system or hardware on either or both sides of that . interface must be developed, an ICD will be generated, usually by the participant who first identifies the need for its development.

- Organizational interfaces, programmatic information; and operating parameters will be documented and controlled through Memoranda of Understanding and/or * formal contractual language. The Retrieval and Disposal Program will manage 
these required interfaces by establishing formal agreements between the performing organizations.

\subsection{STAFFING AND PERSONNEL TRAINING AND QUALIFICATIONS}

Staffing and Personnel Training and Qualifications strategies ensure that qualified people are available for the TWRS Project and its Retrieval and Disposal Mission. A range of options including training and education, hiring and recruitment, and temporary assignments are considered. The Staffing and Personnel Training and Qualifications approach addresses numerous areas including succession planning, cross-training, compliance training, developmental training, and turnover rate management.

\subsubsection{Succession Planning}

Succession planning is a Lockheed Martin Corporate commitment as well as a TWRS Project commitment. As defined in Lockheed Martin Corporate Policy Statement CPS-550, Leadership Development and Succession Planning, this process identifies "ready now," "high potential," and "development required" candidates and is dedicated to diversity, not only within succession planning but also in staffing functions. The TWRS Project performs a gap analysis to identify areas where recruitment or cross-training is imperative.

The PHMC team has a sitewide posting system that movement of personnel among the PHMC companies. The PHMC team works to fill open positions throughout the Hanford Site. In times of growth, the PHMC team determines the recruitment and skill mix needs and staffs accordingly. The PHMC team complies with Federal requirements for recruitment by providing careful consideration and hiring preference. Further, open positions are posted with the Reemployment Opportunity Center. Lockheed Martin Corporate Policy Statement CPS 541, Temporary - Domestic Assignments ensures that resources from corporate locations are in supply to meet short-term needs. Identified skill mix gaps are eliminated by recruiting and providing benefits to employees who move to the PHMC team location in accordance with CPS 538, Transfer of Employees - Domestic Assignment. This policy eases family disruptions and assists with certain relocation costs.

\subsubsection{Training}

The PHMC/LMHC training departments provide training and qualification programs that maintain a competent staff. Programs include management, technical, administrative, operations, crafts, safety, environmental, and quality assurance. Not only is the TWRS Project staff highly trained, but TWRS Project subcontractors must have training equivalent to the same level and qualification as their TWRS Project counterparts for the function they hold. These programs are conducted in accordance with the Project Hanford Policies and Procedures (training and 
qualification). There are currently 36 separate qualification/training programs provided to TWRS Project staff. The TWRS Project will train and qualify private contractor personnel to operate the privatization waste immobilization facilities, if so requested by the DOE.

The TWRS Project staff is not just trained to perform a single function. Management encourages cross-training and, as a result, many members of the staff hold multiple qualifications, providing the project with a diverse staff capable of fulfilling a variety of positions.

Qualification training is just one component in the training and qualification strategy. The TWRS Project must also have a workforce trained in a variety of safety issues. Compliance training provides that avenue of success. Compliance training (HNF-IP-1184, Training Requirements and Instructions, Section 2.0 "Mandated/Directed Training Requirement Summaries" [FDH 1996c]) and the LMHC Corporate Compliance Training Plan (LMHC 1997b) is provided through a cooperative effort between the FDH Training Department and the TWRS Project Training Department. Management ensures proper compliance and qualification training is maintained current by using the Training Matrix Subsystem (TMXS n.d.) database. The TMXS provides position training requirements against which an individual's qualifications can be compared to ensure he/she is qualified to perform that job.

The TWRS management not only encourages its staff to pursue higher education, but ensures employee expenses are reimbursed (HNF-PRO-039, Reimbursing Educational Costs [FDH 1996a]). Along with this encouragement, TWRS Project management ensures an aggressive development program by including areas for focused improvement on staff performance reviews.

The TWRS Project management's dedication to training excellence is evident by the accomplishment of having its staff positions (required by DOE 5480.20A, Personnel Selection, Qualification, and Training Requirements at DOE Nuclear Facilities) $100 \%$ compliant in mandated and directed training on September 20,1997, meeting a 1997 commitment.

\subsubsection{Turnover Rate and Management}

The PHMC team provides a clean, safe and well-appointed work environment for its employees. The PHMC team works to provide challenging assignments to enhance both depth and breadth in career development, encouraging a sense of loyalty to both the mission and to the companies involved. This is reinforced with a service and merit-based fee sharing and recognition programs. In 1997 the TWRS Project had a $2 \%$ voluntary attrition rate which is substantially below industry average. History reflects our commitment to managing our attrition and demonstrates the ability to staff the TWRS Project organization for maximum efficiency. 
HNF-1883 Rev 1

\subsection{STAKEHOLDER AFFAIRS}

\subsubsection{Public Participation}

The TWRS ROD (62 FR 8693) commits to periodic scientific and technical reviews and evaluations "with an appropriate level of public involvement."

The HNF-MP-012, Integrated Hanford Communications Plan (FDH 1997d) submitted by FDH to DOE identifies key Hanford Site stakeholders and provides a framework for integrated communications and public involvement for the Hanford Site. That plan identifies the two major DOE/stakeholder public involvement documents as (1) Community Relations Plan for the Hanford Federal Facility Agreement and Consent Order (DOE et al. 1996), which outlines public involvement opportunities associated with activities mandated by the Tri-Party Agreement (Ecology et al. 1996) and (2) Public Involvement Policy (McClure 1997), which reaffirms RL's commitment to engaging stakeholders in decision-making and sets forth programmatic guidelines.

The Public Involvement Policy assigns responsibility for public involvement to RL management. The $\mathrm{RL}$ has conducted public involvement activities as appropriate in each stage of its TWRS Project activities and has been active in communicating plans and program details through media, public meetings, and responses to the requests of interested individuals and - organizations. The LMHC and FDH support RL in the communication of the TWRS Project activities to stakeholders, tribes, and other interested parties.

\subsubsection{Economic Transition}

Economic transition is an integral part of the PHMC team scope and a corollary to the cleanup work that reduces site mortgage costs, frees up site assets, and converts internal workscope to competitively subcontracted activities. The potential economic transition value of Hanford Site assets is a factor in identifying cleanup priorities and execution alternatives, making decisions about the use or disposition of site assets, and evaluating PHMC team performance.

Within the PHMC team, the Office of Economic Transition is the primary conduit for the transfer of Hanford Site physical and intellectual assets that can promote regional business growth. Target prospects for the Office of Economic Transition arise primarily from opportunities for asset conversion, technology transfer, and outsourcing or spinoff of traditionally self-performed site functions that can be launched as new local enterprises.

The HNF-MP-006, Economic Transition and Outsourcing Plan (FDH 1997b) will provide specific guidance to PHMC team members on accomplishing the goals of economic diversification, site stabilization, and local economy investments. This guidance will be incorporated, as required, in TWRS Project and TWRS retrieval and disposal mission planning and implementation procedures. 


\subsection{REFERENCES}

Acts

National Environmental Policy Act of 1969, as amended, 42 USC 4321 et seq.

\section{Code of Federal Regulations}

10 CFR 830, "Quality Assurance Requirements," Code of Federal Regulations, as amended.

10 CFR 835, "Occupational Radiation Protection," Code of Federal Regulations, as amended.

\section{Databases}

ERMI, n.d., Environmental Requirements Management Interface Database, database maintained by Lockheed Martin Hanford Corporation for Fluor Daniel Hanford, Inc., Richland, Washington.

HSTD, n.d., Hanford Site Technical Baseline Database, maintained by Lockheed Martin Hanford Corporation for Fluor Daniel Hanford, Inc., Richland, Washington.

TMXS, n.d., Training Matrix Subsystem, database maintained by Fluor Daniel Hanford Daniel, Inc.

\section{Federal Register}

62 FR 8693, 1997, "Record of Decision for the Tank Waste Remediation System, Hanford Site, Richland, WA," Federal Register, Vol. 62, pp. 8693-8704 (February 26).

\section{Lockheed Martin Corporate Policy Statements}

CPS-538, Transfer of Employees - Domestic Assignment, Lockheed Martin, Bethesda, Maryland.

CPS-541, Temporary - Domestic Assignments, Lockheed Martin, Bethesda, Maryland.

CPS-550, Leadership Development and Succession Planning, Lockheed Martin, Bethesda, Maryland. 
HNF-1883 Rev 1

\section{U.S. Department of Energy Good Practice Guides}

GPG-FM-002, Critical Decision Criteria, Life Cycle Asset Management, Good Practice Guide, U.S. Department of Energy, Washington, D.C.

GPG-FM-010, Project Execution and Engineering Management Planning, Life Cycle Asset Management, Good Practice Guide, U.S. Department of Energy, Washington, D.C.

GPG-FM-013, Interface Management, (Draft) Life Cycle Asset Management, Good Practice Guide, U.S. Department of Energy, Washington, D.C.

\section{U.S. Department of Energy Orders}

DOE Order 425.1, Startup and Restart of Nuclear Facilities, U.S. Departiment of Energy, Washington, D.C.

DOE Order 430.1, Life Cycle Asset Management, U.S. Department of Energy, Washington, D.C.

DOE Order 5480.20A, Personnel Selection, Qualification, and Training Requirements for DOE Nuclear Facilities, U.S. Department of Energy, Washington, D.C.

.DOE Order 5700.6C, Quality Assurance, U.S. Department of Energy, Washington, D.C.

\section{Logic Diagrams}

$\mathrm{FDH}, 1998$, Logic Diagrams, prepared by Lockheed Martin Hanford Corporation for Fluor Daniel Hanford, Inc., Richland, Washington.

- H-2-823148, TWRS Retrieval Level I Logic Immobilized Waste (ILAW)

- H-2-829149, TWRS Retrieval Level 1 Logic Immobilized Waste (IHLW)

- H-2-829150, TWRS Retrieval Level 1 Logic Infrastructure Phase 1 Privatization Support

- H-2-892151, TWRS Retrieval Level I Logic Waste Feed Delivery LAW Ist Feed Batches Tank 24I-AN-105

- H-2-829152, TWRS Retrieval Level I Logic Waste Feed Delivery.LAW 2nd Feed Batches Tank 241-AN-104

- H-2-829153, TWRS Retrieval Level 1 Logic Waste Feed Delivery LAW 3rd Feed Batches Tank 241-AW-10I

- H-2-829154, TWRS Retrieval Level 1 Logic Waste Feed Delivery LAW Ath Feed Batches Tank 24I-AN-103

- H-2-829155, TWRS Retrieval Level 1 Logic Waste Feed Delivery LAW 5th Feed Batches Tanks 241-AP-101 \& 241-AW-104

- H-2-829156, TWRS Retrieval Level I Logic Waste Feed Delivery LAW 6th Feed Batches Tank 241-AY-I01 
- H-2-829157, TWRS Retrieval Level 1 Logic Waste Feed Delivery LAW 7th \& 8th Feed Batches Tank 241-AN-107

- H-2-829158, TWRS Retrieval Level 1 Logic Waste Feed Delivery LAW 9th Feed Batches Tank 241-AN-102

- H-2-829159, TWRS Retrieval Level 1 Logic Waste Feed Delivery LAW 10th Feed Batches Tank 24l-AN-106

- H-2-829160, TWRS Retrieval Level 1 Logic Waste Feed Delivery LAW 11th Feed Batches Tank 241-SY-101

- H-2-829161, TWRS Retrieval Level 1 Logic Waste Feed Delivery LAW 12th Feed Batches Tank 241-SY-103

- H-2-829162, TWRS Retrieval Level 1 Logic Waste Feed Delivery HLW 1st \& 2nd Feed Batches First Tank, 241-AZ-101

- H-2-829163, TWRS Retrieval Level 1 Logic Waste Feed Delivery HLW 3rd \& 4th Feed Batches Second Tank, 241-AZ-102

- H-2-829164, TWRS Retrieval Level 1 Logic Waste Feed Delivery HLW 5th - 9th Feed Batches Third Tank, 24I-AY-102

- H-2-829165, TWRS Retrieval Level 1 Logic Waste Feed Delivery HLW 10th-12th Feed Batches Fourth Tank, 241-C-104

- H-2-829166, TWRS Level O Logic (2 Sheets)

\section{Documents}

Acree, C. D., Jr., 1998, Tank Waste Remediation System Mission Analysis Report, HNF-SD-WM-MAR-008, Rev. 3, prepared by Lockheed Martin Hanford Corporation for Fluor Daniel Hanford, Inc., Richland, Washington.

Baldwin, J. H., T. J. McLaughlin, R. D. Potter, and R. L. Treat, 1998, Tank Waste Remediation System Retrieval and Disposal Mission Key Enabling Assumptions, HNF-1945, Rev. 0, prepared by Lockheed Martin Hanford Corporation for Fluor Daniel Hanford, Inc., Richland, Washington.

Biebesheimer, E., 1996, High-Level Waste Storage Tank Farms/242-A Evaporator Standards/ Requirements Identification Document (S/RID), WHC-SD-MP-SRID-001, Rev. 1, Westinghouse Hanford Company, Richland, Washington.

Borneman, L. E., 1998, Tank Waste Remediation System Environmental Program Plan, HNF-1773, Rev. 0, prepared by Lockheed Martin Hanford Corporation for Fluor Daniel Hanford, Inc., Richland, Washington.

Byers, S. A., 1997, Project Hanford Quality Assurance Program Description, HNF-MP-0599, prepared by MACTEC for Fluor Daniel Hanford, Inc., Richland, Washington. 
Calmus, R. B., 1997, Tank Waste Remediation System Retrieval and Disposal Mission Immobilized High-Level Waste Storage Plan, HNF-1751, Rev. 0, Lockheed Martin Hanford Corporation for Fluor Daniel Hanford, Inc., Richland, Washington.

DOE and BNFL, 1996, Privatization Contract Between U.S. Department of Energy and British Nuclear Fuels Limited, DE-RP06-96RL13308, Richland, Washington.

DOE and Ecology, 1996, Tank Waste Remediation System, Hanford Site, Richland, Washington, Final Environmental Impact Statement, DOE/EIS-0189, U.S. Department of Energy and Washington State Department of Ecology, Washington, D.C.

DOE and LMAES, 1996, Privatization Contract Between U.S. Department of Energy and Lockheed Martin Advanced Environmental Systems, DE-RP06-96RL13309, Richland, Washington.

DOE, EPA, and Ecology, 1997, Community Relations Plan for the Hanford Federal Facility Agreement and Consent Order, U.S. Department of Energy, U.S. Environmental Protection Agency, and Washington State Department of Ecology, Olympia, Washington.

Dunbar, L. R., 1996, LMHC Subcontracting Plan, Lockheed Martin Hanford Corporation, Richland, Washington.

Ecology, EPA, and DOE, 1996, Hanford Federal Facility Agreement and Consent Order, 2 vols., Washington State Department of Ecology, U.S. Environmental Protection Agency, and U.S. Department of Energy, Olympia, Washington.

FDH, 1996a, Reimbursing Educational Costs, HNF-PRO-039, Fluor Daniel Hanford, Inc., Richland, Washington.

FDH, 1996b, Subcontract between Fluor Daniel Hanford Company and Lockheed Martin Hanford Corporation Contract 80232764-9-K001, Richland, Washington.

FDH, 1996c, Training Requirements and Instructions, HNF-IP-1184, Fluor Daniel Hanford, Inc., Richland, Washington.

FDH, 1996d, PHMC Procurement Policy Manual, Fluor Daniel Hanford, Richland, Washington.

FDH, 1997a, Compilation of Interface Control Documents, Recommendations to Resolve Open Issues, Plans to Resolve All Remaining Interface Issues, HNF-SP-1227, Fluor Daniel Hanford, Inc., Richland, Washington.

FDH, 1997b, Economic Transition and Outsourcing Plan, HNF-MP-006, Rev. 0, Fluor Daniel Hanford, Inc., Richland, Washington. 
FDH, 1997c, HANDI 2000 Project Execution Plan, HNF-1743, Fluor Daniel Hanford, Inc., Richland, Washington.

FDH, 1997d, Integrated Hanford Communications Plan, HNF-MP-012, Rev. 0, Flưor Daniel Hanford, Inc., Richland, Washington.

FDH, 1997e, Interface Control Document Between DOE and the PHMC Phase I

Privatization-Raw Water, HNF-SP-1208-ICD-01, DRAFT, prepared by Lockheed Martin Hanford Corporation for Fluor Daniel Hanford, Inc., Richland, Washington.

FDH, 1997f, Interface Control Document Between DOE and the PHMC Phase 1

Privatization-Potable Water, HNF-SP-1209-ICD-02, DRAFT, prepared by Lockheed Martin Hanford Corporation for Fluor Daniel Hanford, Inc., Richland, Washington.

FDH, 1997g, Interface Control Document Between DOE and the PHMC Radioactive Solid Waste, HNF-SP-1210-ICD-03, DRAFT, prepared by Lockheed Martin Hanford Corporation for Fluor Daniel Hanford, Inc., Richland, Washington.

FDH, 1997h, Interface Control Document Between DOE and the PHMC Non-Radioactive, NonDangerous Liquid Effluent for Phase I Privatization, HNF-SP-1211-ICD-05, DRAFT, prepared by Lockheed Martin Hanford Corporation for Fluor Daniel Hanford, Inc., Richland, Washington.

FDH, 1997i, Interface Control Document Between DOE and the PHMC Radioactive Dangerous Liquid Effluents, HNF-SP-1212-ICD-06, DRAFT, prepared by Lockheed Martin Hanford Corporation for Fluor Daniel Hanford, Inc., Richland, Washington.

FDH, 1997j, Interface Control Document Between DOE and the PHMC Land for Siting Part $A$ Privatization, HNF-SP-1213-ICD 04, DRAFT, prepared by Lockheed Martin Hanford Corporation for Fluor Daniel Hanford, Inc., Richland, Washington.

FDH, 1997k, Interface Control Document Between DOE and the PHMC Deactivated Facility and Site for Phase 1 Privatization, HNF-SP-1214-1CD-10, DRAFT, prepared by Lockheed Martin Hanford Corporation for Fluor Daniel Hanford, Inc., Richland, Washington.

FDH, 19971, Interface Control Document Between DOE and the PHMC Electricity, HNF-SP-1215-ICD-11, DRAFT, prepared by Lockheed Martin Hanford Corporation for Fluor Daniel Hanford, Inc., Richland, Washington.

FDH, 1997m, Interface Control Document Between DOE and the PHMC Phase 1 Privatization Roads and Rails, HNF-SP-1216-ICD-12, DRAFT, prepared by Lockheed Martin Hanford Corporation for Fluor Daniel Hanford, Inc., Richland, Washington. 
FDH, 1997n, Interface Control Document Between DOE and the PHMC Phase I Privatization Non-Routine High-Level Solid Wastes, HNF-SP-1217-ICD-13, DRAFT, prepared by Lockheed Martin Hanford Corporation for Fluor Daniel Hanford, Inc., Richland, Washington.

FDH, 19970, Interface Control Document Between DOE and the PHMC Phase 1 Privatization Immobilized High-Level Waste Product, HNF-SP-1218-ICD-14, DRAFT, prepared by Lockheed Martin Hanford Corporation for Fluor Daniel Hanford, Inc., Richland, Washington.

FDH, 1997p, Interface Control Document Between DOE and the PHMC Phase 1 Privatization Immobilized Low-Activity Waste Product, HNF-SP-1219-ICD-15, DRAFT, prepared by Lockheed Martin Hanford Corporation for Fluor Daniel Hanford, Inc., Richland, Washington.

FDH, 1997q, Interface Control Document Between DOE and the PHMC Phase I Privatization Strontium/Transuranic/Entrained Solids, HNF-SP-1220-ICD-16, DRAFT, prepared by Lockheed Martin Hanford Corporation for Fluor Daniel Hanford, Inc., Richland, Washington.

FDH, 1997r, Interface Control Document Between DOE and the PHMC Phase I PrivatizationCesium-137 Intermediate Product, HNF-SP-1221-ICD-17, DRAFT, prepared by Lockheed Martin Hanford Corporation for Fluor Daniel Hanford, Inc., Richland, Washington.

FDH, 1997s, Interface Control Document Between DOE and the PHMC Phase 1 Privatization ${ }^{99}$ Technetium Secondary Product, HNF-SP-1222-ICD-18, DRAFT, prepared by Lockheed Martin Hanford Corporation for Fluor Daniel Hanford, Inc., Richland, Washington.

FDH, 1997t, Interface Control Document Between DOE and the PHMC Low-Activity Waste Feed, HNF-SP-1223-ICD-19, DRAFT, prepared by Lockheed Martin Hanford Corporation for Fluor Daniel Hanford, Inc., Richland, Washington.

FDH, 1997u, Interface Control Document Between DOE and the PHMC Phase 1 Privatization High-Level Waste Feed, HNF-SP-1224-ICD-20, DRAFT, prepared by Lockheed Martin Hanford Corporation for Fluor Daniel Hanford, Inc., Richland, Washington.

FDH, 1997v, Interface Control Document Between DOE and the PHMC Phase 1 Waste Feed Tank Support Systems Low-Activity Waste Product, HNF-SP-1225-ICD-21, DRAFT, prepared by Lockheed Martin Hanford Corporation for Fluor Daniel Hanford, Inc., Richland, Washington.

FDH, 1997w, Interface Control.Document Between DOE and the PHMC Air Emissions, HNF-SP-1225-ICD-22, DRAFT, prepared by Lockheed Martin Hanford Corporation for Fluor Daniel Hanford, Inc., Richland, Washington. 
FDH, 1997x, Project Hanford Management Contract Configuration Management Plan, HNF-MP-013, Rev. 0, Fluor Daniel Hanford, Inc., Richland, Washington.

FDH, 1997y, Project Hanford Management Contract Management and Integration Plan, HNF-MP-001, Rev. 1, Fluor Daniel Fluor Daniel Hanford, Inc., Richland, Washington.

HAMTC, 1997, Agreement Between Fluor Daniel Hanford and Hanford Atomic Metal Trades Council, Richland, Washington.

HSRCM-1, 1994, Hanford Site Radiological Control Manual, Rev. 2, prepared for the U.S. Department of Energy, Richland, Operations Office, by the Hanford Site Contractors and managed by Pacific Northwest National Laboratory Records Management Office, Richland, Washington.

Kirkbride, R.A., G. K. Allen; P. J. Certa, A. F. Manuel, R. M. Orme, L. W. Shelton, E. J. Slaathaug, R. S. Wittman, and G. T. MacLean, and D. L. Pẹnwell (SESC), 1997, Tank Waste Remediation System Operation and Utilization Plan, HNF-SD-WM-SP-012, Rev. 0, Volumes I and II, prepared by Numatec Hanford Corporation for Fluor Daniel Hanford, Inc., Richland, Washington.

LMFC, 1997a, TWRS Administration, FNF-IP-0842, Lockheed Martin Hanford Corporation for Fluor Daniel Hanford, Inc., Richland, Washington.

LMHC, 1997b, LMHC Corporate Compliance Training Plan, Lockheed Martin Hanford Corporation, Richland, Washington.

McClure, G. M., 1997, Public Involvement Policy, U.S. Department of Energy, Richland Operations Office, Richland, Washington.

Mickle, G. D., 1995, Tank Farm Health and Safety Plan, WHC-SD-WM-HSP-002, Rev. 2, Westinghouse Hanford Company., Richland, Washington.

Peck, L.G., 1998, Tank Waste Remediation System Systems Engineering Management Plan, HNF-SD-WM-SEMP-002, Rev. 1, prepared by Lockheed Martin Hanford Corporation for Fluor Daniel Hanford, Inc., Richland, Washington.

Potter, R. D. and R. L. Treat, 1998, Tank Waste Remediation System Retrieval and Disposal Mission Waste Feed Delivery Plan, HNF-881, Rev. 0, Lockheed Martin Hanford Corporation for Fluor Daniel Hanford, Inc., Richland, Washington.

Raymond, R. E., 1998, Tank Waste Remediation System Technical Baseline Summary Description, HNF-2016, Rev. 0, Lockheed Martin Hanford Corporation for Fluor Daniel Hanford, Inc., Richland, Washington. 
Rifaey, S. H., 1998, Tank Waste Remediation System Engineering Plan, HNF-1947, Rev. 0, prepared by Lockheed Martin Hanford Corporation for Fluor Daniel Hanford, Inc., Richland, Washington.

RL, 1996a, British Nuclear Fuels Laboratory Privatization Contract, DE-AC06-96RL13308, U.S. Department of Energy, Richland Operations Office, Richland, Washington.

RL, 1996b, Hanford Strategic Plan, DOE/RL 96-92, Rev. 0, U.S. Department of Energy, Richland Operations Office, Richland, Washington.

RI, 1996c, Lockheed Martin Advanced Environmental Systems Privatization Contract, DE-AC06-96RL13309, U.S. Department of Energy, Richland Operations Office, Richland, Washington.

RL, 1996d, Project Hanford Management Contract (PHMC), DE-AC06-96RL13200, U.S. Department of Energy, Richland Operations Office, Richland, Washington.

Root, R. W., Jr., and R. D. Potter, 1998, Tank Waste Remediation System Retrieval and Disposal Mission Infrastructure Plan, HNF-1882, Rev, 0, Lockheed Martin Hanford Corporation for Fluor Daniel Hanford, Inc., Richland, Washington.

Rosenberry, M. W., 1997, TWRS Change Control, LMH-MD-004, Rev. 0, Lockheed Martin Hanford Corporation, Richland, Washington.

Schaus, P. S., 1997, Hanford Tank Initiative Plan, HNF-SD-HTI-PLN-002, Lockheed Martin Hanford Corporation, Richland, Washington.

Shade, J. W., 1997, Tank Waste Remediation System Retrieval and Disposal Mission Immobilized Low-Activity Waste Disposal Plan, HNF-1517, Rev, 0, Lockheed Martin Hanford Corporation for Fluor Daniel Hanford, Inc., Richland, Washington.

Swita, W. R., M. R. Lewis, and M. J. O'Neill, 1998, Tank Waste Remediation System Retrieval and Disposal Mission Initial Updated Baseline Summary, HNF-1946, Rev. 1, prepared by Lockheed Martin Hanford Corporation for Fluor Daniel Hanford, Inc., Richland, Washington.

Treat, R., P. Bartley, T. J. McLaughlin, R. D. Potter, R. E. Raymond, and W. L. Willis, 1998, Tank Waste Remediation System Retrieval and Disposal Mission Technical Baseline Summary Description, HNF-1901, Rev. 0, prepared by Lockheed Martin Hanford Corporation for Fluor Daniel Hanford, Inc., Richland, Washington. 
Vann, J. M., E. R. Hamm, and R. D. Crisp, 1998, Tank Waste Remediation System Configuration Management Plan, HNF-1900, Rev. 0, prepared by Lockheed Martin Hanford Corporation for Fluor Daniel Hanford, Inc., Richland, Washington.

Zimmerman, B. D., 1988, Tank Waste Remediation System Risk Management Plan, HNF-SD-WM-PMP-018, Rev. 2, prepared by Lockheed Martin Hanford Corporation for Fluor Daniel Hanford, Inc., Richland, Washington. 


\section{HNF-1883 Rev 1}

\section{APPENDIX A}

TANK WASTE REMEDIATION SYSTEM MAINTENANCE ORGANIZATION

EXECUTION PLAN FOR THE

TWRS RETRIEVAL AND DISPOSAL MISSION 
HNF-1883 Rev 1

This page intentionally left blank. 
HNF-1883 Rev 1

\section{CONTENTS}

A1.0 INTRODUCTION $\ldots \ldots \ldots \ldots \ldots \ldots \ldots \ldots \ldots \ldots \ldots \ldots \ldots \ldots \ldots \ldots \ldots \ldots \ldots \ldots \ldots$

A2.0 MISSION AND ORGANIZATION $\ldots \ldots \ldots \ldots \ldots \ldots \ldots \ldots \ldots \ldots \ldots \ldots \ldots \ldots \ldots \ldots$

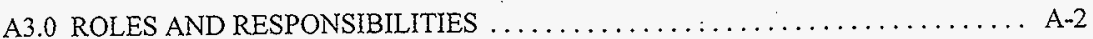

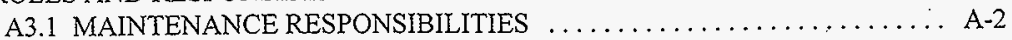

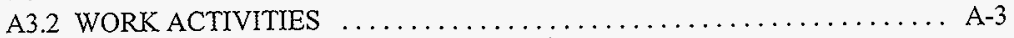

A3.3 INTERFACES $\ldots \ldots \ldots \ldots \ldots \ldots \ldots \ldots \ldots \ldots \ldots \ldots \ldots \ldots \ldots \ldots \ldots \ldots \ldots \ldots \ldots$

A4.0 EXECUTION STRATEGY $\ldots \ldots \ldots \ldots \ldots \ldots \ldots \ldots \ldots \ldots \ldots \ldots \ldots \ldots \ldots \ldots \ldots$

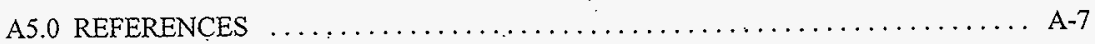

\section{LIST OF TABLES}

A-1 Tank Waste Remediation System Maintenance Organization in Support of Waste Retrieval and Delivery $\ldots \ldots \ldots \ldots \ldots \ldots \ldots \ldots \ldots \ldots \ldots \ldots \ldots$

\section{LIST OF TERMS}

DOE

DST

ES\&H

FY

LMHC

PHMC

SST

TWR

TWRS

WFD
U.S. Department of Energy

double-shell tank

environmental, safety, and health

fiscal year

Lockheed Martin Hanford Corporation

Project Hanford Management Contract

single-shell tank

Tank Waste Retrieval

Tank Waste Remediation System .

Waste Feed Delivery 
HNF-1883 Rev 1

This page intentionally left blank.

A-iv 
HNF-1883 Rev 1

\title{
APPENDIX A
}

\author{
TANK WASTE REMEDIATION SYSTEM \\ MAINTENANCE ORGANIZATION \\ EXECUTION PLAN FOR THE \\ TWRS RETRIEVAL AND DISPOSAL MISSION
}

\section{A1.0 INTRODUCTION}

Before the U.S. Department of Energy (DOE) can authorize the private contractors to proceed with Phase 1B, the Project Hanford Management Contract (PHMC) team must demonstrate that it will be able to provide the necessary support to the private contractors. The PHMC team must conduct a "readiness to proceed" self-assessment of its ability to support the private contractors. The DOE is responsible for reviewing the PHMC assessment and for conducting an independent readiness-to-proceed evaluation. The status of the PHMC team's readiness to proceed is a key consideration in DOE's decision-making about continuing with privatization.

The Tank Waste Remediation System (TWRS) Maintenance organization performs several functions that contribute to the TWRS Retrieval and Disposal Mission and support the private contractors, including maintaining in operating condition those systems, structures, and components that will be used to deliver feed to the private contractors. This Execution Plan describes key technical, programmatic, and management aspects of the TWRS Maintenance organization that are relevant to privatization support, and summarizes the approach and activities for achieving and maintaining readiness to proceed. This Execution Plan will be updated periodically to reflect changes to privatization and as the contributing functions of the TWRS Maintenance organization evolve.

The TWRS Maintenance organization is or will be ready in all respects to maintain the required equipment in operating condition.

The remaining sections of this Execution Plan provide details on the contributions of the TWRS Maintenance organization to the TWRS Retrieval and Disposal Mission.

\section{A2.0 MISSION AND ORGANIZATION}

The TWRS Maintenance organization mission is to maintain tank farm systems, structures, and components as designated by the Operations and Engineering organizations in a safe, reliable, and operable condition. This is to be accomplished through effective work 
planning and scheduling, material control, and efficient resource utilization. The TWRS Maintenance organization must perform within the limits established by applicable DOE orders, project and program plans, company directives, and applicable federal and state laws. Radiological and industrial safety ALARA (as low as reasonably achievable) and strict adherence to the Authorization Basis are required for the performance of maintenance work. The TWRS Maintenance organization is responsible for coordinating the development and implementation of administrative and technical procedures and other program elements that enhance the effectiveness of the Tank Farm maintenance program.

The TWRS Maintenance organization provides overall maintenance support to the TWRS Project. The TWRS Maintenance organization is part of Tank Waste Operations and provides support to double-shell tanks (DSTs), single-shell tanks (SSTs), the Tank Waste Characterization Project, and the TWRS Retrieval and Disposal Mission.

\section{A3.0 ROLES AND RESPONSIBILITIES}

\section{A3.1 MAINTENANCE RESPONSIBILITIES}

The TWRS Maintenance organization has the primary responsibility for ensuring Tank Farm systems, structures, and components are effectively maintained in operating condition to support the TWRS Retrieval and Disposal Mission and Waste Feed Delivery (WFD) retrieval, staging, conditioning, and delivery schedules. Organizationally, the TWRS Maintenance . organization is responsible for three functional areas:

- Production Control. Production Control provides the planning support required to perform work in the field. This is accomplished through work package development, the procurement and staging of parts and materials, and the scheduling of planned corrective and preventive maintenance tasks.

- Maintenance Program Integration. Maintenance Program Integration provides multiple services. Principal among these are ensuring that the infrastructure is in place for compliance with DOE order requirements for Maintenance Management Programs, performing assessments to ensure that the Maintenance Functional Area of the applicable Standards/Requirements Identification Documents (S/RIDS) are consistent with current standards and requirements, and providing changes to the administrative infrastructure when changes occur. In addition, Maintenance Program Integration is the responsible point of interface with Engineering to ensure that adequate maintenance procedures are in place and approved to support the TWRS Retrieval and Disposal Mission and WFD.

- Craft Services Support. The TWRS Maintenance organization is responsible for providing the craft resources needed to perform predictive corrective and 
preventive maintenance in support of TWRS Project missions in a manner consistent with Tank Farm program production schedules. Maintenance is to be accomplished using the proper combination of preventive and predictive corrective maintenance while using the best available technology to ensure maximum efficiency and cost effectiveness.

\section{A3.2 WORK ACTIVITIES}

Table A-1 summarizes the actions and interfaces that must be accomplished by the TWRS Maintenance organization, including the functional areas outlined above, to support the TWRS Retrieval and Disposal Mission and WFD.

\section{A3.3 INTERFACES}

To ensure optimum support to the TWRS Retrieval and Disposal Mission and WFD, effective interfaces between affected organizations will be required. The TWRS Maintenance organization will continue to rely and build on strong communications with the following organizations: Retrieval Projects; Tank Waste Operations; Radiological Control; Environmental Safety and Health (ESH\&H) and Quality Assurance; Engineering; Procurement Services; Hoisting and Rigging Services; Material Warehousing; Material Transportation; and the private contractors.

The methods for defining the customer/servicer relationships between these points of interface and the TWRS Maintenance organization will be accomplished through well defined scope statements that include clear expectations and criteria for success. These scope statements will be transmitted by several methods. In the case of the TWRS Retrieval and Disposal . Mission, the scope will be identified through HNF-MD-017, Multi-Year Work Plan (FDH 1997), and the budgeting process. It can be assumed that Retrieval Projects will be the primary point of interface between the TWRS Maintenance organization and the private contractors. In the case of Procurement Services, Material Warehousing, and Transportation, the scope and method of interface are well defined by Lockheed Martin Hanford Corporation (LMHC) contract provisions and internal procedures. Interfaces with Radiological Control, Environmental, Safety, and Health (ES\&H), Engineering, and Hoisting and Rigging Services will be established through the budgeting processes. In some cases these interfaces may have to be reinforced through the use of Memoranda of Understanding. In addition, interfaces with Radiological Control, ES\&H and Quality Assurance, and Engineering are well defined in organizational charters, policies and procedures. 
Table A-1. Tank Waste Remediation System Maintenance Organization in Support of Waste Retrieval and Delivery.

\begin{tabular}{|c|c|c|}
\hline $\begin{array}{l}F Y \\
1998\end{array}$ & • & $\begin{array}{l}\text { Decomposition of the Level } 1 \text { Logics (FDH 1998) developed from the Master Project Plan. } \\
\text { Reconcile issues identified in the decomposition of the Level } 1 \text { Logic to support } \\
\text { development of the Master Program Schedule. } \\
\text { Develop and start implementing a maintenance strategy that will support Level } 1 \text { Logic } \\
\text { Task 130.B15 (Prepare to Support Waste Feed Staging Production Mode). }\end{array}$ \\
\hline $\begin{array}{l}\text { FY } \\
1999\end{array}$ & - & $\begin{array}{l}\text { Finish implementing the maintenance strategy started in FY } 1998 . \\
\text { In support of Level } 1 \text { Logic Task } 130 . \text { B } 16 \text { (Maintain Waste Transfer Systems Operable): } \\
\text { - Develop task and staffing plans that will support waste transfers through the year } \\
2009 .\end{array}$ \\
\hline $\begin{array}{l}\text { FYs } \\
2000 \\
\text { through } \\
2009\end{array}$ & - & $\begin{array}{l}\text { Accomplish transfer system turnover to Tank Farms. } \\
\text { Provide day-to-day maintenance support to the TWRS Retrieval and Disposal Mission and } \\
\text { WFD as required to maintain production schedules, including but not limited to work } \\
\text { planning, work scheduling, work execution, craft support, materials, maintenance } \\
\text { procedures, and maintenance engineering. } \\
\text { Provide support as required to ensure efficient facility upgrades provided by Project W-314. }\end{array}$ \\
\hline
\end{tabular}

FDH, 1998, Logic Diagrams, prepared by Lockheed Martin Hanford Corporation for Fluor Daniel Hanford, Inc., Richland, Washington.

- H-2-823148, TWRS Retrieval Level 1 Logic Immobilized Waste (ILAW)

- H-2-829149, TWRS Retrieval Level 1 Logic Immobilized Waste (IHLW)

- H-2-829150, TWRS Retrieval Level I Logic Infrastructure Phase I Privatization Support

- H-2-892151, TWRS Retrieval Level 1 Logic Waste Feed Delivery LAW Ist Feed Batches Tank 24I-AN-105

- H-2-829152, TWRS Retrieval Level l Logic Waste Feed Delivery LAW 2nd Feed Batches Tank 241-AN-104

- H-2-829153, TWRS Retrieval Level I Logic Waste Feed Delivery LAW 3rd Feed Batches Tank 24I-AW-101

- H-2-829154, TWRS Retrieval Level 1 Logic Waste Feed Delivery LAW 4th Feed Batches Tank 241-AN-103

- H-2-829155, TWRS Retrieval Level 1 Logic Waste Feed Delivery LAW Sth Feed Batches Tanks 24I-AP-I01 \& 24I-AW-I04

- H-2-829156, TWRS Retrieval Level 1 Logic Waste Feed Delivery LAW 6th Feed Batches Tank 241-AY-10I

- H-2-829157, TWRS Retrieval Level 1 Logic Wasle Feed Delivery LAW 7th \& 8th Feed Batches Tank 24I-AN-107

- H-2-829158, TWRS Retrieval Level 1 Logic Waste Feed Delivery LAW 9th Feed Batches Tank 241-AN-102

- H-2-829159, TWRS Retrieval Level 1 Logic Waste Feed Delivery LAW 10th Feed Batches Tank 241-AN-106

- H-2-829160, TWRS Retrieval Level I Logic Waste Feed Delivery LAW IIth Feed Batches Tank 241-SY-10I

- H-2-829161, TWRS Retrieval Level 1 Logic Waste Feed Delivery LAW 12th Feed Batches Tank 241-SY-103

- H-2-829162, TWRS Retrieval Level 1 Logic Waste Feed Delivery HLW Ist \& 2nd Feed Batches First Tank, 241-AZ-101

- H-2-829163, TWRS Retrieval Level 1 Logic Waste Feed Delivery HLW 3rd \& 4th Feed Batches Second Tank, 241-AZ-102

- H-2-829164, TWRS Retrieval Level I Logic Waste Feed Delivery HLW 5th-9th Feed Basches Third Tank, 241-AY-I02

- H-2-829165, TWRS Retrieval Level I Logic Waste Feed Delivery HLW I0th-12th Feed Batches Fourth Tank, 24I-C-104

- H-2-829166, TWRS Level 0 Logic (2 Sheets)

$\mathrm{FY}=$ fiscal year

TWR $=$ Tank Waste Retrieval.

WFD $=$ Waste Feed Delivery. 


\section{A4.0 EXECUTION STRATEGY}

The TWRS Maintenance organization maintenance strategy is and will continue to be based on the requirements established by DOE Order 4330.4B, Maintenance Management Program, Chapter 2, "Nuclear Facilities." The elements contained in this order provide the basics for an effective maintenance program. While the order does not provide a prescriptive direction on how the program will be implemented, it recognizes that different facilities and projects have different maintenance program needs and provides the flexibility to develop a program that supports those needs.

The current maintenance program has been almost exclusively focused on the operation of Tank Farms in a storage and surveillance mode. Movement to an emphasis on the TWRS Retrieval and Disposal Mission requires the maintenance program to shift to a production mode orientation. In order for the TWRS Maintenance organization to accomplish this transition, several changes in the operation of the maintenance program are required.

A Tank Farm Integrated Schedule is currently being developed by Waste Tank Operations. This schedule must incorporate the requirements for day-to-day operation of the Tank Farms as they relate to safe storage and surveillance, the TWRS Retrieval and Disposal Mission, and construction project needs. Waste sampling as well as waste transfers must also be incorporated in the integrated schedule. The integrated schedule must be resource loaded consistent with authorized budget and staffing levels. Only $65 \%$ to $80 \%$ of the available maintenance resources should be loaded into the integrated schedule, leaving the remaining $20 \%$ to $35 \%$ of the resources available to respond to crisis/emergent work. This schedule must then be agreed to and signed by the organizations responsible for implementing the schedule and providing the required resources as identified on the schedule. The integrated schedule establishes work priorities. Effective change control with the concurrence of the TWRS Maintenance organization is essential to ensure that the TWRS Retrieval and Disposal Mission priorities are adequately addressed. The integrated schedule is a living document and must be maintained current to reflect changes in the work scope when applicable. Waste Tank Operations has responsibility for maintaining this schedule.

In order to ensure that equipment supplied by construction projects to the Tank Farms in support of the TWRS Retrieval and Disposal Mission can be maintained operable, it is essential that the TWRS Maintenance organization be involved early in project review. This involvement will ensure that project plans are reviewed for equipment maintainability. Facility operating costs are significantly increased when equipment maintainability is not properly considered (e.g., when equipment is less than easily accessible or when a specific piece of equipment becomes a high maintenance item due to the application for which it is being used). Early involvement of the TWRS Maintenance organization with construction projects also provides essential input to Engineering related to spare parts, procedures, and craft training needs.

Transition from performing maintenance that supports safe storage and surveillance to the TWRS Retrieval and Disposal Mission will require an effective preventive and predictive 
maintenance program that is specific to the anticipated retrieval and delivery activities. This program must focus on the early detection of conditions that will lead to equipment failure and take action that will ensure reliability of equipment over its design life. An efficient preventive maintenance program will identify the majority of the corrective maintenance items. When corrective maintenance items are discovered using effective preventative maintenance techniques, corrective actions may be able to be performed when the condition is discovered without impacting production schedules, or they can be scheduled in a manner that does not shut down critical equipment.

The introduction of reliability-centered predictive maintenance will significantly reduce the potential for unplanned equipment shutdown by replacing components that have a history of failure prior to failure. Implementation of predictive maintenance techniques permits the monitoring of operating equipment in a nonintrusive manner. This will permit the early detection of future equipment failures. Using predictive maintenance techniques ensures early signs of failure will be detected, and corrective action can be scheduled during planned equipment downtime. The use of reliability-centered maintenance and predictive maintenance techniques is supported by DOE Order 4330:4B; WHC-SP-1179, Maintenance Optimization for Essential Equipment Reliability; and Good.Practices MA-307, Preventive Maintenance (INPO 85-032), and MA-316, Plant Predictive Maintenance (INPO 89-009).

The effective scheduling of maintenance is essential to meeting production commitments. The majority of maintenance activities should be planned during planned equipment downtime or scheduled system outages. Outage planning and scheduling is effectively used in many production operations where it is critical to achieve maximum operating system run-time. Planned outages should be identified on the integrated schedule with each outage having its own detailed schedule. The principles of outage planning and scheduling enable the TWRS Maintenance organization to plan, schedule, stage materials, and execute corrective and preventative maintenance for a single system within the time constraints permitted without impacting the production schedule. These planned outages will be communicated to the private contractors through IPT meetings.

Dedicated maintenance staffing will be required to support the TWRS Retrieval and Disposal Mission. The TWRS Maintenance organization has sufficient depth to ensure that the proper resources can be focused to provide the required level of support. These staffing requirements were identified as part of the Level 1 Logic Decomposition of Tasks $130 . \mathrm{B} 15$ and 130.B16. Staffing resources will be loaded in the TWRS Retrieval and Disposal Mission resource-loaded program schedule. Resources identified in the program schedule are used to develop the multi-year work plan.

Initial staffing increases will be made during fiscal year (FY) 1999 and completed by the end of FY 2000. This will provide a core group of trained and qualified maintenance-related and support personnel to support the turnover of four transfer system upgrades in FY 2001 by Project W-211. Additional staffing will be put in place to support future turnover of the ten remaining transfer system upgrades by Project W-211 over the next five years. 
HNF-1883 Rev 1

\section{A5.0 REFERENCES}

\section{U.S. Department of Energy Orders}

DOE Order 4330.4B, Maintenance Management Program, U.S. Department of Energy, Washington, D.C.

\section{Logic Diagrams}

FDH, 1998, Logic Diagrams, prepared by Lockheed Martin Hanford Corporation for Fluor Daniel Hanford, Inc., Richland, Washington.

- H-2-823148, TWRS Retrieval Level 1 Logic Immobilized Waste (ILAW)

- H-2-829149, TWRS Retrieval Level 1 Logic Immobilized Waste (IHLW)

- H-2-829150, TWRS Retrieval Level 1 Logic Infrastructure Phase 1 Privatization Support

- H-2-892151, TWRS Retrieval Level 1 Logic Waste Feed Delivery LAW 1st Feed Batches Tank 241-AN-105

- H-2-829152, TWRS Retrieval Level I Logic Waste Feed Delivery LAW 2nd Feed Batches Tank 241-AN-104

- H-2-829153, TWRS Retrieval Level 1 Logic Waste Feed Delivery LAW 3rd Feed Batches Tank 241-AW-101

- H-2-829154, TWRS Retrieval Level 1 Logic Waste Feed Delivery LAW 4th Feed Batches Tank 241-AN-103

- H-2-829155, TWRS Retrieval Level I Logic Waste Feed Delivery LAW 5th Feed Batches Tanks 241-AP-101 \& 241-AW-104

- H-2-829156, TWRS Retrieval Level I Logic Waste Feed Delivery LAW 6th Feed Batches Tank 241-AY-101

- H-2-829157, TWRS Retrieval Level 1 Logic Waste Feed Delivery.LAW 7th \& 8th Feed Batches Tank 241-AN-107

- H-2-829158, TWRS Retrieval Level I Logic Waste Feed Delivery LAW 9th Feed Batches Tank 24I-AN-102

- H-2-829159, TWRS Retrieval Level I Logic Waste Feed Delivery LAW 10th Feed Batches Tank 24I-AN-106

- H-2-829160, TWRS Retrieval Level 1 Logic Waste Feed Delivery LAW 11th Feed Batches Tank 241-SY-101

- H-2-829161, TWRS Retrieval Level 1 Logic Waste Feed Delivery LAW 12th Feed Batches Tank 24I-SY-103

- H-2-829162, TWRS Retrieval Level 1 Logic Waste Feed Delivery HLW 1st \& 2nd Feed Batches First Tank, 241-AZ-10I

- H-2-829163, TWRS Retrieval Level I Logic Waste Feed Delivery HLW 3rd \& 4th Feed Batches Second Tank, 241-AZ-102

- H-2-829164, TWRS Retrieval Level I Logic Waste Feed Delivery HLW 5th - 9th Feed Batches Third Tank, 241-AY-102 
HNF-1883 Rev 1

- H-2-829165, TWRS Retrieval Level I Logic Waste Feed Delivery HLW 10th-12th Feed Batches Fourth Tank, 24l-C-104

- H-2-829166, TWRS Level O Logic (2 Sheets)

\section{Documents}

FDH, 1997, Multi-Year Work Plan, HNF-MD-017, Rev. 0, Fluor Daniel Hanford, Inc., Richland, Washington.

INPO 85-032, 1985, Preventive Maintenance, Good Practice MA-307, Rev. 1, Institute of Nuclear Power Operations, Atlanta, Georgia.

INPO 89-009, 1989, Plant Predictive Maintenance, Good Practice MA-316, Institute of Nuclear Power Operations, Atlanta, Georgia.

Steffen, D. H., 1996, Maintenance Optimization for Essential Equipment Reliability, WHC-SP-1179, Rev. 0, Westinghouse Hanford Company, Richland, Washington. 
HNF-1883 Rev 1

\section{APPENDIX B}

TANK WASTE REMEDIATION SYSTEM TANK FARM OPERATIONS ORGANIZATION EXECUTION PLAN FOR THE TWRS RETRIEVAL AND DISPOSAL MISSION 


\section{HNF-1883 Rev I}

This page intentionally left blank.

\section{B-ii}




\section{CONTENTS}

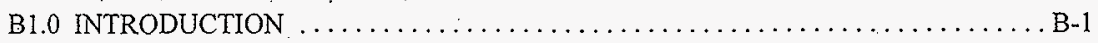

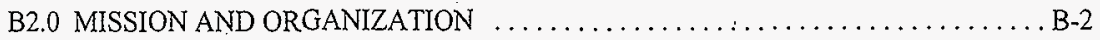

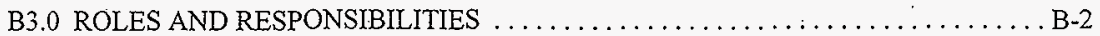

B3.1 DOUBLE-SHELL TANK OPERATIONS $\ldots \ldots \ldots \ldots \ldots \ldots \ldots \ldots \ldots$ B-2

B3.2 SINGLE-SHELL TANK OPERATIONS $\ldots \ldots \ldots \ldots \ldots \ldots \ldots \ldots \ldots$ B-4

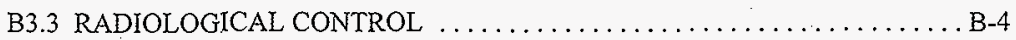

B3.4 INTERFACES . . . . . . . . . . . . . . . . . . . .

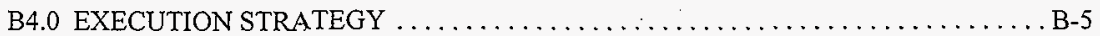

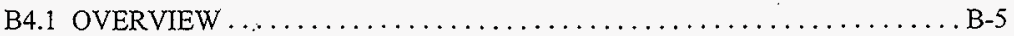

B4.2 LOW-ACTIVITY WASTE RETRIEVAL AND FEED DELIVERY . . . . . . B-6

B4.3 HIGH-LEVEL WASTE RETRIEVAL AND FEED DELIVERY $\ldots \ldots \ldots \ldots$ B-8

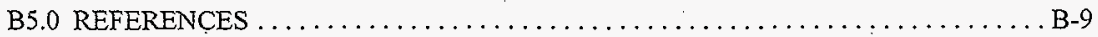

\section{LIST OF TERMS}

$\begin{array}{ll}\text { ALARA } & \text { as low as reasonably achievable } \\ \text { DOE } & \text { U.S. Department of Energy } \\ \text { DST } & \text { double-shell tank } \\ \text { FDH } & \text { Fluor Daniel Hanford, Ine. } \\ \text { FY } & \text { fiscal year } \\ \text { HLW } & \text { high-level waste } \\ \text { LAW } & \text { low-activity waste } \\ \text { LMHC } & \text { Lockheed Martin Hanford Corporation } \\ \text { PHMC } & \text { Project Hanford Management Contract } \\ \text { RTP } & \text { readiness to proceed } \\ \text { SST } & \text { single-shell tank } \\ \text { TWRS } & \text { Tank Waste Remediation System } \\ \text { WBS } & \text { work breakdown structure }\end{array}$


HNF-1883 Rev 1

This page intentionally left blank. 
HNF-1883 Rev 1

APPENDIX $B$

TANK WASTE REMEDIATION SYSTEM

TANK FARM OPERATIONS ORGANIZATION

EXECUTION PLAN FOR THE

TWRS RETRIEVAL AND DISPOSAL MISSION

\section{B1.0 INTRODUCTION}

Before the U.S. Department of Energy (DOE) can authorize the private contractors to proceed with Phase 1B, the Project Hanford Management Contract (PFMC) team must . demonstrate that they will be able to provide the necessary support to the private contractors. The PHMC team must conduct a "readiness to proceed" (RTP) self-assessment of its ability to support the private contractors. The $\mathrm{DOE}$ is responsible for reviewing the $\mathrm{PHMC}$ assessment and for conducting an independent RTP evaluation. The status of the PHMC team's RTP is a key consideration in DOE's decision-making about continuing with privatization.

The Tank Waste Remediation System (TWRS) Tank Farm Operations organization performs several functions that contribute to the TWRS Retrieval and Disposal Mission and support the private contractors, including the tank farm operations required to transfer lowactivity waste (LAW) to tanks AP-106 and AP-108 and the tank farm operations required to mobilize and transfer high-level waste (HLW) to the private contractor. This Execution Plan describes key technical, programmatic, and management aspects of the TWRS Tank Farm Operations organization that are relevant to privatization support, and summarizes the approach and activities for achieving and maintaining RTP. This Execution Plan will be updated periodically to reflect changes to privatization and as the contributing functions of the organization evolve.

In general, the TWRS Tank Farm Operations organization is or will be ready in all respects to:

- $\quad$ Prepare LAW and HLW to meet envelope specifications

- Transfer LAW to tanks AP-106 and AP-108

- Transfer HLW to the private contractor

- Receive by-product slurries from the private contractors.

Areas where the TWRS Tank Farm Operations organization plans to improve its current RTP status include:

- Additional training to execute all operations

- Updating the integration schedule to ensure timely execution of the mission. 
The remaining sections of this Execution Plan provide more details on the contributions of the TWRS Tank Farm Operations organization to the TWRS Retrieval and Disposal Mission.

\section{B2.0 MISSION AND ORGANIZATION}

Tank Farm Operations manages TWRS Project facilities and 177 underground storage tanks (149 single-shell tanks [SST], 28 double-shell tanks [DST]) in a safe and efficient manner ensuring compliance with DOE Orders and federal, state, and local laws and regulations to achieve the business goals and objectives of Lockheed Martin Hanford Corporation (LMHC); the PHMC; and RL. Tank Farm Operations is responsible for the safe handling, treatment, storage, and monitoring of highly radioactive liquid waste. Radioactive liquid wastes are received for interim storage into the DST system by truck, rail car, or transfer lines from external sources such as B Plant, the Plutonium Finishing Plant, and 222-S. Liquid wastes are staged as feed for 242-A Evaporator campaigns to conserve DST space through waste volume reduction. Evaporator output slurries are received for interim storage. Surveillance activities necessary to support the safe storage mission are performed using approved procedures.

Tank Farm Operations is the TWRS Project organization that directs operational activities at the TWRS Project permitted treatment, storage, and disposal facility. Tank Farm Operations comprises SST Operations and DST Operations. Radiological Control is matrixed, but has a fundamental relationship to Tank Farm Operations. Tank Farm Operations also receives matrix support from Maintenance; Engineering; Project Planning; Integration \& Control; and Environmental, Safety, and Health (ES\&H) and Quality Assurance.

\section{B3.0 ROLES AND RESPONSIBILITIES}

\section{B3.1 DOUBLE-SHELL TANK OPERATIONS}

It is the responsibility within DST Operations to receive, store, and transfer liquid.waste from approved generators into underground storage tanks via the waste transfer system ensuring activities adhere to the requirements contained within the current Authorization Basis and using the disciplined approach outlined in DOE Order 5480.19, Conduct of Operations Requirements for DOE Facilities. The DST Operations will ensure facilities are operated, maintained, repaired, and upgraded to protect the environment, the site workforce, and the general population from potential release of contaminants. The DST Operations will contribute to the planning and preparation for ultimate retrieval and disposal of this tank waste. The DST Operations will manage and direct the Radiological Health and Safety Programs established for TWRS Project activities; this ensures that each facility meets their radiological protection goals by providing disciplined, technically sound, professional radiological services. The DST Operations will 
maintain a standard of performance for formal conduct of operations, maintenance, and radiological control by personnel in accordance with the approved TWRS Project Safety/Requirements Identification Documents.

An objective of DST Operations is to ensure the availability of systems, structures, and components for current and future planned operations within the boundary of the current Authorization Basis. The DST Operations obtains, evaluates, and retains tank waste surveillance data to ensure up-to-date records status of facilities and equipment. The objective includes conducting activities pertaining to operations of a permitted treatment, storage, and disposal facility, ensuring compliance with the WAC 173-303, "Dangerous Waste Regulations," Washington Administrative Code. The small quantities of solid wastes that are generated in tank farms are disposed of through the Subcontract between Fluor Daniel Hanford Company and Waste Management Federal Services of Hanford, Inc. Contract 80232764:9-K003 (FDH 1996).

The Shift Manager is in charge of the operation at all times. The shift organization is comprised of dedicated Nuclear Process Operators, Stationary Operating Engineers, and Health Physics Technicians. Individual tank parameters such as level, temperature, pressure, and flammable gas concentration are monitored through a combination of remote monitoring and operator surveillance using approved Rounds Sheets. General housekeeping in and around the tank farms receives a high degree of attention as means to enhance personnel safety. Exceptions to proper material condition are recorded in Equipment Deficiency Logs and corrected through the use of the Job Control System.

Approved Operating Procedures govern operation of tank farm systems and components under the direct control of the Shift Manager. Examples include primary tank ventilation systems, annulus ventilation systems, waste transfers, in-tank videos, operational tests, and alarm response actions. Preventive and corrective maintenance is performed using approved work packages released for field work by the Shift Manager. Construction upgrades are integrated with operations and maintenance activities; this work is controlled using approved construction work packages and is released for field work by the Shift Manager.

It is fundamental to the success of DST Operations and the TWRS Project to diligently pursue active communications and establish effective team interfaces with Maintenance; Engineering; Health Physics; Tank Waste Retrieval and Disposal Projects; Environment, Safety, and Health and Quality Assurance organizations to ensure safe, efficient, and cost-effective operations. The DST Operations will continue to establish an effective interface with Fluor Daniel Hanford, Inc. (FDH) and oversight agencies regarding the status of ongoing work and performance agreements. The execution of an integrated schedule derived from the multi-year work plan ensures timely completion of commitments and agreements. Fully compliant Emergency Preparedness and Occurrence Notification programs are in place. 


\section{B3.2 SINGLE-SHELL TANK OPERATIONS}

The SST Operations is focused on safe storage of high-level radioactive waste contained within the SSTs. The same methodologies described in Section B3.1 apply to SST Operations. Additional scope accomplished includes the recovery of remaining pumpable SST waste into the DST system through the interim stabilization program. These liquids are a potential source of feed for Phase 1 retrieval, while the remaining solids are destined for the Phase 2 retrieval mission. An aggressive contamination area reduction program is ongoing. Mortgage reduction is accomplished at The TWRS Project through preparation of retired facilities for turnover to the Environmental Restoration Contractor.

\section{B3.3 RADIOLOGICAL CONTROL}

The goal of the Radiological Control organization is to provide radiological protection for employees within The TWRS Project. Radiological Control provides resources necessary to effectively manage and administer the TWRS Radiological Protection Program. The development, implementation, and maintenance of the program is required by HSRCM-1, Hanford Site Radiological Control Manual (1994), and 10 CFR 835, "Occupational Radiation Protection." The objective includes the conduct of activities pertaining to operations of the SST and DST facilities in a manner that ensures compliance with applicable federal, state, and local environmental regulations to ensure a safe work environment for site workers.

Radiological Control has a fundamental involvement in the development of tank farm procedures and the preparation of work packages. Safe execution of field work receives top priority. Field deficiencies are tracked through Radiological Problem Reports, and trends are analyzed.

Radiological Health and Safety maintains the Access Control Entry System which restricts tank farm access to authorized and trained individuals while ensuring contamination and radiation exposure remains as low as reasonably achievable (ALARA). Specific activities include radiation and contamination surveys of the work area, assignment of personnel dosimetry devices, operation of the Access Control Entry System station for work control, maintenance of postings, response to abnormal and emergency conditions, and technical guidance for pre-job and post-job evaluations.

Radiological Control field support provides performance of radiation, contamination, and airborne radiological surveys to evaluate and verify radiological protection for personnel and the environment using routine and special detection instruments and sampling techniques. Radiological Control will perform required radiological surveys according to established frequencies. 


\section{B3.4 INTERFACES}

In order to ensure optimum support to the Retrieval and Disposal Mission, effective interfaces between affected organizations will be required. The TWRS Tank Farm Operations organization will continue to rely and build on strong communications with the following organizations: Retrieval Projects; Tank Waste Maintenance; Radiological Control; Environment, Safety, and Health and Quality Assurance; Engineering; Procurement Services; Hoisting and Rigging Services; Material Warehousing; Material Transportation; and the Private contractors.

The methods for defining the customer/servicer relationship between these points of interface and the TWRS Tank Farm Operations organization will be accomplished through well defined scope statements that include clear expectations and criteria for success. These scope statements will be transmitted by several methods, including through the multi-year work plan, contract provisions, budget authorizations, and other written agreements. In some cases, interfaces may be reinforced through the use of Memoranda of Understanding. In addition, interfaces with Maintenance, Radiological Control, Environment, Safety, and Health and Quality Assurance, and Engineering are well defined in organizational charters, policies, and procedures.

\section{B4.0 EXECUTION STRATEGY}

\section{B4.1 OVERVIEW}

Tank Farm Operations ensures work is properly prioritized, planned, and executed in accordance with the integrated schedule. Management ensures the tank farm staff possesses the - training, skills, and resources necessary to safely conduct their assigned tasks. Tank Farm Operations will ensure that appropriate training systems, processes, and controls are in place throughout the Retrieval and Disposal Mission life cycle so that qualified individuals are available and ready to operate and maintain the retrieval systems using approved technical and administrative procedures. Tank Farm Operations will ensure that work is performed in a disciplined and highly professional manner that reflects a strong commitment to safety, practices ALARA to limit personnel exposure to hazards, and champions issues raised to ensure prompt corrective action is completed.

The Facility Manager for DST Operations reports to the Director of Tank Farm Operations. Field-level line management includes Operations Support, Project Support, Field Operations; and Shift Operations. The Phase 1 retrieval mission will be directly supported by a Retrieval Operations organization that expands as the mission develops. Matrixed organizations include Radiological Control, Maintenance, Production Control, Engineering, and Business Management. The use of enterprise companies is provided through task orders for limited work scope where their knowledge or expertise is required. 
The approval of the multi-year work plan, including work breakdown structure (WBS) dictionaries, capital equipment/expense not related to construction, cost account authorizations, cost account plans, and milestone description sheets are used to generate the integrated schedule that determines the prioritization of work. Formal change control is used to maintain Technical Baselines, documents, and hardware requirements, as well as schedule and cost baselines to ensure priorities are managed and maintained in accordance with the multi-year work plan. Key technical issues and uncertainties that may impact successful execution of the TWRS Retrieval and Disposal Mission and waste feed delivery are managed at the Director level. Appropriate action is taken to resolve issues and meet delivery schedules.

The DST Operations Manager leads the DST Waste Inventory Control Board that reviews proposed transfers and resolves technical issues affecting the DST waste inventory. This board assesses technical activities necessary to facilitate management of tank waste inventory and feed staging and ensures that construction project interface agreements, private contractor usage restrictions, environmental requirements, and configuration of tank waste are followed and current. This board, through its review and approval authority, prioritizes and determines the path forward for waste retrieval and feed delivery transfers, evaporator campaign feed staging, external transfers from waste generators, and internal transfers to empty catch tanks/optimize tank space. Particular emphasis is placed on arranging the work-around during calendar years 1999 through 2000 when waste transfer system upgrades supporting.Phase 1 retrieval take significant portions of the DST transfer system out of service.

\section{B4.2 LOW-ACTIVITY WASTE RETRIEVAL AND FEED DELIVERY}

The LAW retrieval operation commences with the completion of the Project W-211 construction for the AN-105 retrieval system and the upgrades to the mix and blend tanks AP-102 and AP-104. Tank Farm Operations supports the construction effort on these tanks and is responsible for the completion of the Operational Readiness Review specified in DOE Order 425.1, Startup and Restart of Nuclear Facilities. The paragraphs below delineate the expected sequence of operations to accomplish retrieval and feed delivery to the LAW immobilization facilities. The planning details of the retrieval campaign are documented by Tank Farm Process Engineering in the tank-specific Process Control Plan. Tank Farm Operations staff will receive additional training to execute these operations, and the integrated schedule will be updated to ensure timely execution of the mission.

Execution of the principal activities associated with the initial transfers of LAW is expected to occur as follows.

1. Waste transfers are performed to make tank space available in the AP Farm. Tanks AP-102 and AP-104 are the tanks to which the Phase 1 tank waste is retrieved. Tanks AP-106 and AP-108 will serve as the private contractor feed tanks. Tank AP-107 will be used to receive byproduct slurries from the LAW immobilization facilities. Waste transfers are frequently made into and out of the AP Farm, and this work is considered routine. 
2. Treated water is added to the tank to be retrieved to soften the surface crust. Tank Farm Operations routinely performs water additions to tanks.

3. A variable suction transfer pump is then used to transfer supernate that exists in the layer beneath the surface crust to AP-102 and AP-104. Removal of this supernate allows space to add diluent later on. This activity lowers the tank level, and the surface crust collapses into the tank center.

4. A large volume of diluent is added to the tank to dissolve the remaining tank slurry. This is similar to Activity 2, above, but much greater quantity.

5. The tank is then mixed using the Project W-211 installed mixer pumps. With vigorous mixing and the appropriate amount of diluent, the tank contents dissolves into a decantable liquid. The mixing system is anticipated to be similar to the Project W-151 system already installed in AZ-101. Resource requirements and training will be of a magnitude similar to that required for the operation of the SY-101 mixer system.

6. The tank is then sampled, and nondissolvable solids are allowed to settle for a period of time determined by analysis.

7. Final retrieval involves the transfer of the dissolute into AP-102 and AP-104. Several transfer routes are currently available from any DST into the AP Farm. Project W-314 provides additional transfer lines in the DST transfer system with a centralized leak-detection system to ensure reliability and flexibility throughout the TWRS Retrieval and Disposal Mission.

8. Feed in AP-102 and AP-104 is mixed, and chemicals are added if required to adjust the contents to meet the contractually required feed envelope. Project W-211 provides the chemical addition system for this purpose.

9. After feed qualification samples are taken for analysis and the batch is deemed acceptable within the feed envelope, feed is transferred into the LAW immobilization facility feed tanks, AP-106 and AP-108.

10. The LAW immobilization facilities will periodically send small quantities of compatible slurry mixtures (about 8,000 gal per year) into AP-107.

Phase $1 \mathrm{LAW}$ retrieval involves the following tanks in the order listed: AN-105, AN-104, AW-101, AN-103, AY-101 (supernate from AZ-101 and AZ-102), AN-107 (supernate), AN-102 (supernate), AN-106, SY-101, and SY-103. Tank Farm Operations will be ready to move this and any other fiture designated DST wastes into the AP Farm for processing. 


\section{B4.3 HIGH-LEVEL WASTE RETRIEVAL AND FEED DELIVERY}

The HLW retrieval operations commences with the completion of upgrade construction on AZ-101, which adds the transfer capability to move HLW slurries directly to the HLW immobilization facility. Completion of the Project W-151 mixer pump process test in fiscal year (FY) 1998 will prove the technology necessary to mobilize sludge and accomplish sludge washing. This equipment will be maintained operable and used for the actual retrieval mission, currently scheduled to start in FY 2001. Tank Farm Operations supports the construction effort on these tanks and is responsible for the completion of the appropriate readiness review specified in DOE Order 425.1. The paragraphs below delineate the expected sequence of operations to accomplish HLW feed delivery. The planning details of the retrieval campaign is documented by Tank Farm Process Engineering in the tank-specific Process Control Plan. Tank Farm Operations staff will be trained to execute these operations, and the integrated schedule will be updated to ensure timely execution of the mission.

Execution of the principal activities associated with the initial transfers of HLW is expected to occur as follows.

1. Existing tank supernate is transferred to other DSTs for use as future LAW feed. These types of transfers routinely occur at the tank farms.

2. . Large quantities of $\mathrm{pH}$-adjusted, temperature-controlled water are added to the tank for sludge washing. The first wash occurs at high caustic concentration to promote leaching of aluminum from the sludge. This operation greatly reduces the volume of HLW glass. Mixer pumps are operated to keep the mixture suspended and to control temperature.

3. Wash solutions are decanted to available DST space through the DST transfer system and will be transferred as future evaporator feed and/or LAW feed. Three washes are planned per tank with sampling activities between each cycle to evaluate the progress of the wash.

4. After the final wash and decant, water is added to the washed sludge to prepare the transfer solution meeting the required feed envelope specifications. The sludge is then mobilized and transferred in batches to the HLW immobilization facility. The pumping system designed and installed during the tank upgrades period along with the dedicated transfer lines being constructed directly to the HLW immobilization facility are crucial to the success of the mission as solids transfers are not currently made.

Phase $1 \mathrm{HLW}$ retrieval involves the following tanks in the order listed: AZ-101, AZ-102, AY-102, and C-104. The AY-102 solids include existing tank sludge plus the solids recovered from C-106 into AY-102 during the Project W-320 sluicing effort. Tank Farm Operations will be ready to move this waste to the HLW immobilization facility. 
HNF-1883 Rev I

\section{B5.0 REFERENCES}

\section{Code of Federal Regulations}

10 CFR 835, "Occupational Radiation Protection," Code of Federal Regulations, as amended.

\section{Washington Administrative Code}

WAC 173-303, "Dangerous Waste Regulations," Washington Administrative Code, as amended.

\section{U.S. Department of Energy Orders}

DOE Order 425.1, Startup and Restart of Nuclear Facilities, U.S. Department of Energy, Washington, D.C.

DOE Order 5480.19, Conduct of Operations Requirements for DOE Facilities, U.S. Department of Energy, Washington, D.C.

\section{Documents}

FDH, 1996, Subcontract between Fluor Daniel Hanford Company and Waste Management Federal Services of Hanford, Inc. Contract 80232764-9-K003, Richland, Washington.

HSRCM-1, 1994, Hanford Site Radiological Control Manual, Rev. 2, prepared for the U.S.

Department of Energy, Richland Operations Office, by the Hanford Site Contractors and managed by Pacific Northwest National Laboratory Records Management Office, Richland, Washington. 


\section{HNF-1883 Rev 1}

This page intentionally left blank. 
HNF-1883 Rev 1

APPENDIX C

TANK WASTE REMEDIATION SYSTEM CHARACTERIZATION PROJECT EXECUTION PLAN FOR THE TWRS RETRIEVAL AND DISPOSAL MISSION 
HNF-1883 Rev 1

This page intentionally left blank.

C-ii 
HNF-1883 Rev 1

CONTENTS

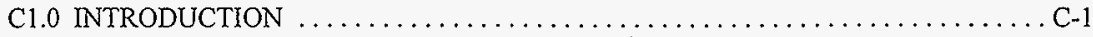

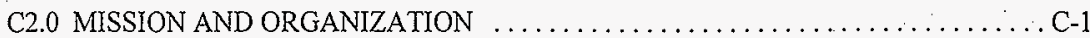

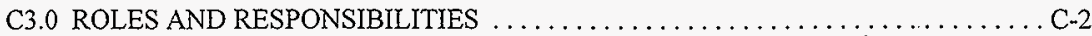

C3.1 CHARACTERIZATION PROJECT RESPONSIBILITIES $\ldots \ldots \ldots \ldots \ldots$ C-2

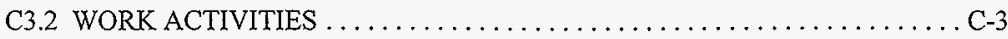

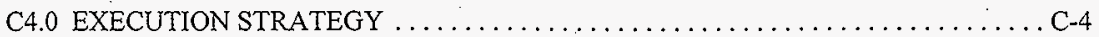

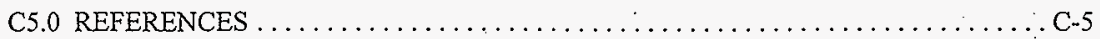

\section{LIST OF TERMS}

DOE

DQO

Ecology

ES\&H

FDH

HLW

LAW

LMHC

PHMC

$\mathrm{RL}$

RTP

Tri-Party Agreement TWRS
U.S. Department of Energy

Data Quality Objectives

Washington State Department of Ecology

environmental, safety, and health

Fluor Daniel Hanford, Inc.

high-level waste

low-activity waste

Lockheed Martin Hanford Corporation

Project Hanford Management Contract

U.S. Department of Energy, Richland Operations Office readiness to proceed

Hanford Federal Facility Agreement and Consent Order

Tank Waste Remediation System 
HNF-1883 Rev 1

This page intentionally left blank.

\section{C-iv}




\section{APPENDIX C}

\section{TANK WASTE REMEDIATION SYSTEM \\ CHARACTERIZATION PROJECT EXECUTION PLAN FOR THE \\ TWRS RETRIEVAL AND DISPOSAL MISSION}

\section{C1.0 INTRODUCTION}

Before the U.S. Department of Energy (DOE) can authorize the Private contractors to proceed with Phase 1B, the Project Hanford Management Contract (PHMC) team must demonstrate that it will be able to provide the necessary support to the Private contractors. The PHMC team must conduct a "readiness to proceed" (RTP) self-assessment of its ability to support the Private contractors. The DOE is responsible for reviewing the PHMC assessment, and for conducting an independent RTP evaluation. The status of the PHMC-team's RTP is a key consideration in DOE's decision-making about continuing with privatization.

The Tank Waste Remediation System (TWRS) Characterization Project performs several functions that contribute to the TWRS Waste Retrieval and Disposal Mission and support the Private contractors, including tank waste physical properties for retrieval systems design, information on tank solids for dissolution and settle/decant testing, and information on supernate for dilution and solubility limits. This Execution Plan describes key technical, programmatic, and management aspects of the TWRS Characterization Project that are relevant to privatization support, and summarizes the approach and activities for achieving and maintaining RTP. This Execution Plan will be updated periodically to reflect changes to privatization and as the contributing functions of the TWRS Characterization Project evolve.

In general, the TWRS Characterization Project is or will be ready in all respects to:

- Determine tank waste chemistry and radiochemistry

- Determine tank waste physical properties.

The remaining sections of this Execution Plan provide more details on the contributions of the TWRS Characterization Project to the Waste Retrieval and Disposal Mission.

\section{C2.0 MISSION AND ORGANIZATION}

The TWRS Characterization Project is a key project within the overall TWRS Project. The TWRS Characterization Project provides high-level waste (HLW) characterization data in 
support of both the Tank Waste Retrieval and Disposal Mission and the Tank Waste Storage mission.

The TWRS Characterization Project conducts the following activities: program management, data development, sampling equipment engineering, sampling operations, and laboratory sample analysis. The data development function is supplied by matrix support from the TWRS Process Engineering organization. The sampling equipment engineering function is supplied by matrix support from the Characterization Engineering organization. The laboratory sample analysis function is supplied by matrix support from Hanford Analytical Services, an organization managed by Waste Management Federal Services of Hanford. The TWRS Characterization Project also receives matrix support from the following LMHC support organizations: Radiological Control; Maintenance; Project Planning, Integration and Control; Nuclear Safety and Licensing; and Environmental, Safety, and Health (ES\&H) and Quality Assurance.

The TWRS Characterization Project has the responsibility for characterizing tank waste in accordance with Data Quality Objectives (DQO) and test plans to allow for safe operation and to provide the tank waste data necessary to store, transfer, retrieve, condition, and manage the waste. Project leadership and integration will be provided to facilitate the identification of information needs, provide data assessment and management, identify the sampling technical basis, deploy new sampling equipment, accomplish modifications to existing sampling equipment, maintain sampling equipment, acquire samples, and analyze samples. Additionally, the TWRS Characterization Project has full authority and responsibility, as delegated to LMHC by Fluor Daniel Hanford, Inc. (FDH) and the U.S. Department of Energy, Richland Operations Office (RL), for the timely execution of the Hanford Federal Facility Agreement and Consent Order (Tri-Party Agreement) (Ecology et al. 1996) tank characterization milestones and implementation of DOE/RL-94-0001, Recommendation 93-5 Implementation Plan (RL 1996), regarding tank characterization.

\section{C3.0 ROLES AND RESPONSIBILITIES}

\section{C3.1 CHARACTERIZATION PROJECT RESPONSIBILITIES}

The TWRS Characterization Project fulfills six primary areas of responsibility in support of Waste Retrieval and Disposal Mission and waste feed delivery. Each of these roles is discussed below.

Program Management. Activities for the management of the project are supplied. Work scope includes program management; baseline planning and integration; Environmental, Safety, and Health and Quality Assurance; and Radiological Control. 


\section{HNF-1883 Rev 1}

Characterization Data Development. Technical bases are developed, and information management is supplied. Work scope includes characterization data development; historical data, models, and inventory; data assessment and reports; and, characterization data management.

The TWRS Characterization Project facilitates development of DQOs, which identify the decisions to be made, the data required to make those decisions, and the required data quality for tank farm and transferred waste samples. The TWRS Characterization Project ensures customer data quality requirements as defined in the DQOs are met and provides guidance in interpretation and evaluation of analytical results.

The best estimates of tank contents are provided based on historical information, modeling, and actual analytical data. The tank waste characterization data are maintained and managed. Information is documented in tank characterization reports and in electronic databases, both of which will be controlled and maintained under change control.

Sampling Equipment. Equipment and operational techniques are analyzed, and improvements are implemented to optimize efficiency. Work scope includes management of sampling equipment, maintaining core sampling systems, improving sampling availability and effectiveness, and providing aiternate sampling systems.

Acquire Samples and Measurements. Specific sampling methodologies are performed for sampling tank contents and for sampling vapor in tank dome spaces. Work scope includes management of waste sampling; obtaining physical samples by core sampling, grab sampling, auger sampling, and vapor sampling; and maintenance of sampling equipment.

Acquire Sample Analyses. Timely sample analyses are acquired to support safe storage and disposal of tank wastes. A laboratory analysis report is issued to document results. Work scope includes management of sample analyses; analyses for core, grab, auger, and vapor samples; and technology applications.

Other Responsibilities. The TWRS Characterization Project interfaces with outside organizations to deliver or receive waste samples and perform required analyses. Archiving of samples is provided as determined necessary.

\section{C3.2 WORK ACTIVITIES}

Tank sampling data needs are identified by the internal or external organizations. The DQOs are developed and integrated into a Tank Sampling and Analysis Plan that directs the field sampling and analytical activities. Required field samples are obtained as vapor, liquid, or core samples and delivered to the analytical laboratory. The samples are analyzed, and suitable reports are generated to document the results. Samples may be taken one time to characterize tank contents or be ongoing to show results as tank contents are mixed or changed. The overall strategy for identifying, prioritizing, scoping, and assigning specific work activities is discussed in Section C4.0. 


\section{C4.0 EXECUTION STRATEGY}

Sampling program drivers for The TWRS Project are derived from the following sources: Tri-Party Agreement (Ecology et al. 1996) milestones, Defense National Facilities Safety Board recommendations, RL directions, Authorization Basis needs, operational activities, and retrieval data requirements. Many of the tank data requirements for retrieving, processing, and disposal of wastes are being met by evaluating historical data and sampling conducted for other programs. However, future needs include in-situ measurements and ex-situ analysis of tank samples in support of specific retrieval activities. The retrieval DQO focuses on the physical property measurement needed to design appropriate waste retrieval equipment. Tank wastes will be separated into HLW and low-activity waste (LAW) streams. The HLW stream consists of the bulk of the radionuclides. The LAW stream contains the bulk of the chemical waste in the tanks, in a much larger volume. Information requirements fall into the following two categories:

- Information on tank solids to evaluate chemical and physical behavior of solids washing, dissolution, and settle decant testing

- Information on tank supernate to evaluate liquid processing technologies (especially cesium removal). Characterization to evaluate dilution and solubility limits is also needed.

To date, a number of tanks have been evaluated for sludge washing characteristics. Additional tanks samples will be required for sludge washing and are being scheduled.

The immobilization of tank waste will be contracted to private contractors. Gathering information on the composition of waste in specific tanks is a high priority so that contractors can develop and construct the proper process for waste immobilization and the PHMC contractor can select, stage, and provide waste to the Private contractors. Additional DQOs are being developed to identify characterization data requirements to support resolution of feed staging issues.

The priorities for sampling tanks were developed by and in consensus with TWRS Projects, the RL, and the Washington State Department of Ecology (Ecology); the sampling priorities are listed in HNF-SD-WM-PLN-126, Draft FY 1997 - 1998 Waste Information Requirements Document (Winkleman et al. 1997). Once program information requirements are prioritized, these requirements are integrated with operational constraints to form the basis of the TWRS Characterization Project workscope. This document is produced each year and provides the TWRS Characterization Project deliverables for the coming years. When approved, this document, along with the multi-year work plan, provides the budget and schedule for characterization work to meet organization needs.

The TWRS Characterization Project is organized to support the needs of many different customers and drivers and uses the priorities approved in HNF-SD-WM-PLN-126 (Winkleman 
et al. 1997) to develop fiscal year schedules. Certified operators and analysts are available to perform the required tasks. Training programs are in place to ensure changes to procedural requirements are implemented. An engineering staff is available to develop new technology for new sampling evolutions. Formal change control is used to prepare and maintain Technical Baselines, documents, and hardware and to manage and control changes to these baselines. Policies and procedures are controlled formally through appropriate change control procedures.

\section{C5.0 REFERENCES}

Ecology, EPA, and DOE, 1996, Hanford Federal Facility Agreement and Consent Order, 2 vols., Washington State Department of Ecology, U.S. Environmental Protection Agency, and U.S. Department of Energy, Olympia, Washington.

RL, 1996, Recommendation 93-5 Implementation Plan, DOE/RL-94-0001, Rev. 1, U.S. Department of Energy, Richland Operations Office, Richland, Washington.

Winkleman, W. D., M. R. Adams, T. M. Brown, J. W. Hunt, D. J. McCain (LMHC), L. J. Fergestrom (Technical Resources International, Inc.), 1997, Draft FY 1997- 1998 Waste Information Requirements Document, HNF-SD-WM-PLN-126, Rev. B; prepared by Lockheed Martin Hanford Corporation for Fluor Daniel Hanford, Inc., Richland, Washington: 
HNF-1883 Rev 1

This page intentionally left blank. 
HNF-1883 Rev 1

\section{APPENDIX D}

TANK WASTE REMEDIATION SYSTEM

TECHNICAL OPERATIONS AND ENGINEERING ORGANIZATION EXECUTION PLAN FOR THE TWRS WASTE RETRIEVAL AND DISPOSAL MISSION

D-i 
HNF-1883 Rev 1

This page intentionally left blank. 
HNF-1883 Rev 1

CONTENTS

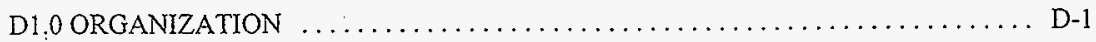

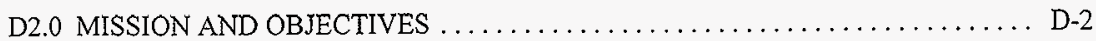

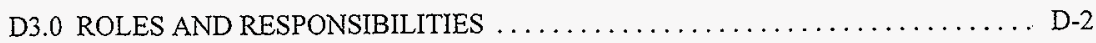

D3.1 TECHNICAL OPERATIONS AND ENGINEERING RESPONSIBILITIES . D-2

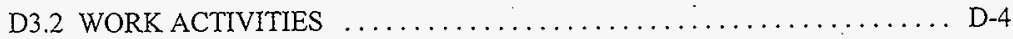

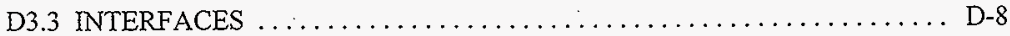

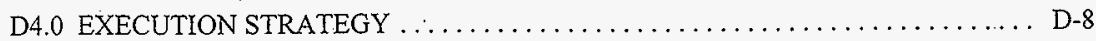

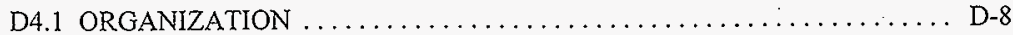

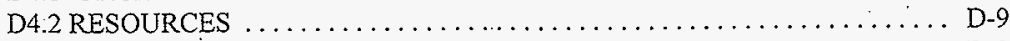

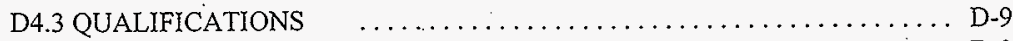

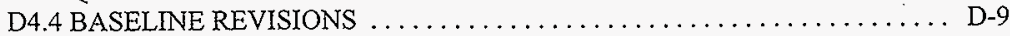

D4.5 PROCEDURAL FLOW $\ldots \ldots \ldots \ldots \ldots \ldots \ldots \ldots \ldots \ldots \ldots \ldots \ldots \ldots \ldots \ldots \ldots \ldots$

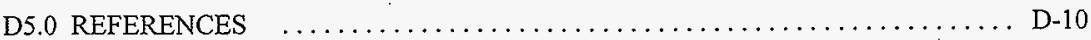

\section{LIST OF TERMS}

DOE

DST

U.S. Department of Energy

LMHC

double-shell tank

PHMC

Lockheed Martin Hanford Corporation

SSC

Project Hanford Management Contract

SST system, structure, and component

TWRS

single-shell tank

Tank Waste Remediation System 
HNF-1883 Rev 1

This page intentionally left blank. 


\title{
APPENDIX D
}

\author{
TANK WASTE REMEDIATION SYSTEM \\ TECHNICAL OPERATIONS AND ENGINEERING ORGANIZATION \\ EXECUTION PLAN FOR THE \\ TWRS WASTE RETRIEVAL AND DISPOSAL MISSION
}

\section{D1.0 ORGANIZATION}

Before the U.S. Department of Energy (DOE) can authorize the Private contractors to proceed with Phase 1B, the Project Hanford Management Contract (PHMC) team must demonstrate that it will be able to provide the necessary support to the private contractors. The PHMC team must conduct a "readiness to proceed" self-assessment of its ability to support the private contractors. The DOE is responsible for reviewing the PHMC assessment and for conducting an independent readiness-to-proceed evaluation. The status of the PHMC Team's readiness to proceed is a key consideration in DOE's decision-making about continuing with privatization.

The Tank Waste Remediation System (TWRS) Technical Operations and Engineering organization is a Lockheed Martin Hanford Corporation (LMHC) group that provides overall engineering support to the TWRS Project. This support is given to the following TWRS organizations: Operations, Maintenance, Quality Assurance, Environmental, Safety, and the various business management organizations. These organizations in turn support the following projectized effort: Double-shell Tanks (DSTs), Single-shell Tanks (SSTs), Tank Waste Characterization, and Tank Waste Retrieval.

This Execution Plan describes key technical, programmatic, and management aspects of the TWRS Technical Operations and Engineering organization that are relevant to privatization support and summarizes the approach and activities for achieving readiness to proceed. This plan will be updated periodically to reflect changes to privatization and as the contributing functions of the TWRS Technical Operations and Engineering organization evolve.

The Technical Operations and Engineering organization is, or will be, ready to provide support to the TWRS Retrieval and Disposal Mission in achievement of its goals and in the management of its technical and safety baselines. 


\section{D2.0 MISSION AND OBJECTIVES}

The mission of the Technical Operations and Engineering organization is to provide technical leadership to the TWRS Project for the management of its technical and safety baselines.

The objectives of this management activity is two-fold, centered around either the existing baselines or the future "to-be" installed baselines. First, the Technical Operations and Engineering organization establishes, improves, and maintains under configuration control the technical and safety baselines for all physically installed systems, inciuding computer software. This involves troubleshooting of failed hardware, technical dispositioning of nonconformances, providing technical leadership to operation and maintenance activities, interpretation of technical and safety baselines, and technical support to environmental, safety, and quality assurance issues. Second, the Technical Operations and Engineering organization provides technical leadership or consultation for new system technical and safety baselines. This involves development of specifications, design reviews, and testing.

\section{D3.0 ROLES AND RESPONSIBILITIES}

\section{D3.1 TECHNICAL OPERATIONS AND ENGINEERING RESPONSIBILITIES}

The Technical Operations and Engineering organization has the primary responsibility to ensure that existing tank farm systems, structures, and components (SSCs) necessary to support retrieval, staging, conditioning, and delivery schedules are effectively maintained according to their technical and safety baselines. In addition; the Technical Operations and Engineering organization ensures that new SSCs are integrated with the existing technical and safety baselines as needed to ensure mission support for waste retrieval and delivery. Organizationally, the Technical Operations and Engineering organization is responsible for four functional areas:

- Technical Baseline Management. The Technical Baseline is managed through the usage of two engineering technical authorities: Design Authorities and Cognizant Engineers. Both types of engineers ensure that existing facility SSCs function and are maintained according to established Technical Baselines. Also, these technical authorities ensure that new hardware is properly integrated into these baselines, which may involve effort ranging from technical review to actual new baseline development and project activities coordination (e.g., design, fabrication, testing, and installation). The differences in Design. Authority and Cognizant Engineering effort center on the safety function of the related Technical Baseline. Design Authorities are responsible for the Technical Baseline of safety (as defined in the safety baseline) SSCs, while Cognizant Engineers are responsible for the baseline of non-safety hardware. These technical authorities 
directly support SST and DST equipment, Characterization Project equipment, and newly installed retrieval equipment.

Safety Baseline Management. Management of the safety baseline is handled by the Nuclear Safety and Licensing organization. The technical authorities within this organization manage existing hazard databases, safety analyses, and supporting calculations comprising the Authorization Basis and related safety bases. The primary responsibility of the Nuclear Safety and Licensing organization with new SSCs related to retrieval activities is to ensure the integration of new safety analyses with the existing safety baseline. This ensures that hazard evaluation and mitigation is consistently applied to new and existing hardware. The following list summarizes the activities of the Nuclear Safety and Licensing organization:

- Develops, delivers, and maintains Authorization Basis documents for TWRS Project facilities including supporting safety analysis and attendant Technical Safety Requirements .

- Develops, implements, and maintains a system for managing safety documentation

- Maintains Unreviewed Safety Question process

- Coordinates interactions with FDH, the DOE and the Defense Nuclear Facilities Safety Board for safety and licensing issues

- $\quad$ Addresses and resolves waste tank safety issues

- $\quad$ Provides management of the criticality program for The TWRS Project.

A specific execution plan for this baseline management is detailed in Appendix $F$.

- Configuration Management. The responsibility of this function is to manage the configuration of the technical and safety baseline. This effort allows proper integration with new retrieval activities by ensuring a controlled and stable documentation match to hardware form, fit, and function. This also allows accurate integration with programmatic cost and schedule baselines. The following list summarizes their activities:

- Establishes, coordinates, and maintains process methods, mechanisms, and procedures governing the "Conduct of Engineering"

- Performs interpretive authority responsibilities for assigned Standards/Requirements Identification Document functional areas 


\section{HNF-1883 Rev 1}

- Develops and manages the implementation of the TWRS Project configuration management program, in accordance with the Tank Waste Remediation System Configuration Management Plan (Vann et al. 1998).

- Operations and Maintenance Support. The responsibility for this function is distributed between all Technical Operations and Engineering organizations to ensure technical support for all operational and maintenance activities. The following list summarizes their activities:

- Provides technical expertise during facility operations with qualified cognizant engineers and design authorities

- Identifies and maintains the facility SSC configuration in agreement with Technical Baseline and Authorization Basis

- Ensures operations are governed by technically correct limits incorporated into procedures

- Monitors equipment and process performance and identifies items for further evaluation

- Reviews and controls proposed changes to the facility/activity to ensure consistency with design basis

Ensures test and surveillance procedures applicable to safety-related equipment correctly evaluate functionality of such equipment.

\section{D3.2 WORK ACTIVITIES}

Specific work activities are classified into the following four chronological phases: Baseline Establishment/Improvement, Waste Retrieval, Waste Delivery, and Waste Handling. Significant effort for the first phase has already been accomplished by establishment of a new TWRS primary Authorization Basis, qualification of upper-tiered Technical Baseline, initiation of major projects for waste retrieval and delivery operations, and implementation of more rigorous procedures for configuring and managing the Technical Baseline. Details for the remaining effort of the first phase and the remaining three phases are detailed below. (As noted in Section 3.1, Appendix F covers the work activities associated with management of the safety. baseline.) 
HNF-1883 Rev 1

First Phase--Baseline Establishment/Improvement

Basic Scope -. Stage Waste and Prepare Tank Farm SSCs for Retrieval and Disposal Operations

- Issue formal plan for coordination and detailed scoping of Baseline Establishment/Improvement activities listed below and identifying approval authorities and their interfaces.

- Identify functional criteria for detailed SSCs based on mission objectives; federal, state, local, and DOE regulations; permitting and permit application requirements; Authorization Basis requirements and similar safety baselines; and engineering codes and standards.

- Evaluate existing systems against functional criteria to determine need of Technical Baseline modification and/or new hardware.

- Complete Technical Baseline management tools in progress (e.g. Master Equipment List).

- For the condition where existing hardware can meet functional criteria on a system level:

- Define system and components.

- Evaluate system and components for operability and functionality.

- $\quad$ Revise Technical Baseline as necessary to assure single, as-built Technical Baseline document and archive unneeded Technical Baseline.

$\therefore \quad$ Issue revised Technical Baseline documentation.

- Update existing configuration management tools from revised Technical Baseline (e.g. Master Equipment List, Spare Parts List, Safety Equipment List).

- Issue System Design Descriptions for required physical hardware to qualify operational parameters consistent with functional criteria, technical and safety baselines, and future phases.

- Evaluate adequacy of existing configuration control processes and install new tools as appropriate (e.g. hypertext-linked safety and Technical Baselines).

- Verify and approve design. 
HNF-1883 Rev 1

- Perform reliability, availability, and maintainability evaluation.

- Modify functional criteria if necessary and proceed with new construction project work.

- For the condition requiring new hardware, including construction projects in progress:

- Prepare and approve engineering option studies.

- $\quad$ Review and approve design.

- Review and approve specifications.

- Conduct and approve reliability, availability, and maintainability evaluations.

- Conduct and approve constructability, operability, and implementability evaluations.

- Monitor and support procurement, fabrication, testing, delivery, and commercial grade item dedication.

- Support Technical Baseline as-building, issuance, and delivery of related technical information (e.g., vendor data, test data, spares recommendations).

- Verify acceptance of remaining Acceptance for Beneficial Usage documents and issue matrix evaluating physical hardware compliance with functional criteria.

- Support Operations and Maintenance organization in revision or issuance of operational and maintenance documentation (e.g., operating and preventive maintenance procedures and data sheets).

- Update existing configuration management tools from revised Technical Baseline (e.g., Master Equipment List, Spare Parts List, Safety Equipment List).

- Issue/revise System Design Descriptions for required physical hardware to qualify operational parameters consistent with functional criteria, technical and safety baselines, and future phases.

- Evaluate adequacy of existing configuration control processes and install new tools as appropriate. 
Second Phase--Waste Retrieval

Basic Scope - Remove Waste from Tank Farm Vessels and Stage for Transfer

- Maintain technical and safety baselines from field replacements/upgrades, changing regulatory requirements, $D O E$ requirements, and retrieval functional criteria.

- Revise technical and safety baselines with new SSCs as necessary to adjust to revised waste characterization data.

- Provide technical expertise during facility operation with qualified Cognizant Engineers and Design Authorities to ensure reliability and maintainability of required hardware systems, operations are governed by technically correct limits incorporated into procedures, hardware performance is consistent with specifications, facility changes and activities are consistent with technical and safety baselines, and that test and surveillance procedures correctly evaluate functionality.

\section{Third Phase--Waste Delivery}

Basic Scope - Transfer Liquid Waste to Waste Transfer and Treatment Facilities Maintain technical and safety baselines from field replacements/upgrades, changing regulatory requirements, DOE requirements, and waste delivery functional criteria.

- Revise technical and safety baselines with new SSCs as necessary, per revised waste characterization data.

- Provide technical expertise during facility operation with qualified Cognizant Engineers and Design Authorities to ensure reliability and maintainability of required hardware systems, operations are governed by technically correct limits incorporated into procedures, hardware performance is consistent with specifications, facility changes and activities are consistent with technical and safety baselines, and that test and surveillance procedures correctly evaluate functionality.

\section{Fourth Phase--Waste Handling}

Basic Scope - Receive and Stage Waste Streams from Waste Disposal and Transfer Facilities

- Revise technical and safety baselines with new SSCs as necessary, per revised data involving Waste Disposal and Treatment facilities' waste characterization.

- $\quad$ Provide technical expertise during facility operation with qualified Cognizant Engineers and Design Authorities to ensure reliability and maintainability of required hardware systems, operations are governed by technically correct limits 
incorporated into procedures, hardware performance is consistent with specifications, facility changes and activities are consistent with technical and safety baselines, and that test and surveillance procedures correctly evaluate functionality.

\section{D3.3 INTERFACES}

Continual communication and interface with TWRS Project and TWRS Retrieval and Disposal program personnel is critical to the success of Technical Baseline management and configuration control. A formal plan will be issued per the Phase 1 activity list identifying approval authorities for new project interfaces to ensure clear design authority procedural roles.

Interface with TWRS Operations, TWRS Maintenance, and TWRS Project independent support and review groups (e.g., Environmental, Safety, and Quality Assurance) is also essential. This interface is controlled by current procedures. These procedures are modified to address new requirements and communication needs as appropriate.

Interfaces with safety baseline and program baseline (cost and schedule) functions are managed by organizational structure and representation on retrieval and disposal teams.

\section{D4.0 EXECUTION STRATEGY}

\section{D4.1 ORGANIZATION}

The technical authority functions of Design Authority and Cognizant Engineer are the critical elements in Technical Baseline management. They are currently assigned throughout several Technical Operations and Engineering subgroups. This structure allows performance of the majority of work activities described in the First Phase, which primarily involve interface with the existing baselines.

Future organizational alignment may be changed to best support interface with new baselines and operational organizations such as the Waste Treatment Facilities. The present structure best supports any future changes by development of technical authorities across a wide range of organizational assignments. For example, Cognizant Engineers are assigned at a tank farm level (e.g., AP- tank farm), at systems level (e.g., ventilation), and for specific pieces of baselines (e.g., maintenance functional testing criteria). This allows multiple resources to be applied to physical hardware. Design Authorities are assigned to projects during the full cycle of hardware management, from design inception to operation until final turnover to the Decontamination and Disposal Project. 


\section{D4.2 RESOURCES}

Technical Baseline revisions and enhancements will be accomplished through present technical authority staffing levels supplanted by contract engineering. The TWRS Project has a successful history in applying contract engineering resources to support mission needs. The maintenance of the Technical Baseline and configuration control tools in the Second through Fourth Phases can be managed with existing technical staffing levels with only minor contract engineering support, assuming that new information does not involve significant changes in current plans for facility modification.

\section{D4.3 QUALIFICATIONS}

The existing qualification and training process will be maintained. The technical . authorities are assigned on the basis of their meeting educational and experience requirements. Approval authority of the Design Authorities and Cognizant Engineers is based on successful completion of qualification/training program. This program is documented in HNF-IP-0842, TWRS Administration, Volume III, Section 10.3, "Technical Staff Qualification Program Description" (LMHC 19.97). Continued training is tracked by site and organizational databases and will managed to current practices. A turnover process is used to facilitate changes in individual assignments without disruption to the project.

\section{D4.4 BASELINE REVISIONS}

Technical Baseline revisions, including system description documentation, master equipment list, drawings, and supporting technical evaluations will establish a complete Technical Baseline for the TWRS Retrieval and Disposal Program. The information will aid in applying limited resources to configuration management of critical hardware. An example of this is the newly revised tank farms Authorization Basis, HNF-SD-WM-BIO-001, Tank Waste Remediation System Basis for Interim Operation (FDH 1997). This safety baseline qualifies newly identified safety class SSCs allowing the Design Authorities better prioritization of maintenance and engineering functions.

\section{D4.5 PROCEDURAL FLOW}

Conduct of engineering by Technical Operations and Engineering technical authorities is performed according to written and approved procedures. The majority of these procedures are at the TWRS-facility level and included in LMHC (1997). These existing TWRS Project administrative procedures are adequate for technical authority activity. The derivation source for these procedures and a higher level of procedural requirements are the Hanford Procedures. These in turn are derived from $\mathrm{DOE}$ orders and good practice guidelines and other regulatory documents. 


\section{D5.0 REFERENCES}

FDH, 1997, Tank Waste Remediation System Basis for Interim Operation, HNF-SD-WM-BIO-001, Fluor Daniel Hanford, Inc., Richland, Washington.

LHMC, 1997, TWRS Administration, HNF-IP-0842, Fluor Daniel Hanford, Inc., Richland, Washington.

Vann, J. M., E. R. Hamm, and R. D. Crisp, 1998, Tank Waste Remediation System Configuration Management Plan, HNF-1900, Rev. 0, prepared by Lockheed Martin Hanford Corporation for Fluor Daniel Hanford, Inc., Richland, Washington. 
HNF-1883 Rev 1

\section{APPENDIX E}

TANK WASTE REMEDIATION SYSTEM

SYSTEMS ENGINEERING \& INTEGRATION ORGANIZATION

EXECUTION PLAN FOR THE

TWRS RETRIEVAL AND DISPOSAL MISSION 
HNF-1883 Rev 1

This page intentionally left blank. 


\section{HNF-1883 Rev 1}

\section{CONTENTS}

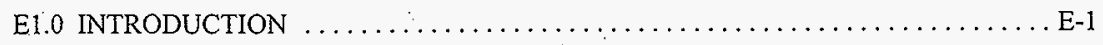

E2.0 MISSION AND ORGANIZATION $\ldots \ldots \ldots \ldots \ldots \ldots \ldots \ldots \ldots \ldots \ldots \ldots \ldots \ldots \ldots \ldots \ldots \ldots$

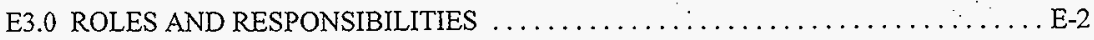

E4.0 EXECUTION STRATEGY $\ldots \ldots \ldots \ldots \ldots \ldots \ldots \ldots \ldots \ldots \ldots \ldots \ldots \ldots \ldots \ldots \ldots \ldots$

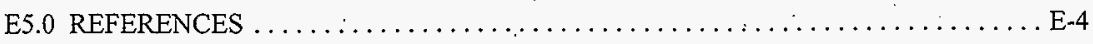

\section{LIST OF TERMS}

DOE

HSTB

LMHC

PHMC

SE\&I

TWR

TWRS

WBS
U.S. Department of Energy

Hanford Site Technical Baseline

Lockheed Martin Hanford Corporation

Project Hanford Management Contract

Systems Engineering \& Integration

Tank Waste Retrieval organization

Tank Waste Remediation System

work breakdown structure 
HNF-1883 Rev 1

This page intentionally left blank.

E-iv 
HNF-1883 Rev 1

APPENDIX E

TANK WASTE REMEDIATION SYSTEM

SYSTEMS ENGINEERING \& INTEGRATION ORGANIZATION

EXECUTION PLAN FOR THE

TWRS RETRIEVAL AND DISPOSAL MISSION

\section{E1.0 INTRODUCTION}

Before the U.S. Department of Energy (DOE) can authorize the private contractors to proceed with Phase 1B, the Project Hanford Management Contract (PHMC) team must demonstrate that it will be able to provide the necessary support to the private contractors. The PHMC team must conduct a "readiness to proceed" self-assessment of its ability to support the private contractors. The DOE is responsible for reviewing the PHMC assessment and for conducting an independent readiness-to-proceed evaluation. The status of the PHMC team's readiness to proceed is a key consideration in DOE's decision-making about continuing with privatization.

The Tank Waste Remediation System (TWRS) Systems Engineering and Integration (SE\&I) organization performs several functions that contribute to the TWRS Retrieval and Disposal Mission and support the Private contractors, including providing the chief systems engineer for Tank Waste Retrieval (TWR), integrating the TWRS Technical Baseline, and providing a bridge from the Hanford Site to the TWRS Retrieval and Disposal Mission. This Execution Plan describes key technical, programmatic, and management aspects of the TWRS SE\&I organization that are relevant to privatization support, and summarizes the approach and activities for achieving and maintaining readiness to proceed. This Execution Plan will be updated periodically to reflect changes to privatization and as the contributing functions of the TWRS SE\&I organization evolve.

In general, the TWRS SE\&I organization is or will be ready in all respects to:

- Integrate the TWRS Technical Baseline

- $\quad$ Provide a bridge from the Hanford Site to the TWRS Retrieval and Disposal Mission.

The remaining sections of this Execution Plan provide more details on the contributions of the TWRS SE\&I organization to the waste retrieval and disposal mission. 


\section{E2.0 MISSION AND ORGANIZATION}

The mission of the SE\&I organization is to provide systems engineering support to the TWRS Retrieval and Disposal Mission program. The support is provided primarily during the system definition phases involving retrieval of tank wastes, storage and disposal of immobilized tank wastes, and infrastructure development for tank waste immobilization facilities. Consistent with HNF-IP-0842, TWRS Administration, Volume X, "LMHC Business," Section 2.2, "TWRS Systems Engineering Management Policy" (LMHC 1997), the SE\&I organization support to the TWRS Retrieval and Disposal Mission program is directed at supporting the following objectives:

- Transform the TWRS Retrieval and Disposal Mission operational needs and requirements into a configured system that integrates all life-cycle stages (e.g., development, design, construction, testing, operation) of the TWRS Retrieval and Disposal Mission.

- Integrate related TWRS Retrieval and Disposal Mission technical parameters into a coordinated effort that meets established TWRS Retrieval and Disposal Mission cost, schedule, and performance objectives and that is integrated with the Hanford Site Technical Baseline (HSTB).

- Ensure compatibility of the functional and physical interfaces for the TWRS Retrieval and Disposal Mission (both internal and external).

- Integrate the efforts of engineering specialties supporting the TWRS Retrieval and Disposal Mission into the total engineering effort.

The TWRS SE\&I organization provides Systems Engineering support for the TWRS Retrieval and Disposal Mission. Organizationally, the SE\&I organization reports to the Vice-President and Manager of Information Resource Management/SE\&I within the Lockheed Martin Hanford Corporation (LMHC).

\section{E3.0 ROLES AND RESPONSIBILITIES}

The SE\&I organization is made up of two subgroups: SE\&I Projects and SE\&I Support. The SE\&I Projects organization acts as the "program manager" for TWRS systems engineering support. It establishes the major pieces of work in the systems engineering area and secures and provides funding to the SE\&I Support organization. The SE\&I Support organization provides the staffing to accomplish the work and is responsible for developing and maintaining SE standards and requirements specific to The TWRS Project. 
Specific roles and responsibilities of the SE\&I organization for the TWRS Retrieval and Disposal Mission are as follows.

- Provide systems engineering services to the TWRS Retrieval and Disposal Mission and its construction projects. The SE\&I organization provides the chief systems engineer for the TWRS Retrieval and Disposal Mission, reviews program and project systems engineering products, and provides systems engineers for direct support to the TWRS Retrieval and Disposal Mission and its construction projects.

- Integrate and maintain the TWRS Technical Baseline in support of the TWRS Retrieval and Disposal Mission. The SE\&I organization works with TWR construction projects to develop requirements for incorporation into the TWRS Technical Baseline, which is captured in the Hanford Site Technical Baseline Database (HSTD).

- Develop and maintain systems engineering expertise available for use in the TWRS Retrieval and Disposal Mission. To ensure ready access to needed services, the SE\&I organization maintains and trains a core staff of systems engineers and àcquires and maintains contracts with independent systems engineering contractors.

- Develop and maintain TWRS systems engineering infrastructure for use in the TWRS Retrieval and Disposal Mission. The SE\&I organization writes and maintains systems engineering procedures, plans, and policies; provides systems engineering training; and maintains up-to-date systems engineering tools.

- Conduct technical systems analyses. The SE\&I organization carries out strategic and operations analyses for the TWRS Retrieval and Disposal Mission and for the TWRS Project, and conducts risk and decision analyses.

- $\quad$ Provide a bridge from the Hanford Site to the TWRS Retrieval and Disposal Mission Program. The SE\&I organization works with Site Systems Engineering to maintain traceability between TWRS Retrieval and Disposal Mission construction projects and the HSTB, and participates in Site Systems Engineering Integration Group meetings to keep other site programs apprised of TWRS Retrieval and Disposal Mission integration needs.

\section{E4.0 EXECUTION STRATEGY}

Systems engineering work for the TWRS Retrieval and Disposal Mission is accomplished by the SE\&I Support organization, which is responsible for developing and maintaining the 
systems engineering standards and requirements specific to the mission. Funding for systems engineering support, development and maintenance of systems engineering infrastructure, and integration of TWRS Retrieval and Disposal Mission with other Hanford Site programs is through the Management Systems activity of the work breakdown structure (WBS), WBS Number 1.1.1.1.1.

. The SE\&I Support organization is staffed with a small number of individuals having different systems engineering skills. The majority of the systems engineering work done by the organization is accomplished through use of contract systems engineers, who are available through several basic ordering agreements maintained by the SE\&I organization. Systems engineering support to the TWRS Project is provided as necessary by the organization(s) directly involved in the work.

The SE\&I organization is not responsible for any specific activities identified in Level 1 Logics (FDH 1998). However, one of the main objectives of the SE\&I organization is to help the TWRS Retrieval and Disposal Mission construction projects resolve uncertainties by developing traceability of requirements to the HSTB. The plan is to assist in developing this traceability so technical issues or problems with key requirements are visible.

The TWRS Technical Baseline is developed in accordance with HNF-SD-WM-SEMP-002, Tank Waste Remediation System Systems Engineering Management Plan (Peck 1998). Development of construction project specifications and linking these specifications to facility specifications is done in accordance with HNF-IP-0842, Volume IV, Section 3.14, "Level 2 Specification Development Guide," (LMHC 1997). Changes to the Techinical Baseline will be controlled through HNF-MD-008, Baseline Change Control (FDH 1997a), and HNF-MD-029, Hanford Site Technical Baseline Change Control (FDH 1997b).

Work, cost, and schedules are established through the normal multi-year work plan process. Milestones are captured through Milestone Description Sheets; cost estimates are made through cost estimating spreadsheets; and scheduling is accomplished by engineers and entered into the standard P3 software scheduling tool. Work, cost, and schedule baselines are controlled through standard TWRS Project change control. As needed changes are identified, they are written into change requests and sent to the appropriate change control board(s) for action.

\section{E5.0 REFERENCES}

\section{Database}

HSTD, n.d., Hanford Site Technical Baseline Database, database maintained by Lockheed Martin Hanford Corporation for Fluor Daniel Hanford, Inc., Richland, Washington.

\section{Logic Diagrams}




\section{HNF-1883 Rev 1}

FDH, 1998, Logic Diagrams, prepared by Lockheed Martin Hanford Corporation for Fluor

Daniel Hanford, Inc., Richland, Washington.

- H-2-823148, TWRS Retrieval Level 1 Logic Immobilized Waste (ILAW)

- H-2-829149, TWRS Retrieval Level 1 Logic Immobilized Waste (IHLW)

- H-2-829150, TWRS Retrieval Level 1 Logic Infrastructure Phase 1 Privatization Support

- H-2-892151, TWRS Retrieval Level 1 Logic Waste Feed Delivery LAW Ist Feed Batches Tank 241-AN-105

- H-2-829152, TWRS Retrieval Level I Logic Waste Feed Delivery LAW 2nd Feed Batches Tank 24l-AN-104

- H-2-829153, TWRS Retrieval Level 1 Logic Waste Feed Delivery LAW 3rd Feed. Batches Tank 241-AW-101

- H-2-829154, TWRS Retrieval Level I Logic Waste Feed Delivery LAW 4th Feed Batches Tank 241-AN-103

- H-2-829155, TWRS Retrieval Level I Logic Waste Feed Delivery LAW 5 th Feed Batches Tanks 24I-AP-101 \& 24I-AW-104

- H-2-829156, TWRS Retrieval Level I Logic Waste Feed Delivery LAW 6th Feed Batches Tank 241-AY-101

- H-2-829157, TWRS Retrieval Level 1 Logic Waste Feed Delivery LAW 7th \& 8th Feed Batches Tank 241-AN-107

- H-2-829158, TWRS Retrieval Level 1 Logic Waste Feed Delivery LAW 9th Feed Batches Tank 241-AN-102

- H-2-829159, TWRS Retrieval Level 1 Logic Waste Feed Delivery LAW 10th Feed Batches Tank 241-AN-106

- H-2-829160, TWRS Retrieval Level 1 Logic Waste Feed Delivery LAW 1Ith Feed Batches Tank 241-SY-101

- H-2-829161; TWRS Retrieval Level 1 Logic Waste Feed Delivery LAW 12th Feed Batches Tank 24I-SY-103

- H-2-829162, TWRS Retrieval Level I Logic Waste Feed Delivery HLW Ist \& 2nd Feed Batches First Tank, 241-AZ-101

- H-2-829163, TWRS Retrieval Level 1 Logic Waste Feed Delivery HLW 3rd \& 4th Feed Batches Second Tank, 24I-AZ-102

- H-2-829164, TWRS Retrieval Level I Logic Waste Feed Delivery. HLW 5th - 9th Feed Batches Third Tank, 241-AY-102

- H-2-829165, TWRS Retrieval Level I Logic Waste Feed Delivery HLW 10th - 12th Feed Batches Fourth Tank, 241-C-104

- H-2-829166, TWRS Level 0 Logic (2 Sheets)

\section{Documents}

FDH, 1997a, Baseline Change Control, HNF-MD-008, Fluor Daniel Hanford, Inc., Richland, Washington. 


\section{HNF-1883 Rev I}

FDH, 1997b, Hanford Site Technical Baseline Change Control, HNF-MD-029, Fluor Daniel Hanford, Inc., Richland, Washington.

LMHC, 1997, TWRS Administration, HNE-IP-0842, Fluor Daniel Hanford, Inc., Richland, Washington.

Peck, L. G., 1998, Tank Waste Remediation System Systems Engineering Management Plan, HNF-SD-WM-SEMP-002, Rev. 1, prepared by Lockheed Martin Hanford Corporation for Fluor Daniel Hanford, Inc., Richland, Washington. 
HNF-1883 Rev 1

\section{APPENDIX F}

TANK WASTE REMEDIATION SYSTEM

NUCLEAR SAFETY AND LICENSING ORGANIZATION EXECUTION PLAN FOR THE

TWRS RETRIEVAL AND DISPOSAL MISSION 
HNF-1883 Rev I

This page intentionally left blank. 


\section{CONTENTS}

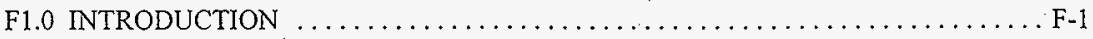

F2.0 MISSION AND.ORGANIZATION $\ldots \ldots \ldots \ldots \ldots \ldots \ldots \ldots \ldots \ldots \ldots \ldots$ F-2

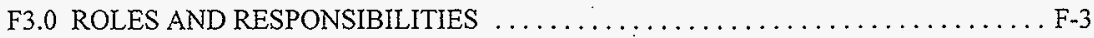

F3.1 NUCLEAR SAFETY AND LICENSING RESPONSIBILITIES $\ldots \ldots \ldots \ldots \ldots$ F-3

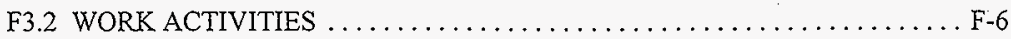

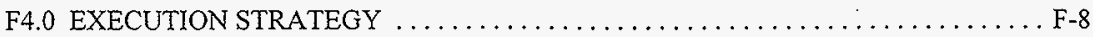

F4.1 ORGANIZATION AND RESOURCES TO EXECUTE RESPONSIBILITIES

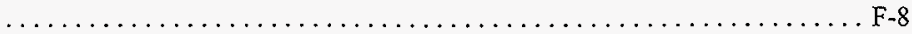

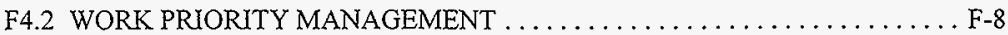

F4.3 MAINTAINING COGNIZANCE OF RELEVANT POLICIES, STANDARDS,

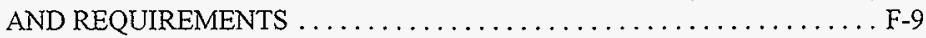

F4.4 RESOLUTION OF KEY TECHNICAL ISSUES AND UNCERTAINTIES . . F-10

F4.5 PROCEDURES THAT GOVERN PERFORMANCE OF WORK . . . . . . F F-11

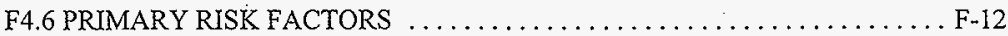

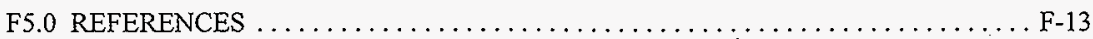

\section{LIST OF TERMS}

$\begin{array}{ll}\text { BIO } & \text { Basis for Interim Operation } \\ \text { DOE } & \text { U.S. Department of Energy } \\ \text { DST } & \text { double-shell tank } \\ \text { FDH } & \text { Fluor Daniel Hanford, Inc. } \\ \text { FY } & \text { fiscal year } \\ \text { IHLW } & \text { immobilized high-level waste } \\ \text { ICD } & \text { Interface Control Document } \\ \text { ILAW } & \text { immobilized low-activity waste } \\ \text { NS\&L } & \text { Nuclear Safety \& Licensing } \\ \text { PHMC } & \text { Project Hanford Management Contract } \\ \text { SSC } & \text { systems, structures, and components } \\ \text { SST } & \text { single-shell tank } \\ \text { TENS } & \text { TWRS Engineering and Nuclear Safety } \\ \text { TSR } & \text { Technical Safety Requirements } \\ \text { TWRS } & \text { Tank Waste Remediation System } \\ \text { USQ } & \text { Unreviewed Safety Question }\end{array}$


HNF-1883 Rev 1

This page intentionally left blank.

F-iv 
HNF-1883 Rev 1

APPENDIX F

\author{
TANK WASTE REMEDIATION SYSTEM \\ NUCLEAR SAFETY AND LICENSING ORGANIZATION \\ EXECUTION PLAN FOR THE \\ TWRS RETRIEVAL AND DISPOSAL MISSION
}

\title{
F1.0 INTRODUCTION
}

Before the U.S. Department of Energy (DOE) can authorize the private contractors to proceed with Phase 1B, the Project Hanford Management Contract (PHMC) team must demonstrate that it will be able to provide the necessary support to the private contractors. The PHMC team must conduct a readiness to proceed self-assessment of its ability to support the private contractors. The DOE is responsible for reviewing the PHMC assessment and for conducting an independent readiness to proceed evaluation. The status of the PHMC team's readiness to proceed is a key consideration in DOE's decision-making about continuing with privatization.

The Tank Waste Remediation System (TWRS) Nuclear Safety and Licensing (NS\&L) organization performs several functions that contribute to the TWRS Waste Retrieval and Disposal Mission and support the private contractors, including developing an overall licensing strategy and modification of HNF-SD-WM-BIO-001, Tank Waste Remediation System Basis for Interim Operation (BIO) (FDH 1997), or Final Safety Analysis Report (FSAR) and technical safety requirements (TSRs) for the mission. This Execution Plan describes key technical, programmatic, and management aspects of the TWRS NS\&L organization that are relevant to privatization support and summarizes the approach and activities for achieving and maintaining readiness to proceed. This Execution Plan will be updated periodically to reflect changes to privatization and as the contributing functions of the TWRS NS\&L organization evolve.

In general, the TWRS NS\&L organization is or will be ready in all respects to:

- Develop an overall licensing strategy

- Modify the TWRS BIO (FDH 1997) for the mission.

The remaining sections of this Execution Plan provide more details on the contributions of the TWRS NS\&L organization to the TWRS Retrieval and Disposal Mission. 
HNF-1883 Rev 1

\section{F2.0 MISSION AND ORGANIZATION}

As stated in HNF-IP-0842, TWRS Administration, Volume 1, Section 3.30, "TWRS Engineering and Nuclear Safety Charter" (LMHC 1997), the NS\&L organization is responsible for the following:

- Developing, delivering, and maintaining the Authorization Basis documents for TWRS facilities including supporting safety analyses and attendant TSRs

- Developing, implementing, and maintaining a system for managing TWRS safety documentation

- $\quad$ Maintaining the Unreviewed Safety Question (USQ) process

- Coordinating interactions with the DOE and the Defense Nuclear Facilities Safety Board for safety and licensing issues

- Addressing and resolving waste tank safety issues

- $\quad$ Providing management of the Criticality Program for the TWRS Project.

The Manager of the TWRS Engineering and Nuclear Safety (TENS) organization reports to the Director, Technical Operations and Engineering, who functions as the TWRS Project Chief Engineer. Supporting the Manager, TENS are three fundamental disciplines: (1) TWRS Configuration Management; (2) Engineering (Single-Shell Tank [SST], Double-Shell Tank [DST], Equipment, and Characterization); and (3) NS\&L. The centralized organizational structure ensures that these three disciplines are developed and applied uniformly across the fundamental aspects of the TWRS Project, including Waste Storage, Waste Retrieval, Facility Deactivation, Waste Characterization, Waste Management, and Waste Disposal.

The NS\&L organization within TWRS Engineering and Nuclear Safety consists of four groups: (1) Operations and Projects Safety Support, (2) Safety Analysis, (3) Authorization Basis Management and Implementation, and (4). Safety Issue Resolution. 


\section{F3.0 ROLES AND RESPONSIBILITIES}

\section{F3.1 NUCLEAR SAFETY AND LICENSING RESPONSIBILITIES}

The responsibilities outlined in Section F2.0 are achieved through the detailed assignment of functions for each of the four groups which comprise the NS\&L organization. The functional assignments and responsibilities are as follows.

\section{Operations and Projects Safety Support}

- Formulation of approach to ensure either that TWRS Project activities are within the approved nuclear safety Authorization Basis or that the TWRS Project Authorization Basis is appropriately modified to accommodate mission activities. The "approach" is referred to as the "licensing strategy."

- Preparation of task plans to carry out licensing strategies. Task plans include identification of work to be performed including, but not limited to, facility walkdowns, hazards identifications, performance of safety analyses, preparation of documentation for DOE approval, and conduct of internal technical review process.

- Compilation of Authorization Basis amendment packages where the existing Authorization Basis cannot accommodate mission activities and DOE approval is required to expand or modify the TWRS Authorization Basis accordingly.

- Preparation of licensing position papers: Position papers, presentations, or correspondence are sometimes required to elaborate upon and gain regulator/ contractor agreement on the specific application of DOE orders and standards to the TWRS Project. Examples include definition and purpose of Continued Operation; purpose and limitations of preliminary safety documentation;: definition of "risk envelope" and application of the USQ process to preserve it; and success criteria for closure of open Discovery USQs.

- $\quad$ Preparation of Justifications for Continued Operations for Discovery USQs in order to continue mission activities until permanent USQ closure is achieved (e.g., modification of the Authorization Basis, correction of field conditions).

- Formulation of licensing strategies for closure of Discovery USQs

(e.g., Flammable Gas USQ); preparation of licensing submittals for DOE approval to close Discovery USQs and amend the TWRS Project Authorization Basis accordingly. 


\section{Authorization Basis Management and Implementation}

- Development and management of a TWRS Project-wide USQ process that is consistent with DOE Order 5480.21, Unreviewed Safety Questions. This includes maintenance of the procedure which governs performance of USQ screenings and evaluations; setting training standards for USQ evaluators; ensuring an adequate number of trained evaluators to support TWRS Project activities; maintaining a USQ data base; assessing quality and integrity of the process and initiating selfcorrection as required; and meeting periodic reporting requirements to $\mathrm{DOE}$.

- Provision of administrative support to the TWRS Project Plant Review Committee. This includes provision of a committee secretary, issuance of meeting agendas, provision of agenda item materials for committee member review, administration of meetings, development and maintenance of meeting minutes, and action item tracking.

- Provision of Authorization Basis Configuration Management. This includes maintenance of the official listing of TWRS Project Authorization Basis documents; maintenance of a number of configuration-controlled libraries containing Authorization Basis documents; maintenance of DOE Safety Evaluation Reports and key supporting references; development and maintenance of a relational database defining the connection between the TWRS Authorization Basis and TWRS field procedures; and, provision of the TWRS Authorization Basis "annual update" which includes accumulated changes to Authorization Basis documents arising out of negative USQ determinations.

- Implementation of the consolidated TWRS Authorization Basis (i.e., BIO [FDH 1997] and FSAR). This includes development and maintenance of implementation procedures for the TSR Administrative Controls.

- Provision of a TWRS Facility Criticality Representative; development of Criticality Safety Evaluation Reports and conduct of work in accordance with emerging directions such as DNFSB 97-2, Defense Nuclear Facilities Safety Board Recommendation 97-2 to the Secretary of Energy Addressing the Continuation of Criticality Safety at Defense Nuclear Facilities in the DOE Complex (Conway 1997).

\section{Safety Analysis}

- Performance of safety analyses and evaluations related to the potential uncontrolled release of radiological and toxicological materials. These analyses and evaluations include, but are not limited to, considerations related to: airborne dispersion of materials, structural responses to loads and energetic events, assessments of chemical compatibility, assessments of potential for nuclear criticality, radiological shielding, and thermal analysis. 
- Development and justification of assumptions regarding sources of toxicological and radiological materials that may possibly be involved in an uncontrolled release to the environment. This includes quantities, concentrations, and forms of materials.

- Performance of safety analyses of specially formulated accident scenarios used to conservatively assess risk to facility workers, onsite workers, and the offsite public. Results of the analyses are used to specify which systems, structures and components (SSCs) are important to safety and what the procurement and design pedigree of the SSCs need to be (i.e., Safety Class; Safety Significant, or General Service). Results are also used to identify TSRs, consistent with DOE Order 5480.22, Technical Safety Requirements, which govern the conduct of operations.

- Development of a consolidated TWRS-wide Authorization Basis document which is compliant with DOE Order 5480.23, Nuclear Safety Analysis Reports, and consistent with DOE-STD-3009-94, Preparation Guide for U.S. DOE Nonreactor Nuclear Facility Safety Analysis Report (DOE 1994). This document is the TWRS. FSAR.

\section{Safety Issue Resolution}

- Resolution of defined safety "issues." These presently include flammable gas, organic solvents, organic complexants, high-heat tank C-106, and criticality. Two of the safety issues, flammable gas and organic complexants, also include USQs. Safety Issue Resolution activities include formulation of tests, experiments, and technical analyses that are used to learn more about suspected or known safety concerns. The Safety Issue Resolution activities also include preparation of detailed technical documentation that provides the basis for reaching resolution with regulators and stakeholders on safety issues.

- Provision of hardware for installation in the Tank Farms specifically aimed at collecting information relevant to Safety Issue Resolution.

- Implementation of the technical approaches for closure of Discovery USQs related to safety issues. These presently include the Flammable Gas and Organic Complexant USQS.

- Definition of safety issue mitigation strategies and implementation, if required.

- Serve as TWRS Project primary interface with the Defense Nuclear Facilities Safety Board and the DOE Tanks Advisory Panel subpanel on chemical reactions ("Chemical Reactions Sub-Tanks Advisory Panel") on progress toward issue resolution and USQ closure for defined safety issues. 


\section{F3.2 WORK ACTIVITIES}

The NS\&L organization supports the TWRS Retrieval and Disposal Mission through the following work activities:

1. Preparation of integrated work plans and Level 1 Logics (FDH 1998) to ensure that safety work is technically and temporally aligned with process development, project design, major procurements, construction, scheduled operations, and interfaces with the private contractors.

2. Development and documentation of an overall licensing strategy designed to show which portions of the TWRS Retrieval and Disposal Mission are within the current TWRS Project Authorization Basis, which portions require amendment to the Authorization Basis, and, in the latter case, what activities are required to prepare a successful licensing submittal for DOE approval.

3. Communication to the TWRS Retrieval and Disposal program of the types of information (degree of detail, documentation pedigree, technical content) required to prepare the overall licensing strategy and any follow-on licensing submittal for DOE approval.

4. Preparation of an Authorization Basis assessment using the configuration controlled engineering baseline documentation associated with the TWRS Retrieval and Disposal Mission. The assessment is patterned after the USQ process as documented in Title 10, Code of Federal Regulations, Part 50, "Domestic Licensing of Production and Utilization Facilities," Section 59, "Changes, text and experiments," and DOE Order 5480.21. The product of the process is an identification of work activities, operations, and field conditions arising out of the TWRS Retrieval and Disposal Mission which may not be within the risk envelope established by the current approved Authorization Basis.

5. Identification of tasks required to properly modify the TWRS Authorization Basis in order to specifically address the results of Step 4 . The product of this step is an update of the licensing strategy document with specific tasks, resource requirements, deliverables, and schedules.

6. Performance of the tasks identified in Step 5. This will include hazard identification activities such as hazard and operability studies and preliminary hazards analyses, reanalysis of existing BIO accidents, and identification and analysis of any new accidents not previously analyzed for the BIO (FDH 1997). Analyses will be documented in engineering documents.

7. Based on the results of Step 6, identification of the SSCs that are important to 
safety. This includes the specification of SSCs that are Safety Class, Safety Significant, or General Service, and identification of which of these are Defense-in-Depth. This information is forwarded to the appropriate project and operation engineering design authorities for use in design and preparation of Safety Equipment Lists.

8. Also based on the results of Step 6, formulation of the operational controls that are credited in the safety analyses for the prevention and mitigation of accidents. This includes the preparation of Safety Limits, Limiting Control Settings, Limiting Conditions for Operation, Surveillance Requirements, and Administrative Controls.

9. Modification of the TWRS BIO (FDH 1997) or FSAR and TSRs to incorporate the results of Steps 6,7 and 8. This requires preparation of an Authorization Basis submittal package to DOE for approval.

10. Administration of internal review processes for Authorization Basis amendments and administration of the response to DOE Tier 2 and 3 reviews.

11. Incorporation of approved amendments into the Authorization Basis list and Authorization Basis document configuration management scheme.

12. Modification and development of procedures required to implement revised or new TSR Administrative Controls.

13. Development of training modules and any operational readiness review or readiness assessment briefings related to the amended TWRS Authorization Basis.

14. Preparation of interface control documents (ICDs) related to the nuclear safety Authorization Basis of the private contractor-assigned waste staging tanks, and . preparation of ICDs related to the nuclear safety Authorization Basis for the facilities receiving immobilized low-activity waste (ILAW), immobilized high-level waste (IHLW), and any interim process products.

15. Preparation of hazards assessments, preliminary safety evaluations, and final Authorization Basis documentation associated with the transport, receipt, and storage of ILAW and IHLW. The basic process for Authorization Basis development is the same as that described above for TWRS Retrieval and Disposal Mission and waste feed delivery. However, additional Authorization Basis documents beyond the TWRS BIO (FDH 1997) or FSAR will be affected.

16. Performance of USQ screenings and evaluations throughout the design, construction, and operation phases of TWRS Retrieval and Disposal Mission, waste feed delivery, and receipt of immobilized waste or interim process products. 


\section{HNF-1883 Rev 1}

These work activities are encompassed by activities and projects captured within the TWRS Retrieval and Disposal Mission Program Level 1 Logics (FDH 1998), including but not limited to $620.050,620.030,150 . B 10,150 . B 14,150 . B 16,150 . B 17,440.120,460.085$, and 460.130 .

\section{F4.0 EXECUTION STRATEGY}

\section{F4.1 ORGANIZATION AND RESOURCES TO EXECUTE RESPONSIBILITIES}

The work activities described above will be executed by the centralized NS\&L organization. The centralized organization will ensure technical consistency across the TWRS Project in terms of hazards identification, control development, specification of SSCs, Authorization Basis document preparation, DOE order compliance, and approach to dealing with technical uncertainty. The NS\&L organization will maintain a core of permanent employees; staff will be augmented by contractor support when work load and schedule demands exceed the performance capacity of the permanent staff.

A Licensing Engineer from the Operations and Project Safety Support organization is assigned as the primary point of contact for tank waste retrieval and disposal. This person, therefore, serves as the Licensing Engineer for Projects W-151 and W-211. Another individual serves as the Licensing Engineer for Projects W-314 and W-519. A third Licensing Engineer supports Projects W-464, W-465, and W-520. A representative from the Safety Analysis group provides in-office coordination and interface at the office of the Retrieval Program organization. Additional engineers within the Operations and Project Safety Support, Authorization Basis Management and Implementation, and Safety Analysis organizations (augmented by contractors) provide support, as formulated by the Licensing Engineers, to perform Authorization Basis assessments, USQ evaluations, hazard identifications, safety analyses, controls development, and licensing submittal preparation. Credentials and training of staff and contractors will be managed by a "Qualification Card" system currently under development for the following areas of work: Performance of Technical Reviews, Preparation of Technical Documents, Development of TSRs, Development of BIO, FSAR, Safety Analysis Report Changes, Preparation of Procedures to Implement TSR Administrative Controls, and Criticality Engineering.

\section{F4.2 WORK PRIORITY MANAGEMENT}

The scope of work managed and conducted by the NS\&L organization during any given fiscal year is documented in the multi-year work plan. The multi-year work plan is built on detailed planning which includes NS\&L products and services supporting (1) specific projects, programs, and operations; (2) general tank farms operations; (3) closure of Discovery USQs; (4) resolution of defined safety issues; (5) Authorization Basis configuration management; 


\section{HNF-1883 Rev 1}

(6) maintenance of the USQ process; and (7) administration of the Plant Review Committee. A significant portion of the NS\&L work planning is built on the identified need for specific products.(e.g., Authorization Basis amendment packages) in support of specific scheduled events (e.g., startup of the replacement cross-site transfer line). Another aspect of NS\&L work planning addresses essential level-of-effort functions such as Authorization Basis configuration management. A third aspect of NS\&L work planning is based on prior experience and the expectation that the need for certain NS\&L services will be inevitable. These services respond to items that cannot be specifically defined at the time of multi-year work plan development (e.g., identification and resolution of Potential Inadequacies in the Authorization Basis, declaration of Discovery USQs, preparation of Basis of Continued Operations, review and response to Defense Nuclear Facilities Safety Board recommendations).

The work priorities of the NS\&L organization reflect those communicated by the TWRS Project President and General Manager. Deviations to the priorities evident in the multi-year work plan are processed formally through change request, as necessary. Issues related to work priority management are identified by line management and raised successively to the NS\&L, TWRS Engineering and Nuclear Safety, or TWRS president level, as appropriate. The need for management direction on work priority is not uncommon given the centralized nature of the NS\&L function and the attendant responsibility to provide service across unrelated elements in the TWRS Project (e.g., facility deactivization, waste feed delivery). Two other factors that may require management direction and mid-course correction involve the emergence of unplanned work and shifts in major project/program direction or schedule. Particularly in the case of unplanned work, work priority management is closely tied to resource management. In some cases, contracted staff augmentation is an appropriate solution. In other cases, the need for training and intense mentoring rules out short-term staff augmentation as a practical solution. In situations such as these, or any other where an apparent conflict between schedule and quality arise, guidance on work priorities is sought from management.

In the case of the NS\&L efforts to support the TWRS Retrieval and Disposal Mission, waste feed delivery, and receipt of ILAW and immobilized IHLW, there are numerous avenues to status work progress and communicate work priority conflicts. These avenues involve the licensing engineers and safety analysts assigned to support the Waste Retrieval and Disposal Mission Program and its major TWRS Projects (W-151, W-211, W-314, W-519, W-464, W-465, and. W-520). These engineers, their line management, and the NS\&L Department Manager are responsible for reporting status and anticipated risks associated with workscope agreed to and documented in Task Package Commitment Agreements.

\section{F4.3 MAINTAINING COGNIZANCE OF RELEVANT POLICIES, STANDARDS, AND REQUIREMENTS}

The policies, standards and requirements that are relevant to the work the NS\&L organization does in support of the TWRS Retrieval and Disposal Mission are defined in the TWRS Standards/Requirements Identification Documents (S/RIDs); PHMC procedures; TWRS procedures; project-specific engineering baseline documentation; and, TWRS Retrieval and 


\section{HNF-1883 Rev 1}

Disposal Mission specific engineering baseline documentation. Cognizance of these sources is primarily enabled by ready access to configuration-managed documentation. Additional means to maintain cognizance include the following.

- The NS\&L organization is author and technical owner of TWRS procedures related directly to the USQ process and preparation of analyses and documentation to upgrade, update, and amend the Authorization Basis.

- The revision process for other TWRS procedures relevant to NS\&L workscope allows for NS\&L formal review.

- The NS\&L organization has designated points of contact for Fluor Daniel Hanford, Inc. (FDH) procedures directly related to NS\&L work scope.

- The NS\&L organization has a review point of contact for any changes to the Standards/Requirements Identification Documents.

- The FDH has assigned TWRS Project interfaces (presently six) to the NS\&L organization, which is readily accessible for consultations regarding contract requirements.

- Engineering baseline documentation relied upon in development of USQ evaluations, safety analyses, and licensing submittals are referenced in the associated documentation; these documents are reviewed by project and program customers and cost account managers, as appropriate.

\section{F4.4 RESOLUTION OF KEY TECHNICAL ISSUES AND UNCERTAINTIES}

To date, no technical issues or uncertainties have been identified that are considered to be barriers to the development, approval, and implementation of Authorization Basis for TWRS retrieval and disposal. Existing safety issues are either not applicable to TWRS retrieval and disposal, or their resolution is not considered to be essential to commence mission activities. Safety issue resolution is a long-term process that is broader than USQ closure and Authorization Basis approval. In fact, full resolution of a safety issue may involve completion of mission activities. For instance, resolution of the High-Heat Safety Issue consists of retrieval of tank $\mathrm{C}-106$ contents. The existence of a safety issue is not a barrier to performing mission activities that eliminate or decrease levels of concern, as long as the proper Authorization Basis is in place. 
Open USQs or issues regarding the appropriate level of conservatism in the formulation of operational controls and design requirements could conceivably pose risks to the TWRS Retrieval and Disposal Mission. The NS\&L approach to minimizing these risks is three-fold:

- First, the NS\&L organization has scheduled tasks and commitments leading to the submittal of Authorization Basis amendment packages to close the Flammable Gas and Organic Complexant USQs in fiscal years (FY) 1998 and 1999. Closure of these USQs will signify DOE confidence in the ability of the PHMC team to control these hazards. This issue closure will be of great benefit for the review and approval of Authorization Basis amendments in support of waste retrieval and feed delivery.

- Second, in areas involving technical controversy, the approach is to base controls development on simple, bounding, defensible solutionis unless significant cost or operational impediments are identified. In the latter case, it has been found that the PHMC team needs to provide sufficient cost and operational information to DOE before a decision can be made to accept a better solution.

- Third, it is essential that proposed Authorization Basis documentation and supporting safety documentation (e.g., hazards analyses, USQ evaluations, calculation notes, control decision board records, Flammable Gas Equipment Advisory Board reports, Plant Review Committee meeting minutes, Tier 1 review comment resolution forms) are clearly written, technically correct, retrievable, and configuration managed.

\section{F4.5 PROCEDURES THAT GOVERN PERFORMANCE OF WORK}

The procedures that govern the work of the NS\&L organization in support of the TWRS Retrieval and Disposal Mission are those FDH and TWRS procedures pertaining to preparation of technical documents; performance of technical reviews; development of BIO, FSAR, and Safety Analysis Report changes; implementation of TSR Administrative Controls; and criticality engineering.

The FDH procedures, in various stages of release and development, that are unique to the NS\&L workscope include the following:

- Safety Analysis Program, HNF-PRO-430

- Hazard Classification of Facilities and Segments, HNF-PRO-511

- $\quad$ Risk Guidelines, HNF.PRO-514

- Safety Structures, Systems, and Components, HNF-PRO-516 


\section{HNF-1883 Rev 1}

- Identifying and Resolving Unreviewed Safety Questions, HNF-PRO-062

- Safety Analysis and Technical Safety Requirements, HNF-PRO-700

- Safety Analysis Process - Existing Facility, HNF-PRO-701

- Safety Analysis Process - Facility Change or Modification, HNF-PRO-702

- Safety Analysis Process - New Project, HNF-PRO-703

- Safety Basis Planning, Documentation, Review, and Approval, ENNF-PRO-705.

Two primary TWRS procedures that govern a significant portion of the work are:

- $\quad$ HNF-IP-0842, Volume IV, "Engineering," Section 5.10, "Authorization Basis Amendments and Annual Updates" (LMHC 1997)

- HNF-IP-0842, Volume IV, Section 5.4, "Unreviewed Safety Questions," (LMHC 1997).

Nuclear Safety and Licensing is in the process of upgrading existing TWRS procedures to (1) reflect the new contract organizational structure; (2) customize the FDH procedure requirements to TWRS; and (3) make improvements on important lessons learned in the areas of USQ process, Basis for Continued Operation development, internal technical review process, Authorization Basis documentation management and control, safety basis documentation management and control, and preparation of Authorization Basis documents. Upgrade and issuance of these TWRS procedures is scheduled for FY 1998.

\section{F4.6 PRIMARY RISK FACTORS}

There are two fundamental risks in the area of nuclear safety support to the TWRS Retrieval and Disposal Mission. These risks, and their mitigators, are discussed as follows.

- Risk Item \#1. The safety bases are in some way incorrect and do not support the mission as intended.

Risk Mitigators: The primary cause of such a failure would be the lack of configuration management of the engineering documentation that defines the mission. This includes the engineering documentation for each of the major TWRS Projects which comprise the mission as well as that which describes the major operations and expense upgrades. The responsibility for this risk mitigator belongs to the Project Managers and the Retrieval Program Director. A secondary cause of such a failure could be the unavailability of engineering baseline documentation of sufficient detail to support the safety work on the Project and 


\section{HNF-1883 Rev 1}

Program schedules. A key mitigator of this risk is the NS\&L organization strategy to construct a bounding risk envelope based on the available engineering information. No critical problems have been identified to date related to this risk.

- Risk Item \#2. The safety bases are considered to be inadequate or unacceptable by the DOE:

Risk Mitigators: The primary causes for such a failure could rest with poor quality in the use and management of the existing approved Authorization Basis (i.e., negative USQ evaluations, Authorization Basis list, Authorization Basis document configuration management) or poor quality in Authorization Basis amendments submitted for DOE review and approval. The responsibility for risk mitigation lies with the TWRS NS\&L organization. The primary risk mitigators are adherence to work procedures, management oversight, and personnel training.

\section{F5.0 REFERENCES}

\section{Code of Federal Regulations}

10 CFR 50, "Domestic Licensing of Production and.Utilization Facilities," Code of Federal Regulations, as amended.

\section{U.S. Department of Energy Orders}

DOE Order 5480.21, Unreviewed Safety Questions, U.S. Department of Energy, Washington, D.C.

DOE Order 5480.22, Technical Safety Requirements, U.S. Department of Energy, Washington, D.C.

DOE Order 5480.23, Nuclear Safety Analysis Reports, U.S. Department of Energy, Washington, D.C.

\section{U.S. Department of Energy Standards}

DOE-STD-3009-94, Preparation Guide for U.S. DOE Nonreactor Nuclear Facility Safety Analysis Report, U.S. Department of Energy, Washington, D.C. 


\section{HNF-1883 Rev 1}

\section{Procedures}

HNF-PRO-062, Identifying and Resolving Unreviewed Safety Questions, Fluor Daniel Hanford, Richland, Washington.

HNF-PRO-430, Safety Analysis Program, Fluor Daniel Hanford, Inc., Richland, Washington.

HNF-PRO-511, Hazard Classification of Facilities and Segments, Fluor Daniel Hanford, Inc., Richland, Washington.

HNF-PRO-514, Risk Guidelines, Fluor Daniel Hanford, Inc., Richland, Washington.

HNF-PRO-516, Safety Structures, Systems, and Components, Fluor Daniel Hanford, Inc., Richland, Washington.

HNF-PRO-700, Safety Analysis and Technical Safety Requirements, Fluor Daniel Hanford, Inc., Richland, Washington.

HNF-PRO-701, Safety Analysis Process-Existing Facility, Fluor Daniel Hanford, Inc., Richland, Washington.

HNF-PRO-702, Safety Analysis Process-Facility Change or Modification, Fluor Daniel Hanford, Inc., Richland, Washington.

HNF-PRO-703, Safety Analysis Process-New Project, Fluor Daniel Hanford, Inc., Richland, Washington.

HNF-PRO-705, Safety Basis Planning, Documentation, Review, and Approval, Fluor Daniel Hanford, Inc, Richland, Washington.

\section{Logic Diagrams}

FDH, 1998, Logic Diagrams, prepared by Lockheed Martin Hanford Corporation for Fluor Daniel Hanford, Inc., Richland, Washington.

- H-2-823148, TWRS Retrieval Level 1 Logic Immobilized Waste (ILAW)

- H-2-829149, TWRS Retrieval Level 1 Logic Immobilized Waste (IHLW)

- H-2-829150, TWRS Retrieval Level 1 Logic Infrastructure Phase 1 Privatization. Support

- H-2-892151, TWRS Retrieval Level 1 Logic Waste Feed Delivery LAW Ist Feed Batches Tank 241-AN-105

- H-2-829152, TWRS Retrieval Level 1 Logic Waste Feed Delivery LAW 2nd Feed Batches Tank 241-AN-104 


\section{HNF-1883 Rev 1}

- H-2-829153, TWRS Retrieval Level 1 Logic Waste Feed Delivery LAW 3rd Feed Batches Tank 241-AW-101

- H-2-829154, TWRS Retrieval Level 1 Logic Waste Feed Delivery LAW 4th Feed Batches Tank 24I-AN-103

- H-2-829155, TWRS Retrieval Level I Logic Waste Feed Delivery LAW 5th Feed Batches Tanks 241-AP-101 \&241-AW-104

- H-2-829156, TWRS Retrieval Level I Logic Waste Feed Delivery LAW 6th Feed Batches Tank 24I-AY-10I

- H-2-829157, TWRS Retrieval Level 1 Logic Waste Feed Delivery LAW 7th \& 8th Feed Batches Tank 241-AN-107

- H-2-829158, TWRS Retrieval Level 1 Logic Waste Feed Delivery LAW 9th Feed Batches Tank 241-AN-102

- H-2-829159, TWRS Retrieval Level 1 Logic Waste Feed Delivery LAW 10th Feed Batches Tank 24l-AN-106

- H-2-829160, TWRS Retrieval Level 1 Logic Waste Feed Delivery LAW IIth Feed Batches Tank 241-SY-101

- H-2-829161, TWRS Retrieval Level I Logic Waste Feed Delivery LAW 12th Feed Batches Tank 241-SY-103

- H-2-829162, TWRS Retrieval Level I Logic Waste Feed Delivery HLW 1st \& 2nd Feed Batches First Tank, 241-AZ-101

- H-2-829163, TWRS Retrieval Level 1 Logic Waste Feed Delivery HLW 3rd \& 4th Feed Batches Second Tank, 241-AZ-102

- H-2-829164, TWRS Retrieval Level 1 Logic Waste Feed Delivery HLW 5 th - 9th Feed Batches Third Tank, 24I-AY-102

- H-2-829165, TWRS Retrieval Level 1 Logic Waste Feed Delivery HLW 10th - 12th Feed Batches Fourth Tank, 241-C-104

- $\quad \mathrm{H}-2-829166$, TWRS Level 0 Logic (2 Sheets)

\section{Documents}

Conway J. T., 1997, Defense Nuclear Facilities Safety Board Recommendation 97-2 to the Secretary of Energy Addressing the Continuation of Criticality Safety at Defense Nuclear Facilities in the DOE Complex, DNFSB 97-2, Defense Nuclear Facilities Safety Board, Washington, D.C.

FDH, 1997, Tank Waste Remediation System Basis for Interim Operation, HNF-SD-WM-BIO-001, Rev. 0, Fluor Daniel Hanford, Inc., Richland, Washington.

LMHC, 1997, TWRS Administration; HNF-IP-0842, Fluor Daniel Hanford, Inc., Richland, Washington. 


\section{HNF-1883 Rev 1}

This page intentionally left blank. 
HNF-1883 Rev 1

APPENDIX G

TANK WASTE REMEDIATION SYSTEM PROJECTS AND DESIGN ORGANIZATION EXECUTION PLAN FOR THE

TWRS RETRIEVAL AND DISPOSAL MISSION

G-i 
HNF-1883 Rev 1

This page intentionally left blank. 


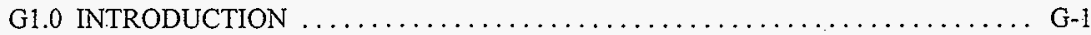

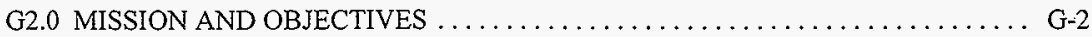

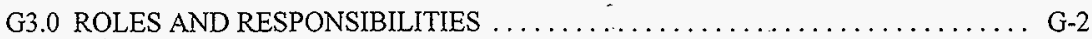

3.1 RESPONSIBILITIES $\ldots \ldots \ldots \ldots \ldots \ldots \ldots \ldots \ldots \ldots \ldots \ldots \ldots \ldots, \mathrm{G}-2$

3.2 WORK ACTIVITIES $\ldots \ldots \ldots \ldots \ldots \ldots \ldots \ldots \ldots \ldots \ldots \ldots \ldots, \mathrm{G}-3$

3.3 INTERFACES $\ldots \ldots \ldots \ldots \ldots \ldots \ldots \ldots \ldots \ldots \ldots \ldots, \mathrm{G}-4$

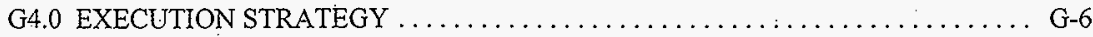

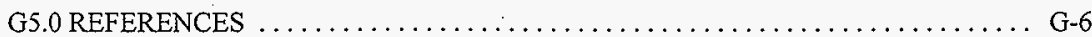

\section{LIST OF TERMS}

DOE U.S. Department of Energy

DST double-shell tank

HLW high-level waste

LAW low-activity waste

NEPA National Environmental Policy Act of 1969

PHMC Project Hanford Management Contract

QA quality assurance

RTP readiness to proceed

TWRS Tank Waste Remediation System 
HNF-1883 Rev 1

This page intentionally left blank. 


\title{
HNF-1 1883 Rev 1
}

\section{APPENDIX G}

\author{
TANK WASTE REMEDIATION SYSTEM \\ PROJECTS AND DESIGN ORGANIZATION \\ EXECUTION PLAN FOR THE \\ TWRS RETRIEVAL AND DISPOSAL MISSION
}

\section{G1.0 INTRODUCTION}

Before the U.S. Department of Energy (DOE) can authorize the private contractors to proceed with Phase 1B, the Project Hanford Management Contractor (PHMC) team must demonstrate that it will be able to provide the necessary support to the private contractors. The PHMC team must conduct a "readiness-to-proceed" (RTP) self-assessment of its ability to support the private contractors. The DOE is responsible for reviewing the PHMC assessment and for conducting an independent RTP evaluation. The status of the PHMC teams' RTP is a key consideration in DOE's decision making about continuing with privatization.

The Tank Waste Remediation System (TWRS) Projects and Design organization performs several functions that contribute to the TWRS Waste Retrieval and Disposal mission and support the private contractors, including the design and construction of equipment to demonstrate in-tank sludge mobilization, retrieval sluicing system for tank $\mathrm{C}-106$, upgrades to the waste transfer system, waste mixing and retrieval systems storage/disposal facilities for immobilized products, and the infrastructure to support the private contractor facilities. This execution plan describes key technical, programmatic, and management aspects of the TWRS Projects and Design organization that are relevant to privatization support and summarizes the approach and activities for achieving and maintaining RTP. This execution plan will be updated periodically to reflect changes to privatization and as the contributions functions of the TWRS Projects and Design organization evolve. to:

In general, the TWRS Projects and Design organization is or will be ready in all respects

- Provide the designs for required systems that support the mission.

- Provide the completed systems needed to deliver waste and dispose of the immobilized products.

The remaining sections of this execution plan provide more details on the contributions of the TWRS Projects and Design organization to the Waste Retrieval and Disposal Mission. 


\section{HNF-1883 Rev 1}

\section{G2.0 MISSION AND OB.JECTIVES}

The Tank Waste Remediation System (TWRS) Projects and Design organization's mission is to provide overall design and construction project support to the TWRS Project. This support includes project design and construction activities from conceptual design to the beginning of hot operations. The support is provided to both the Tank Waste Operations organization for tank upgrade projects and the Tank Waste Retrieval organization for tank retrieval and disposal projects. The TWRS Projects and Design organization's mission also includes the management of the design agent subcontractor .

The promary objective of the TWRS Projects and Design organization is to manage the design and construction projects in compliance with the design criteria defined by Tank Waste Operations and Tank Waste Retrieval organizations.

\section{G3.0 ROLES AND RESPONSIBILITIES}

\subsection{RESPONSIBILITIES}

The TWRS Projects and Design organization is responsible for the management of the following projects necessary to support Tank Waste Retrieval and Waste Feed Delivery:

- Tank AZ-101 mixer pump test (Project W-151) provides a waste mixing system in double-shell tank (DST) AZ-101 and performs a demonstration test of this system in support of waste retrieval and sludge washing activities.

- Tank C-106 waste retrieval sluicing system (Project W-320) provides a retrieval system in tank C-106 for retrieving the C-106 sludge as part of the high-level waste (HLW) feed.

- Tank Färm Restoration and Safe Operations (Project W-314) provides upgrades to the waste transfer system necessary to ensure safe, reliable transfer capability to support feed delivery.

- Initial Tank Retrieval Systems (Project W-211) provides waste mixing and retrieval systems in ten DSTs to prepare waste feed for delivery to private contractors.

- Immobilized Low-activity Waste (LAW) Storage and Disposal (Projects W-465 and W-520) provide storage and disposal facilities for the immobilized LAW delivered by the private contractors. 
- Immobilized HLW Storage (Project W-466) provides a storage facility for the immobilized HLW delivered by the private contractors.

- Infrastructure Project (Project W-519) provides utilities and effluent pipelines to the private contractor facilities.

\subsection{WORK ACTIVITIES} follows:

Specific work activities of the TWRS Projects and Design on each project are listed as

- $\quad$ Provide dedicated project management empowered to authorize and direct all project work scope by supporting subcontractors.

- Manage authorized project funds/resources and approve project cost/schedule baselines.

- Provide for development of project planning and baseline documents.

- Provide contractual direction to the design agent for the performance of design, procurement, and construction. Provide to the design agent, the project technical baseline and safety basis for design.

- Ensure definitive design media is compliant with the project baselines with consideration for safety, quality, operability, maintainability, environmental compliance, and cost-effectiveness factors and provide approval of that design.

- Involve Design Authority, tank farm operations, safety, quality assurance (QA), environmental compliance, etc., in project design reviews, as appropriate, and ensure documented closeout of all design review team comments.

- Provide the administration of overall project baseline change control to ensure appropriate management of scope, cost, and schedule commitments.

- Develop project design and construction schedules.

- Provide project direction to optimize the design in terms of quality, safety, cost reliability, maintainability, life-cycle costs, and environmental requirements, and ensure compliance with applicable codes, standards, criteria, regulations, and DOE orders. Ensure that design/construction 


\section{HNF-1 883 Rev 1}

complies with applicable National Environmental Policy Act 1969 (NEPA)/safety documentation/permits.

- Coordinate construction activities with TWRS Project personnel (e.g., Operations liaison, person-in-charge, health physics, industrial safety) and perform oversight of construction contractor safety programs. Provide immediate notification of accidents, incidents, significant problems, and work stoppages.

- Ensure accurate as-built drawings are prepared.

- Coordinate development of safety analyses, authorization basis amendments, NEPA documentation, and other related documentation in support of the project.

- Procure long-lead engineered equipment.

\subsection{INTERFACES}

TWRS Projects and Design responsibility involves critical interfaces with the following organizations:

1. The TWRS Tank Waste Operations and Tank Waste Retrieval Program organizations, which:

- $\quad$ Provide and maintain the technical baseline.

- Provide programmatic project support, as required, for design, construction, startup testing, readiness reviews; and turnover of completed systems.

2. The TWRS Technical Operations organization which:

- Provides safety documentation for projects and ensures the integration of new safety analyses with the existing safety baseline.

- Manages the TWRS technical baseline through the usage of two engineering technical authorities: design authorities and cognizant engineers. These authorities perform review and approval of designated technical documents.

3. TWRS Project independent support and review groups (e.g., Environmental, Safety and Health, and QA). This interface is controlled by current procedures. 
4. TWRS Operations and Maintenance, which:

- Provides operations and health physics support, as required, for project design, construction, startup testing, readiness reviews, and turnover of completed systems.

- Participates and concurs with final inspection and acceptance testing and accepts completed facilities for operation

- Develops operator procedures and trains Operations' personnel, as required.

- Performs readiness reviews for completed components/systems and obtains the required approvals.

5. The Design Agent subcontractor, which:

Has responsibility and authority for day-to-day management of project design, construction, and inspection.

- Provides engineering studies, conceptual design, definitive design, alternative generation and analysis documents, cost estimating, and scheduling services for all phases of project activities, as described in the letter(s) of instruction and/or statement(s) of work provided by the project manager.

- Ensures that established project quality objectives and technical requirements are mutually understood and can be satisfied.

- Ensures industrial safety and security requirements are implemented at the construction site, as required.

- Establishes and implements an overall project QA program and ensures that design and construction activities are performed consistent with this program (i.e., the project-specific QA program plan).

- Manages an effective cost and schedule control system for construction activities. Provides construction work progress and cost information to the project manager on a routine basis and inproject status reports.

- Provides construction site safety inspections and surveillance.

- Prepares accurate as-built drawings of the completed project. 


\section{G4.0 EXECUTION STRATEGY}

The TWRS Projects and Design organization assigns a project manager, reporting to the TWRS Projects and Design Director, to each construction project. The project manager has final responsibility for meeting the cost, schedule, and technical objectives for the project.

Each project manager issues a project management plan as part of the project baseline. The project management plan describes the project justification, objectives, organization, baseline, change control process, performance monitoring and reporting, configuration management, design verification, Systems Engineering, QA, environmental assurance, safety documentation, procurement plan, test and evaluation plan, and human factors engineering program plan.

The current TWRS Projects and Design staff is sized to support project scope execution. Future project phases will involve staff adjustments including the use of contract resources. Projects and Design staff are trained in accordance with current TWRS Project requirements. Continued training is tracked by site and organizational databases.

Project managers are assisted in the management of interfaces with other organizations by the following cross-cutting direct reports to the TWRS Projects and Design director:

- Technical direction

- Environmental, Safety, and Health

- QA

- Procedures

- $\quad$ Systems Engineering

- Procurement

- Construction

- Testing.

\section{G5.0 REFERENCES}

National Environmental Policy Act of 1969 
HNF-1883 Rev 1

APPENDIX H

TANK WASTE REMEDIATION SYSTEM SAFETY AND HEALTH ORGANIZATION EXECUTION PLAN FOR THE TWRS RETRIEVAL AND DISPOSAL MISSION 


\section{HNF-1883 Rev 1}

This page intentionally left blank. 


\section{CONTENTS}

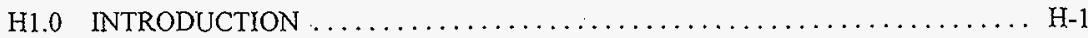

H2.0 MISSION AND ORGANIZATION $\ldots \ldots \ldots \ldots \ldots \ldots \ldots \ldots \ldots \ldots \ldots \ldots \ldots$

H3.0 ROLES AND RESPONSIBILITIES $\ldots \ldots \ldots \ldots \ldots \ldots \ldots \ldots \ldots \ldots \ldots \ldots \ldots \ldots$

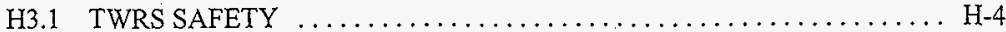

H3.1.1 Responsibilities ........................ H

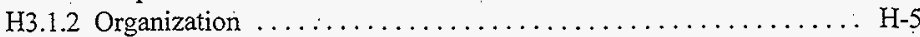

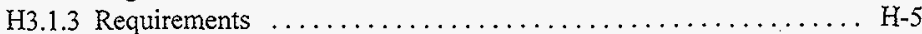

H3.1.4 Authorities . . . . . . . . . . . . . . . . . . . . . . . .

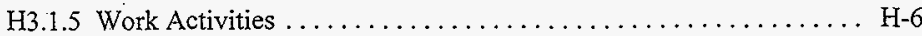

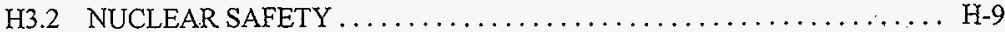

H3.2.1 Responsibilities . ........................ H-9

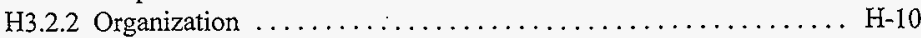

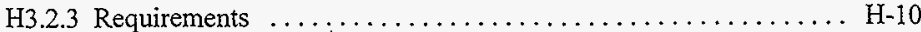

H3.2.4 Authorities ......................... H

H3.2.5 Work Activities . . . . . . . . . . . . . . . . . $\ldots \ldots \ldots$

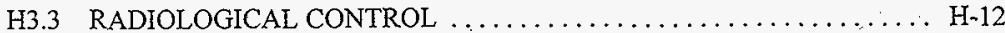

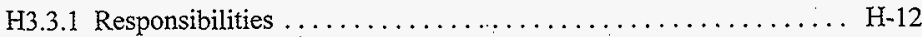

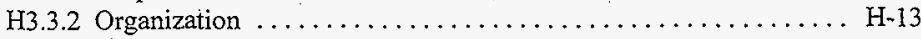

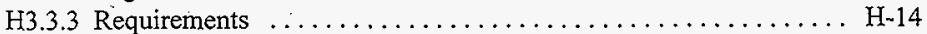

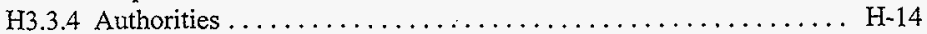

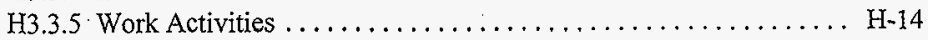

$\mathrm{H} 3.4$ EMERGENCY PREPAREDNESS $\ldots \ldots \ldots \ldots \ldots \ldots \ldots \ldots \ldots \ldots \ldots \ldots \ldots$

H3.4.1 Responsibilities ....................... H-16

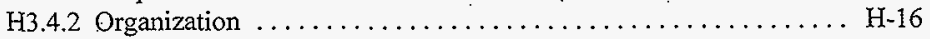

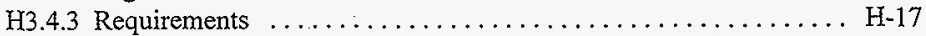

$\mathrm{H} 3.4 .4$ Authorities . ............................

H3.4.5 Work Activities . . . . . . . . . . . . . . . . . . . $\ldots \ldots \ldots$

H3.5 INTERFACES $\ldots \ldots \ldots \ldots \ldots \ldots \ldots \ldots \ldots \ldots \ldots \ldots \ldots \ldots \ldots$

H4.0 EXECUTION STRATEGY $\ldots \ldots \ldots \ldots \ldots \ldots \ldots \ldots \ldots \ldots \ldots \ldots \ldots \ldots$

H4.1 WORK PLANNING AND PRIORITIZATION $\ldots \ldots \ldots \ldots \ldots \ldots \ldots \ldots$ H-18

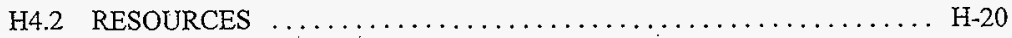

H4.3 WORK IMPLEMENTATION/SAFETY MANAGEMENT . . . . . . . H-20

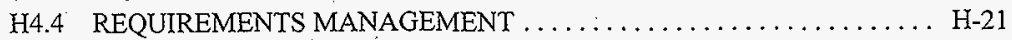

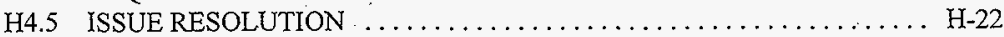

H5.0 REFERENCES $\ldots \ldots \ldots \ldots \ldots \ldots \ldots \ldots \ldots \ldots \ldots \ldots \ldots \ldots \ldots \ldots \ldots$ 
HNF-1883 Rev 1

\section{LIST OF FIGURES}

H-1. Tank Waste Remediation System Safety and Health Organizations. . . . . . . . . H-3

H-2. The Integrated Safety Management System Concept. ................ H-4

\section{LIST OF TABLES}

H-1. External Interfaces. . . . . . . . . . . . . . . .

\section{LIST OF TERMS}

$\mathrm{BIO}$

DOE

DST

ES\&H

FDH

FSAR

FY

HLW

ISMS

PHMC

RL

RTP

SST

TENS

TWR

TWRS

USQ

WBS
Basis for Interim Operation

U.S. Department of Energy

double-shell tank

environmental, health, and safety

Fluor Daniel Hanford, Inc.

Final Safety Analysis Report

fiscal year

high-level waste

Integrated Safety Management System

Project Hanford Management Contract

U.S. Department of Energy, Richland Operations Office

readiness to proceed

single-shell tank

TWRS Engineering and Nuclear Safety

Tank Waste Retrieval

Tank Waste Remediation System

unreviewed safety question

work breakdown structure 


\section{APPENDIX H}

\section{TANK WASTE REMEDIATION SYSTEM SAFETY AND \\ HEALTH ORGANIZATION EXECUTION PLAN FOR THE TWRS RETRIEVAL AND DISPOSAL MISSION}

\section{H1.0 INTRODUCTION}

Before U.S. Department of Energy (DOE) can authorize the Private contractors to proceed with Phase 1B, the Project Hanford Management Contract (PHMC) Team must demonstrate that they will be able to provide the necessary support to the Private contractors. The PHMC Team must conduct a "readiness to proceed" (RTP) self-assessment of its ability to support the private contractors. The DOE is responsible for reviewing the PHMC assessment, and for conducting an independent RTP evaluation. The status of the PHMC Team's RTP is key consideration in DOE's decision making about continuing with privatization.

The Tank Waste Remediation System (TWRS) Safety and Health organizations perform several functions that contribute to the TWRS Retrieval and Disposal Mission and support the private contractors, in Environmental, Nuclear Safety, Industrial Safety, Industrial Hygiene, Fire Protection, Emergency Preparedness, Quality Assurance and Radiological Control areas. This Execution Plan describes key technical, programmatic, and management aspects of the TWRS Safety and Health organizations that are relevant to privatization support, and summarizes the approach and activities for achieving RTP. This Execution Plan will be updated periodically to reflect changes to privatization and as the contributing functions of the TWRS Safety and Health organizations evolve.

- The TWRS Safety and Health Organizations are or will be ready in all respects to maintain a safe and healthful working environment.

The remaining sections of this Execution Plan provide more details on the contributions of the TWRS Safety and Health organization to the waste retrieval and disposal mission.

\section{H2.0 MISSION AND ORGANIZATION}

The Environmental, Safety, Health, and Quality Assurance (ESH\&QA) department provides professional services in the areas of Environmental, Nuclear Safety, Industrial Safety, Industrial Hygiene, Fire Protection, Emergency Preparedness and Quality Assurance to TWRS Operations, Engineering, Maintenance, Characterization, Retrieval, Storage, and Disposal Projects. These services are an independent oversight function to maintain and improve public 
safety, healthful and safe working conditions, and safety of the environment; and to ensure that validation measurements and quality standards are met.

Safety and Health (TWRS Safety, Nuclear Safety, Radiological Control, and Emergency Preparedness) provides technical and support services to all TWRS Project functions. Success in these areas is accomplished through document review, field support, and oversight activities. The specific work activities delineated in Section H3.0, describes the support that will be provided to the TWRS Retrieval and Disposal Program.

The ESH\&QA department is managed by a director who reports to the Company President and is authorized by the same to carry out assigned functions. The Radiological Control Manager reports through the TWRS Operations organization, with a direct line to the company president. Safety and health responsibilities are shared, however, across each organization within the TWRS Project. Senior management is directed by the company president to comply with ESH\&QA requirements and to integrate safety considerations into all activities to ensure a safe and compliant workplace. Line managers are responsible for mentoring their workers in safe work practices and holding them accountable for safety performance. Finally, each employee is responsible to recognize how his/her actions directly affect safety and utilize safe work practices.

Figure $\mathrm{H}-1$ depicts organizational alignment of the Safety and Health functions. The Nuclear Safety and Licensing group is responsible for the development of Safety Basis documentation, reporting to the director of Engineering, Nuclear Safety, and Licensing, and this scope is covered under the Nuclear Safety and Licensing Execution Plan. Likewise, Environmental and Quality Assurance activities and responsibilities are also addressed separately in HNF-1773, Tank Waste Remediation System Environmental Program Plan (Borneman 1998), and HNF-IP-0842, TWRS Administration, Volume I, "Administration," Section 5.1, "Quality Assurance Program Plan."

ESH\&QA and TWRS Radiological Control oversee the implementation of DOE orders, and federal, state, and local laws and regulations; perform audits to verify compliance with regulatory and legal operational requirements; and provide guidance and policy direction for continuous improvement in the conduct of work. These functions are facilitated through a single, defined, environmental, safety, and health management system. The objective of the Integrated Safety Management System (ISMS) is to facilitate safe work.

The ISMS integrates requirements into work planning and execution and identifies a set of requirements that reflects DOE's commitment to a "standards based" safety program and the safety concepts reflected by these requirements. The ISMS concept is depicted in Figure H-2, and described in Section H4.3, Work Implementation/Safety Management. 
Figure H-1. Tank Waste Remediation System Safety and Health Organizations.

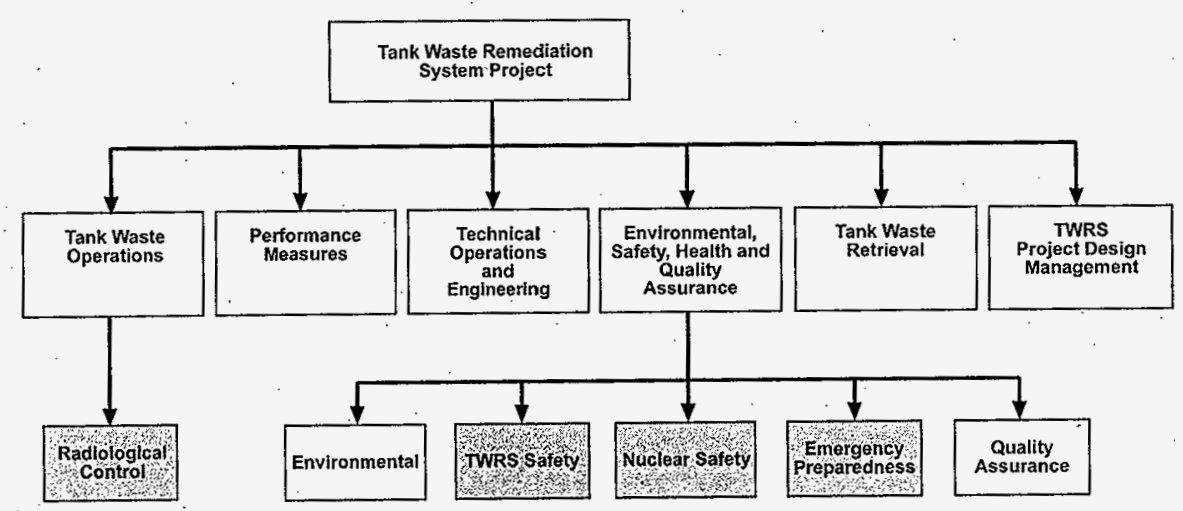

TWRS = Tank Waste Remediation System 
HNF-1883 Rev 1

Figure H-2. The Integrated Safety Management System Concept.

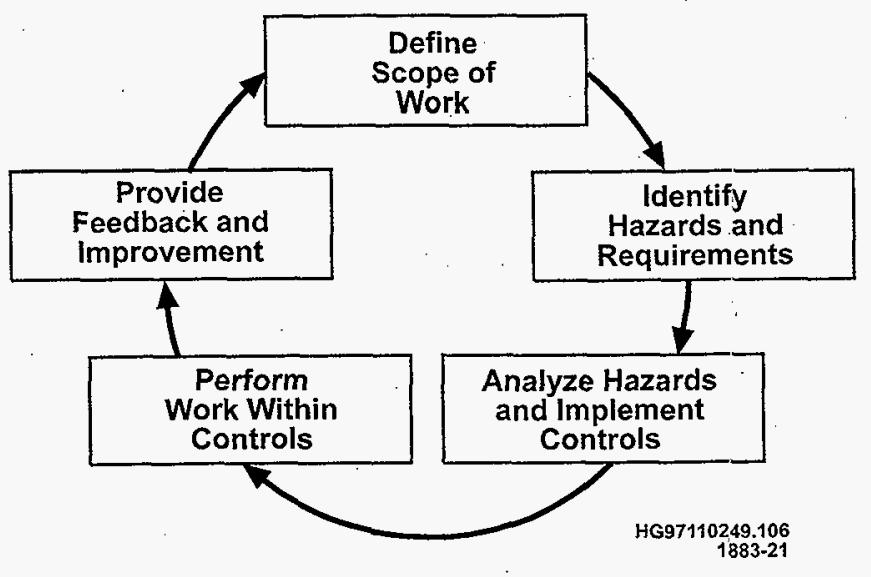

\section{H3.0 ROLES AND RESPONSIBILITIES}

This section outlines the roles and responsibilities of the safety and health organizations within the ESH\&QA and Radiological Control departments. The responsibilities, organization, requirements, authorities, and work activities for each group are described. Safety, Nuclear Safety, and Radiological and health work activities will be incorporated into all phases of the Retrieval and Disposal Program, from design and construction, through operations and maintenance, to closure and deactivation. Interfaces with internal and external organizations are also described.

\section{H3.1 TWRS SAFETY}

\section{H3.1.1 Responsibilities}

TWRS Safety is a multi-disciplined organization encompassing Industrial Safety, Industrial Hygiene, and Fire Protection. As an integrated entity, TWRS Safety is responsible for the following:

1. Development and implementation of specific safety and health related programs.

2. Technical support to work planning and performance.

3. Compliance oversight and assessment. 


\section{H3.1.2 Organization}

Staff representing the above disciplines are supportive of three functional areas within the TWRS Safety organization. They are:

- Safety Operations. This is a support function and includes implementing programs; participating in employee involvement activities (safety councils, Facility Excellence Program, and VPP steering committee); mentoring operational teams in hazard recognition and control; ensuring safety considerations are incorporated into each document through review of work packages, procedures, job hazard analyses, safety basis documents, and projects; inspecting and walking down facilities; evaluating and monitoring chemical, physical, biological, and ergonomic hazards; assessing effectiveness of controls; and providing training and guidance on safety issues.

- Safety Compliance and Oversight. This function encompasses OSHA-type inspections, construction surveillance and oversight; and the performance of safety program assessments based on S/RID criteria.

- Employee Involvement and Investigations. This function is tasked with organization and mentoring of employee safety councils; representing the TWRS Project in sitewide safety activities; overseeing case management of occupational injuries/ilinesses; maintaining the LMHC OSHA $200 \mathrm{log}$ and associated case files; and the development, implementation, and oversight of safety recognition systems that encourage positive behaviors.

\section{H3.1.3 Requirements}

The safety organization responsibilities are accomplished in accordance with the governing documents in the DOE-approved WHC-SD-MP-SRID-001, High-Level Waste Storage Tank Farms/242-A Evaporator Standards/Requirements Identification Document (S/RID) (Tank Waste Remediation System S/RID) (Biebesheimer 1996). The S/RID (Biebesheimer 1996) is a compilation of applicable requirements from 29 CFR 1910, "Occupational Safety and Health Standards," and 29 CFR 1926, "Safety and Health Requirements for Construction;" DOE Orders, Washington Administrative Code, and industry standards. These requirements are implemented through Project Hanford Policies and Procedures for Occupational Safety and Health and Fire Protection, HNF-SD-WM-HSP-002, Tank Farm Health and Safety Plan (HASP) (Mickle 1995), the HNF-IP-0842, Volume IX, "Safety," Section 1.1, "TWRS Safety Program Plan," and TWRS specific administrative and quality procedures.

\section{H3.1.4 Authorities}

The TWRS Safety organization provides oversight to all safety and health activities performed under the TWRS Project. The manager of TWRS Safety organization reports directly to the TWRS director of ESH\&QA. 


\section{HNF-1883 Rev 1}

TWRS Safety authority includes: 1) access to records, information, property or plans to form sound industrial safety, industrial hygiene, and fire protection judgements; and 2) physical. access to all areas of the site to perform surveys, inspections, or other industrial safety and health related activities. This includes access to management to recommend adopting policies or actions necessary or desirable for achieving the objective of the program.

TWRS Safety has the authority to assess the compliance of TWRS Project organizations, operations, facilities, and subcontractors to applicable health and safety standards. TWRS Safety has the authority to identify and document deficiencies, recommend remedial actions, and verify adequacy of corrective actions taken. If imminent danger exists, TWRS Safety staff, like all employees, are authorized to direct that activities be stopped or employees removed from a hazardous area or environment until the issues are resolved.

\section{H3.1.5 Work Activities}

TWRS Safety will support the Retrieval and Disposal mission through the following major work activities:

1. Assist in the preparation of integrated work plans and mid-level logic diagrams to assure that safety work is technically and temporally aligned with process development, project design, major procurements, construction, scheduled operations and interfaces with the private contractors.

2. Analysis of new operations, processes, materials, or equipment before initial use to determine potential hazards.

3. Analysis of any changes in operations, processes, materials, control equipment, work practices, or personnel that have the potential to cause new or additional hazardous exposures.

4. Assessment of physical work spaces and activities identified as having potential health and safety hazards. This is a systematic approach to identify work place hazards, evaluate controls and their effectiveness, and verify implementation of applicable safety and health requirements within a facility. Facilities are reviewed by an integrated team potentially consisting of industrial safety, industrial hygiene, fire protection, health physics, operations, and safety council members.

5. A comprehensive, qualitative characterization and analysis of the work place to recognize significant potential physical, biological, and ergonomic exposures to workers. Results of the analyses, professional judgement, and trends identified through the characterization process are used for prioritizing program emphasis, identifying further studies using the Qualitative Exposure Assessment Program, and establishing an industrial hygiene monitoring schedule. 
6. Quantitative monitoring of potentially hazardous exposures:

a. Personal monitoring and sampling will be performed using breathing zone samples that reflect the eight hour time weighted average, short term exposure limit, or ceiling exposure of employees as appropriate. Sampling and analysis will be done in accordance with methods specified by OSHA or NIOSH. Analysis will be by a laboratory accredited by the American Industrial Hygiene Association for the general class of hazardous substance being analyzed.

b. Source monitoring identifies potential sources of personnel exposure.

c. Area monitoring determines exposure levels in the general work environment. When potential exposures are well-defined, then knowledge of worker activity is sufficient to estimate exposure. Since this is not the case in tank farms, this is a qualitative tool that is a part of a complete monitoring program. Area monitoring will be used as one of the indicators to determine personnel monitoring requirements.

7. Specific program audits, surveillances, and self-assessments (e.g., crane safety, electrical safety, hazard communication, fire protection) will be conducted to comprehensively review implementation and effectiveness of safety programs.

8. Evaluation of compliance with safety, health, and fire protection requirements will be conducted through both scheduled and unannounced field surveys of the work place.

9. Development and maintenance of written hazard assessment and control records is essential for a comprehensive program. TWRS Safety will ensure that hazard assessment, control, and site survey records are accurate, complete, factual and in accordance with site documentation standards. Conclusions and recommendations will be communicated to the appropriate facility management and affected personnel for corrective actions. Exposure monitoring results will be provided to affected employees within 15 days of receipt of analysis results in accordance with Project Hanford Policies and Procedures.

10. In accordance with guidelines presented in 29 CFR 1904 , "Recording and Reporting Occupational Injuries and IIInesses," a record of all OSHA recordable injuries and illnesses involving Retrieval and Disposal and other TWRS Project employees will be maintained by TWRS Safety: This also includes TWRS Project site and subcontract employees.

11. Safety program implementation ensures applicable requirements, regulations, and sound safety principles are applied in the work place, including daily work activities in the office or field and associated planning and follow-up activities. It 


\section{HNF-1883 Rev 1}

involves developing and implementing training, providing guidance to employees in the basic principles of safety programs, performing hazard assessments and controls, and performing inspections and documenting reviews to ensure those principles are applied. TWRS Safety will work with Retrieval and Disposal management in all of these facets to ensure that the program is implemented properly.

12. TWRS Safety will perform document reviews to ensure safety and health requirements are incorporated into designs and operations and implemented through work procedures. Documents will be reviewed and approved by professionals who ensure activities and operations will be carried out in a safe manner according to procedures, ensure potential hazards are addressed in an appropriate manner, and make recommendations for resolving safety issues. The following is a partial listing of types of documents reviewed by safety professionals. A more complete listing and matrix of who reviews them is provided in HNF-PRO-233, Review and Approval of Documents.

- Work packages/plans

- Health and Safety Plans

- Readiness Reviews

- Program Plans
- Engineering/design changes

- Procedures

- Permits

13. HNF-SD-WM-HSP-002 (Mickle 1995) was developed to implement OSHA requirements governing hazardous operations and emergency response. The document also provides facility specific requirements and general guidelines to minimize health and safety risk to workers and other personnel at Tank Farms. Through ongoing hazard assessments, the document is periodically revised by TWRS Safety to reflect current information and controls. As applicable and necessary, information specific to Retrieval and Disposal will be incorporated.

14. Support Authorization Basis documents preparation.

15. Provide technical expertise on the preparation and revision of fire hazards analysis. TWRS Safety also authors/manages fire hazard analysis preparation as necessary, and provides oversight/review. TWRS Safety will provide direction relative to the need for modification of the fire hazards analysis as a result of operations and mission changes to support the Retrieval and Disposal Project.

16. TWRS Safety will review subcontractor health and safety programs to assure compliance with regulatory requirements and provide field oversight to assure effective implementation.

17. TWRS Safety will represent Retrieval and Disposal through participation in PHMC technical integration groups, site-wide technical forums and safety boards. 
18. TWRS Safety will support program integration by providing input to lessons learned, holding facility/topic specific safety meetings, participating in incident and accident investigations, and receiving/disseminating timely information on Industrial Safety, Industrial Hygiene and Fire Protection related issues.

19. TWRS Safety will provide S/RID functional area ownership of Occupational Safety and Health, and Fire Protection. Changes will be made as necessary, to facilitate the Retrieval and Disposal mission.

20. TWRS Safety will coordinate the President's Zero Accident Council and Subcouncil activities. The councils increase safety knowledge and awareness and instill safety values through employee participation. The councils also foster information exchange by providing a forum for safety concerns to be voiced, potential solutions addressed, and safety statistics provided.

21. TWRS Safety will provide the company and Retrieval and Disposal focus on ISMS implementation activities through promotion of employee involvement in work planning, including hazard and environmental impact identification, analysis, and control; work execution; and feedback/improvement processes. Effective implementation of the ISMS incorporates the best practices and supports the accomplishment of the Voluntary Protection Program, Enhanced Work Planning, Hanford Occupational Health Process, and other environmental, safety, and health (ES\&H) performance improvement initiatives.

22. Concerning Voluntary Protection Program activities, TWRS Safety will coordinate and lead steering committees and participate in employee driven and grass root activities. TWRS Safety will also continue to provide the lead in the development/application activities for VPP star status.

23. TWRS Safety will track and trend Retrieval and Disposal safety and health performance indicators as part of the TWRS Safety program.

24. Retrieval and Disposal will be included as part of TWRS Project external audits.

\section{H3.2 NUCLEAR SAFETY}

\section{H3.2.1 Responsibilities}

Nuclear Safety is the area of safety that encompasses activities and systems that prevent the potential for uncontrolled nuclear criticality and the release of fission products or other radioactive materials that could adversely affect the environment, the workers, and the public. 


\section{HNF-1883 Rev I}

\section{H3.2.2 Organization}

Nuclear Safety activities are encompassed by two different departments from within TWRS; namely, TWRS Engineering and Nuclear Safety (TENS) and Environmental, Safety, Health, and Quality Assurance (ESH\&QA). See Figure 1.

The main functions of Nuclear Safety and Licensing, under the direction of TENS, are:

- $\quad$ Preparation of Authorization Basis documents for Operations and Projects Safety Support, such as HNF-SD-WM-BIO-001, Tank Waste Remediation System Basis for Interim Operation (BIO) (FDH 1997), and Facility Safety Analysis Report

- Performance of safety analyses and evaluations to issue safety basis documents

- Authorization Basis Management and Implementation

- Resolution of safety issues.

The main functions of TWRS Nuclear Safety, under the direction of ESH\&QA, are:

- Review of safety basis documents to ensure compliance with S/RIDs

- Review of all other applicable documents to ensure compliance with Authorization Basis

- Perform oversight function to ensure that activities and systems of operations/maintenance are in compliance with the Authorization Basis

- Perform oversight function to prevent the potential for nuclear criticality.

- The TENS organization performs the analyses and writes the documents that require review and oversight by ESH\&QA. The organizational structure ensures that the integrity of an Independent Safety Review is preserved. Good communication ensures that the roles between the two groups are clearly defined and that duplication of work is avoided.

\section{H3.2.3 Requirements}

The Nuclear Safety group is responsible for ensuring that compliance to the appropriate waste tank nuclear safety requirements, as described in the S/RID (Biebesheimer 1996) and specifically in the Authorization Basis, is achieved through prevention and mitigation.

The procedures which govern the work of Nuclear Safety in support of Retrieval and Disposal mission are those Fluor Daniel Hanford, Inc. (FDH) and TWRS Project procedures pertaining to: preparation of technical documents, performance of technical reviews, development of BIO, Final Safety Analysis Report (FSAR), SAR changes, unreviewed safety 
question (USQ) evaluations, preparation of procedures to implement TSR Administrative Controls, and criticality engineering.

\section{H3.2.4 Authorities}

The TWRS Nuclear Safety organization provides oversight to all nuclear activities performed under the TWRS Project umbrella. The manager of Nuclear Safety reports directly to the TWRS director of Environmental, Safety, Health, and Quality Assurance (ESH\&QA).

Nuclear Safety has the authority to: 1) assess the compliance of TWRS Project waste tank organizations, operations, and facilities by utilizing Operation Safety Assessments (OSA); 2) identify deficiencies that require corrective action, and follow-up to ensure corrective action is taken by performing reviews, OSAs, audits, etc.; 3) evaluate that the corrective action taken is adequate to reduce the probability of recurrence; and 4) direct that work be stopped, if necessary, to protect personnel or property from clear and imminent danger.

\section{H3.2.5 Work Activities}

Nuclear Safety supports the retrieval and Retrieval and Disposal activity in the following ways. Major work activities are:

1. Review of integrated work plans and Level 1 Logic diagrams to assure that nuclear safety requirements and concerns are addressed in process development, construction project design, major procurements, scheduled operations/maintenance, and interfaces with the private contractors.

2. Participate in the process to identify and evaluate new or modified hazards based on a review of the new or changed operations, processes, materials, facilities, or equipment.

3. Review of the Authorization Basis assessment document prepared by the Safety Analysis group. This assessment will be patterned after the USQ process as documented in 10 CFR 50, "Domestic Licensing of Production and Utilization Facilities," Section 59, "Changes, test and experiments," and DOE Order 5480.21, Unreviewed Safety Questions.

4. Review of documents (FSAR, BIO [FDH 1997], TSRs) required to modify the TWRS Authorization Basis.

5. Review of design media (drawings, specifications, analytical reports, etc.).

6. Review the Safety Equipment List (SEL) to ensure that the identification of the systems, structures, and components (SSC) supports all nuclear safety requirements. 
7. Review of Interface Control Documents (ICD) for the private contractors' waste staging tanks, facilities receiving immobilized low-activity waste (ILAW), highlevel waste (IHLW), and any interim process products.

8. Review of hazards assessments, Preliminary Safety Evaluation (PSE) and final Authorization Basis documents associated with the transport, receipt, and storage of immobilized ILAW and IHLW waste. As noted in item 2 above, Nuclear Safety will participate in the hazards review and assessment for this task.

9. Review USQ screenings and evaluations throughout the life cycle of this project.

10. Review the Criticality Safety Evaluation Reports (CSER) associated with all phases of this project. Support engineering to ensure that nuclear criticality safety is maintained for storage, retrieval, treatment, and disposal.

11. Review design modifications, maintenance, and operation documents, procedures, and manuals to assess compliance with mandated DOE, LMHC, and statutory nuclear safety requirements. In addition, standards, specifications, and recommended practices are considered to ensure compliance and that a good quality document is issued.

12. Perform/participate in audits/appraisals, and compliance inspections such as Operational Safety Assessments (OSA) to monitor compliance with LMHC governing documents.

13. Provide independent oversight of Operational Readiness Reviews to verify that the nuclear safety aspects of the facility, staff, procedures, and technical safety basis for operation are in place and ready for the defined operation.

14. Nuclear Safety will participate in Plant Review Committee (PRC), Technical Review Groups (TRG), and Data Review Committee (DRC).

15. Ensure that the Authorization Basis requirements are implemented in all work packages and procedures before any Retrieval and Disposal operations are started.

\section{H3.3 RADIOLOGICAL CONTROL}

\section{H3.3.1 Responsibilities}

Radiological Control responsibilities are shared across every organization within the TWRS Project. Each employee is responsible to recognize how their actions directly affect proper radiological controls and accordingly use good radiological work practices.

The TWRS Project management team is responsible for demonstrating a commitment to the establishment of high performance standards in the area of radiological control. Senior 
managers communicate this commitment to their organizations, and demonstrate their commitment by providing adequate staffing levels and by allocation of sufficient resources to ensure all workers are trained to effectively perform work. Management also establishes goals, policies and procedures to direct the organization in the implementation of the radiological control program.

Senior managers solicit feedback from workers and encourage problems to be identified at an early stage so proper corrective actions can be taken. Senior management also fosters a spirit of cooperation between the work force and the Radiological Control Organization (RCO).

Line managers hold their workers accountable for radiological control performance. Line managers spend sufficient time observing work performance to identify problem areas, and mentor their workers in the use of good radiological work practices.

The TWRS RCO implements the requirements of applicable regulatory documents, and sets standards for radiological work practices. The TWRS RCO accomplishes this by providing qualified Radiological Control Technicians (RCT's) to perform required radiological duties and ensure workers follow good radiological work practices.

\section{H3.3.2 Organization}

The TWRS RCM reports directly to the Tank Waste Operations Director. The TWRS RCM is responsible for the operation of the TWRS RCO. The TWRS RCM also maintains an adequate RCO staff to ensure that radiological control programs are maintained in accordance with regulations and requirements.

Each major activity within the TWRS Project, Single-Shell Tanks (SST), Double-Shell Tanks (DST), and Characterization, is assigned a RCM who reports directly to the TWRS RCM. The TWRS Retrieval and Disposal Mission will also have radiological control support staff. These facility managers are responsible for implementation of the radiological control programs within their facility. Each facility RCM is matrixed to their respective facility manager to ensure the RCO fully supports the facility mission.

Within each facility, radiological work activities are supported by a staff of Radiological Control Technicians (RCTs). These RCTs are supervised by first line supervisors. These supervisors ensure adequate radiological support is provided to the facility and manage the hands-on activities of the RCTs, such as work schedules, training activities and resource support.

Field support of radiological work activities is the direct responsibility of the RCTs. Duties handled by the RCTs include routine and job support surveys for radiation and contamination, enforcement of good radiological work practices, and documentation of radiological conditions.

A separate support staff reports directiy to the TWRS RCM. This support staff has a manager and two support organizations. One organization assists facilities in radiological work 
HNF-1883 Rev 1

planning and ALARA implementation. The second organization supports the TWRS Project by reviewing procedures and providing technical direction on radiological programs.

\section{H3.3.3 Requirements}

The Code of Federal Regulations, Title 10, Part 835 (10 CFR 835), Occupational Radiation Protection, sets forth the requirements for radiological control programs at Department of Energy sites. Each site is required under 10 CFR 835 to develop a Radiation Protection Program (RPP) and receive approval of the Radiation Protection Program from Department of Energy headquarters.

The Hanford Site used applicable portions of HSRCM-1, Hanford Site Radiological Control Manual (1994) to document compliance with 10 CFR 835. This Radiation Protection Program compliance is formally promulgated in HNF-SP-1145, Fluor Daniel Hanford Company Radiation Protection Implementation Program of Title 10 Code of Federal Regulations, Part 835, 1997 (McKenzie 1997).

Both 10 CFR 835 and HSRCM-1 (1994) requirements are contained in the TWRS S/RID (Biebesheimer 1996). Implementation of these requirements is contained in site and facility procedures. Site procedures are managed by FDH, and contained on the Hanford Intranet. TWRS Project procedures implementing the RPP are contained in HNF-IP-0842 (LMHC 1997) procedures and are available on the Hanford Procedure Information system.

\section{H3.3.4 Authorities}

Proper operation of the TWRS RCO is tracked by the Tank Waste Operations Director and reported to the LMHC President and General Manager. The Radiological Control Manager has the authority to run the RCO in accordance with applicable requirements and regulations.

\section{H3.3.5 Work Activities}

TWRS Radiological Control will provide the structure for the TWRS Retrieval and Disposal Mission Radiological Protection Program by:

1. Incorporating Retrieval and Disposal Mission radiological work into the existing TWRS Project.

2. Managing the RCTs associated with Retrieval and Disposal Mission activities.

3. Utilizing the radiological work planning processes in TWRS Administrative Procedures to assist in the planning of safe work.

4. Managing and overseeing required programs such as temporary shielding, fixed contamination areas, radioactive material storage, and high efficiency particulate filter vacuum cleaner control: 
HNF-1883 Rev 1

- Source Control

- Emergency Planning

- Instrumentation

- Area Dosimetry

- Postings

- Shipping
- High Radiation Access Control

- External/Internal Dosimetry

- Work Place Air Sampling

- Tracking/Trending of Work Place Contamination

- Access Control Entry System (ACES)

5. Providing access and support to site support services such as dosimetry (provided by PNNL), radiological access control entry system (ACES), bioassay monitoring, and radiological training.

6. Representing the interests of Retrieval and Disposal in the Radiological Control Center of Expertise process.

7. Identifying, tracking and correcting radiological deficiencies through the Radiological Problem Reporting system.

8. Pursuing continuous improvement in the implementation of radiological programs.

TWRS Radiological Control will evaluate the Retrieval and Disposal Mission for compliance to applicable radiological regulations and requirements and complete necessary corrective actions by:

1. Conducting internal assessments using the TWRS Project assessment database (Environmental Requirements Management Interface Database [ERMI]) as outlined in HNF-IP-0842, Volume I, Section 2.10, "Management Assessment Program."

2. Mentoring facility management in the observation of radiological performance in the field and correction of identified deficiencies:

3. Tracking and trending radiological performance indicators as part of the TWRS Project.

4. Including Retrieval and Disposal as a part of the TWRS Project external audits (i.e., FEB and Lockheed Martin Corporate).

5. Providing facility technical authority oversight of issues which might constitute non-compliance with 10 CFR 835 regulations.

6. Driving improvements identified during assessments and audits. 


\section{HNF-1883 Rev 1}

by:

TWRS Radiological Control will provide support to the Retrieval and Disposal Mission

1. Providing radiological job coverage, as necessary, to monitor and control radiation and contamination hazards.

2. Providing engineering support on radiological issues.

3. Assisting in the radiological work planning process and ALARA planning activities.

4. Development of Radiological Work Permits and ALARA Management Worksheets.

5. Incorporating Retrieval and Disposal ALARA program requirements into the existing ALARA programs of the TWRS Project, and representing Retrieval and Disposal in any ALARA capacities.

6. Assisting in the development of ALARA goals and performance indicators.

7. Improving the performance of radiological workers in the field by teaching good radiological work practices.

8. Reviewing technical procedures and other documents, and providing input into readiness activities.

9. Providing emergency response support in the event of a radiological occurrence.

\section{H3.4 EMERGENCY PREPAREDNESS}

\section{H3.4.1 Responsibilities}

Primary responsibility for emergency preparedness (EP) and emergency response within the TWRS Project is with the LMHC President and General Manager. The EP program is part of the ESH\&QA organization, under the direction of the ESH\&QA director. The EP program manager is responsible to ensure the TWRS EP program is conducted in accordance with applicable regulations, requirements, and procedures.

\section{H3.4.2 Organization}

The EP program manager ensures that the EP coordinators conduct the day-to-day activities, which include planning, procedure development and review, training, and conduct of drills for TWRS facilities. Other job functions within the EP program are described in WHC-IP-0971, Tank Waste Remediation System (TWRS) Emergency Preparedness Program 


\section{HNF-1883 Rev 1}

Plan (Rowland 1996), and are temporary assignments filled by TWRS Project personnel during training, drills, and actual emergencies.

The TWRS EP organization works in conjunction with the sitewide EP organization, which includes RL and PMHC team subcontractors. The TWRS Project facility-specific requirements are identified and implemented by TWRS EP.

\section{H3.4.3 Requirements}

The EP organization responsibilities are accomplished in accordance with the governing documents in the DOE-approved TWRS S/RID (Biebesheimer 1996). The S/RID (Biebesheimer 1996) is a compilation of applicable requirements from 29 CFR 1910 and 40 CFR 265, "Interim Status Standards for Owners and Operators of Hazardous Waste Treatment Storage and Disposal Facilites." These requirements are implemented through Project Hanford Policies and Procedures, and TWRS specific administrative and operating procedures.

\section{H3.4.4 Authorities}

The TWRS EP organization has the authority to conduct drills in accordance with applicable TWRS Project procedures, evaluate the performance of emergency response personnel, and make recommendations for improving the EP program. The EP program provides controllers and evaluators for the drills.

The TWRS EP program personnel are authorized to conduct training for TWRS Project personnel, and develop and maintain TWRS EP procedures, emergency response checklists, and drill packages.

\section{H3.4.5 Work Activities}

TWRS Emergency Preparedness will support the TWRS Retrieval and Disposal Mission in the following areas:

1. Establishing and maintaining necessary emergency equipment and facility needs, and provide input to the Mission.

2. Interfacing with site, state, and federal emergency preparedness organizations.

3. Developing and reviewing EP plans, procedures, and emergency response checklists.

4. Identifying appropriate lines of EP notification and communication, and incorporating the information into applicable procedures.

5. Establishing a coordinated emergency response team with the capability of handling emergencies. 


\section{HNF-1883 Rev 1}

6. Training Retrieval and Disposal Mission emergency preparedness and response personnel in accordance with procedures and requirements.

7. Developing Retrieval and Disposal Mission objectives and criteria for drill scenarios and conducting emergency drills.

8. Training drill coordinators and evaluators to perform their respective functions.

9. Providing Retrieval and Disposal Mission management with recommendations for improvements based on strengths and weaknesses observed during drills.

10. Evaluating meteorological monitoring to support tracking of hazardous or radiological material releases.

\section{H3.5 INTERFACES}

In order to ensure optimum support to the TWRS Retrieval and Disposal Mission, effective interfaces between affected organizations is vitally important. Communication ties exist between: TWRS Safety; Nuclear Safety; Radiological Control; Environmental; Quality Assurance; TWRS Engineering and Nuclear Safety; Emergency Preparedness; Retrieval and Disposal Construction Projects; Tank Waste Operations; Engineering; Maintenance; and with private contractors. The methods for defining the customer/service relationships between these points of interface and the safety organizations will be accomplished through well defined scope statements that will include clear expectations and criteria for success.

External interfaces are necessary with the organizations shown in Table H-1 for the purposes contained in each description. These interfaces are established and continue through ongoing process improvement activities.

\section{H4.0 EXECUTION STRATEGY}

TWRS Safety, Nuclear Safety, Radiological Control, and Emergency Preparedness will use an integrated approach to support TWRS Project work activities. This integrated approach ensures the involvement of safety personnel in all aspects of projects including design and construction, work planning and performance, and on-going follow-up activities.

\section{H4.1 WORK PLANNING AND PRIORITIZATION}

The multi-year work plan (MYWP), including work breakdown structure (WBS) dictionaries, capital equipment/expense not related to construction, cost account authorizations; 
Table H-1. External Interfaces.

\begin{tabular}{|c|c|}
\hline Company/Organization & Interface Description \\
\hline $\begin{array}{l}\text { Fluor Daniel Hanford, Integrating } \\
\text { Contractor }\end{array}$ & $\begin{array}{l}\text { FDH provides policies and procedures, and acts as interpretive } \\
\text { authority for the site-wide safety, fire protection, nuclear safety, } \\
\text { emergency preparedness, and radiological program requirements. } \\
\text { Specific activities include participation in the FDH President's Zero } \\
\text { Accident Council; the Environmental, Safety, and Health } \\
\text { Management Council; the Radiological Control Center of Expertise; } \\
\text { and technical exchanges. }\end{array}$ \\
\hline Medical Service Contractor & $\begin{array}{l}\text { Provides occupational medical services, including employment } \\
\text { physicals, fitness for duty exams, and medical surveillance. TWRS } \\
\text { Safety recommends enrollment of personnel into the medical } \\
\text { surveillance programs and provides data regarding health hazards in } \\
\text { the workplace. }\end{array}$ \\
\hline DOE RL & $\begin{array}{l}\text { Provides and receives safety, nuclear safety, radiation protection, and } \\
\text { emergency preparedness information through FDH, to and from RL. }\end{array}$ \\
\hline Numatec Hanford Corporation & Interfaces with all construction project management activities. \\
\hline Corporate Lockheed Martin & $\begin{array}{l}\text { Performs audits of health and safety, nuclear safety, and radiological } \\
\text { protection program implementation and compliance. }\end{array}$ \\
\hline Defense Nuclear Facilities Safety Board & $\begin{array}{l}\text { Provides recommendations related to safety, nuclear safety, and } \\
\text { radiological protection. }\end{array}$ \\
\hline $\begin{array}{l}\text { Worker Safety and Heaith Sub-Panel } \\
\text { Committee }\end{array}$ & Provides recommendations on health, safety, and radiological issues. \\
\hline DynCorp Tri-Cities Services, Inc. & $\begin{array}{l}\text { Provides services in the areas of emergency response, emergency } \\
\text { preparedness, property management, etc. }\end{array}$ \\
\hline Waste Management Services, Inc. & Provides packaging, certification, and disposition of waste. \\
\hline $\begin{array}{l}\text { Duke Engineering Services Hanford, } \\
\text { Inc. }\end{array}$ & $\begin{array}{l}\text { Provides technical services issues relative to Authorization Basis } \\
\text { documentation. }\end{array}$ \\
\hline Fluor Daniel Northwest & Provides construction services. \\
\hline Pacific Northwest National Laboratories & Provides analytical laboratory and dosimetry services. \\
\hline $\begin{array}{l}\text { Radiological Control Center of } \\
\text { Expertise }\end{array}$ & $\begin{array}{l}\text { Forum of PHMC contractor radiological control managers who } \\
\text { formulate site-wide policy. }\end{array}$ \\
\hline Facility Evaluation Board & $\begin{array}{l}\text { Performs independent oversight to verify safety, nuclear safety, and } \\
\text { radiological control program compliance. }\end{array}$ \\
\hline Lockheed Martin Services, Inc. & Provides computer, software, and graphic design support. \\
\hline $\begin{array}{l}\text { Federal Emergency Management } \\
\text { Agency (FEMA) }\end{array}$ & Provides federal emergency response guidance. \\
\hline Other External Organizations & Varies, as needed. \\
\hline
\end{tabular}


cost account plans, and milestone description sheets will be used to generate the integrated schedule. The MYWP is built upon detail planning, which includes safety services. TWRS Safety, Nuclear Safety, Radiological Control, and Emergency Preparedness will provide input during the development of the MYWP to ensure support for the various project activities is incorporated. Personnel and equipment resources will be provided based on the authorized plan.

Formal change control will be used to maintain configuration controlled Technical Baselines, documents, and hardware requirements, as well as schedule and cost baselines to ensure priorities are managed and maintained in accordance with the MYWP. The need for management direction on work priority is not uncommon given the centralized nature of the ESH\&QA and Radiological Control functions, and the attendant responsibility to provide service across unrelated elements in the TWRS Project (e.g., facility deactivation and waste feed delivery). Two other factors which may require management direction and mid-course correction involve the emergence of unplanned work and shifts in major project/program direction or schedule. Particularly in the case of unplanned work, work priority management is closely tied to resource management.

\section{H4.2 RESOURCES}

The safety organizations will be responsible for providing individuals qualified in the anticipation, recognition, evaluation, and control of hazards in the workplace. Personnel must complete minimum training requirements, with refresher training provided annually. Training requirements will be established and tracked through the training matrix system, and management ensurès that qualified safety, nuclear safety, and radiological control personnel are available and ready to perform their function using approved technical and administrative procedures. Permanent staff will be augmented by contractor support when workload and schedule demands exceed the capacity of the permanent staff.

\section{H4.3: WORK IMPLEMENTATION/SAFETY MANAGEMENT}

The objectives discussed above will be carried out through the implementation of Integrated Safety Management. The objective of an Integrated Safety Management System (ISMS) is to facilitate safe work. The TWRS organization is committed to performing work safely and efficiently and in a manner that ensures the protection of the public, the workers, and the environment. The overall management of safety functions and activities is an integral part of the TWRS Project. This is accomplished through the effective integration of safety management into all facets of work planning and execution.

The ISMS establishes a single, defined ES\&H management system that integrates requirements into work planning and execution and identifies a set of requirements that reflects DOE's commitment to a "standards based" safety program and the safety concepts reflected by these requirements. 
The ISMS provides the mechanisms for increasing worker involvement in: work planning, including hazard and environmental impact identification, analysis, and control; work execution; and feedback/improvement processes. Effective implementation of the ISMS incorporates the best practices and supports the accomplishment of the Voluntary Protection Program, Enhanced Work Planning/Hanford Occupational Health Process, and other ES\&H performance improvement initiatives.

Tailoring of safety management is essential in work planning (design work, analyze hazards, establish controls) and implementation (perform work, assess feedback). Examples of tailoring include: (1) selecting a method for hazard analysis commensurate with the facility (nuclear or non-nuclear), (2) selecting methods for hazard analysis commensurate with the activity, (3) selecting methods for hazard analysis commensurate with the life-cycle of the process or facility, (4) selecting methods for hazard analysis commensurate with the work to be performed and the type and magnitude of the hazards involved, and (5) identifying work planning teams based on hazards while considering staff experience and expertise.

Tailoring also allows for work to be managed at the appropriate level of the organization and for choices to be made from among a variety of engineering and administrative controls to provide reasonable assurance that the workers, the public, and the environment are adequately protected during the performance of work. Overall risk management decisions are made at the facility level in the facility Authorization Basis. As an example of tailoring of controls, risk decisions are also made at the activity level for worker protection through the integration of safety and health requirements in the selection of personal protective equipment.

Examples of how the ISMS principles are implemented include the development of Job Hazard Analyses for specific jobs through multi-discipline work planning teams and an Employee Job Task Analysis for each TWRS Project employee which identifies potential hazards the person may be exposed to based on assigned duties.

\section{H4.4 REQUIREMENTS MANAGEMENT}

Retrieval and Disposal requirements will be identified and managed as part of the integrated safety management process. Requirements management includes:

- Establishing and managing the requirements basis.

- Establishing functions to be performed and allocating requirements associated with those functions.

- Developing design and safety analysis for systems that perform the functions and implement the requirements.

- Implementing systems in accordance with designs and requirements.

- Maintaining S/RID documentation. 
- Operating equipment and systems within design and safety limits and requirements, in accordance with Technical Safety Requirements and per approved operating procedures.

The Tank Farm S/RID (Biebesheimer 1996) defines the requirements agreed to by the contractor and DOE and is implemented through contractor policies and procedures. The approved S/RID (Biebesheimer 1996) is a contractual requirement that replaces the more generic list of ES\&H requirements, usually identified as part of general contract requiremients.

At the TWRS Project, applicable standards and requirements are identified and agreedupon in accordance with the site-wide S/RID process (HNF-PRO-265, Developing and Maintaining S/RIDs). The Tank Farms S/RID (Biebesheimer 1996) captures the applicable safety requirements of Code of Federal Regulations, Washington Administrative Codes, DOE orders and regulations, and other requirement source documents (i.e., industry standards) that embody the necessary and sufficient requirements to ensure the safety of the public, the workers, and the environment. Tank Farms has an S/RID approved by DOE-RL (Wagoner 1996). A tank waste retrieval and disposal S/RID is under development.

To verify implementation of the S/RID (Biebesheimer 1996), Phase 1 and 2 assessments are used. A Phase 1 S/RID administrative assessment is used to determine if requirements are appropriately characterized in implementing documents; and a Phase 2 S/RID performance assessment determines whether personnel are adhering to actions as specified in the implementing documents.

The requirements contained in the S/RID (Biebesheimer 1996) are implemented through site wide policies and procedures, HSRCM-1 (1994), WHC-SD-WM-HSP-002 (Mickle 1995), TWRS Project specific administrative and operating procedures, and project-specific engineering baseline documentation. Cognizance of these sources is primarily enabled by ready access to configuration management documentation. Additional means to maintain cognizance include: 1) technical review of TWRS Project procedures and documentation, and 2) functional area ownership of relevant S/RID sections.

\section{H4.5 ISSUE RESOLUTION}

The TWRS Project safety and health team is participating in the resolution of several open issues at the TWRS Project (Flammable Gas USQ, Organic Salt-Nitrate USQ, Feasibility of Waste Sluicing (W-320 Project), Feasibility of Waste Mixing (W-151 Project)). These issues are expected to be closed/resolved by the close of fiscal year (FY) 1999 and are not expected to pose a barrier to the development, approval, and implementation of Authorization Basis for TWRS Retrieval and Disposal activities. Other key technical issues and uncertainties that may arise that would impact successful execution of Retrieval and Disposal will be managed at the Director level. Appropriate action will be taken to resolve issues and meet delivery schedules. 


\section{H5.0 REFERENCES}

\section{Code of Federal Regulations}

10 CFR 50, "Domestic Licensing of Production and Utilization Facilities," Code of Federal Regulations, as amended.

10 CFR 835, "Occupational Radiation Protection," Code of Federal Regulations, as amended.

29 CFR 1904, "Recording and Reporting Occupational Injuries and Illnesses," Code of Federal Regulations, as amended.

29 CFR 1910, "Occupational Safety and Health Standards," Code of Federal Regulations, as amended.

29. CFR 1926, "Safety and Health Requirements for Construction," Code of Federal Regulations, as amended.

40 CFR 265, "Interim Status Standards for Owners and Operators of Hazardous Waste Treatment Storage and Disposal Facilities," Code of Federal Regulations, as amended.

\section{U.S. Department of Energy Orders}

DOE Order 5480.21, Unreviewed Safety Questions, U.S. Department of Energy, Washington, D.C.

\section{Database}

ERMI, n.d., Environmental Requirements Management Interface Database, database maintained by Lockheed Martin Hanford Corporation for Fluor Daniel Hanford, Inc., Richland, Washington.

\section{Procedures}

HNF-PRO-233, Review and Approval of Documents, Fluor Daniel Hanford, Inc., Richland, Washington.

HNF-PRO-265, Developing and Maintaining S/RIDs, Fluor Daniel Hanford, Inc., Richland, Washington. 


\section{Documents}

Biebesheimer, E., 1996, High-Level Waste Storage Tank Farms / 242-A Evaporator Standards/ Requirements Identification Document (S/RID), WHC-SD-MP-SRID-001, Rev. 1, Westinghouse Hanford Company, Richland, Washington.

Borneman, L. E., 1998, Tank Waste Remediation System Environmental Program Plan, HNF-1773, Rev. 0, prepared by Lockheed Martin Hanford Corporation for Fluor Daniel Hanford, Inc., Richland, Washington.

FDH, 1997, Tank Waste Remediation System Basis for Interim Operation,

HNF-SD-WM-BIO-001, Rev. 0, Fluor Daniel Hanford, Inc., Richland, Washington.

HSRCM-1, 1994, Hanford Site Radiological Control Manual, Rev. 2, prepared for the U.S. Department of Energy, Richland Operations Office, by the Hanford Site Contractors and managed by Pacific Northwest National Laboratory Records Management Office, Richland, Washington.

LMHC, 1997, TWRS Administration, HNF-IP-0842, Fluor Daniel Hanford, Inc., Richland, Washington.

McKenzie, L. J., 1997, Fluor Daniel Hanford Company Radiation Protection Implementation Program of Title 10 Code of Federal Regulations, Part 835, 1997, HNF-SP-1145, Rev. 2, prepared by DE\&S Hanford, Inc. for Fluor Daniel Hanford, Inc., Richland, Washington.

Mickle, G. D., 1995, Tank Farm Health and Safety Plan, WHC-SD-WM-HSP-002, Rev. 2, Westinghouse Hanford Company, Richland, Washington.

Rowland, D. J., 1996, Tank Waste Remediation System (TWRS) Emergency Preparedness Program Plan, WHC-IP-0971, Rev. 1, prepared by Lockheed Martin Hanford Corporation for Fluor Daniel Hanford, Inc., Richland, Washington. 


\section{APPENDIX I}

TANK WASTE REMEDIATION SYSTEM BUSINESS MANAGEMENT ORGANIZATION EXECUTION PLAN FOR THE

TWRS RETRIEVAL AND DISPOSAL MISSION 
HNF-1883 Rev 1

This page intentionally left blank. 
HNF-1883 Rev 1

\section{CONTENTS}

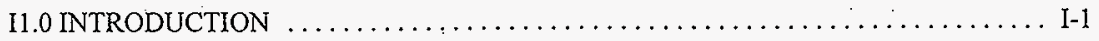

I2.0 MISSION AND ORGANIZATION $\ldots \ldots \ldots \ldots \ldots \ldots \ldots \ldots \ldots \ldots \ldots \ldots \ldots$

13.0 ROLES AND RESPONSIBILITIES $\ldots \ldots \ldots \ldots \ldots \ldots \ldots \ldots \ldots \ldots \ldots \ldots \ldots \ldots \ldots \ldots$

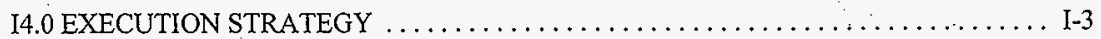

\section{LIST OF TERMS}

CAM Cost Account Manager

DOE $\quad$ U.S. Department of Energy

FDH Fluor Daniel Hanford, Inc.

LMHC $\quad$ Lockheed Martin Hanford Corporation

PHMC. Project Hanford Management Contract

$\mathrm{RL}$

TWR

U.S. Department of Energy, Richland Operations Office

TWRS

Tank Waste Retrieval organization

Tank Waste Remediation System 


\section{HNF-1 883 Rev 1}

This page intentionally left blank. 
HNF-1883 Rev 1

\title{
APPENDIX I
}

\author{
TANK WASTE REMEDIATION SYSTEM \\ BUSINESS MANAGEMENT ORGANIZATION \\ EXECUTION PLAN FOR THE \\ TWRS RETRIEVAL AND DISPOSAL MISSION
}

\section{I1.0 INTRODUCTION}

Before the Department of Energy (DOE) can authorize the private contractors to proceed with Phase 1B, the Project Hanford Management Contract (PHMC) team must demonstrate that it will be able to provide the necessary support to the private contractors. The PHMC team must conduct a "readiness to proceed" (RTP) self-assessment of its ability to support the private contractors. The DOE is responsible for reviewing the PHMC assessment, and for conducting an independent RTP evaluation. The status of the PHMC team's RTP is a key consideration in DOE's decision making about continuing with privatization.

The Business Management organization performs several functions that contribute to the Tank Waste Remediation System (TWRS) Project and the Waste Retrieval and Disposal Mission and support the private contractors. This Execution Plan describes key technical, programmatic, and management aspects of the Business Management organization that are relevant to privatization support, and summarizes the approach and activities for achieving and maintaining RTP. This Execution Plan will be updated periodically to reflect changes to privatization and as the contributing functions of the Business Management organization evolve.

In general, the Business Management organization is, or will be, ready to support the TWRS Project and Waste Retrieval and Disposal Mission as follows:

- $\quad$ Provide the Planning, Financial Control and Business Operations Coordination \& Administration necessary to support the Retrieval mission.

The remaining sections of this Execution Plan provide more details on the contributions of the Business Management organization to the TWRS Project and the Waste Retrieval and Disposal Mission.

\section{I2.0 MISSION AND ORGANIZATION}

The TWRS Project Business Management organization is the Lockheed Martin Hanford Corporation (LMHC) organization which directs the planning, budgeting and cost control 
activities under the PHMC at the Hanford Site for the TWRS Project, including the Waste Retrieval and Disposal Mission (e.g., Phase 1B) activities. It is the vision of the Business Management organization to provide detailed, accurate schedules and cost analyses in order to assure that key activities are identified and accurately resource loaded.

The Business Management organization controls and manages funds authorized by LMHC to ensure that authorized amounts are not exceeded. This includes reviewing, negotiating, and approving the authorizing documents; monitoring costs versus budget/funds performance to detect potential changes in funding requirements; assisting in the preparation and approval of the program/projects fiscal year spending forecast (FYSF); and reviewing and authorizing change requests. The Tank Waste Retrieval (TWR) Program Managers are responsible for properly distributing and communicating project funds to the cost account managers (CAMs) for similar implementation, management, and control.

The Business Management organization is responsible for the Planning, Financial Control, and Business Operations Coordination and Administration for the TWRS Project. The Business Management organization utilizes other Fluor Daniel Hanford major subcontractors, enterprise companies, and offsite contractors as resources to complete the programmatic work scope. Business Management interfaces with all organizations required to provide support within the TWRS Project and Waste Retrieval and Disposal Mission. These organizations include Tank Farm Operations, Maintenance, Radiological Control, TWRS Program Management, Engineering, Environmental, Safety \& Health and Quality Assurance.

\section{I3.0 ROLES AND RESPONSIBILITIES}

Within the TWR Business Management arena, there are three main elements of work:

- $\quad$ Planning

- Financial control

- Business operations coordination and administration.

The Planning piece of Business Management consists of the development of Project Management Baseline Summary (PMBS) schedules using input from CAMs and Program/Project Managers. Each schedule activity is resource loaded using estimating worksheets that the CAMs and Project Managers have submitted for their respective activities. Cost estimating worksheets are maintained in order to provide back-up for resource allocation and audit purposes. The schedules that are maintained reflect the current project Work Breakdown Structure coding. Preparation and status of a detailed working level schedule for major project milestones/ Performance Agreements (PAs) as directed by each Program/Project Manager is also performed. Status of all schedules at least once a month is performed, and analysis is performed to ensure that the budgeted cost of work performed is consistent with current schedule progress. Assistance is given to CAMs and Project Managers in developing 


\section{HNF-1883 Rev 1}

work-around plans as needed based on schedule input that is received or variances that exist. The planning area also assists in the development of change requests.

Financial Control ensures that cost estimates from schedule databases are accurately reflected in site cost/schedule performance systems (presently the Financial Data System). Staffing analysis reports are provided to CAMs and Program/Project Managers, including (as requested) budgeted versus actual full-time equivalents. Analysis reports by cost elements for budget versus actuals is provided to CAMs and Project Managers. This type of reporting feature will help to manage and prioritize the critical resources needed over the life-cycle of the project. These data are used to assist in the development and issuance of work orders and purchase orders ensuring procurements are within budget/funds baseline. This reporting will allow management to identify potential problems in cost or schedule and take corrective action as required. Financial control will also provide support to CAMs in the preparation of change requests, spend forecasts, and accurate accrual data for cost accounting.

Business Operations Coordination \& Administration is responsible for coordinating and directing the preparation and integration of the TWR Project Multi-Year Work Plan (MYWP), the PMBSs, and Unit of Analysis sheets. Business Operations Coordination \& Administration is also responsible for assisting in the development of TWR PAs, maintaining monthly status reports for PAs, and maintaining auditable files of documentation supporting completion of PAs. Work also consists of ensuring TWR Project compliance to applicable LMHC business rules, developing TWR Business Plans, preparing and maintaining the Responsibility Assignment Matrix, ensuring Fluor Daniel Hanford and LMHC cost estimating standards are met for each project, and estimates are accurately documented and defensible. Business Operations Coordination \& Administration performs administrative functions (e.g., property control, equipment inventories, performance indicator charts with documented trend analysis), and develops strategies to ensure TWR Project progress is well planned, executed, and communicated upon completion.

\section{I4.0 EXECUTION STRATEGY}

The Business Management organization.will ensure that all work within the TWR Project and Waste Retrieval and Disposal Mission is properly prioritized, planned, estimated and costed. Business Management will ensure that the roles and responsibilities of each CAM and Program/Project Manager is communicated so they can conduct their assigned tasks and perform. their required functions in accordance with LMHC business rules.

The approval of the MYWP, including work breakdown structure dictionaries, capital equipment/expense not related to construction, cost account authorizations, cost account plans, and milestone description sheets are used as the basis for performance monitoring and control. Formal change control will be used to maintain technical baselines, documents, and hardware requirements, as well as schedule and cost baselines to ensure priorities are managed and 


\section{HNF-1883 Rev 1}

maintained in accordance with the MYWP. Key technical, cost or schedule issues which could impact successful execution of the TWRS Project and Waste Retrieval and Disposal Mission will be managed at the Director Appropriate Level. action will be taken to resolve issues and meet delivery schedules. 
HNF-1883 Rev 1

\author{
APPENDIX J \\ TANK WASTE REMEDIATION SYSTEM \\ QUALITY ASSURANCE ORGANIZATION \\ EXECUTION PLAN FOR THE \\ TWRS RETRIEVAL AND DISPOSAL MISSION
}


HNF-1883 Rev 1

This page intentionally left blank. 


\section{HNF-1883 Rev 1}

\section{CONTENTS}

J1.0 INTRODUCTION $\ldots \ldots \ldots \ldots \ldots \ldots \ldots \ldots \ldots \ldots \ldots \ldots \ldots \ldots \ldots \ldots \ldots \ldots \ldots$

J2.0 MISSION AND OBIECTIVE $\ldots \ldots \ldots \ldots \ldots \ldots \ldots \ldots \ldots \ldots \ldots \ldots \ldots \ldots \ldots$

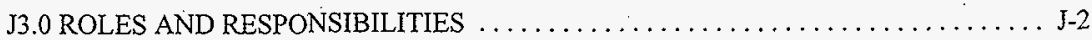

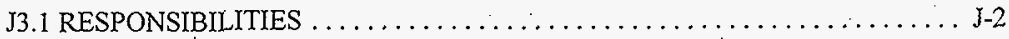

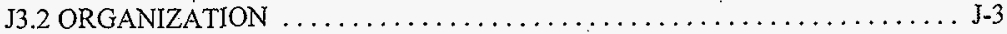

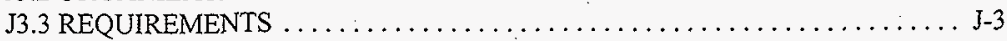

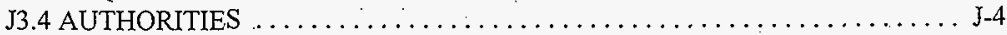

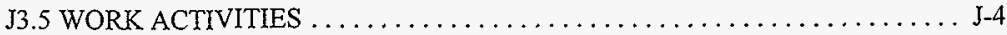

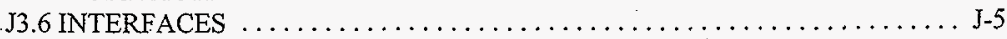

J4:0 EXECUTION STRATEGY $\ldots \ldots \ldots \ldots \ldots \ldots \ldots \ldots \ldots \ldots \ldots \ldots \ldots \ldots \ldots \ldots$

J4.1 WORK PLANNING AND PRIORITIES $\ldots \ldots \ldots \ldots \ldots \ldots \ldots \ldots \ldots \ldots \ldots$

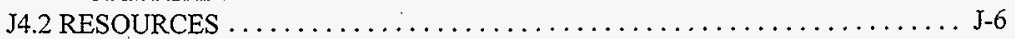

J4.3 WORK IMPLEMENTATION $\ldots \ldots \ldots \ldots \ldots \ldots \ldots \ldots \ldots \ldots \ldots \ldots \ldots \ldots \ldots \ldots$

J4.4 REQUIREMENTS MANAGEMENT $\ldots \ldots \ldots \ldots \ldots \ldots \ldots \ldots \ldots \ldots \ldots \ldots$ J-7

J4.5 ISSUE RESOLUTION $\ldots \ldots \ldots \ldots \ldots \ldots \ldots \ldots \ldots \ldots \ldots \ldots \ldots \ldots$

J5.0 REFERENCES $\ldots \ldots \ldots \ldots \ldots \ldots \ldots \ldots \ldots \ldots \ldots \ldots \ldots \ldots \ldots \ldots \ldots$

\section{LIST OF TERMS}

DOE

DST

FDH

ICD

LMHC

PAAA

PHMC

QAPD

QAPP

SSC.

SST

TWRS
U.S. Department of Energy

double-shell tank

'Fluor Daniel Hanford, Inc.

Interface Control Document

Lockheed Martin Hanford Corporation

Price Anderson Amendments Act

Project Hanford Management Contract

Quality Assurance Program Description

Quality Assurance Program Plan

system, structure, or component

single-shell tank

Tank Waste Remediation System 
HNF-1883 Rev 1

This page intentionally left blank. 
HNF-1883 Rev 1

APPENDIX $\mathbf{J}$

\author{
TANK WASTE REMEDIATION SYSTEM \\ QUALITY ASSURANCE ORGANIZATION \\ EXECUTION PLAN FOR THE \\ TWRS RETRIEVAL AND DISPOSAL MISSION
}

\title{
J1.0 INTRODUCTION
}

Before the U. S. Department of Energy (DOE) can authorize the private contractors to proceed with Phase 1B, the Project Hanford Management Contract (PHMC) team must demonstrate that it will be able to provide the necessary support to the private contractors. The PHMC team must conduct a "readiness to proceed" self-assessment of its ability to support the private contractors. The DOE is responsible for reviewing the PHMC assessment and for conducting an independent readiness to proceed evaluation. The status of the PHMC Team's readiness to proceed is a key consideration in DOE's decision to continue with privatization.

The Tank Waste Remediation System (TWRS) Quality Assurance organization will contribute to the TWRS Retrieval and Disposal Mission and will support private contractors. In addition to quality assurance functions now performed in support of the TWRS Project, the Quality Assurance organization will be ready to provide oversight of interface activities associated with transfer of waste and receipt of immobilized product. This execution plan describes the mission and objective of the Quality Assurance organization, the roles and responsibilities of the organization that are relevant to privatization, and a summary of the execution strategy. The execution plan may be updated periodically to accommodate changes in the overall privatization program or in the TWRS Quality Assurance program.

.The TWRS Quality Assurance organization is prepared to include the TWRS Retrieval and Disposal Mission in the TWRS Quality Assurance Program. In addition to continuing current activities; TWRS Quality Assurance will review analyses and provide independent verification of the composition of waste feed being delivered to the private contractors. TWRS Quality Assurance will review analytical data to confirm that waste returned to TWRS for storage or disposal complies with regulatory requirements.

\section{J2.0 MISSION AND OBJECTIVE}

The mission of TWRS Quality Assurance organization is to support and guide all TWRS organizations in their deployment of the TWRS Quality Policy as stated in HNF-IP-0842, TWRS Administration, Volume XI, Section 1.1, "TWRS Quality Assurance Program Plan" (QAPP) 
(LMHC 1997). The objective of this activity is to produce a quality culture in TWRS based on continuous process improvement and to thereby ensure that TWRS products meet customer expectations.

The TWRS Quality Assurance Manager reports to the Director, Environment, Safety, Health and Quality Assurance (ESH\&QA), who in tum reports to the President and General Manager of the Lockheed Martin Hanford Corporation (LMHC). The Quality Assurance organization is thus independent of the organizations it supports and oversees. Quality assurance engineers and quality control inspectors report to the Quality Assurance Manager but are assigned by matrix to the various organizations supported by Quality Assurance. In addition, a core group of quality assurance engineers provides support for analysis of issues that affect the TWRS Project as a whole.

\section{J3.0 ROLES AND RESPONSIBILITIES}

\section{J3.1 RESPONSIBILITIES}

Overall responsibility for establishing and executing the QAPP (LMHC 1997) lies with the President and General Manager of LHMC. The TWRS Quality Assurance Manager is responsible for development and administration of the QAPP (LMHC 1997). Individual division and unit managers are responsible for developing and maintaining the necessary administrative controls for implementing the portions of the QAPP (LMHC 1997) related to their activities. All LMHC personnel are responsible for executing those requirements that are pertinent to their respective assignments. The TWRS Quality Assurance organization conducts audits, surveillances, and other investigations of TWRS facilities and activities to verify the presence of management systems sufficient to ensure deployment of the TWRS Quality Policy.

The TWRS Quality Assurance organization identifies quality assurance requirements and maintains the QAPP (LMHC 1997) to document how those requirements are implemented at the TWRS Project. Quality professionals assigned to other organizations help those organizations develop and implement quality management systems specific to their processes and products: Such a system is being developed for the TWRS Retrieval and Disposal Mission.

Quality assurance engineers and quality control inspectors work with planners to ensure that quality assurance requirements are observed during planning and performance of work and to provide technical assistance during work planning. The Quality Assurance staff reviews documents associated with design, modification, maintenance, and operation of TWRS facilities and equipment, and oversees certain field work activities performed by others. Quality control inspectors often check routes and valve alignment prior to a waste transfer, perform inspections of equipment being installed, and witness operational testing. The TWRS Quality Assurance organization administers the nonconformance reporting system and works with the Engineering organization to promptly disposition nonconforming items. 
The TWRS Quality Assurance organization provides oversight of construction projects' quality programs and interface with projects during turnover activities (e.g., operational testing). Interface activities associated with the transfer of waste feed and the receipt of immobilized waste and by-products will be similarly supported. TWRS Quality Assurance will confirm the suitability of waste feed for delivery and immobilized waste for receipt from the private contractors. TWRS Quality Assurance will support Tank Waste Operations by periodically assessing the process by which feed qualification samples are collected, analyzed, and dispositioned. Similarly, for receipt of immobilized waste, TWRS Quality Assurance will assess the process by which conformance with requirements is demonstrated.

The Manager of TWRS Quality Assurance participates on the Tank Waste Operations Corrective Action Management Board and the Plant Review Committee. Other members of the staff participate on Readiness Review teams (e.g., Basis for Interim Operation implementation, W-030 startup), the Flammable Gas Committee, and Requirements Engineering process improvement teams.

\section{J3.2 ORGANIZATION}

Quality assurance engineers and quality control inspectors report to the Quality Assurance Manager but are assigned by matrix to the various organizations supported by the Quality Assurance organization. Staff is dedicated to the TWRS Retrieval and Disposal Mission. In addition, a core group of quality assurance engineers provides support for analysis of issues that affect the TWRS Project as a whole, such as corrective action management, Basis for Interim Operation implementation, Price-Anderson Amendments Act screening and reporting, and quality data analysis.

\section{J3.3 REQUIREMENTS}

The PHMC team members are directed by Fluor Daniel Hanford, Inc. (FDH) to prepare a contractor QAPP that is subordinate to HNF-MP-599, Project Hanford Quality Assurance Program Description (QAPD) (FDH 1997). Subtier contractors not on the FDH Evaluated Supplier List will be required to either work to the QAPP (LMHC 1997) or to develop their own QAPP that addresses FDH QAPD (FDH 1997) requirements.

The QAPP is Volume XI of HNF-IP-0842, TWRS Administration. The QAPP (LMHC 1997) contains an implementation matrix that identifies the ten major elements of the requirements from DOE Order 5700.6C, Quality Assurance, and 10 CFR 830, "Quality Assurance Requirements," Section 120, "Nuclear Safety Management," the subelements for each major element as specified in the FDH QAPD (FDH 1997), and the associated implementation documents for each of the subelements. The ten major elements are:

\footnotetext{
- Program

- Personnel Training and Qualification
} 


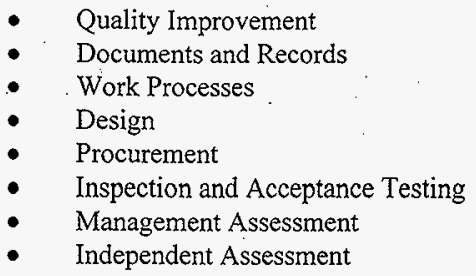

DOE Order 5700.6C, 10 CFR 830.120, and the QAPD requirements are contained in WHC-SD-MP-SRID-001, High-Level Waste Storage Tank Farms / 242-A Evaporator Standards/Requirements Identification Document (S/RID) (TWRS S/RID) (Biebesheimer 1996). The implementation documents cited in the QAPP implementation matrix constitute the TWRS approach for achieving the requirements specified in the FDH QAPD (FDH 1997). The TWRS Retrieval and Disposal Mission is subject to the same implementation documents. The PHMCwide procedures are available electronically on the Hanford Internet; TWRS procedures are available electronically through PROCINFO. In all cases, the current document is the electronic version.

\section{J3.4 AUTHORITIES}

The TWRS Quality Assurance organization reviews and approves engineering documents with "Q" approval designation. The TWRS Quality Assurance Manager has the authority to stop work to ensure compliance with the QAPP (LMHC 1997). Matters concerning quality assurance that cannot be resolved at the normal interfaces must be referred to the Quality Assurance Manager for resolution.

\section{J3.5 WORK ACTIVITIES}

Quality Assurance support to TWRS Operations organizations and the TWRS Retrieval and Disposal Mission consists mainly of level-of-effort activities, with some exceptions where discrete deliverables may be identified. These activities include, but are not limited to:

- Review and, when appropriate, approval of Job Control System packages, Engineering Change Notices, test plans and results, procedures, Tank Sample Analysis Plans, Data Quality Objectives, procurement documents, technical support documents

- Review of analytical results and other data to confirm suitability of waste feed for delivery to private contractor, per ICD requirements.

- Review of process documentation to confirm that immobilized waste complies with ICD and regulatory requirements 
- Oversight of record management activities by others

- Field oversight assessments

- Inspections and field walk downs

- Administration of the nonconforming item reporting process

- Price Anderson Amendments Act screening and reporting

- Collect, analyze, and report quality information

- Maintain QAPP, review and revise implementing procedures

- Program evaluation.

In addition to the above, the TWRS Quality Assurance organization is undertaking an improvement plan conceived to identify specific actions that people in the organization will take to improve their performance and that of the organization as a whole. Continuous process improvement is the theme of this improvement plan. This statement represents a profound change in thinking about how the Quality Assurance organization should do business. It means that Quality Assurance will use continuous process improvement throughout its organization, applying the principle to all internal activities as well as to interaction with other organizations. In this way, the TWRS Quality Assurance organization will first examine its own performance and improve certain areas, and then seek to influence other organizations, to act as an agent of change in creating a quality culture across the TWRS Project.

Implementation of the improvement plan will cause priorities to be reevaluated, with the result that some current activities may no longer be performed. In turn, new activities will be identified as providing greater value to the mission.

\section{J3.6 INTERFACES}

The TWRS Quality Assurance organization interacts with nearly every other TWRS organization in fulfilling its support and oversight roles. Key interfaces include the Operations organizations, the TWRS Retrieval and Disposal Mission, and construction projects. An interface to be developed is that with the private contractors. 


\section{J4.0 EXECUTION STRATEGY}

The TWRS Quality Assurance Program is based on three things: (1) senior management commitment to and vigorous support of the principle of continuous process improvement, which is the central tenet of the TWRS Quality Policy, (2) deployment of this policy by all other managers throughout all TWRS organizations and activities and (3) the TWRS Quality. Assurance organization's function as an agent of change to nurture growth of a strong quality culture within the TWRS Project. TWRS Quality Assurance is working with TWRS Retrieval and Disposal Mission management to develop and implement a quality management system by which the Quality Policy will be deployed.

\section{J4.1 WORK PLANNING AND PRIORITIES}

The multi-year work plan will be used to produce an integrated schedule. The multi-year work plan is based on detailed planning, which includes both support from TWRS Quality Assurance and implementation of quality assurance requirements by all TWRS organizations. The TWRS Quality Assurance organization provides input during annual multi-year work plan planning to ensure appropriate support. A significant portion of Quality Assurance's work consists of level-of-effort support of Operations organizations (i.e. Single-Shell Tank (SST), Double-Shell Tank (DST), Characterization Project Operations, and TWRS Retrieval and Disposal Mission). As such, schedule and deliverables are set and controlled by those organizations. Program and project priorities may change during the year, requiring Quality Assurance management to frequently review requirements and adjust staff assignments. Emerging unplanned work is not uncommon and requires similar attention.

\section{J4.2 RESOURCES}

The TWRS Quality Assurance organization engineers and quality control inspectors are assigned to support different organizations as appropriate for the work being performed. Currently, the majority of the quality staff is assigned to either SST, DST, or Characterization Project Operations, although staff is dedicated to construction projects and to the TWRS Retrieval and Disposal Mission. As the overall TWRS focus shifts from Tank Waste Operations to the TWRS Retrieval and Disposal Mission, the distribution of Quality Assurance resources will be evaluated during the multi-year work plan process and reapportioned as appropriate.

The existing qualification and training process will continue. Technical authorities are assigned on the basis of staff meeting educational and experience requirements. Approval authority of Quality Assurance engineers is based on successful completion of the Quality Assurance Engineer Qualification Program. Quality control inspectors maintain specific certifications (e.g., mechanical, welding, electrical, receipt). 


\section{HNF-1883 Rev 1}

\section{J4.3 WORK IMPLEMENTATION}

Fluor Daniel Hanford, Inc. requires PHMC team members to explain in their respective QAPPs how the requirements of FDH's QAPD (FDH 1997) are applied in a graded manner. The LMHC has chosen to apply quality assurance requirements commensurate primarily with an item's importance to safety. That is, graded application of quality assurance requirements is based primarily on the safety function that a system, structure, or component (SSC) provides. However; sources of quality assurance requirements other than the FDH QAPD (FDH 1977) (e.g., DOE/RW-0333P, Quality Assurance Requirements and Description (QARD) for the Civilian Radioactive Waste Management Program [DOE-OCRWM 1995], ISO 9000, EPA's QAMS 4/5), and contracts or other agreements related to interface with private contractors) are also considered on a case-by-case basis in determining the set of applicable quality assurance requirements.

Each SSC is evaluated and given a designation that relates to the SSC's ability to mitigate or prevent radiological or toxicological exposure to the public, on-site personnel, or workers. That designation then is related to a set of quality assurance requirements that are to be applied. The graded approach not only identifies the relevant quality assurance requirements for a safetyrelated SSC, it also influences the degree and rigor with which the quality assurance requirements are applied.

The program elements of the QAPP (LMHC 1997) as listed in the implementation matrix are applicable for all SSCs for safety-class and safety-significant designations.

The rigor and degree to which the applied requirements are to be implemented is jointly determined by the Design Authority and the cognizant Quality Assurance engineer. The quality assurance measures and controls selected for application to a SSC are chosen to ensure that the $\mathrm{SSC}$ will reliably perform its safety function(s). The rigor and degree of requirements applied from sources other than the FDH QAPD (FDH 1997) are jointly determined, as well.

Drawings, specifications, procedures, and other work instructions will further identify the scope of inspection, oversight, or testing needed to ensure the SSC.conforms to defined acceptance criteria.

\section{J4.4 REQUIREMENTS MANAGEMENT}

Quality assurance requirements for the TWRS Retrieval and Disposal Mission will be identified and managed as part of the TWRS Quality Assurance Program described in the QAPP (LMHC 1997). The QAPP (LMHC 1997) contains an implementation matrix that identifies the ten major elements of the requirements from DOE Order 5700.6C and 10 CFR 830.120, the subelements for each major element as specified in the FDH QAPD (HNF-MP-599), and the associated implementation documents for each of the subelements. The TWRS QAPP (LMHC 1997) is subject to all document and change control requirements. 
HNF-1883 Rev 1

\section{J4.5 ISSUE RESOLUTION}

The TWRS Quality Assurance organization participates in special issue resolution committees: Corrective Action Management Board, Plant Review Committee, Readiness Review teams, and the Senior Review Board for Price Anderson Amendments Act matters. The TWRS Quality Assurance organization administers the nonconforming item reporting process.

Matters concerning quality assurance that cannot be resolved at the normal interfaces must be referred to the Quality Assurance Manager for resolution.

\section{J5.0 REFERENCES}

\section{Code of Federal Regulations}

10 CFR 830.120, "Quality Assurance Requirements," Section 120, "Nuclear Safety Management," Code of Federal Regulations, as amended.

\section{U.S. Department of Energy Orders}

DOE Order 5700.6C, Quality Assurance, U.S. Department of Energy, Washington, D.C.

\section{Documents}

Biebesheimer, E., 1996, High-Level Waste Storage Tank Farms/242-A Evaporator Standards/ . Requirements Identification Document (S/RID), WHC-SD-MP-SRID-001, Rev.1B, Westinghouse Hanford Company, Richland, Washington.

DOE-OCRWM, 1995, Quality Assurance Requirements and Description (QARD) for the Civilian Radioactive Waste Management Program, DOE/RW-0333P, Rev.5, U.S. Department of Energy and Office of Civilian Radioactive Waste Management, Washington, D.C.

QAMS-004, 1980, Guidelines and Specifications for Preparing Quality Assurance Program Plans - USEPA Quality Assurance Management Staff.

QAMS-005, 1980, Interim Guidelines and Specifications for Preparing Quality Assurance Project Plans- USEPA Quality Assurance Management Staff.

FDH, 1997, Project Hanford Quality Assurance Program Description, HNF-MP-599, Rev. 0, Fluor Daniel Hanford, Inc., Richland, Washington.

LMHC, 1997, TWRS Administration, HNF-IP-0842, Fluor Daniel Hanford, Inc., Richland, Washington. 
HNF-1883 Rev 1

APPENDIX K

GUIDANCE AND REQUIREMENTS TO

DELIVERABLES CROSSWALK

K-i 
HNF-1883 Rev 1

This page intentionally left blank.

$\mathrm{K}$-ii 
Table K-l. Guidance and Requirements to Deliverables Crosswalk - TWRS Program Plan.

\begin{tabular}{|c|c|c|}
\hline Guidance or Requirement & Status & Implementing Location \\
\hline $\begin{array}{l}\text { A 1 DOE Letter to H. J Hatch, FDH, from W J } \\
\text { Taylor, DOE, dated August } 8,1997, \# 9757162 \mathrm{~A}(36 \\
\text { ITEM CHECKLIST) }\end{array}$ & 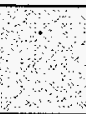 & r \\
\hline $\begin{array}{l}\text { 2. Requirements are identified, validated, and } \\
\text { documented. }\end{array}$ & I & $\begin{array}{l}\text { Section 2.0, Mission references MAR } \\
\text { established mission requirements; } \\
\text { Section 3.0, Requirements, covers } \\
\text { sources and documentation; Section } \\
4.0 \text {, Technical Approach, covers } \\
\text { process; and Section 9.2, Engineering, } \\
\text { covers process }\end{array}$ \\
\hline 3. Requirements are allocated to functions. & $\mathrm{I}$ & $\begin{array}{l}\text { Section 4.0, Technical Approach, } \\
\text { covers process; and Section } 9.2 \\
\text { Engineering, covers process }\end{array}$ \\
\hline $\begin{array}{l}\text { 7. Technical logic are complete at all levels; the } \\
\text { program makes sense logically; and lower level-logic } \\
\text { rolls up properly to higher-level logic. }\end{array}$ & I & $\begin{array}{l}\text { Section 4.0, Technical Approach; } \\
\text { Section 6.0, TWRS Project Logic; and } \\
\text { Section 9.1.1, Program Baseline } \\
\text { Development }\end{array}$ \\
\hline $\begin{array}{l}\text { 8. Operations plans that describe how the PHMC team } \\
\text { will execute the tech baseline have been prepared for all } \\
\text { projects and are supported by lower-tier plans. The } \\
\text { operation plans are consistent with MYWP and LCAM. } \\
\text { Operations and Maintenance plans are integrated. }\end{array}$ & I & $\begin{array}{l}\text { Section } 8.2 .2 \text {, Tank Waste Retrieval } \\
\text { Organization describes the three key } \\
\text { plans prepared for Waste Feed } \\
\text { Delivery, Infrastructure and } \\
\text { Immobilization, and Waste Storage } \\
\text { and Disposal. Plans exist and are } \\
\text { consistent with MYWP and LCAM. }\end{array}$ \\
\hline $\begin{array}{l}\text { 12. Infrastructure support plan and implementing } \\
\text { actions and procedures are on track. }\end{array}$ & $\mathrm{I}$ & $\begin{array}{l}\text { Sections } 8.2 .2 .5 \text {, Infrastructure } \\
\text { Support describes responsibilities and } \\
\text { refers reader to Infrastructure Program } \\
\text { Plan. }\end{array}$ \\
\hline 17. The technical baseline under configuration control. & I & $\begin{array}{l}\text { Section 9.6, Configuration } \\
\text { Management describes Configuration } \\
\text { Management and refers reader to } \\
\text { Configuration Management Plan for } \\
\text { details. Section 9.1, Business } \\
\text { Operations discusses configuration } \\
\text { control. }\end{array}$ \\
\hline $\begin{array}{l}\text { 21. The ability of the PHMC team to support } \\
\text { alternatives other than the baseline has been evaluated } \\
\text { from a technical perspective. }\end{array}$ & I & $\begin{array}{l}\text { Section } 9.2 .4 \text {, Alternatives, discusses } \\
\text { requirement to analyze alternatives. }\end{array}$ \\
\hline
\end{tabular}


Table K-1. Guidance and Requirements to Deliverables Crosswalk - TWRS Program Plan.

\begin{tabular}{|c|c|c|}
\hline Guidance or Requirement & Status & Implementing Location \\
\hline $\begin{array}{l}\text { 28. The programmatic baseline is under configuration } \\
\text { management and a change control system is } \\
\text { implemented. }\end{array}$ & I & $\begin{array}{l}\text { Section 9.6, Configuration } \\
\text { Management describes Configuration } \\
\text { Management and refers reader to } \\
\text { Configuration Management Plan for } \\
\text { details. Section 9.1, Business } \\
\text { Operations discusses configuration } \\
\text { control. }\end{array}$ \\
\hline $\begin{array}{l}\text { 29. The ability to support alternatives other than the } \\
\text { baseline has been evaluated from a programmatic } \\
\text { perspective. }\end{array}$ & I & $\begin{array}{l}\text { Section 9.2.4, Alternatives } \\
\text { Management }\end{array}$ \\
\hline $\begin{array}{l}\text { 30. Management systems are in place to track and } \\
\text { report cost, schedule, and technical performance and } \\
\text { take appropriate corrective actions. }\end{array}$ & I & $\begin{array}{l}\text { Section 9.0, Management Approach; } \\
\text { and Section 9.1.3, Performance } \\
\text { Measures and Reporting }\end{array}$ \\
\hline $\begin{array}{l}\text { 31. Program planning encompasses all organizations } \\
\text { and facilities, including support, that contribute to the } \\
\text { mission. }\end{array}$ & I & $\begin{array}{l}\text { Section } 8.2, \text { Roles and } \\
\text { Responsibilities; and Section 9.1.1, } \\
\text { Program Baseline Development } \\
\text { Planning }\end{array}$ \\
\hline 33. Staff, including managers, are in place and trained. & $\mathrm{I}$ & $\begin{array}{l}\text { Section 9.8, Staffing and Personnel } \\
\text { Training/Qualification }\end{array}$ \\
\hline $\begin{array}{l}\text { 34. A records management program, including } \\
\text { technical drawings, has been implemented. }\end{array}$ & I & $\begin{array}{l}\text { Section } 9.6, \text { Configuration } \\
\text { Management describes systems used } \\
\text { to support Configuration Management } \\
\text { and these systems include records } \\
\text { management }\end{array}$ \\
\hline $\begin{array}{l}\text { 35. A risk and decision management program has been } \\
\text { implemented at all levels. }\end{array}$ & $I$ & $\begin{array}{l}\text { Section 9.4, Decision Management, } \\
\text { and Section 9.5, Risk Management }\end{array}$ \\
\hline $\begin{array}{l}\text { A2 DOE Tetter to H I Hatch, } \mathrm{FDH} \text { from W J } \\
\text { aylor, DOE dated August } 8,1997,19757162 \mathrm{~A} \\
\text { (BODYOF TEXT) }\end{array}$ & & 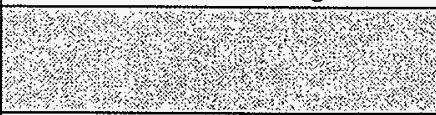 \\
\hline $\begin{array}{l}\text { General PHMC Responsibilities from RL's } 8 / 8 / 97 \\
\text { letter, Section } 2.1\end{array}$ & & \\
\hline $\begin{array}{l}\text { 2. Develop a resource-loaded, logic driven schedule, } \\
\text { including critical path }\end{array}$ & I & $\begin{array}{l}\text { Section 4.0, Technical Approach, } \\
\text { Section 6.0, TWRS Program Logic, } \\
\text { and Section 7.0, TWRS Program } \\
\text { Schedule all discuss process and } \\
\text { progress on developing logics. }\end{array}$ \\
\hline
\end{tabular}


Table K-1. Guidance and Requirements to Deliverables Crosswalk - TWRS Program Plan.

\begin{tabular}{|c|c|c|}
\hline Guidance or Requirement & Status & Implementing Location \\
\hline 3. An executable programmatic baseline exists & $\mathrm{I}$ & $\begin{array}{l}\text { Section 4.0, Technical Approach; } \\
\text { Section 6.0, TWRS Program Logic all } \\
\text { discuss process to develop executable } \\
\text { program Baseline; and Section 9.1.1, } \\
\text { Program Baseline Development }\end{array}$ \\
\hline $\begin{array}{l}\text { 6. Critical path analysis is done to determine the } \\
\text { impacts of budget shortfalls on the programmatic } \\
\text { baseline }\end{array}$ & $\mathrm{I}$ & $\begin{array}{l}\text { Section 9.1.1, Program Baseline } \\
\text { Development Planning, discusses this } \\
\text { subject }\end{array}$ \\
\hline $\begin{array}{l}\text { 7. The technical and programmatic baselines are under } \\
\text { configuration management }\end{array}$ & I & $\begin{array}{l}\text { Section 9:6, Configuration } \\
\text { Management, and Section 9.1.1, } \\
\text { Program Baseline Development, } \\
\text { discusses configuration management } \\
\text { and refers reader to the Configuration } \\
\text { Management Plan for details. }\end{array}$ \\
\hline $\begin{array}{l}\text { 8. Management systems and program controls are } \\
\text { established }\end{array}$ & $\mathrm{I}$ & $\begin{array}{l}\text { Section 9.0, Management Approach } \\
\text { and Section 9.1.3 Performance } \\
\text { Measures and Reporting discuss the } \\
\text { various management systems that are } \\
\text { in place. }\end{array}$ \\
\hline $\begin{array}{l}\text { 9. A risk management program exists and includes } \\
\text { evaluation of performance and reporting of that } \\
\text { performance to DOE }\end{array}$ & I & \begin{tabular}{|l|} 
Section 9.5, Risk Management, \\
discusses process and refers reader to \\
Risk Management Plan for details. \\
\end{tabular} \\
\hline 10. Performance measures can be integrated into plans & I & $\begin{array}{l}\text { Section 9.1.3.1, Performance Measures } \\
\text { and Reporting }\end{array}$ \\
\hline 11. PHMC programs are coordinated & I & $\begin{array}{l}\text { Section 9.7, Interface Management, } \\
\text { discusses approach to physical, } \\
\text { functional, and organizational } \\
\text { interfaces. }\end{array}$ \\
\hline $\begin{array}{l}\text { Specific Responsibility from RL's August 8, } 1997 \\
\text { letter, Section } 2.2\end{array}$ & . & \\
\hline $\begin{array}{l}\text { 6. Self Assessment functional areas are identified for } \\
\text { assessment for readiness-to-proceed }\end{array}$ & $\mathrm{I}$. & $\begin{array}{l}\text { Section 9.1.3.4, Continuous Process } \\
\text { Improvement describes commitment } \\
\text { of all organizations to self-assessment } \\
\text { processes. }\end{array}$ \\
\hline $\begin{array}{l}\text { 7. All required administrative actions are understood } \\
\text { and planned }\end{array}$ & $\mathrm{I}$ & $\begin{array}{l}\text { Section 9.0, Management Approach, } \\
\text { discusses overall approach to } \\
\text { addressing mission requirements } \\
\text { including required administrative } \\
\text { actions required. }\end{array}$ \\
\hline
\end{tabular}


Table K-1. Guidance and Requirements to Deliverables Crosswalk - TWRS Program Plan.

\begin{tabular}{|c|c|c|}
\hline \multirow{2}{*}{$\begin{array}{l}\text { Guidance or Requirement } \\
\text { A3 DoE Letter H I Hatch, FDH, from William J. } \\
\text { Taylor, DOE, dated December } 2,1997, \$ 9761291\end{array}$} & Status & Implementing Location \\
\hline & & अ \\
\hline \multicolumn{3}{|l|}{$\begin{array}{l}\text { 5. Provide specific information to address the ten areas } \\
\text { in Paragraph } 4.2 .4 \text { of the August } 8 \text { DOE letter of } \\
\text { direction }\end{array}$} \\
\hline $\begin{array}{l}\text { j. Deliver to DOE or make available for DOE review, } \\
\text { Draft Program Plans }\end{array}$ & 1 & $\begin{array}{l}\text { Section 8.2.2, Tank Waste Retrieval } \\
\text { Organization, discusses need to } \\
\text { maintain close interface with FDH } \\
\text { counterparts to ensure expectations are } \\
\text { met. TWRS Program Plan and } \\
\text { subordinate plans are RTP } \\
\text { Deliverables. } \\
\end{array}$ \\
\hline $\begin{array}{l}\text { 6. RTP deliverables and their support must address the } \\
\text { readiness of supporting facilities outside of TWRS, and } \\
\text { understand FDH's readiness to receive secondary } \\
\text { wastes. }\end{array}$ & I & $\begin{array}{l}\text { Section 9.7, Interface Management, } \\
\text { discusses the interfaces that will be } \\
\text { part of the TWRS project and the } \\
\text { process to control them. }\end{array}$ \\
\hline $\begin{array}{l}\text { 9. Identify the decisions that are being deferred, when } \\
\text { they are projected to be finalized and the assumptions } \\
\text { relating to those decisions. }\end{array}$ & I & $\begin{array}{l}\text { Section 9.4, Decision Management, } \\
\text { describes processes for decision- } \\
\text { making and refers reader to SEMP and } \\
\text { Decision Management procedure } \\
\text { where details reside. }\end{array}$ \\
\hline \multicolumn{3}{|l|}{$\begin{array}{l}\text { 11. Make a QA plan available for DOE review in } \\
\text { January. }\end{array}$} \\
\hline a. Address implementing procedures (of the QA Plan) & $\mathrm{I}$ & $\begin{array}{l}\text { Section 9.3.3, ISMS/QA, describes } \\
\text { process and refers reader to QAPP } \\
\text { which includes a flow down matrix } \\
\text { (requirements to procedures) }\end{array}$ \\
\hline $\begin{array}{l}\text { B } 1 \text { DOE Order } 401 \text { Good practice Guide, GPG- } \\
\mathrm{FM} 002\end{array}$ & & 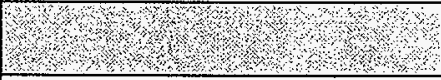 \\
\hline \multicolumn{3}{|l|}{ 2.2.1 DOE Strategic Plan } \\
\hline 1. Program Strategic Plan & $\mathrm{I}$ & $\begin{array}{l}\text { Sections 9.1.1, Program Baseline } \\
\text { Development, and Section 9.2.1, } \\
\text { Systems Engineering, describe how } \\
\text { program Baseline has been developed } \\
\text { using the Hanford Strategic Plan as a } \\
\text { driver. }\end{array}$ \\
\hline \multicolumn{3}{|l|}{ 2.2.5 Baseline: Schedule Criteria } \\
\hline 1. Milestones & I & Section 7.0 \\
\hline 2.2.6 ES\&H Program Plan & I & Section 9.3 .3 and appendices \\
\hline
\end{tabular}


Table K-1. Guidance and Requirements to Deliverables Crosswalk - TWRS Program Plan.

\begin{tabular}{|l|c|l|}
\hline \multicolumn{1}{|c|}{ Guidance or Requirement } & Status & \multicolumn{1}{|c|}{ Implementing Location } \\
\hline 2.2.7 Project Risk Criteria & I & $\begin{array}{l}\text { Section 9.5, Risk Management, covers } \\
\text { process }\end{array}$ \\
\hline 2.2.8 Acquisition Strategy Criteria & I & Section 9.1.2, Acquisition Strategy \\
\hline 1. Diversity & I & Section 9.1.2, Acquisition Strategy \\
\hline 2. Contracting Methods & I & Section 9.1.2, Acquisition Strategy \\
\hline 2.2.9 Project Management Criteria & . & \\
\hline 1. Organizational Planning & I & Section 8.0, Organization \\
\hline 2.2.10 Stakeholder Considerations & I & Section 9.9, Stakeholder Affairs \\
\hline 2.3.2 Funding Profile & I & $\begin{array}{l}\text { Section 9.1.1, Program Baseline } \\
\text { Development refers to HNF-1946, } \\
\text { TWRS Retrieval and Disposal Mission } \\
\text { Initial Updated Baseline Summary }\end{array}$ \\
\hline 2.3.3 Baseline: Work Scope (Technical) Criteria & . & \\
\hline 1. QA Requirements & I & Section 9.3, ISMS, and Appendix J \\
\hline 2.3.6 Environment, Safety and Health Criteria & . & \\
\hline 1. Safety Analysis & I & $\begin{array}{l}\text { Section 8.2.1.3, Technical Operations, } \\
\text { and Appendix F }\end{array}$ \\
\hline 2. Permits, Licenses, and Regulatory Approval & I & $\begin{array}{l}\text { Section 8.2.1, Technical Operations, } \\
\text { and Appendix F }\end{array}$ \\
\hline 2.3.7 Project Risk Criteria & . & \\
\hline 1. Risk Assessment & I & Section 9.5, Risk Management \\
\hline 2. Risk Management & I & Section 9.5, Risk Management \\
\hline 2.3.8 Acquisition Strategy & I & Section 9.1.2, Acquisition Strategy \\
\hline 1. Diversity & I & Section 9.1.2, Acquisition Strategy \\
\hline 2. Partnering & I & Section 9.1.2, Acquisition Strategy \\
\hline 3. Contracting Methods & I & Section 9.1.2, Acquisition Strategy \\
\hline 4. Procurement & I & Section 9.1.2, Acquisition Strategy \\
\hline 2.3.9 Project Management Criteria & . & \\
\hline 1. Project Planning Documentation & I & $\begin{array}{l}\text { Section 9.0, Management Approach, } \\
\text { and Section 9.2.1, Systems } \\
\text { Engineering }\end{array}$ \\
\hline 2. Baseline Change Control & I & $\begin{array}{l}\text { Section 9.6, Configuration } \\
\text { Management }\end{array}$ \\
\hline
\end{tabular}


Table K-1. Guidance and Requirements to Deliverables Crosswalk - TWRS Program Plan.

\begin{tabular}{|c|c|c|}
\hline Guidance or Requirement & Status & Implementing Location \\
\hline 5. Contingency Management & I & $\begin{array}{l}\text { If contingency exists under LMHC } \\
\text { control, on other than projects, it will } \\
\text { be managed through a formal change } \\
\text { methodology as is done on projects. }\end{array}$ \\
\hline 2.3.10 Stakeholder Considerations & I & Section 9.9, Stakeholder Affairs \\
\hline 1. Stakeholders & $I$ & Section 9.9, Stakeholder Affairs \\
\hline 2. Public Participation & I & Section 9.9, Stakeholder Affairs \\
\hline \multicolumn{3}{|l|}{ 2.4.3 Work Scope (Technical) Criteria } \\
\hline $\begin{array}{l}\text { 1. Performance measures (see Contracting } \\
\text { Options/Acquisition Resource Planning/Application of } \\
\text { Performance Measures, GPG-FM-020). }\end{array}$ & $\mathrm{I}$ & Section 9.1.3, Performance Measures \\
\hline \multicolumn{3}{|l|}{ 2.4.5 Baseline: Schedule Criteria } \\
\hline 3. Thresholds & I & $\begin{array}{l}\text { Section } 9.6, \text { Configuration } \\
\text { Management discusses critical aspects } \\
\text { of change control thresholds and refers } \\
\text { to the Configuration Management Plan }\end{array}$ \\
\hline 2.4.6 Environment, Safety and Health Criteria & $\therefore$ & \\
\hline 3. D\&D Plans & I & $\begin{array}{l}\text { This subject will be addressed in a } \\
\text { later revision to program plan (not part } \\
\text { of Phase 1B). }\end{array}$ \\
\hline 2.4.8 Acquisition Strategy & 1 & Section 9.1.2, Acquisition Strategy \\
\hline 1. Diversity & $I$ & Section 9.1.2, Acquisition Strategy \\
\hline 2. Contracting Methods & $I$ & Section 9.1.2, Acquisition Strategy \\
\hline 2.4.9 Project Management & . & \\
\hline 1. Project Planning Documentation & I & $\begin{array}{l}\text { Section 9.0, Management Approach, } \\
\text { and Section 9.2.1, Systems } \\
\text { Engineering }\end{array}$ \\
\hline 2. Baseline Change Control & I & $\begin{array}{l}\text { Section 9.6, Configuration } \\
\text { Management }\end{array}$ \\
\hline 2.4.10 Stakeholder Considerations & 1 & Section 9.9, Stakeholder Affairs \\
\hline 2.5.3 Baseline Workscope Technical Criteria & I & Entire Document \\
\hline 2.5.6 Environment, Safety and Health Criteria & $\cdot$ & \\
\hline 1. Safety Analysis & I & $\begin{array}{l}\text { Section 8.2.1.3, Technical Operations, } \\
\text { and Appendix F }\end{array}$ \\
\hline 2. Occupational Safety Concerns & I & $\begin{array}{l}\text { Section 8.2.1.3, Technical Operations, } \\
\text { and Appendix F }\end{array}$ \\
\hline
\end{tabular}


Table K-1. Guidance and Requirements to Deliverables Crosswalk - TWRS Program Plan.

\begin{tabular}{|c|c|c|}
\hline Guidance or Requirement & Status & Implementing Location \\
\hline 3. D\&D Plans & I & $\begin{array}{l}\text { This subject will be addressed in a } \\
\text { later revision to program plan (not part } \\
\text { of Phase 1B). }\end{array}$ \\
\hline 2.5.9 Project Management & . & \\
\hline 1. Configuration Management & $\mathrm{I}$ & $\begin{array}{l}\text { Section } 9.7, \text { Configuration } \\
\text { Management }\end{array}$ \\
\hline 2.5.10 Stakeholder Considerations & $I$ & Section 9.9, Stakeholder Affairs \\
\hline 1. Public Participation & $\mathrm{I}$. & Section 9.9, Stakeholder Affairs \\
\hline $\begin{array}{l}\text { B } 2 \text { DOE Order } 4251 \text {, Start Up and Restart of } \\
\text { Nuclear Facilities, section } 4 \text { d }(1)(20)\end{array}$ & 4 & 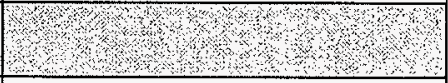 \\
\hline $\begin{array}{l}425.1 \text { Core Requirement (1) - Procedures and Safety } \\
\text { Limits }\end{array}$ & I & $\begin{array}{l}\text { Appendix A, Maintenance and } \\
\text { Appendix B Operations }\end{array}$ \\
\hline $\begin{array}{l}425.1 \text { Core Requirement (2) - Training and } \\
\text { Qualification }\end{array}$ & $\mathrm{I}$ & $\begin{array}{l}\text { Section 9.8, Staffing, and Appendices } \\
\text { A and B }\end{array}$ \\
\hline $\begin{array}{l}425.1 \text { Core Requirement (3) - Operations Level of - } \\
\text { Knowledge }\end{array}$ & I & Section 9.8, Staffing \\
\hline $\begin{array}{l}\text { 425.1 Core Requirement (6) - Audit Deficiency } \\
\text { Resolution }\end{array}$ & I & Section 9.0, Management Approach \\
\hline $\begin{array}{l}425.1 \text { Core Requirement (8) - Management Programs } \\
\text { are established; Personnel and Supporting Personnel are } \\
\text { Adequate }\end{array}$ & I & Section 9.8, Staffing \\
\hline $\begin{array}{l}\text { 425.1 Core Requirement (9) - Routine and Emergency } \\
\text { Operations Drill Program }\end{array}$ & I & Appendix $\mathrm{H}$ \\
\hline $\begin{array}{l}425.1 \text { Core Requirement (11) - Functions; } \\
\text { Assignments; Responsibilities; Relationships } \\
\end{array}$ & I & $\begin{array}{l}\text { Section } 8.0, \text { Organization, and all } \\
\text { appendices }\end{array}$ \\
\hline 425.1 Core Requirement (12) - Conduct of Operations & 1 & Appendix B, Operations \\
\hline $\begin{array}{l}\text { 425.1 Core Requirement (13) - Personnel } \\
\text { Qualifications }\end{array}$ & I & Section 9.8, Staffing \\
\hline $\begin{array}{l}425.1 \text { Core Requirement (14) - ES\&H Site-Wide } \\
\text { Safety Culture }\end{array}$ & I & Section 9.3, ISMS, and Appendix H \\
\hline $\begin{array}{l}\text { 425.1 Core Requirement (17) - Adequacy of Contractor } \\
\text { Operational Readiness Review }\end{array}$ & I & Appendices $\mathrm{B}$ and $\mathrm{G}$. \\
\hline $\begin{array}{l}425.1 \text { Core Requirement (18) - Procedures and } \\
\text { Training Reflect Actual Facility }\end{array}$ & I & $\begin{array}{l}\text { Section 9.6, Configuration } \\
\text { Management, and Appendix B }\end{array}$ \\
\hline $\begin{array}{l}\text { 425.1 Core Requirement (19) - Technical and } \\
\text { Management Qualifications for Operations of the } \\
\text { Facility are Adequate }\end{array}$ & I & Section 9.8 , Staffing \\
\hline Clanterface Control Documents & 8 & 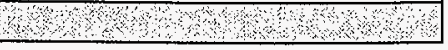 \\
\hline
\end{tabular}


Table K-1. Guidance and Requirements to Deliverables Crosswalk - TWRS Program Plan.

\begin{tabular}{|c|c|c|}
\hline Guidance or Requirement & Status & Implementing Location \\
\hline 1. Raw Water & . & \\
\hline $\begin{array}{l}\text { 7. Notify the Contractor in advance of scheduled } \\
\text { interruption of services. }\end{array}$ & I & $\begin{array}{l}\text { Section } 9.7 \text {, Interface Management } \\
\text { covers how we operate }\end{array}$ \\
\hline 2. Potable Water & . & \\
\hline $\begin{array}{l}\text { 5. Notify the Contractor in advance of scheduled } \\
\text { interruption of services. }\end{array}$ & $\mathrm{I}$ & $\begin{array}{l}\text { Section } 9.7 \text {, Interface Management } \\
\text { covers how we operate }\end{array}$ \\
\hline 3. Radioactive Solid Wastes & . & \\
\hline $\begin{array}{l}\text { 6. Notify the Contractor in advance of scheduled } \\
\text { interruption of services. }\end{array}$ & 1 & $\begin{array}{l}\text { Section 9.7, Interface Management } \\
\text { covers how we operate }\end{array}$ \\
\hline 5. Non-Radioactive, Non-Dangerous Liquid Effluents & . & \\
\hline $\begin{array}{l}\text { 5. Notify the Contractor in advance of scheduled } \\
\text { interruption of services. }\end{array}$ & I & $\begin{array}{l}\text { Section } 9.7 \text {, Interface Management } \\
\text { covers how we operate }\end{array}$ \\
\hline 6. Radioactive, Dangerous Liquid Effluents & . & \\
\hline $\begin{array}{l}\text { 8. Notify the Contractor in advance of scheduled } \\
\text { interruption of services. }\end{array}$ & I & $\begin{array}{l}\text { Section } 9.7, \text { Interface Management } \\
\text { covers how we operate }\end{array}$ \\
\hline 11. Electricity & . & \\
\hline $\begin{array}{l}\text { 5. Notify the Contractor in advance of scheduled } \\
\text { interruption of services. }\end{array}$ & $\mathrm{I}$ & $\begin{array}{l}\text { Section 9.7, Interface Management } \\
\text { covers how we operate }\end{array}$ \\
\hline 12. Roads and Rails & . & \\
\hline $\begin{array}{l}\text { 4. Notify the Contractor in advance of scheduled } \\
\text { interruption of services. }\end{array}$ & $\mathrm{I}$ & $\begin{array}{l}\text { Section } 9.7 \text {, Interface Management } \\
\text { covers how we operate }\end{array}$ \\
\hline 13. Non-Routine High-Level Solid Wastes & . & \\
\hline $\begin{array}{l}\text { 7. Notify the Contractor in advance of scheduled } \\
\text { interruption of services. }\end{array}$ & $\mathrm{I}$ & $\begin{array}{l}\text { Section } 9.7 \text {, Interface Management } \\
\text { covers how we operate }\end{array}$ \\
\hline 14. Immobilized High-Level Waste & $\therefore$ & \\
\hline $\begin{array}{l}\text { 6. Notify the Contractor in advance of scheduled } \\
\text { interruption of services. }\end{array}$ & I & $\begin{array}{l}\text { Section } 9.7 \text {, Interface Management } \\
\text { covers how we operate }\end{array}$ \\
\hline 15. Immobilized Low-Activity Waste & $\dot{-}$ & \\
\hline $\begin{array}{l}\text { 6. Notify the Contractor in advance of scheduled } \\
\text { interruption of services. }\end{array}$ & I & $\begin{array}{l}\text { Section 9.7, Interface Management } \\
\text { covers how we operate }\end{array}$ \\
\hline 16. 90Strontium/Transuranics/Entrained Solids & . & \\
\hline $\begin{array}{l}\text { 2. Notify the Contractor in advance of scheduled } \\
\text { interruption of services. }\end{array}$ & 1 & $\begin{array}{l}\text { Section } 9.7 \text {, Interface Management } \\
\text { covers how we operate }\end{array}$ \\
\hline 17. 137Cesium & . & \\
\hline $\begin{array}{l}\text { 6. Notify the Contractor in advance of scheduled } \\
\text { interruption of services. }\end{array}$ & I & $\begin{array}{l}\text { Section } 9.7 \text {, Interface Management } \\
\text { covers how we operate }\end{array}$ \\
\hline
\end{tabular}


Table K-1. Guidance and Requirements to Deliverables Crosswalk - TWRS Program Plan.

\begin{tabular}{|c|c|c|}
\hline Guidance or Requirement & Status & Implementing Location \\
\hline $\begin{array}{l}\text { D. } 1 \text { Betailed Instructions for Assessment of RTP }- \\
\text { Appendix C, November } 14,1997,\end{array}$ & & moln \\
\hline $\begin{array}{l}\text { 12. Identify projects that directly support infrastructure, } \\
\text { based on project plans. }\end{array}$ & I & $\begin{array}{l}\text { Section } 8.2 .2, \text { Tank Waste Retrieval } \\
\text { Organization and referenced } \\
\text { Infrastructure Plan }\end{array}$ \\
\hline $\begin{array}{l}\text { 14. Show what contractual arrangements have been } \\
\text { made with Team Organizations for support. }\end{array}$ & 1 & $\begin{array}{l}\text { Support will be covered under current } \\
\text { (or modified) contracts which are } \\
\text { available. }\end{array}$ \\
\hline $\begin{array}{l}\text { 19. Describe the PHMC Team's risk management } \\
\text { program and show it will be used to support the } \\
\text { privatization contractor(s). }\end{array}$ & $\mathrm{I}$ & Section 9.5, Risk Management \\
\hline $\begin{array}{l}\text { 26. Describe the PHMC Team's administrative } \\
\text { procedures regarding the ability to support private } \\
\text { contractors. }\end{array}$ & I & $\begin{array}{l}\text { Section } 9.0, \text { Management Approach, } \\
\text { describes functional support which } \\
\text { will cover what we have to do. All } \\
\text { appendices also support this criteria }\end{array}$ \\
\hline $\begin{array}{l}\text { 27. Describe the PHMC Team's personnel } \\
\text { qualifications regarding the ability to support private } \\
\text { contractors. }\end{array}$ & $\mathrm{I}$ & Section 9.8 , Staffing \\
\hline $\begin{array}{l}\text { 29. Describe the PHMC Team's training programs } \\
\text { regarding the ability to support private contractors. }\end{array}$ & I & Section 9.8, Staffing \\
\hline 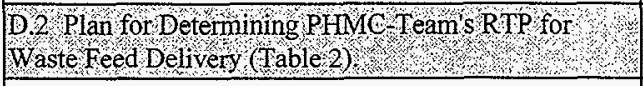 & & \\
\hline \multicolumn{3}{|l|}{$\begin{array}{l}\text { PHMC provide deliverables necessary to support RTP, } \\
\text { as follows: }\end{array}$} \\
\hline 1. TWD Program Plan & $I$ & $\begin{array}{l}\text { Program Plan describes documents } \\
\text { needed for RTP. }\end{array}$ \\
\hline 2. TWD Manuals & 1 & $\begin{array}{l}\text { Program Plan describes documents } \\
\text { needed for RTP. }\end{array}$ \\
\hline 5. PHMC Management and Planning & I & $\begin{array}{l}\text { Program Plan describes documents } \\
\text { needed for RTP. }\end{array}$ \\
\hline 16. Updated Program Documents/Plans & I & $\begin{array}{l}\text { Program Plan describes documents } \\
\text { needed for RTP. }\end{array}$ \\
\hline 33. PHMC-Team Work Packages & I & $\begin{array}{l}\text { Program Plan describes documents } \\
\text { needed for RTP. }\end{array}$ \\
\hline 38. PHMC Team Decision Support Documentation & $I$ & To be provided with RTP package \\
\hline $\begin{array}{l}\text { Q.3 Plan for Determining PHMC Teams RTP for } \\
\text { Waste Feed Delivery - Bocument Checklist (Table } 3 \text { ) }\end{array}$ & & W. \\
\hline
\end{tabular}


Table K-1. Guidance and Requirements to Deliverables Crosswalk - TWRS Program Plan.

\begin{tabular}{|c|c|c|}
\hline Guidance or Requirement & Status & Implementing Location \\
\hline $\begin{array}{l}\text { 41. Plans describe PHMC's admin. functions of the } \\
\text { retrieval project and feed delivery subproject., incl. } \\
\text { mgmt. oversight, detailed planning, MYWP and PBS } \\
\text { prep., performance reporting, records mgmt, personnel } \\
\text { management, QA, tech. integration, \& interface with } \\
\text { regulators/DOE. }\end{array}$ & I & Section 9.0, Management Approach \\
\hline $\begin{array}{l}\text { 42. Plans describe PHMC's M\&I activities for the } \\
\text { PHMC Tank Waste Division, incl. program mgmt, EM- } \\
30 / 50 \text { interface support, PBS program logic/WBS, } \\
\text { interface with Hanford Mast Baseline Scheduling, dev. } \\
\text { of risk dec. mgmt program, PHMC Program Plan, } \\
\text { System Engineering Interface Plan, QAPP, \& Part B } \\
\text { App support. }\end{array}$ & $\mathrm{I}$ & $\begin{array}{l}\text { Section } 4.0, \text { Technology and Section } \\
\text { 9.0, Management Approach }\end{array}$ \\
\hline $\begin{array}{l}\text { 50. Plans describe PHMC managing the interface } \\
\text { during prep of Phase } 1 \text { feed envelope } w / \text { Waste } \\
\text { Processing Project. }\end{array}$ & $\mathrm{I}$ & Section 9.7, Interface Management \\
\hline $\begin{array}{l}\text { 66. Plans include PHMC admin of the TWR Project } \\
\text { and the SST and DST closure subprojects, incl. mgmt. } \\
\text { oversight, detailed planning, MYWP and PBS prep., } \\
\text { performance reporting, records mgmt, personnel } \\
\text { management, QA, tech. integration, \& interface with } \\
\text { regulators/DOE. }\end{array}$ & I & $\begin{array}{l}\text { Section 9.0, Management Approach } \\
\text { and appendices }\end{array}$ \\
\hline $\begin{array}{l}\text { D } 4 \text { PHMCRTP Approach for the Evaluation of } \\
\text { dininistrative Readiness December } 4,1997 \text {. }\end{array}$ & & 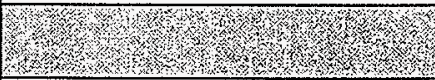 \\
\hline $\begin{array}{l}\text { 1. Organizational Maturity - Indicate or show evidence } \\
\text { of the following: }\end{array}$ & & \\
\hline $\begin{array}{l}\text { e. Work is planned and implemented to accomplish the } \\
\text { strategic objectives. }\end{array}$ & I & $\begin{array}{l}\text { Section 9.1.1, Program Baseline } \\
\text { Development and Section } 9.2 .2 \text {, } \\
\text { Systems Engineering. Both cover } \\
\text { defining work on basis of strategic } \\
\text { objective. }\end{array}$ \\
\hline $\begin{array}{l}\text { f. Continuous improvement occurs based on feedback, } \\
\text { outside information and analysis. }\end{array}$ & I & $\begin{array}{l}\text { Section 9.1.3.4, Continuous Process } \\
\text { Improvement }\end{array}$ \\
\hline $\begin{array}{l}\text { 2. Direction - Direction includes having a clearly- } \\
\text { defined purpose, considering alternative approaches for } \\
\text { success, and having definition of the desired.technical } \\
\text { and cultural end state. }\end{array}$ & I & $\begin{array}{l}\text { Section 2.0, Mission, references MAR, } \\
\text { Section } 9.2 .2 \text {, Systems Engineering, } \\
\text { describes process including alternative } \\
\text { approaches, Section } 9.2 .4 \text {, Alternative } \\
\text { Management }\end{array}$ \\
\hline
\end{tabular}


Table K-1. Guidance and Requirements to Deliverables Crosswalk - TWRS Program Plan.

\begin{tabular}{|c|c|c|}
\hline Guidance or Requirement & Status & Implementing Location \\
\hline $\begin{array}{l}\text { 3. Sponsorship - Sponsorship begins with the DOE } \\
\text { Richland Operations Office Manager, flows to the } \\
\text { PHMC/PHMC Team, to the integrated contractors and } \\
\text { ends where the work is actually performed. }\end{array}$ & I & $\begin{array}{l}\text { Section 8.0, Organization and Section } \\
9.0 \text {, Management Approach }\end{array}$ \\
\hline $\begin{array}{l}\text { 4. Ownership - Systems, processes and behaviors } \\
\text { promote outcome-ownership, buy-in of the approach to } \\
\text { achieve the outcome, commitment to success and } \\
\text { individual involvement. }\end{array}$ & I & $\begin{array}{l}\text { Section 9.0, Management Approach } \\
\text { and appendices }\end{array}$ \\
\hline $\begin{array}{l}\text { 5. Planning and Implementation - Mature planning } \\
\text { management considers customer's needs, determines } \\
\text { org priorities, defines technical approaches, establishes } \\
\text { schedules, and develops annual and long-term budgets } \\
\text { in order to accomplish objectives. }\end{array}$ & I & Section 9.0, Management Approach \\
\hline $\begin{array}{l}\text { 6. Planning and Implementation - Mature planning } \\
\text { recognizes the impacts of proposed actions on the } \\
\text { business elements and culture. }\end{array}$ & $\overline{\mathrm{I}}$ & Section 9.0, Management Approach \\
\hline $\begin{array}{l}\text { 7. Continuous Improvement - Feedback provides } \\
\text { information for course correction to meet strategic } \\
\text { objectives. }\end{array}$ & I & $\begin{array}{l}\text { Section 9.1.3.4, Continuous Process } \\
\text { Improvement }\end{array}$ \\
\hline $\begin{array}{l}\text { 11. Administrative Processes - The necessary } \\
\text { management processes exist and the PHMC Team is } \\
\text { likely to achieve the TWRS goals using them. }\end{array}$ & $\mathrm{I}$ & $\begin{array}{l}\text { Section 9.0, Management Approach } \\
\text { describes key administrative processes } \\
\text { in place }\end{array}$ \\
\hline $\begin{array}{l}\text { 13. Records Management - TWRS uses clearly defined } \\
\text { and documented operating processes for managing } \\
\text { records, with effective process features regarding } \\
\text { content, distribution, timeliness, retrievability, } \\
\text { availability and pertinent data. }\end{array}$ & $I$ & $\begin{array}{l}\text { Section 9.6, Configuration } \\
\text { Management describes process; } \\
\text { identifies records management as } \\
\text { critical element, and refers reader to } \\
\text { Configuration Management Plan for } \\
\text { details. }\end{array}$ \\
\hline $\begin{array}{l}\text { 14. Issues \& Decision Management - Issues are } \\
\text { identified, analyzed and prioritized and resolved as } \\
\text { decisions to ensure that the strategic objectives are } \\
\text { defined and achieved. }\end{array}$ & $\mathrm{I}$ & Section 9.4, Decision Management \\
\hline $\begin{array}{l}\text { 15. Project Control Management Systems - Project } \\
\text { control systems provide all levels of management with } \\
\text { reliable and consistent assessment of work planned and } \\
\text { completed. }\end{array}$ & I & $\begin{array}{l}\text { Section 9.1.4, Management Systems } \\
\text { and Section 9.2, Management } \\
\text { Approach }\end{array}$ \\
\hline $\begin{array}{l}\text { 16. Project Control Management Systems - Project } \\
\text { control systems support forecasting activities needed to } \\
\text { generate estimates of cost-at-completion and schedule } \\
\text { projections. }\end{array}$ & I & $\begin{array}{l}\text { Sections 9.1.1, Program Baseline } \\
\text { Development }\end{array}$ \\
\hline
\end{tabular}


Table K-1. Guidance and Requirements to Deliverables Crosswalk - TWRS Program Plan.

\begin{tabular}{|c|c|c|}
\hline Guidance or Requirement & Status & Implementing Location \\
\hline $\begin{array}{l}\text { 17. Configuration Management - CM provides an } \\
\text { orderly and efficient process for identifying and } \\
\text { defining configuration items (the integrated site } \\
\text { baseline) in a system, controlling, reporting on and } \\
\text { verifying the status of these items throughout the } \\
\text { system life. }\end{array}$ & I & $\begin{array}{l}\text { Section } 9.6 \text {, Configuration } \\
\text { Management describes process and } \\
\text { refers reader to Configuration } \\
\text { Management Plan for details. }\end{array}$ \\
\hline $\begin{array}{l}\text { 19. Staffing, Personnel Training and Qualification - } \\
\text { SPT\&Q strategies for TWRS ensure qualified personnel } \\
\text { are available when needed. }\end{array}$ & I & Section 9.8, Staffing \\
\hline $\begin{array}{l}\text { 20. Staffing, Personnel Training and Qualification - } \\
\text { SPT\&Q strategies consider a range of options including } \\
\text { training and education, hiring and recruitment, } \\
\text { subcontracting, part time employment, and others. }\end{array}$ & I & Section 9.8, Staffing \\
\hline $\begin{array}{l}\text { 21. Systems Engineering - SE is the PHMC Team's } \\
\text { way of doing business. There is management } \\
\text { sponsorship, worker ownership, and continuous } \\
\text { improvement. }\end{array}$ & I & $\begin{array}{l}\text { Section 9.2, Engineering, and Section } \\
9.2 .2 \text {, Systems Engineering }\end{array}$ \\
\hline $\begin{array}{l}\text { D6 Draft Plan for Determining RTP for Infrastructure } \\
\text { \& Byproducts Delivery, Appendix A Technical } \\
\text { Baseline Checklist }\end{array}$ & & \\
\hline $\begin{array}{l}\text { 22. Validation of enabling assumptions and planning } \\
\text { document update is scheduled, funded, proceduralized } \\
\text { and/or managed. }(6.1 .1-6.1 .2)\end{array}$ & 1 & $\begin{array}{l}\text { Section 9.1:1, Program Baseline } \\
\text { Development covers process and talks } \\
\text { about refinement of program/ technical } \\
\text { baseline as part of annual planning } \\
\text { process. }\end{array}$ \\
\hline $\begin{array}{l}\text { 27. Show that the schedule status report is available, } \\
\text { used for management, and rolls-up to the next level. } \\
(6.7 .1-6.7 .4)\end{array}$ & I & $\begin{array}{l}\text { Section 7.0, Program Schedules, } \\
\text { Section 9.1.1, Program Baseline } \\
\text { Development, and Section 9.1.3.1, } \\
\text { Performance Measures and Reporting } \\
\end{array}$ \\
\hline $\begin{array}{l}\text { D. } 1 \text { Draft plan for Determining RTP forlnfrastructire } \\
\text { \& Byproducts pelivery, Appendix B, Programmatic } \\
\text { Baseline Checklist }\end{array}$ & & 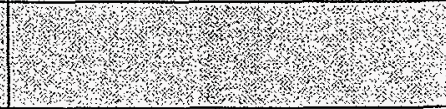 \\
\hline $\begin{array}{l}\text { 35. Provide schedule risks and identify how schedules } \\
\text { are managed to reduce risk. }(2.5 .1-2.5 .7)\end{array}$ & I & $\begin{array}{l}\text { Section 9.5, Risk Management } \\
\text { discusses process and covers schedule } \\
\text { risks. }\end{array}$ \\
\hline $\begin{array}{l}\text { B } 8 \text { Oraft Plan for Determining RTP for Infrastructure } \\
\text { \& Byproducts Belivery Appendix C, Infrastructure } \\
\text { Management Baseline) Checklist }\end{array}$ & & \\
\hline
\end{tabular}


Table K-1. Guidance and Requirements to Deliverables Crosswalk - TWRS Program Plan.

\begin{tabular}{|c|c|c|}
\hline Guidance or Requirement & Status & Implementing Location \\
\hline $\begin{array}{l}\text { 39. Indicate that adequate reports of schedule, cost, } \\
\text { cost variances, project status, DOE requirements, } \\
\text { problem resolution, and task tracking by WBS are in } \\
\text { place and timely. }(1.1 .1-1.1 .8 ; 1.1 .10-1.1 .11)\end{array}$ & 1 & $\begin{array}{l}\text { Section 9.1.3, Performance Measures } \\
\text { and Reporting }\end{array}$ \\
\hline $\begin{array}{l}\text { 41. Confirm the Organizational Breakdown Structure } \\
\text { (OBS) crosswalks to WBS }(1.2 .1-1.2 .3 \text { ) }\end{array}$ & I & Section 5.0, WBS, Table 2 \\
\hline $\begin{array}{l}\text { 44. Provide Acquisition Plan or Procurement Plan } \\
\text { which contains vendor prequalification and } \\
\text { testing/verification and which provide procurement } \\
\text { event-sequence leading to project completion on time. } \\
(1.2 .9)\end{array}$ & $\mathrm{I}$ & $\begin{array}{l}\text { Section 9.1.2, Acquisition } \\
\text { Management }\end{array}$ \\
\hline $\begin{array}{l}\text { 46. Confirm that if USQs exist, strategy for resolving } \\
\text { them is in the baselines, and strategy to implement } \\
\text { Safety Authority. Bases to get to hot start are in place. } \\
(1.3 .3)\end{array}$ & I & $\begin{array}{l}\text { Section 8.2.1.3, Technical Operations } \\
\text { and Engineering; and Appendix F, } \\
\text { Nuclear Safety and Licensing }\end{array}$ \\
\hline $\begin{array}{l}\text { 48. Show that the records management program is } \\
\text { acceptable or is not needed. }(1.4 .1-1.4 .2)\end{array}$ & I & $\begin{array}{l}\text { Section } 9.6, \text { Configuration } \\
\text { Management discusses records } \\
\text { management as a critical element of } \\
\text { configuration management and refers } \\
\text { reader to Configuration Management } \\
\text { Plan. }\end{array}$ \\
\hline $\begin{array}{l}\text { 50. Show that the training program is acceptable or is } \\
\text { not needed. (1.6.1) }\end{array}$ & I & Section 9.8, Staffing \\
\hline $\begin{array}{l}\text { 52. Indicate that Project Critical Decision Planning is } \\
\text { in place. (2.1.6) }\end{array}$ & I & Section 9.4, Decision Management \\
\hline 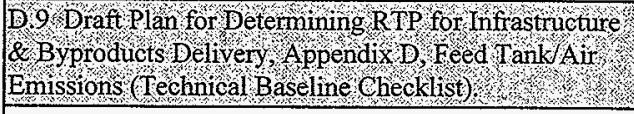 & . & W \\
\hline $\begin{array}{l}\text { 66. Validation of enabling assumptions and planning } \\
\text { document update is scheduled, funded, proceduralized } \\
\text { and/or managed. }(6.1 .1-6.1 .2)\end{array}$ & I & $\begin{array}{l}\text { Section 9.1.1, Program Baseline } \\
\text { Development covers process and talks } \\
\text { about refinement of program/ technical } \\
\text { baseline as part of annual planning } \\
\text { process. }\end{array}$ \\
\hline $\begin{array}{l}\text { 71. Show that the schedule status report is available, } \\
\text { used for management, and rolls-up to the next level. } \\
(6.7 .1-6.7 .4)\end{array}$ & $\mathrm{I}$ & \begin{tabular}{|l|} 
Section 7.0, Program Schedules, \\
Section 9.1.1, Program Baseline \\
Development, and Section 9.1.3.1, \\
Performance Measures and Reporting
\end{tabular} \\
\hline
\end{tabular}


Table K-1. Guidance and Requirements to Deliverables Crosswalk - TWRS Program Plan.

\begin{tabular}{|c|c|c|}
\hline \multirow[b]{2}{*}{$\begin{array}{l}\text { Guidance or Requirement } \\
\text { B10 Draft Plan for Determining RTP for Infrastructure } \\
\text { \& Byproducts Delivery, Appendix E, Infrastrúcture } \\
\text { Eed Tank Transfer (Programmatic Baseline) } \\
\text { Checklist. }\end{array}$} & Status & Implementing Location \\
\hline & & $\begin{array}{lll}2 \\
2\end{array}$ \\
\hline $\begin{array}{l}\text { 79. Provide schedule risks and identify how schedules } \\
\text { are managed to reduce risk. }(2.5 .1-2.5 .7)\end{array}$ & $\dot{I}$ & $\begin{array}{l}\text { Section 9.5, Risk Management } \\
\text { discusses process and covers schedule } \\
\text { risks. }\end{array}$ \\
\hline $\begin{array}{l}\text { D11 Draft Plan for Determining RTP for Infrastructure } \\
\text { \& Byproducts Delivery Appendix } \mathrm{E} \text {, Infrastructure } \\
\text { Feed Tank Transfer (Management Baseline) Checklist }\end{array}$ & & \\
\hline $\begin{array}{l}\text { 83. Indicate that adequate reports of schedule, cost, } \\
\text { cost variances, project status, DOE requirements, } \\
\text { problem resolution, and task tracking by WBS are in } \\
\text { place and timely. }(1.1 .1-1.1 .8 ; 1.1 .10-1.1 .11)\end{array}$ & $I$ & $\begin{array}{l}\text { Section 9.1.3, Performance Measures } \\
\text { and Reporting. }\end{array}$ \\
\hline $\begin{array}{l}\text { 85. Confirm the Organizational Breakdown Structure } \\
\text { (OBS) crosswalks to WBS }(1.2 .1-1.2 .3)\end{array}$ & I & Section 5.0, WBS, Table 2 \\
\hline $\begin{array}{l}\text { 88. Provide Acquisition Plan or Procurement Plan } \\
\text { which contains vendor prequalification and } \\
\text { testing/verification and which provide procurement } \\
\text { event-sequence leading to project completion on time. } \\
\text { (1.2.9) }\end{array}$ & I & $\begin{array}{l}\text { Section } 9.1 .2, \text { Acquisition } \\
\text { Management }\end{array}$ \\
\hline $\begin{array}{l}\text { 90. Confirm that if USQs exist, strategy for resolving } \\
\text { them is in the baselines, and strategy to implement } \\
\text { Safety Authority. Bases to get to hot start are in place. } \\
\text { (1.3.3) }\end{array}$ & I & $\begin{array}{l}\text { Section 8.2.1.3, Technical Operations } \\
\text { and Engineering; and Appendix F, } \\
\text { Nuclear Safety and Licensing }\end{array}$ \\
\hline $\begin{array}{l}\text { 92. Show that the records management program is } \\
\text { acceptable or is not needed. }(1.4 .1-1.4 .2)\end{array}$ & I & $\begin{array}{l}\text { Section } 9.6, \text { Configuration } \\
\text { Management discusses records } \\
\text { management as a critical element of } \\
\text { configuration management and refers } \\
\text { reader to the Configuration } \\
\text { Management Plan. }\end{array}$ \\
\hline $\begin{array}{l}\text { 94. Show that the training program is acceptable or is } \\
\text { not needed. (1.6.1) }\end{array}$ & I & Section 9.8, Staffing \\
\hline $\begin{array}{l}\text { 96. Indicate that Project Critical Decision Planning is } \\
\text { in place. (2.1.6) }\end{array}$ & $\mathrm{I}$ & Section 9.4, Decisions Management \\
\hline
\end{tabular}


Table K-1. Guidance and Requirements to Deliverables Crosswalk - TWRS Program Plan.

\begin{tabular}{|c|c|c|}
\hline Guidance or Requirement & Status & Implementing Location \\
\hline $\begin{array}{l}\text { E. } 1 \text { TWRS Waste Disposal Division Planning } \\
\text { Guidance dated July } 7,1997 \text { (Updated December } 12 \text {, } \\
1997)\end{array}$ & +1, & (1) \\
\hline $\begin{array}{l}\text { Division will prepare integrated plans consistent with } \\
\text { the technical baseline and fully coordinated across } \\
\text { projects. }\end{array}$ & $\mathrm{I}$ & $\begin{array}{l}\text { Section 8.2.2, Tank Waste Retrieval } \\
\text { Organization }\end{array}$ \\
\hline Mandatory completion of approved TPA milestones. & I & $\begin{array}{l}\text { Section 3.0, Tri-Party Agreement } \\
\text { considered one of the "requirements" } \\
\text { sources under "laws and regulations." }\end{array}$ \\
\hline $\begin{array}{l}\text { TD (EM-50) will be supported through the STCG } \\
\text { Process. }\end{array}$ & I & Section 4.0, Technology \\
\hline $\begin{array}{l}\text { Baseline schedule for Retrieval will be a subset of the } \\
\text { TWRS Project Master Baseline Schedule. }\end{array}$ & I & $\begin{array}{l}\text { Section 7.0, Program Schedules; and } \\
\text { Section 9.1.1, Program Baseline } \\
\text { Development }\end{array}$ \\
\hline $\begin{array}{l}\text { Interfaces between elements and external interfaces } \\
\text { must be represented in the PBMS (of which WDD } \\
\text { baseline scheduling is a subset). }\end{array}$ & I & $\begin{array}{l}\text { Section 7.0, Program Schedule; and } \\
\text { Section 9.7, Interface Management }\end{array}$ \\
\hline $\begin{array}{l}\text { Use the Phase } 1 \text { and } 2 \text { schedules to establish the WDD } \\
\text { scheduled. }\end{array}$ & I & Section 7.0, Program Schedule \\
\hline $\begin{array}{l}\text { Plan WDD at greatest detail in CY, less in next two (but } \\
\text { sufficient. for logic-driven cost), less in next } 7 \text {, and } \\
\text { sufficient detail beyond ten to define baseline for entire } \\
\text { project. }\end{array}$ & $\mathrm{I}$ & $\begin{array}{l}\text { Section 9.1.1, Program Baseline } \\
\text { Development }\end{array}$ \\
\hline $\begin{array}{l}\text { Prepared detailed planning describing work scope, } \\
\text { schedule, milestones and budget to complete work } \\
\text { scope. }\end{array}$ & I & $\begin{array}{l}\text { Section 9.1.1, Program Baseline } \\
\text { Development }\end{array}$ \\
\hline $\begin{array}{l}\text { Show PHMC preparing, reviewing, signing interface } \\
\text { control documents (PHMC assisting in integration of } \\
\text { PHMC and private contractor functions) in WDD Plans. }\end{array}$ & I & Section 9.7, Interface Management \\
\hline $\begin{array}{l}\text { Show scope and schedule for WIT and PHMC in the } \\
\text { WDD plans. }\end{array}$ & $I$ & Not applicable to LMHC \\
\hline
\end{tabular}


HNF-1883 Rev 1

This page intentionally left blank.

$\mathrm{K}-16$ 


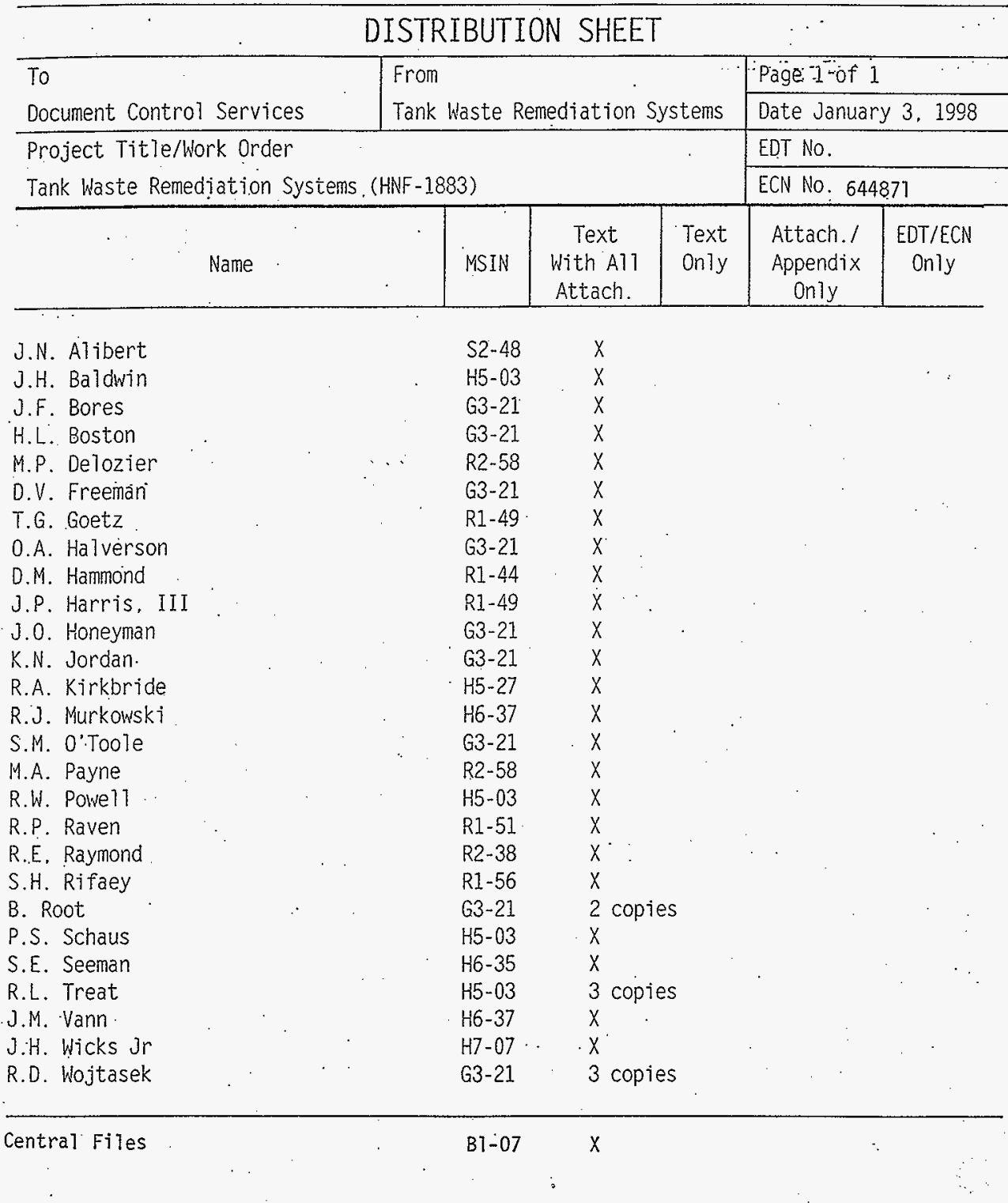

